\title{
Phylogeography, conservation genetics and parasitology of chimpanzees (Pan troglodytes verus) in Guinea-Bissau, West Africa
}

\author{
Rui Miguel Moutinho Sá
}

This dissertation is submitted for the degree of Doctor of Philosophy in Anthropology 
Thesis submitted for partial fulfillment of the requirements for the degree of Doctor of Philosophy in Anthropology, specialty of Biological Anthropology and Ethnoecology, held under the scientific supervision of Professor Cláudia Sousa (Universidade Nova de Lisboa) and Professor Michael W. Bruford (Cardiff University).

Funded by the Portuguese Science Foundation, FCT (SFRH/BD/35797/2007) and by the Great Ape Conservation Fund from the U.S. Fish \& Wildlife Service (GA-0678).

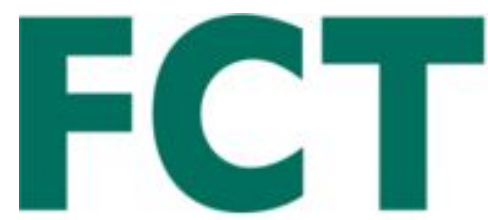

Fundação para a Ciência e a Tecnologia MINISTERro DA EUUCACTOO E CIÉNCIA

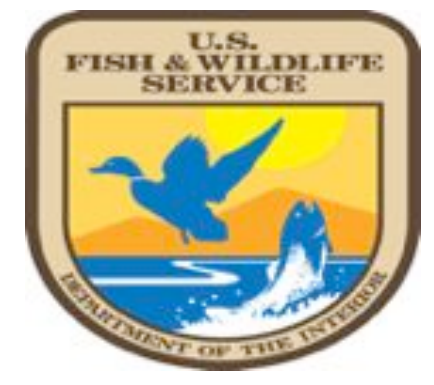

With the institutional and logistical support of:

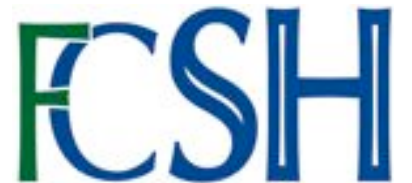

FACULDADE DE CIÊNCIAS SOCIAIS E HUMANAS UNIVERSIDADE NOVA DE LISBOA
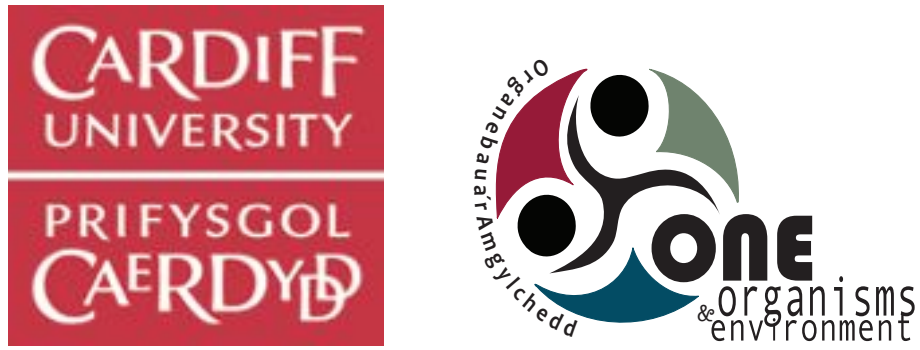
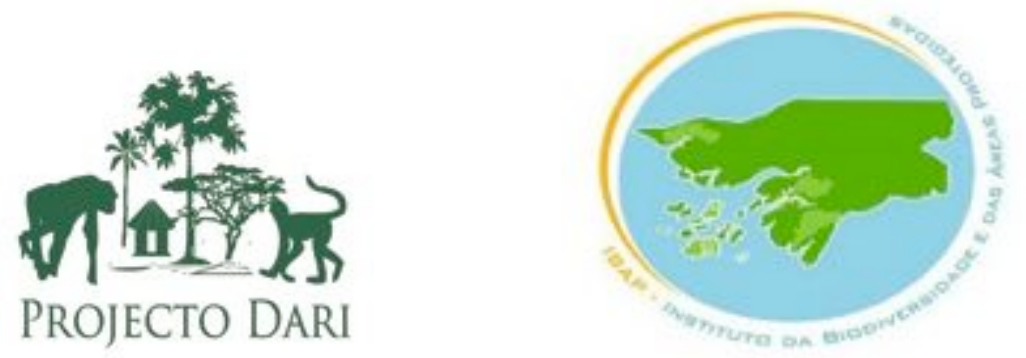

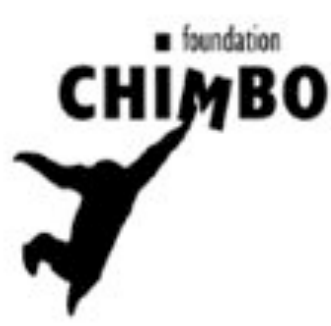




\section{STATEMENTS}

I hereby declare that this thesis is the result of my own personal and independent investigation. Its content is original and all sources are acknowledged by giving explicit references.

The candidate,

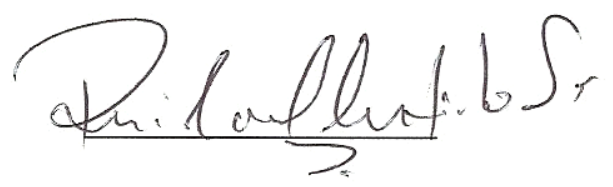

Lisbon, $14^{\text {th }}$ January 2013

I declare that this thesis is ready to be appreciated by a jury to be appointed.

The supervisor,

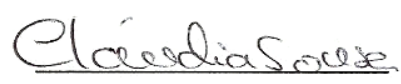

Lisbon, $14^{\text {th }}$ January 2013

I declare that this thesis is ready to be appreciated by a jury to be appointed.

The supervisor,

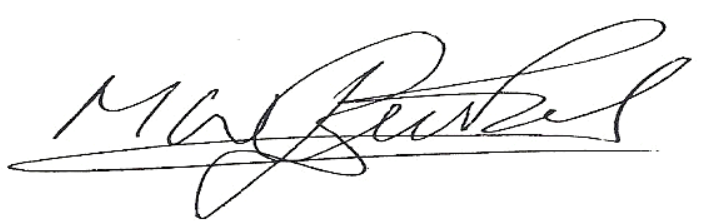

Cardiff, $14^{\text {th }}$ January 2013 


\section{DEDICATION}

To my family for

their unconditional love and constant support.

Dedicated as well to my Guinean human friends for showing me that I don't really need more than what I have and to my chimpanzee ones for convincing me that

“convictions are hopes" (Bertolt Brecht). 


\section{ACKNOWLEDGEMENTS}

I am immensely indebted to my supervisor Prof. Mike Bruford for all his advices and support during the last four years. It has been an inspiration to work with one of the best world experts in Conservation Genetics. You gave me all! I am also very thankful to my supervisor Prof. Cláudia Sousa for supporting and believing in my research, and mainly for giving me the possibility to work in Guinea-Bissau.

In Guinea-Bissau, I am extremely grateful to Instituto da Biodiversidade e das Áreas Protegidas (IBAP) for research authorization and logistical support especially to it's Director, Alfredo Simão, Ayssa Regalla, and all the drivers during the intensive field missions. I am also truly indebted, to Cristina Schwarz for all good advices, help and motivation. I am very grateful to my research assistants, Zeca Dju and Bacari Baiô. The best field assistants ever! I thank all the guards and guides for all the help, incredible hard work and friendship either in: Cantanhez, Cufada and Boé, especially to: láia Camará, Djiby Indjai, Braima Camará, Braima Vieira, Sadjo Camará, Agostinho, Ussumane and Bafodê. I also thank Milza Djulaia for the translation work in the beginning of fieldwork.

I thank the Director of the Cufada Lagoons Natural Park, Honório Silva for all his hospitality and help. I am extremely grateful to Sr. Soares for helping me to get samples from the other side of the Buba River in the Empada sector.

Furthermore, I want to acknowledge for all the help and enthusiasm to Annemarie Goodemakers and Piet Wit from Chimbo Foundation that cooperate with my work in Boé.

I can't express my gratitude for all the help I got from my friend Joost Van Schinjdel! You were just an amazing field expert guy with to whom I'm very honoured to work. I am really indebted to Dári Project and all my friends with whom I had the opportunity to share so many and crazy experiences in the field: Catarina Casanova, 
Joana Roque de Pinho, André Barata, Susana Costa, Joana Sousa and Fernando Sousa.

Many thanks go to all my friends in Cardiff! Thank you: Milena, Mireille, Renata, Gabi, Isa, Dave, Pier, Frauke, Catherine, Rob, Neeza, Niall, Eddie, Xiang Zhan, Rhys, Jeff, Dave Brown, Adam!! I am extremely grateful to Dr. Jo Cable for all support and so much enthusiasm! Thank you so much! Your humanism touched me for life. I want to thank to Jo Lello and Sarah Perkins with the fruitful discussions about the fantastic world of parasites.

In Czech Republic my gratitude goes to Jana Petrášová, Kateřina Pomajbíková, llona Profousová, Magda Ruzicová and Moneeb Qablan. Thank you so much for all your help, friendship and mainly for showing me how much the "parasite world" can be fascinating! I really can't express my gratitude to David Modrý and Klára Petrželková: thank you so much for believing in me, for receiving me always with your open arms and for pushing me forward to the parasitological domain.

I am extreme grateful to Kathelijne Koops and Susana Carvalho for our collaborations and incredible time spent in Cambridge.

Thank you Samrat Mondol for all our incredible discussions comments and revisions, and most important of all for your friendship.

In Portugal I want to thank to Carlos Fernandes from FCUL, and my dear friends: Mafalda Costa and Mafalda Basto!

Thank you Raquel Xavier and Silke Waap for helping me to uncover the phylogenetic analyses and teaching with incredible patience, how to "control" the softwares. 
Thank you Nia Thomas!! Your enthusiasm was touching. Thank you for believing in the petaurista work!

Thank you Annamaria Marra! How can I ever give you a retribution for all your help?!

I am so grateful to my friends and amazing scientists with whom I had the privilege to work with: Maria Joana Silva and Tânia Minhós! Thank you! Thank you! Thank you so much!

I acknowledge all the strength and support my friends in Lisbon gave me during those ups and downs periods of my PhD moments: Paulo Leitão, André Correia, Sofia Almeida, and Paulo Nunes!

Thank you Sílvia Sá for always having time for a coffee and long supportive conversations! You are the best cousin one can have.

I could never ever done this without the help of my fantastic parents and brother. Thank you so much for all your love and unconditional support.

Finally, I want to acknowledge my funding sponsors: Portuguese Science Foundation and the United States Fish and Wildlife Services- Great Ape Conservation Fund.

To all,

Muito Obrigado! Thank you so much! Diolch! Děkuji! Obrigadu! 


\title{
PHYLOGEOGRAPHY, CONSERVATION GENETICS AND PARASITOLOGY OF \\ CHIMPANZEES (PAN TROGLODYTES VERUS) IN GUINEA-BISSAU, WEST AFRICA \\ PHD DISSERTATION
}

RUI MIGUEL MOUTINHO SÁ

\begin{abstract}
KEYWORDS: Chimpanzees; Guinea-Bissau; Phylogeography; Symbionts; Conservation
\end{abstract}

Chimpanzees are disappearing at an alarming rate and it is imperative that strategies should be applied towards their conservation. The evolutionary history of West African chimpanzees remains ambiguous and controversial. Chimpanzees in Guinea-Bissau live at the most western limit of the species distribution and no studies so far have included individuals from this area. Little is known about their ecological, social and behavioural characteristics and their phylogeography and genetic structure has never been evaluated. Furthermore, little is known about their symbiontic fauna.

The aims of my Ph.D. research were to evaluate concomitant threat factors that may have a negative impact on chimpanzee persistence in Guinea-Bissau, and to test a set of hypothesis regarding their phylogeographic and genetic structure. First I report on the trade and ethnobiological use of chimpanzee body parts for traditional practices. Second, I investigate how Guinea-Bissau chimpanzees relate to other members of the Pan troglodytes verus subspecies in West Africa especially those from Guinea Conakry in order to uncover their evolutionary history. Third, I assess their genetic diversity and structure where I expected to find significant population genetic structure among isolated subpopulations. Finally, I investigate the gastrointestinal symbiont diversity of chimpanzees living in a disturbed habitat, especially focusing on infection from parasites with direct life cycles and the effects of increased intra and interspecific contact.

My research shows that in addition to habitat loss and fragmentation and the pet trade, transnational traffic and the use of chimpanzee body parts for traditional purposes constitute additional threats and must be taken into consideration for conservation measures. Second, I showed that Guinea-Bissau chimpanzees have experienced a complex paleodemographic history revealed by the phylogeographic 
analyses suggesting that an historical bottleneck followed by several expansion events. Furthermore, a clear pattern of genetic structure was observed where isolation by distance and vicariance have affected patterns of genetic structure. Chimpanzee females were inferred to disperse in a stepping stone way. Moreover, the two main mitochondrial lineages emerged during the early Pleistocene (1-0.78 MYA) and the divergence time of the haplogroups dates back to middle Pleistocene (0.78-0.12 MYA) coincident with the Gunz (0.68-0.62 MYA) and Mindel (0.45-0.30 MYA) glaciations that caused the contraction of west African tropical forests but followed by an expansion afterwards during the interglaciar periods that restored its connectivity.

Lastly, I identified at least 13 different symbiotic genera (Troglodytella abrassarti, Troglocorys cava, Blastocystis spp., Entamoeba coli, lodamoeba buestcshlii, Giardia intestinalis, Chilomastix mesnilii, Bertiella sp., Probstmayria gombensis, unidentified strongylids, Strongyloides stercoralis, Strongyloides fuelleborni and Trichuris sp.), which have colonized the Guinea-Bissau chimpanzee gastrointestinal tract. Symbiont richness was higher in chimpanzee subpopulations living in fragmented forests compared to the community inhabiting continuous forest area. In fragmented areas chimpanzee density and range-use intensity decreased, which might contribute to low prevalence/total absence of Trichuris sp. in samples from chimpanzees in these areas when compared with those inhabiting continuous forest. 


\title{
PHYLOGEOGRAPHY, CONSERVATION GENETICS AND PARASITOLOGY OF CHIMPANZEES (PAN TROGLODYTES VERUS) IN GUINEA-BISSAU, WEST AFRICA PHD DISSERTATION
}

\author{
RUI MIGUEL MOUTINHO SÁ
}

\begin{abstract}
RESUMO
PALAVRAS-CHAVE: Chimpanzés; Guiné-Bissau; Filogeografia; Simbiontes; Conservação
\end{abstract}

Os chimpanzés estão a desaparecer do seu habitat natural a um ritmo alarmante e é imperativo que estratégias de mitigação sejam aplicadas na sua conservação. A história evolutiva dos chimpanzés na África Ocidental permanece ambígua e controversa. Os chimpanzés da Guiné-Bissau vivem no limite mais ocidental da distribuição da espécie e até agora nenhum estudo genético e parasitológico incluiu indivíduos pertencentes a esta área. Pouco se sabe sobre suas características ecológicas, sociais e comportamentais e a sua filogeografia e estrutura genética nunca foram avaliadas. Além disso, pouco se sabe sobre sua simbionto-fauna.

Os objectivos do meu trabalho de doutoramento foram: I) descrever concomitantes factores de ameaça que têm um impacto negativo na sobrevivência dos chimpanzés na Guiné-Bissau e, II) testar um conjunto de hipóteses sobre sua estrutura filogeográfica e genética. Em primeiro lugar, relatam o uso comercial e etnobiológico reportando o tráfico, de partes do corpo do chimpanzé para práticas de medicina animista tradicional. Em segundo lugar, investiga como os chimpanzés da GuinéBissau se relacionam com os outros membros da subespécie Pan troglodytes verus na África Ocidental e se existe uma relação haplotípica com os chimpanzés da vizinha Guiné-Conacry, a fim de elucidar sobre a sua história evolutiva. Em terceiro lugar, foi avaliada a sua diversidade genética e estrutura onde se esperava encontrar uma estrutura populacional genética significativa entre subpopulações isoladas e baixa diversidade genética entre as populações. Finalmente, no que diz respeito à sua riqueza e prevalência de simbiontes, onde se esperava encontrar uma diversidade elevada de simbiontes gastrointestinais, consequência de um habitat perturbado devido a efeitos de fragmentação, ou seja: uma maior infeç̧ão com parasitas com 
ciclos de vida directos à medida que o contacto intra e interespecífico aumenta, e poucas diferenças na prevalência de simbiontes entre subpopulações.

A minha pesquisa revelou que além, da alteração do habitat (por perda e fragmentação), e comércio de mascotes; o tráfico transnacional e a utilização de partes do corpo dos chimpanzés para fins tradicionais constitui uma ameaça real adicional e deve ser tido em consideração em futuras medidas de conservação. Em segundo lugar, demonstro que na Guiné-Bissau os chimpanzés tiveram uma história paleodemográfica complexa revelada pelas análises filogeográficas que sugerem um "bottleneck" seguido por vários eventos de expansão e que explica os altos níveis de diversidade haplotípica observados. Além disso, demonstra que existe um claro padrão de estrutura genética e que esta pode ser explicada tanto por um padrão de isolamento por distância mas também por vicariância e que afectam o fluxo de genes. As fêmeas chimpanzés tendem a dispersar seguindo o modelo "step and stone". Além disso, as duas principais linhagens mitocondriais observadas surgiram durante o Pleistoceno Inferior (1-0,78 MYA) e o tempo de divergência entre haplogrupos remonta ao Pleistoceno Médio (0,78-0,12 MYA) em consonância, em termos paleoclimáticos, com as glaciações de Gunz (0,68 MYA -0,62) e Mindel $(0,45-$ $0,30 \mathrm{MYA})$. As glaciações causaram a contracção da floresta tropical na África Ocidental intercalando com diversos episódios de expansão, durante os períodos interglaciares e que restauraram a sua conectividade e enquadram o cenário filogenético promovendo um contacto secundário entre linhagens.

Por fim, identifico a presença de pelo menos 13 géneros de simbiontes (Troglodytella abrassarti, Troglocorys cava, Blastocystis spp., Entamoeba coli, lodamoeba buestcshlii, Giardia intestinalis, Chilomastix mesnilii, Bertiella sp., Probstmayria gombensis, de estrongilídeos não identificados, Strongyloides stercoralis, Strongyloides fuelleborni e Trichuris sp.), que colonizam o ecossistema gastrointestinal dos chimpanzé da Guiné-Bissau. A riqueza simbiótica foi maior em subpopulações de chimpanzés que vivem em florestas fragmentadas, em contraste com outras comunidades que habitam áreas mais contínuas de floresta. Surpreendentemente, em áreas fragmentadas: a alta densidade de chimpanzés e a sua utilização do território contribuem para uma baixa prevalência ou total ausência de Trichuris sp. em amostras de chimpanzés nestas áreas quando comparados com aqueles que habitam floresta contínua. Por fim, apresentam-se também algumas recomendações de conservação para que o seu futuro seja duradouro e se mantenha persistente. 


\section{TABLE OF CONTENTS}

$\begin{array}{lc}\text { STATEMENTS } & 3\end{array}$

$\begin{array}{lr}\text { DEDICATION } & 4\end{array}$

$\begin{array}{lr}\text { ACKNOWLEDGEMENTS } & 5\end{array}$

$\begin{array}{lr}\text { ABSTRACT } & 8\end{array}$

$\begin{array}{lr}\text { RESUMO } & 10\end{array}$

$\begin{array}{ll}\text { TABLE OF CONTENTS } & 12\end{array}$

$\begin{array}{lc}\text { LIST OF FIGURES } & 18\end{array}$

$\begin{array}{ll}\text { LIST OF TABLES } & 21\end{array}$

LIST OF ACRONYMS AND ABREVIATIONS 23

$\begin{array}{lr}\text { CHAPTER } 1 & 26\end{array}$

$\begin{array}{ll}\text { GENERAL INTRODUCTION } & 26\end{array}$

1.1- Chimpanzee conservation: does it matter? 26

$\begin{array}{ll}\text { 1.2- The genus Pan } & 27\end{array}$

$\begin{array}{ll}\text { 1.2.1- Taxonomy } & 27\end{array}$

$\begin{array}{ll}\text { 1.2.2- Habitat and Distribution } & 27\end{array}$

1.2.3- Diet, community structure and social organization 29

1.2.4- Behaviour and cultural aspects: $\quad 30$

1.3- Major threats to chimpanzee in situ conservation 33

1.4- Consequences of habitat destruction 36

1.5- Parasitism and its effects on hosts 38

1.6- Paleoclimate and Biogeography 40

1.7- The contribution of Phylogeography 44

1.8- Non invasive genetics and molecular markers 46

1.8.1- Mitochondrial DNA $\quad 47$ 
1.8.2- Microsatellites

1.9- Chimpanzee phylogeographic and parasitological studies: an overview 50

1.10- Research questions, hypothesis and predictions 60

$\begin{array}{ll}\text { 1.11- Aims and objectives } & 61\end{array}$

1.12-Thesis structure $\quad 62$

$\begin{array}{ll}\text { 1.13-References } & 63\end{array}$

$\begin{array}{lr}\text { CHAPTER } 2 & 96\end{array}$

GENERAL MATERIAL AND METHODS 96

2.1- Fieldwork 96

2.2- Republic of Guinea-Bissau 96

$\begin{array}{ll}\text { 2.2- Study Areas } & 102\end{array}$

2.2.1- Study Area 1: Tombali Region 102

2.2.2- Study Area 2: Quínara Region 105

2.2.3- Study Area 3: Gabú Region 106

$\begin{array}{ll}\text { 2.3- Non-invasive sampling strategy } & 109\end{array}$

2.4- Ethnographic observations 112

2.5- Genetic procedures 112

2.5.1- DNA extraction 112

"Wash" protocol 113

2.5.2- DNA amplification and sequencing 114

$\begin{array}{ll}\text { 2.5.3- Sequences authenticity } & 115\end{array}$

2.5.4- Microsatellites and molecular sexing 116

$\begin{array}{ll}\text { 2.5.5- Data analysis } & 119\end{array}$

$\begin{array}{ll}\text { 2.6- Parasitological screening } & 121\end{array}$

$\begin{array}{ll}\text { 2.6.1- Laboratory techniques } & 121\end{array}$

$\begin{array}{ll}\text { 2.6.2- Statistical analyses } & 121\end{array}$

2.7- References 122 
THE TRADE AND ETHNOBIOLOGICAL USE OF CHIMPANZEE BODY PARTS IN GUINEA-BISSAU: IMPLICATIONS FOR CONSERVATION

3.1- ABSTRACT 131

3.2- INTRODUCTION 132

3.3- METHODS 134

3.4- RESULTS AND DISCUSSION 135

3.4.1- Traded species 135

3.4.2- Costs, origin and scale 136

3.4.3- Symbolic and medicinal use 137

3.4.4- Guinea-Bissau in the context of previous studies 138

3.4.5- Implications for conservation 140

3.5- ACKNOWLEDGEMENTS 141

3.6- REFERENCES 141

3.7- FIGURES 146

CHAPTER 4 148

INFERRING THE EVOLUTIONARY HISTORY OF A PERIPHERAL AND ENDANGERED APE POPULATION: THE CHIMPANZEES OF GUINEA-BISSAU 148

4.1- ABSTRACT 149

4.2- INTRODUCTION 150

4.3- MATERIALS AND METHODS

4.3.1- Study areas 153

4.3.2- Non-invasive populations sampling strategy 154

4.3.4- DNA extraction, amplification and sequencing 154

4.3.4- Sequence authenticity 155

4.3.5- Phylogenetic and population genetic analyses 157 4.4- RESULTS 159

4.4.1- mtDNA HVR1 diversity 159

4.4.2- Phylogenetic analysis 160 
$\begin{array}{ll}\text { 4.4.3- Phylogeographic structure } & 160\end{array}$

4.4.4- Demographic history and divergence time 162

$\begin{array}{ll}\text { 4.5- DISCUSSION } & 163\end{array}$

4.5.1- Conservation considerations 166

4.6- ACKNOWLEDGMENTS 168

$\begin{array}{ll}\text { 4.7- REFERENCES } & 168\end{array}$

4.8-TABLES 182

$\begin{array}{ll}\text { 4.9- FIGURES } & 187\end{array}$

$\begin{array}{lr}\text { CHAPTER } 5 & 194\end{array}$

GASTROINTESTINAL SYMBIONTS OF CHIMPANZEES IN CANTANHEZ NATIONAL PARK, GUINEA-BISSAU WITH RESPECT TO HABITAT FRAGMENTATION 194

$\begin{array}{ll}\text { 5.1- ABSTRACT } & 195\end{array}$

5.2- INTRODUCTION 196

$\begin{array}{ll}\text { 5.3- METHODS } & 198\end{array}$

$\begin{array}{ll}\text { 5.3.1- Study Site } & 198\end{array}$

$\begin{array}{ll}\text { 5.3.2- Study Population } & 199\end{array}$

5.3.3- Sampling Strategy 200

5.3.4- Parasitological Screening 201

5.3.5- Data analyses 201

5.4- RESULTS 202

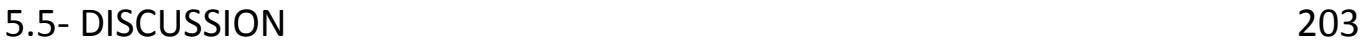

5.6- ACKNOWLEDGEMENTS 211

5.7- REFERENCES 211

$\begin{array}{ll}\text { 5.8- TABLES } & 226\end{array}$

$\begin{array}{ll}\text { 5.9- FIGURES } & 228\end{array}$

$\begin{array}{lr}\text { CHAPTER } 6 & 231\end{array}$

$\begin{array}{ll}\text { GENERAL DISCUSSION } & 231\end{array}$

6.1- Overview of major findings, limitations, and further research 231 
6.2 Reflection about the future of Guinea-Bissau forests

6.3 Conservation recommendations 238

6.4- Conclusion: Why should we conserve chimpanzees in Guinea-Bissau? 240

6.5- References

APPENDIXES

248

Appendix A: Prevalence table of gastrointestinal symbionts of Chimpanzees in Cantanhez, Cufada, and Boé, Guinea-Bissau (2010)

Appendix B: Prevalence table of gastrointestinal symbionts of babboons in Cantanhez National Park, Guinea-Bissau (2010)

Appendix C: Prevalence table of gastrointestinal symbionts of Western red colobus in Cantanhez National Park, Guinea-Bissau (2010) 250

Appendix D: Prevalence table of gastrointestinal symbionts of Black and White colobus in Cantanhez National Park, Guinea-Bissau (2010) 251

Appendix E: Prevalence table of gastrointestinal symbionts of Humans in Cantanhez National Park, Guinea-Bissau (2010)

Appendix F: List of Guinea-Bissau chimpanzees HVR1 haplotypes, to be deposited in GenBank

Appendix G: Chimpanzee symbiont identification microphotographs

Appendix I: Characterization of the urban primate bushmeat trade in Guinea Bissau using molecular tools for species identification [in prep.] 
Appendix J: Mitochondrial DNA variation of the lesser spot-nosed guenon (Cercopithecus petaurista) from the Canhabaque Island, Bijago Archipelago, West Africa [in prep.]

Appendix K: Using genetics as a tool in primate conservation. Nature Education Knowledge 3 (10): 89.

Appendix L: The trade and ethnobiological use of chimpanzee body parts in Guinea-Bissau: Implications for conservation. Traffic Bulletin 23 (1): 31-34.

Appendix M: Distribution of the Entodioniomorphid ciliate Troglocorys cava Tokiwa, Modry, Pomajbíkpvá, Petrzelková, and Imai 2010, (Entodioniomorphida: Blepharocorythidae) in wild and captive chimpanzees. The Journal of Eucaryotic Microbiology 59:97-99. 


\section{LIST OF FIGURES}

Figure 1.1: Pan troglodytes ssp. geographic range (WWF 2009).

Figure 2.1: Guinea-Bissau location (BBC 2011).

Figure 2.2: Map of land use in Cantanhez National Park, Guinea-Bissau

Figure 2.3: Map of land use in Cufada Lagoons Natural Park, Guinea-Bissau (INEP 2010).

Figure 2.5: Guinea-Bissau Protected Areas and future National Park of Dulombi-Boé (World Bank 2011).

Figure 2.5: Guinea-Bissau sampling sites for this study.

Figure 2.6: PCR results of the best preservation DNA reagent after electrophoresis. The "Two Steps" presented the most convincing results.

Figure 2.7: MtDNA gel picture. Positive amplifications indicated by bright band around 700bp. + positive control; - DNA isolation controls; b blank PCR control. 115

Figure 3.1: All animal-derived products for human traditional purposes in Bandim market, Bissau, Guinea-Bissau.

Figure 4.1: Study areas: A (Guinea-Bissau, Tombali region including the peninsulas of Cantanhez and Catió); B (Guinea-Bissau, Quínara region including the Cufada Lagoons Natural Park and the Empada peninsula); C (Guinea-Bissau, Gabú region across the Boé sector) and D (Guinea, Seringbara and Nimba Mountains).

Figure 4.2: The contribution to the total haplotype diversity (CT) and haplotypic richness (CTR) of each population of chimpanzees using the HVR1 haplotypes. The 
blue and red bars represent the contribution of diversity (CS and CRS) and differentiation (CD and CRD), respectively.

Figure 4.3: Phylogenetic relationships among haplotypes of Guinea and GuineaBissau chimpanzees according to Bayesian inference. The numbers, in each node, refer to the posterior probabilities.

Figure 4.4: Haplotype network recovered by median joining analysis. Haplotypes are represented by circles with size proportional to their frequencies and coloured according to subclades recovered in the phylogenetic analyses. Numbers outside the circles represent the mutational steps, and inside the circles the number of individuals for each haplotype. Grey circles represent missing haplotypes, extinct or not sampled.

Figure 4.5: Map showing the geographic distribution of the HVR1 haplotypes in the P. troglodytes verus populations in Guinea-Bissau. The haplotypes are identified in the legend. The broken lines in red indicate the genetic barriers $(\alpha, \beta, \gamma)$ as defined by the Monmonier algorithm.

Figure 4.6: Mismatch distributions for the Guinea-Bissau and Nimba chimpanzees and respective associated parameters. (A) Mismatch distribution according with the sudden expansion model. (B) Mismatch distribution according with the spatial expansion model. Mean pairwise differences between pairs of haplotypes (k), mismatch derived parameters $\left(\Theta_{0}, \tau, \Theta_{1}\right)$. Sum of squared differences (SSD) and Harpending Raggedness Index with respective P values. Number of female migrants (M).

Figure 5.1: Location of Cantanhez National Park, Republic of Guinea-Bissau, West Africa (after Hockings and Sousa 2011). 
Figure 5.2: Chimpanzee distribution in three principal areas across Cantanhez National Park, Guinea-Bissau.

Figure 6.1: Forest change in Guinea-Bissau between 1990 and 2007 (after Oom et al. 2009, CARBOVEG-GB PROJECT). 238 


\section{LIST OF TABLES}

Table 1.1: Chimpanzees in a glance (after Stumpf 2007).

Table 1.2: Chimpanzee conservation status evolution (after IUCN 2011).

Table 2.1: Non-human primates of Guinea-Bissau

Table 2.2: Major ethnic groups and beliefs of Guinea-Bissau (INEC 2007).

Table 2.3: Major socio-economical and demographic indicators (INEC 2007).

Table 2.4: Chimpanzee non-invasive sampling, Guinea-Bissau, for this study.

Table 2.5: HVR1 chimpanzee primers.

Table 2.6: Multiplex composition, primer information and allelic size ranges.

Table 2.7: Multiplex 3 composition, primer information and allelic size ranges.

Table 4.1: Chimpanzee non-invasive sampling, in Guinea-Bissau and Guinea, for this study. Number of chimpanzees sequenced $(N)$, geographic coordinates: latitude (Lat.), longitude (Lon.).

Table 4.2: Distribution of 51 HVR1 haplotypes found in 334 chimpanzees in GuineaBissau and Nimba (i.e. Guinea) from 28 populations (Sites 1-28)a. Haplotype number $(H)$, total number of animals sequenced (NA), total number of haplotypes (NHT). 183

Table 4.3: Summary statistics and demographic expansion tests observed in the study areas and in all populations, including the mean number of pairwise differences (k), and the theta per site from $S\left(\theta_{W}\right)$ according to Watterson (1975). 184 
Table 4.4: Pairwise $\mathrm{F}_{\mathrm{ST}}$ values between chimpanzee study areas in Guinea-Bissau and Nimba Mountains.

Table 4.5: Hierarchical analysis of molecular variance (AMOVA) for chimpanzee HVR1 mtDNA sequences from Guinea-Bissau and Nimba.

Table 4.6: Results from SAMOVA analysis with different clusters defined a priori. Number of groups (K), group composition and fixation indexes are reported. 186

Table 5.1: Characteristics of chimpanzee communities sampled in Cantanhez National Park, in Guinea-Bissau, West Africa.

Table 5.2: Symbiont prevalence (\%) of western chimpanzees (Pan troglodytes verus) at Cantanhez National Park, Republic of Guinea-Bissau. 


\section{LIST OF ACRONYMS AND ABREVIATIONS}

\begin{tabular}{|c|c|}
\hline AMOVA & Analysis of molecular variance \\
\hline \multirow[t]{2}{*}{ CITES } & Convention on International Trade and in Endangered Species of Wild \\
\hline & Fauna and Flora \\
\hline CLNP & Cufada Lagoons Natural Park \\
\hline CNP & Cantanhez National Park \\
\hline CT & Total Haplotype Diversity \\
\hline CRT & Total Haplotypic Richness \\
\hline DEFRA & Department for Environment, Food and Rural Affairs \\
\hline DNA & Deoxyribonucleic Acid \\
\hline ESUs & Evolutionary Significant Units \\
\hline $\mathrm{F}_{\mathrm{ST}}$ & Fixation Indexes \\
\hline $\mathrm{H}$ & Haplotye diversity \\
\hline IBAP & Instituto da Biodiversidade e das Áreas Protegidas \\
\hline IUCN & International Union for Conservation of Nature \\
\hline
\end{tabular}


mtDNA Mitochondrial Deoxyribonucleic Acid

MUs Management Units

PCR Polymerase Chain Reaction

SAMOVA Sapatial Analysis of Molecular Variance

SD

Standart Deviation

STR

Short Tandem Repeats

$\theta_{\mathrm{w}}$

Watterson estimator of genetic diversity

$\Pi$

Nucleotide Diversity 


\section{CHAPTER 1}

"Today I am proud to say that I am inhuman, that I belong not to men and governments, that I have nothing to do with creeds and principles. I have nothing to do with the creaking machinery of humanity - I belong to the Earth!"

\section{- Henry Miller, Writer}

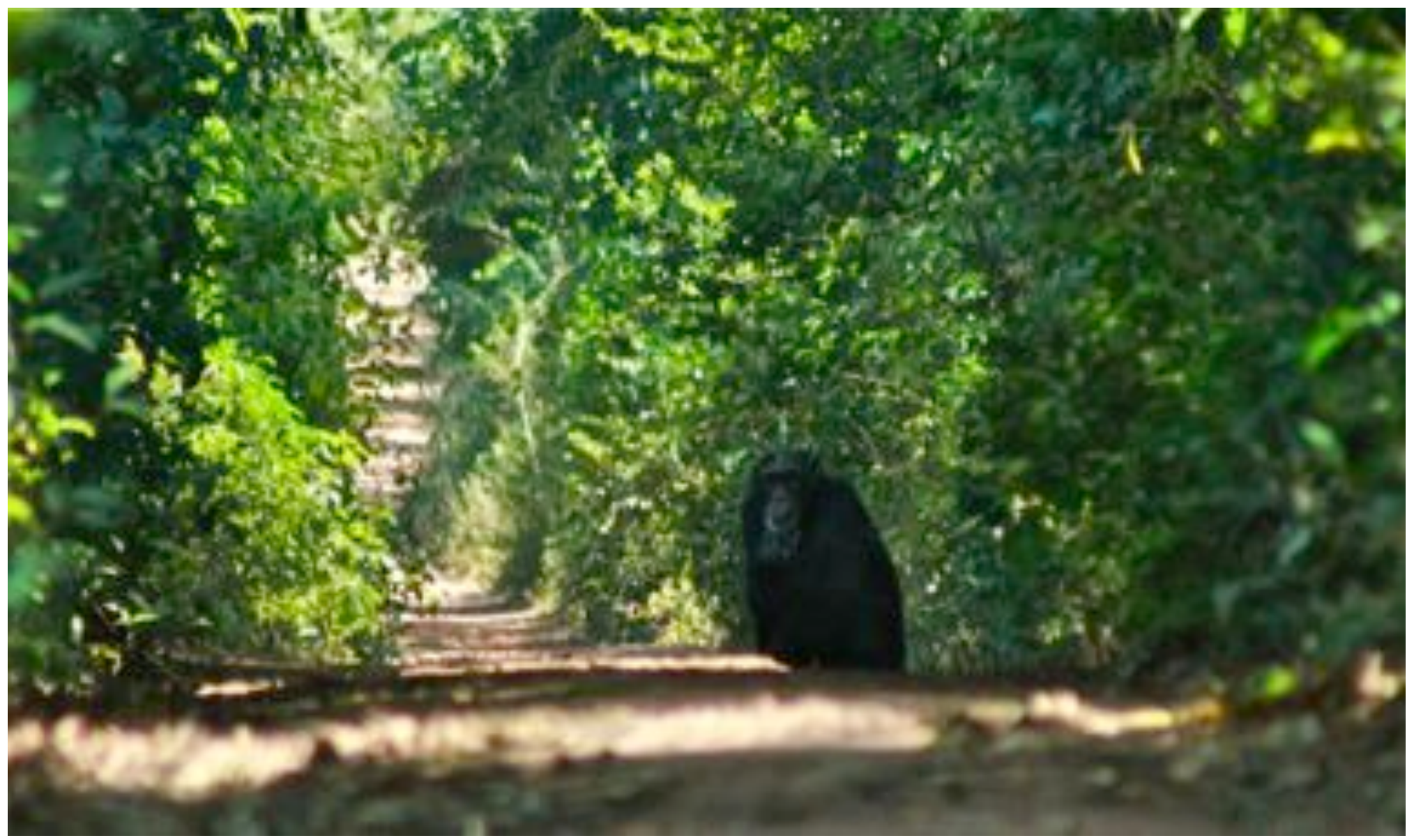




\section{CHAPTER 1}

\section{GENERAL INTRODUCTION}

\section{1- Chimpanzee conservation: does it matter?}

Chimpanzees have an impressive cognitive ability, memory and extraordinary intelligence (Inoue and Matzuzawa 2007), a complex social organization (Goodall 1986) and unique cultures (McGrew 2004). Chimpanzees are man's closest relatives, in evolutionary terms (Jobling et al. 2004). In fact, 4-7 million years ago we shared the same common ancestor (Goodman 1999), and at least $98 \%$ of our DNA is identical (Consortium 2005). Since the early 1960', chimpanzee studies have become key for the understanding of human evolution and biology (Sayers and Lovejoy 2008).

West African chimpanzees are more threatened in any other region across the continent (Kormos and Boesch 2003). It is estimated that there are currently less than 38,000 western chimpanzees (Butynski 2003) and only between 600 to 1000 individuals (Gippoliti et al. 2003) in the Republic of Guinea-Bissau, according to the estimate of UNEP-GRASP (United Nations Environment Programme - Great Apes Survival Project, Caldecott and Miles 2005). In fact, they have even been considered extinct in this almost unknown country (Lee et al. 1988). The scientific community agree unanimously, they affirm that tropical forests are disappearing at an excessive speed and with them the last populations of great apes (Laurance et al. 2012). If we do nothing gorillas, chimpanzees and bonobos are likely to have disappeared from Africa by the middle of the 21st century. The situation for orangutans is even more dramatic. In 20 years time, they might only exist in zoos (Boesch et al. 2008).

Chimpanzees are disappearing at an alarming rate (Campbell et al. 2008). In Guinea-Bissau follows the continent-wide trend: chimpanzees are endangered and, 
if nothing is done, their extinction from this country is certain. In this chapter I set out the conceptual framework for my study, including its scope and subject, objectives, concepts and hypotheses. A literature review is also presented as well as the thesis structure.

\section{2- The genus Pan}

\subsection{1- Taxonomy}

The most recent taxonomy, and the one adopted here, was proposed by Groves (2001) and Grubb et al. (2003) and is used by the IUCN-SSC Primate Specialist Group (http://www.primate-sg.org). It identifies two species in the genus Pan: bonobos (Pan paniscus) and common chimpanzees (Pan troglodytes). Chimpanzees are categorised in four subspecies: the east African chimpanzee (Pan troglodytes schweinfurthii), the central African chimpanzee (Pan troglodytes troglodytes), the west African chimpanzee (Pan troglodytes verus) and the Nigeria-Cameroon chimpanzee (Pan troglodytes ellioti, formerly classified as vellerosus).

\subsection{2- Habitat and Distribution}

Among the hominids (except for the genus Homo) common chimpanzees are the most generalist species, living in several kinds of habitat: humid evergreen forests, mosaic woodlands, mangroves, decidous forests and woodland savannah (Kortlandt 1983). Chimps are distributed all over northern Senegal to the south of the Congo River and in the eastern area of Lake Tanganyika, Tanzania (Stumpf 2007) (Fig. 1.1).

The Eastern African chimpanzee ( $P$. troglodytes schweinfurthii) possesses a geographical range from the north of the Central African Republic, to the southwest of Sudan, east with the Ubangi River and south in the Equator line in the Central Africa Republic. In this area there are many sites where important data have been 
collected during recent decades (Inskipp 2005) including Gombe and Mahale (Tanzania) and Budongo (Uganda).

The Central African chimpanzee (P. t. troglodytes) is distributed south of the Sanaga River (Cameroon; Prescott et al. 1994). It extends from east to the western region of the Central African Republic, to the southern limit of Dzanga Ndoki National Park (Inskipp 2005). It is also widely spread throughout Gabon (Blom et al. 1992).

The chimpanzees from Nigeria-Cameroon are distributed all over southwest Nigeria in small and fragmented populations (Oba Hills Forest Reserve), to the southeast and east of the Niger River delta, throughout the boundaries of Cameroon in Gashaka Gumti National Park (Oates 2003).

West African chimpanzees exist in the southwest of Mount Assirik, Senegal, in the southwest of Mali and southeast in the Cantanhez Woodlands, in Guinea-Bissau. They are also present in Guinea, Sierra Leone, Liberia, Cote D'Ivoire and in the southwest of Ghana (Inskipp 2005). The western chimpanzee is considered extinct in Gambia, Togo and Benin (Brownell 2003). According to the estimations by Butynski (2003) this subspecies' geographic range is about $631000 \mathrm{~km}^{2}$.

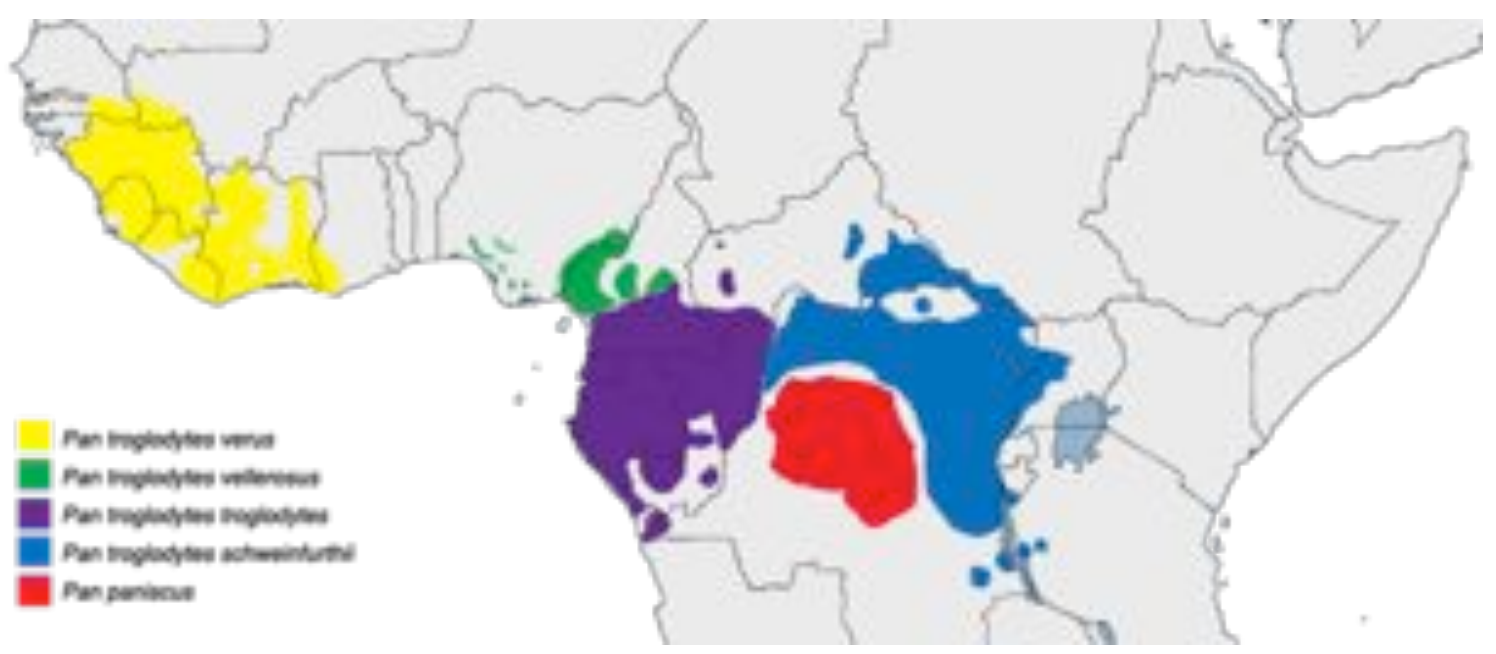

Figure 1.1: Pan troglodytes ssp. geographic range (WWF 2009). 


\subsection{3- Diet, community structure and social organization}

Chimpanzees are essentially omnivorous but show a preference for fruits (Wrangham et al. 1998). In times of food scarcity they increase the proportion of leaves and other less energy-rich food in their diet (Wrangham 1977 and Doran 1977). Hunting behaviour has also been documented in some long-term studies (see Goodall 1986; Boesch and Boesch 1989; Nishida 1979), with considerable interpopulational differences in the sort of prey hunted, their habitat characteristics and hunting tactics.

Chimpanzees are polygynous living in multi-male/multi-female groups and their demographic resident number changes in each population. The social group core lies in males, which are generally related and bounded (male-bounded society) (Goodall 1986). They are characterized as fission-fusion communities, meaning that a chimpanzee community can be divided in parties or sub-units, as a function of the resource availability (Goodal 1986). Community is understood here as a group of individuals that share a range or territory. In the chimpanzee case, besides living in a specific geographic area, the community also demonstrates the sharing of information and bonding. Some food, such as fruits and meat, can also be shared among individuals (Casanova 2006). There are cultural elements that are shared by all the individuals and even a daily interaction concerning social and sexual life aspects (Reynolds 2005). Party composition can vary between one to several individuals and be led by males or females. A community of chimpanzees can include from two to eighty members (Casanova 2006). Their home range, i.e. part of the territory usually employed by community effectives, can vary from 6 to $20 \mathrm{~km}^{2}$ (e.g. in Taï Forest and Budongo; Boesch and Boesch-Achermann 2000; Newton-Fisher 2002). Most of the females leave the original group when they reach adolescence, shifting to another group (Nishida et al. 2003; Boesch and Boesch-Achermann 2000). There are, however, populations where this fact has not been confirmed yet, like the 
case of Bossou (Sugiyama 1999). Males are usually the philopatric sex (Nishida 1979).

At the same time some ecological factors, such as resource abundance, the presence of estrous females or even predation pressure can modify chimpanzee social dynamics and patterns (Wrangham 1980; van Schaik 1983; Symington 1988; Strier 1989; Chapman et al. 1995; Newton-Fisher et al. 2000).

Strong male dominance and male-male alliances characterize chimpanzees at all sites (Goodall 1986; Wrangham 1986; Nishida and Hiraiwa-Hasegawa 1987; Nishida and Hosaka 1996; Boesch and Boesch-Achermann 2000; Watts 2000b; Arnold and Whithen 2003). Chimpanzees perform grooming with those whom they create alliances (Mitani et al. 2000), in a reciprocal way (Watts 2000a; Arnold and Whiten 2003) and according to their status hierarchy, in which the closest individuals to the top are groomed most (Mitani, Merriwether et al. 2000; Takahata 1990; Newton-Fisher 2002). Contrasting with males, female chimpanzee relationships are traditionally ranked as egalitarian and weak (Wrangham 1980; Sterck et al. 1997). Chimpanzees are territorial and the inter-community interactions are very hostile and sometimes deadly (Goodall 1986).

\subsection{4- Behaviour and cultural aspects:}

Chimpanzees are terrestrial, diurnal and can be arboreal (Inskipp 2005). They move mostly on the ground but they build their nests and feed in trees (Groves 2001). Chimpanzees have great mobility, being able to travel up to $12 \mathrm{~km}$ a day (Doran 1997), twice as far as western gorillas (Goldsmith 1999). When there is a lack of resources, for example during the dry season, chimpanzees from Taï have been observed to reduce their daily range, as well as party composition, spending more time feeding, several times a day in small quantities (Inskipp 2005).

Culture has always fascinated scientists through its role as a non-genetically determined evolutionary process (Mesoudi and Whiten 2004). Cultural transmission 
offers a quicker method in which some characteristics can be diffused. It is, however, difficult to define 'culture' (McGrew 1998). Nevertheless several authors agree that cultural behaviours are those that: 1) - are specifically learned from members of the same group (cultural variation can occur in any social level) and 2) - are transmitted by a social apprentice mode. I will adopt this particular definition. For more detailed reviews see (Boesch and Tomasello 1998; Fragaszy and Perry 2003; Laland and Hoppit 2003; McGrew 1998; Russell and Russell 1990; McGrew 2004; Whiten et al. 1999, 2001, 2005 2007).

There are several examples of cultural use by chimpanzees: from the hunting of western red colobus (Procolobus badius) (Wrangham et al. 1994), to termite fishing in Tanzania (McGrew 1998), the use of medicinal plants (Huffman and Wrangham 1994) to nut cracking in western Africa (Carvalho et al. 2008). One other aspect that has also preoccupyied scientists is chimpanzee intelligence. This aspect occurs about the origins and factors that could have led not only chimps, but also other primates and social animals to develop special cognitive abilities and to face social challenges (Casanova 2006).

Tomasello and Call (1997) demonstrated that chimpanzees have the ability to differentiate their own knowledge and the other's knowledge, that is, they can perceive other individuals' mental states. This formulation was named 'Mind Theory' (Tomasello 1999, Call et al. 2000).

In Table 1.1 the main traits of chimpanzees are summarised. 
Table 1.1: Chimpanzees in a glance (after Stumpf 2007).

\begin{tabular}{|c|c|}
\hline Activity pattern & Diurnal \\
\hline Social organization & Fission-fusion \\
\hline Community structure & Multimale/multifemale \\
\hline Dispersing sex & Adolescent females \\
\hline Locomotion & Knuckle walking \\
\hline Substrate use & Arboreal/semiterrestrial \\
\hline Sleep site & Arboreal nests \\
\hline Diet & Primarily frugivorous \\
\hline Sympatric gorillas? & Variable, only in some areas \\
\hline Dominant sex & Male \\
\hline Intercommunity interactions & Usually antagonistic \\
\hline Male-male association & Very strong \\
\hline Male-female association & Weak in eastern, strong in western \\
\hline Female-female association & Very weak in eastern, strong in western \\
\hline Resolve tension with & Aggression \\
\hline Male-female aggression & Common \\
\hline Female-female aggression & Rare \\
\hline Pant-grunt submissive vocalization & Common \\
\hline Grooming & Male-male most, female-female least \\
\hline Infanticide & Rare but present at all sites \\
\hline Tool use & Habitual \\
\hline Consorts & Some but not all sites \\
\hline Boundary patrolling & Habitual \\
\hline Hunting & Occurs at most sites \\
\hline Food sharing & Yes (mainly meat) \\
\hline Vocalizations & Lower pitch \\
\hline Sexual behaviour during nonswelling & Very rare \\
\hline Copulation posture & Dorsoventral \\
\hline Female-female sexual behaviour & Very rare \\
\hline
\end{tabular}




\section{3- Major threats to chimpanzee in situ conservation}

IUCN report chimpanzees as endangered since 1996 and its conservation status has not changed since then (Table 1.2). Chimpanzees have long inter-birth intervals; slow life stories, a high maternal care and a high infant mortality rate and are vulnerable to anthropogenic threats (Stumpf 2007). CITES - the Conservation on International Trade in Endangered Species of Wild Fauna and Flora (2008) classifies chimpanzees as most endangered and inscribe them into their Appendix I. Walsh et al. (2003) recommended that chimps should be part of the Critically Endangered Status list.

Table 1.2: Chimpanzee conservation status evolution (after IUCN 2011).

\begin{tabular}{lc}
\hline Year & Status \\
1986 & Vulnerable \\
1988 & Vulnerable \\
1988 & Vulnerable \\
1990 & Vulnerable \\
1994 & Vulnerable \\
1996 & Endangered \\
2000 & Endangered \\
2003 & Endangered (Butynski 2003) \\
2005 & Endangered (Caldecott and Miles 2005) \\
2007 & Endangered (IUCN 2007) \\
2009 & Endangered (IUCN 2009) \\
2011 & Endangered (IUCN 2011) \\
\hline
\end{tabular}

Recent density estimates point to a range of 0.1 to 6 individuals $/ \mathrm{km}^{2}$, with forested habitats having higher densities than savannah (Miles et al. 2005). The modal density seems to be $1 / \mathrm{km}^{2}$ (Poulsen and Clark 2004). According to a prediction by Jones et al. (2007), 91\% of the areas with resident chimpanzee communities are showing population declines. The viability of these populations depends on a wide variety of factors, including habitat preservation, anti-poaching measures and on the maintenance of their genetic diversity (Miles et al. 2005). Their main direct (short-term) conservation threats are: 1) - the destruction and loss of 
the habitat; 2) - illegal pet trade; 3) - emergence of infectious and contagious diseases and 4) - political instability and economic constraints (IUCN 2007).

Habitat destruction is one of the major anthropogenic threats affecting chimpanzee populations (Nishida and Mwinuka 2005). Deforestation and agricultural practises that use 'slash and burn' techniques, in conjunction with intensive and sometimes illegal logging as well as mining, have a negative impact on chimp density because they modify, fragment and disturb their niches (Miles et al. 2005). Since 1900 western Africa had lost about $75 \%$ of its forest coverage (IUCN 1992). Associated to this there is also human population pressure that continues to expand at a rate of $>3 \%$ annually (Figure 1.2 ).

Hunting, illegal bushmeat consumption, and the exotic pet trade have also contributed to the decline of chimpanzee communities. In some countries they are hunted and their meat is sold in local markets (Caspary et al. 2001; Wilkie and Carpenter 1999; Kormos and Boesch 2003). The infant chimpanzee pet trade is frequently associated with the death of the mother and of other members of the group (Miles et al. 2005). Human beliefs and biomedical investigation can, in an equal manner, contribute to their decline. Some beliefs and some ethnic traditions use parts of chimpanzee body parts for medical purposes (Caldecott and Miles 2005). Chimpanzees can be opportunist and take advantage of crops. In order to prevent crop raiding activity by chimpanzees, it is common for humans to set traps that can, deliberately or not, kill them (Sillero-Zubiri and Switzer 2001).

Infectious-contagious diseases are another main causes of death amongst chimpanzees (Goodall 1986). As human populations are expanding the risk of disease transmission to chimpanzees increases (Hanamura et al. 2008). Some epidemics like Ebola have been responsible for the death of a large number of chimpanzees (Walsh et al. 2003; Huijbregts et al. 2003; Kormos and Boesch 2003; Bermejo et al. 2006; Lahm et al. 2006).

Lastly, major political instability during the past few decades in countries such as Guinea Bissau, Sierra Leone, Liberia and Ivory Coast, in Western Africa, has 
resulted in increasing poverty, increased availability of firearms and increasing number of refugees who hunt and destroy the forests for survival (Draulans and Van Krunkelsven 2002; Dudley et al. 2002; Miles et al. 2005). One of the direct consequences in this decrease in chimpanzee density (as well as other primates) is the impact on the local tropical flora and fauna (Chapman and Russo 2007). Some authors claim that chimpanzees have a major role in seed dispersal, since some large-seeded fruits are not accessible to smaller animals (Andresen 2000). If chimps are considered as flagship species they might have a major role in the preservation of their ecosystem (Sousa and Casanova 2004). 


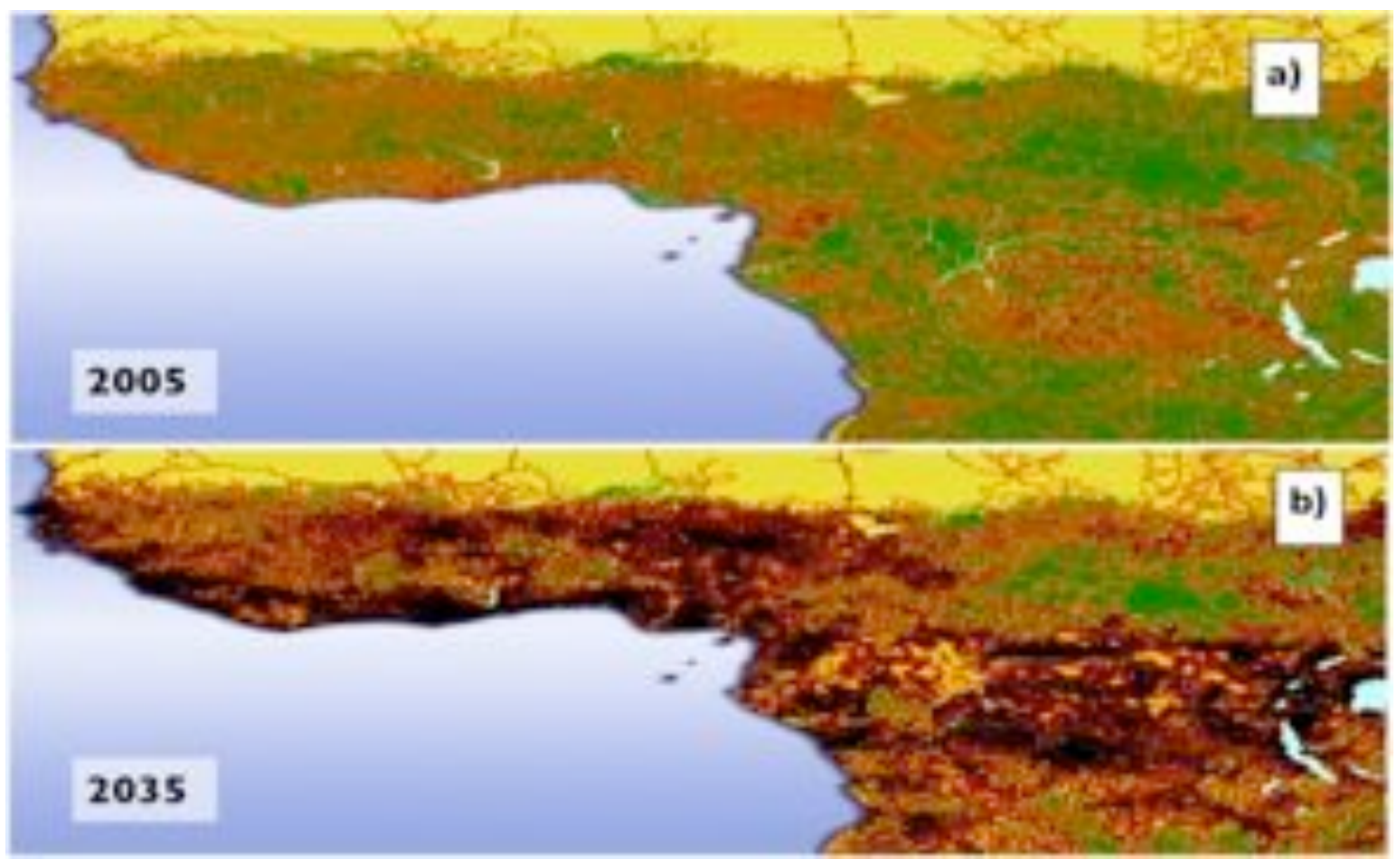

Figure 1.2: a)- Current scenario of human impact in Western Africa (2005), b)- Projection of human pressure for 2035 in the chimpanzee distribution area. The black, red and orange spots show a high, medium and low impact, respectively (after Caldecott and Miles 2005:236-237).

\section{4- Consequences of habitat destruction}

Deforestation in the tropics, where almost $90 \%$ of all primate species can be found, and the subsequent habitat loss and fragmentation affect directly primate populations in many ways (Lewis and Wu 2005). Included among these is that fact that the process of fragmentation may distribute primates randomly and nonadaptively among different forest patches (a stochastic sampling effect; Marsh 2003). In cases where the population size or demographic structure has changed, primate populations can become locally unstable or extinct (Marsh 2003). The fragmentation of continuous landscapes can: i) demographically isolate primate populations, inducing local extinction (Lovejoy et al. 1986); ii) modify group size, 
population density and abundance (Tutin 1999); and iii) change dietary and behavioural habits, sometimes in an unfavourable way (Tutin 1999).

Additionally, fragmentation may also cause genetic changes, e.g. extinction of genetically differentiated populations and changes to the inbreeding level (Sherwin and Moritz 2000). These changes are likely to have a negative impact on population viability and the reduction of genetic diversity within and increased differentiation among populations reduces the chance for adaptation to environmental constraints and therefore, may affect the fitness and viability of the populations (Beebee and Rowe 2004). A reduction of heterozygosity affects the fitness of species and this change can be tracked by analysing the inbreeding coefficient $\left(F_{I S}\right)$. Inbreeding depression often results in elevated homozygosity, although this can also be due to genetic drift, which may or may not exhibit an analogous pattern to inbreeding depression (Sherwin and Moritz 2000). Small populations will lose genetic diversity more quickly through drift and inbreeding, and these effects will increase when such populations are also fragmented (Bergl et al. 2008).

Contact and conflict between humans and non-human primates is another effect of habitat destruction (Hockings and Humble 2009). An increasing number of great ape populations are being forced into proximity with humans (Hockings and Humble 2009). The mechanisms of forest disturbance vary, but subsistence and small- and large-scale commercial agriculture, crop plantations and extractive industries such as logging and mining are significant threats to tropical forests (Caldecott and Miles 2005). The drive for economic growth through unsustainable exploitation of natural resources and/or the establishment of large-scale agricultural projects exacerbate the consequences of the human-primate contact (Hockings and Humble 2009). Increased rates of contact with great apes and human activities may lead as well to increased levels of crop-raiding (Ancrenaz et al. 2007; Hockings and Humble 2009); natural resource competition; domestic animal predation (McLennan 2008). The limitation of human mobility or attacks on humans by great apes could potentially intensify situations of conflict (Hockings and Humble 2009). One 
immediate consequence of such conflicts is that humans sometimes develop negative perceptions towards great apes, retaliating by injuring or killing them to protect their resources (Costa et al. 2007) .

The study by Reynolds et al. (2000) is very instructive on how the development of the sugarcane industry in Western Uganda changed the landscape, the chimpanzee dynamics and the local human local perceptions about them.

Every aspect of chimpanzee and other primate's livelihood can be affected by habitat destruction and many authors have advocated the importance of research on fragmentation effects in order to better understand species responses (Marsh 2003). The chimpanzees of Guinea-Bissau are very good candidates to investigate this deleterious effect in order to develop suitable conservation measures.

\section{5- Parasitism and its effects on hosts}

Anthropogenic habitat change brings humans and primates into closer and more common contact promoting the risk of interspecific disease transmission (Daszak et al. 2001; Dobson and Foufopoulos 2001). Parasitic agents shared with nonhuman primates include several protozoans such as: malarias (Plasmodium spp.) Trypanosoma cruzi, Giardia intestinalis, Cryptosporidium sp. and a variety of gastrointestinal helminths (Chapman et al. 2005). Gastrointestinal parasites and other pathogen agents pose significant conservation risks to nonhuman primate populations, many of which are already threatened or endangered by habitat destruction and hunting (Chapman et al. 2005). Evidence indicates that between 1983 and 2000, Ebola virus outbreaks have contributed to the reduction of gorilla and chimpanzee populations by more than $50 \%$ over a broad geographic scale (Walsh et al. 2003; Bermejo et al. 2006; Walsh et al. 2007). Gastrointestinal and respiratory parasites transmitted between mountain gorillas, trackers, and ecotourists could threaten the long-term viability of gorilla populations in Virunga, as well as the economic sustainability of associated ecotourism (Wallis 2000). 
Quantifying patterns of disease prevalence in nonhuman primate populations might be difficult since, for many parasites it is necessary to obtain clinical samples from individuals to determine their infection status (Chapman et al. 2005). Gastrointestinal parasites are notable exceptions, in that it is possible to diagnose animals by analysing their fecal material (Stuart and Strier 1995). Among gastrointestinal parasites, helminths and protozoans are most easily characterized in wild non-human primates (Stuart and Strier 1995). These parasites can affect host survival and reproduction directly through pathological effects and indirectly by reducing host condition (Dobson and Hudson 1992; Coop and Holmes 1996). Severe parasitosis can lead to blood loss, tissue damage, spontaneous abortion, congenital malformations, and death (Despommier et al. 1995). Less severe infections are more common and may affect nutrition, increasing energy expenditure, and impairing travel, feeding, predator escape, and competition for resources or mates (Dobson and Hudson 1992). Parasitosis emergence frequently results from a change in the ecology of the host, the parasite or both (Fa et al. 1995). Dobson and Foufopoulos (2001) conducted a survey of emerging pathogens of wildlife in North America and found that human involvement facilitated $55 \%$ of pathogen outbreaks. Similarly, Chapman et al. (2005) have documented that certain disturbance-related features of forest fragments are excellent predictors of infection prevalence in primates. In a five-year study, they compared patterns of gastrointestinal parasite infection and infection risk among populations of black-and-white (Colobus guereza) and red colobus (Piliocolobus tephrosceles) inhabiting undisturbed habitats and forest fragments (Chapman et al. 2005). Their results suggest that forest fragmentation alters prevalence and infection risk and that these factors are influenced by host density. They also examined the relationships between forest-fragment attributes and infection patterns. Inter-fragment comparisons were looked for nine potential factors and demonstrated that tree-stump density (i.e a proxy of degradation) had a strongly positive influence on the prevalence of parasitic nematodes. Both fragment size (negative relationship) and primate population density (positive relationship) 
also predicted prevalence of some parasites. These results suggest that transmission dynamics of gastrointestinal parasites are affected by the degree and nature of anthropogenic disturbance of forest fragments (Chapman et al. 2005).

Given the framework of the effects of parasitism on nonhuman primate populations in a context of a very high anthropogenic change it seems important to survey the gastronintestinal parasites of the chimpanzees in Guinea-Bissau.

\section{6- Paleoclimate and Biogeography}

The evolutionary history of chimpanzees is intimately related with the history of their native forests (Gonder et al. 2006). This approach can be inserted into a biogeographic perspective, through the study of the distribution and diversity of organisms in time and space (Cox and Moore 2005). According to Lomolino et al. (2005) there are two ways to test hypotheses about species distribution and biodiversity: ecological and historical biogeography. Ecological biogeography is applied to the understanding of species distribution and diversity patterns, based on the interactions between organisms and their physical and biotic environment (Lomolino et al. 2005). Historical biogeography determines the series of events and processes that led to their speciation (i.e. origin, dispersal and species extinction) (Lehman and Fleagle 2006). The evolutionary history of chimpanzees has been clearly influenced by the biogeographic history of West Africa (Gonder and Disotell 2006). During the last 2.8 MYA (Plio-Pleistocene) the planet's climate has substantially changed (deMenocal 2004) (Fig. 1.3). According to Milankovitch's Astronomical Theory the main cause for these variations is the fluctuation in Earth's orbital parameters that caused expansion and cyclic contractions in the polar ice layers (Imbrie 1985; Imbrie et al. 1992; Livingstone 1993; Maley 1996; deMenocal 2004). Paleoclimatic recordings show that, approximately 800.000 years ago, in the Pleistocene, the amplitude of those cycles increased provoking significant changes in the Artic and Antarctic ice layers (Fischer et al. 1999; Gibbard and van Kolfschoten 
2004). According to this theory the gases on the atmosphere could have interacted with the oceanic currents and provoked changes in the polar ice volume, which, began expanding (Fischer et al. 1999; Zachos et al. 2001; deMenocal 2004). According to fossil records, during this period, several transitions in human evolutionary history also occurred.

Some recent isotopic and atmospheric dust measurement studies show that, as the glacial periods were intensifying, the average temperature of the planet was decreasing, resulting in significant changes in average sea and lake water levels (deMenocal 2004). Consequently atmospheric humidity was locked into the expanding ice, making those periods colder and more barren (deMenocal 2004). However, as the polar sheets decreased, water was again released to the atmosphere, making the interglacial periods milder and more humid (Imbrie 1985; Imbrie et al. 1992; deMenocal 2004).

These climate changes also had their effects on the African continent (Gonder 2000). Evidences strongly suggest that during the maximum glaciations periods, Africa's climate was colder and drier than nowadays (Maley 1996 and Cowling et al. 2008). This climate change is also the result of the variation of the cold sea currents, from northwest and southwest of Africa that were pushed towards the equator (Maley 1996). This chain of events contributed to the reduction of equatorial Africa's temperature and to the decrease of rain levels (Maley 1996). These changes had a direct effect on the landscape: wider habitats appeared, as well as a great abundance of herbaceous species, truly adapted to a more arid climate (Cowling et al. 2008). According to Nichol (1991) atmospheric dust levels had also increased, allowing the creation of dunes in humid areas where this couldn't happen before. On the other hand during interglacial periods there was an increase of pollen levels of species adapted to a humid forest environment, with forest recolonization of wider and more arid habitats (Cowling et al. 2008). From the last glacial period onwards, and in the following interglacial period (Holocene) it was possible for the tropical forest to reach their maximum extension (Maley 1996; Cowling et al. 2008). 
Palinological studies conducted in Lake Bosumtwi (Ghana) have confirmed this prairie into forest species transition (Maley 1996).

Several authors claim that some tropical areas have more diversity and endemism than others (Gonder et al. 2006). This hypothesis deduces that, during the maximum glaciation periods, some original fragments from tropical forests prevailed in favourable climate conditions. It also suggests that as forests were contracting some animals were becoming isolated in those refuges. This 'Refugia Theory' (Haffer 1982; Endler 1982; Mayr and O'Hara 1986) states that forest lineages that persisted could have differentiated due to the isolation of populations in the refuges by vicariance) and/or followed by dispersal during the forests expansion in the holocenic interglacial period (Grubb 1982; 1990). In this way, both forces, vicariance and dispersal, could have influenced African faunal distribution, as well as chimpanzees, even though these distribution patterns are more complex than can be explained only by the 'Refugia Theory' itself (Gagneux 1998).

The geographic determination of these refuges is not universally accepted (Gonder et al. 1997; 2006; Anthony et al. 2007). Areas that today have a bigger biodiversity and higher endemism are strong candidates for being refuges in the past (Grubb 1990; Hamilton 1982; Grubb et al. 2003). Hamilton (1982) and Maley (1996) point out five key-areas as being possible refuges: Guinea, Sierra Leone and Liberia; eastern Ivory Coast's and west of Ghana, Nigeria, Cameroon and Gabon; Congo Basin and eastern Tanzania, Uganda, Rwanda and Burundi, even though some smaller refuges could have existed outside these nuclear areas (Cowling et al. 2008). On another hand, vicariance and dispersal models acknowledge the existence of obstacles or barriers that affect gene flow (Cox and Moore 2005). Subsequent investigations have confirmed rivers and mountain chains as barriers to the tropical fauna dispersal (Eriksson et al. 2003; 2004; Anthony et al. 2007).

One of the barriers that promote the discontinuity of the landscape in Western Africa is the Dahomey Gap (extending from Ghana to the northern frontier of Nigeria and East of Benin). It is $400 \mathrm{~km}$ wide but it is believed that during maximum glacial 
periods it could have been $1400 \mathrm{~km}$. Nowadays it characterizes by the presence of savannah and a dry climate (Gonder et al. 2006). Some authors noticed that more remote areas from the Dahomey Gap have a higher biodiversity, such as the case of Guinea-Congolian vegetal formation, which goes from northern Ghana to the northern coast of Guinea-Bissau (White 1983; Caldecott and Kapos 2005). Other major barriers that block species dispersal and cause genetic structuring are rivers (for instance the Niger River, Volta, Sanaga, Cross River, Comoé, Sassandra, etc.) as some recent studies on chimpanzees, bonobos and gorillas have shown (Eriksson et al. 2004; Gonder et al. 2006; Anthony et al. 2007).

Most likely, this is the scenario in which chimpanzee evolutionary history developed: in several refuges, deprived of contact with other communities due to geographic barriers, with fluctuating vegetation and with the presence of other equally competitive species (Gagneux et al. 2001). 


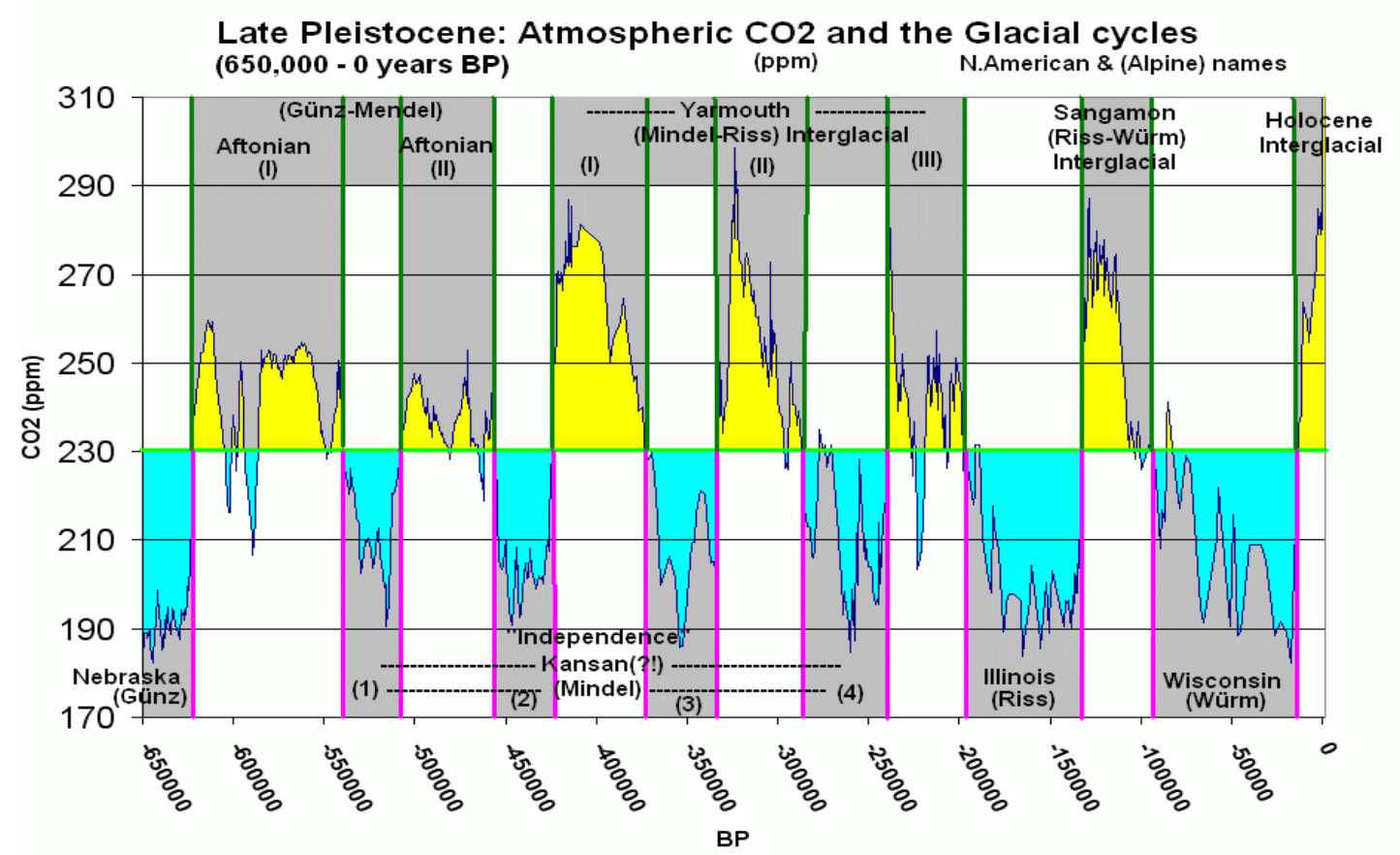

Figure 1.3: Plio-Pleistocene glaciar and interglaciar periods and atmospheric $\mathrm{CO} 2$ (after Kukla 2005:1578).

\section{7- The contribution of Phylogeography}

The term 'Phylogeography' was coined for the first time in 1987 by Avise and can be considered as a subdiscipline of biogeography. Phylogeography articulates concepts and techniques from a broad range of areas: Molecular Genetics, Population Genetics, Demography, Phylogenetic Systematics, Ethology and Paleontology (Avise et al. 1987). Phylogeography is concerned with the spatial distribution of genetic lineages within and its comparison among species (Avise $1998 ; 2009)$. Due to the availability of intraspecific variation data in the form of DNA sequences and the incorporation of coalescent theory to infer demographic and evolutionary processes it is possible to assess hypotheses on species evolutionary history (Avise 2000). 
The statistical phylogeography approach allows a better understanding of the order of events and mechanisms are associated with colonization, diversity and extinction of genetic lineages in particular geographic regions (Avise 2000). With this analysis it is possible to address hypotheses about possible vicariance and/or dispersal and to identify the geological, ecological or ethological causes that might have had some influence in the patterns observed (Avise et al. 1987) The discipline has in vertebrates historically relied mainly on the analysis of mitochondrial DNA (mtDNA) (Avise 1995). Since the haplotypes register a matrilinear history of mutational events is possible to connect them through a phylogenetic network, which can be overlaid on the past and present geographical distribution of the species (Avise 2000).

One central concept in phylogeography is that although many distinct genotypes may currently be present in a population, they all trace back to particular common ancestor at some point in history. The statistical expectation for the ways in which genotypes trace back to a common ancestor, given a particular mutation rate and effective population size is estimated using 'Coalescent Theory' (Hudson 1990; Avise 2009). Coalescence is basically a lineage divergence model that considers genetic drift, and that goes back in time until a most recent common ancestor (MRCA) (Avise 2000). Coalescent theory established a conceptual framework to the study the processes that historically gave shape to the populations and origin to the current distribution of genetic variation. Of the countless contributions and applications of phylogeographic analysis it is possible to: i) point out studies whose purpose was to determine the place of origin and dispersion routes of species considered as pests or that colonized landscapes; ii) explain the population structure of a species; iii) identify the causes of the population variation observed in genetic and chromosomal traits and its correlation with geographic or ecological gradients, iv) uncover speciation modes (sympatric or allopatric) that explain the co-occurrence of distinct morphotypes in one species, v) enhance the detection of endangered populations facing imminent extinction, and finally, v) carry out studies of 
comparative phylogeography that enable to consider the dispersion or vicariant factors on the evolution of codistributed species (Avise and Hamrick 1996; Avise 1995; 1998; 2000; 2004; 2009).

Phylogeographic data have supported the identification of ESUs (Evolutionary Significant Units) and MUs (Management Units) in threatened species, and therefore may improve conservation strategies for Guinea Bissau's chimpanzees (Moritz 1994).

\section{8- Non invasive genetics and molecular markers}

With the advent of PCR it was possible to amplify DNA from new sources such as feathers, hair, and feces (Goossens et al. 1998; Goossens et al. 2003). The application of non-invasive genotyping techniques appeared to be a solution for the problem of handling animals, which most of the time involved trapping, hunting, bleeding and taking biopsies to facilitate genetic sampling (Taberlet et al. 1999).

Morin and Woodruff (1992) pioneered this field by using non-invasive shed hairs and fecal DNA, mostly from wild chimpanzee communities (Morin et al. 1993; Morin et al. 1994a; Morin 1994b). From that point on many non-invasive studies were applied to different species, such as, the Iberian lynx (Lynx pardinus) (Pires and Fernandes 2003; Palomares et al. 2002); bears (Wasser et al. 1997); birds (Otis tarda) (Idaghdour et al. 2003); sea lions (Eumetopias jubatus) (Deagle et al. 2005), mustelids (Riddle et al. 2003; Gómez-Moliner et al. 2004; Hedmark et al. 2004) foxes (Vulpes vulpes) (Dalén et al. 2004), African elephants (Loxodonta cyclotis) (Eggert et al. 2003), etc.

Genetic diversity, besides being a key indicator of biodiversity, allows species, individuals or populations to be compared (Frankham et al. 2005). Molecular markers allow us to infer the distinctiveness of each individual (Parker et al. 1998); clarify their population structure and their differentiation in time and space (Avise 1998; 2000; 2004), and inform about the densities, abundances and effective sizes of the population (Kohn and Wayne 1997; Beebee and Rowe 2004). 
Molecular techniques have a myriad of applications, but are especially useful if conservationists need to ensure the maintenance of genetic diversity and clarify behavioural, demographic and ecological aspects of endangered species, as well as for forensic analysis (Haig 1998). Each genetic marker has its own advantages and disadvantages, according to each research objective (Coote and Bruford 1996). Markers with a faster evolutionary rate have their applicability to the study of the individual, communities and populations, while those which have a slower evolutionary rate, are useful for the phylogenetic studies (Frankham, Ballou et al. 2005). The use of genetic markers is dependent on the studies problematic (Coote and Bruford 1996). This research used the Hyper Variable Region I (HVR1) of the D loop fragment from mtDNA as a preferred genetic marker.

\subsection{1- Mitochondrial DNA}

Mitochondria are fundamental organelles in each cellular unit. Found in all eukaryotic organisms they generate sufficient chemical energy to the cell in the form of adenosine triphosphate so that it can fulfil its basic functions. They could have allied to the eukaryotic cell through an evolutionary process of endosymbiosis (Margulis 1992), seeing that its genesis could be a bacteria that found the benefit of "allying" to another cellular type. Mitochondria also have the particularity of possessing a genome with functional genes, and that, in almost all mammals is transmitted matrilinearly. They are also inherited clonally and do not undergo recombination (Avise 1998; Avise 2000).

MtDNA analysis is one of the most direct methods of studying genetic variation and has been extensively used in primate and other vertebrate populations; it gives direct information about the female population structure and even about the hierarchy of a determined sex "dominated" population (Di Fiori and Gagneux 2007). It can also supply information about founder effects, hybridization and introgression (Avise 2000; Avise 2004). 
mtDNA analysis has been used in two major ways: 1)- to estimate genetic variation within populations, and 2)- to recognize evolutionary divergent sets of populations, including the resolution of evolutionary significant units and management units in order toto evaluate conservation value of populations or areas from an evolutionary or phylogeographic perspective (Moritz 1994).

MtDNA genotypes are described as haplotypes (since they are effectively haploid), which differ from one another by particular mutations accumulated since female ancestors were last shared. Due to the rapid evolutionary rate many different haplotypes often coexist within a species, and it is possible to use these sequences to assess the matrilineal histories of individuals and populations (Avise 2009). The mtDNA control region is a unique non-coding region, which is typically approximately $1 \mathrm{~kb}$ long and contains two hypervariable regions (HVR1 and HVR2). It is involved in the initiation and regulation of mtDNA replication and transcription (Moritz et al. 1987). These non-coding regions of mtDNA have a higher nucleotide substitution rate than both coding mtDNA and nuclear DNA (Morovvati et al. 2007). For this reason hypervariable areas of the mtDNA genome are considered 'mutational hotspots' (Stoneking 2000). This section of mtDNA is thus suitable for intra-population studies as the high mutation rate means that polymorphic sequences, i.e. different haplotypes, are more likely in unrelated individuals (Morovvati et al. 2007). Moreover, the hypervariable regions are flanked by conserved regions, allowing primer design for PCR (Galtier et al. 2009). This study made use of HVR1, which is considered more polymorphic than HVR2 (Lutz et al. 1998. Morovvati et al. (2007) showed that HVR1 was more discriminating than HVR2 in humans due to increased nucleotide differences. This makes the HVR1 region of the mtDNA the most suitable for studying population structure. 


\subsection{2- Microsatellites}

Microsatellites are stretches of DNA sequence consisting of short tandem repeats of mono, di, tri, tetra, penta and hexa nucleotides (Tautz and Schlotterer 1994). Microsatellites have been found in all prokaryotic and eukaryotic genomes analysed to date (Toth et al. 2000). Microsatellite perfect repeats are without interruptions, imperfect repeats are interrupted by non-repeat nucleotides and compound repeats are cases where two or more microsatellites are found adjacent to one another. There may also be combination of these, for example imperfect compound repeats (Toth et al. 2000). Microsatellites are powerful genetic markers, due to their codominance, abundance, dispersal throughout the genome, multiallelic variation, reproducibility and high level of polymorphism (Bruford and Wayne 1993). This high level of polymorphism is due to mutations affecting the number of repeat units. STR's provide a number of advantages over other molecular markers, namely that multiple STR alleles may be detected at a single locus using a simple PCR based screen, very small quantities of DNA are required for screening, and analysis is possible to automated allele detection and sizing (Schlotterer 2000). Microsatellites demonstrate a relatively high degree of transferability between species, as PCR primers designed to a microsatellite within one species frequently amplify a corresponding locus in related species, enabling comparative genetic and genomic analysis (Coote and Bruford 1996).

Studies of the potential biological function and evolutionary relevance are leading to a greater understanding of genomes and genomics. STR's were initially considered to be evolutionary neutral, however more recent evidence suggests they may play an important role in genome evolution and provide hotspots of recombination. Functional roles have been attributed to some microsatellites. They are tought to be involved in gene expression, regulation and function as transcriptional activating elements (Duran et al. 2009). 
Microsatellites have many uses in genetics, such as the detection of alleles associated with disease, genome mapping, association studies, genetic diversity, paternity assessment, forensics and inferences of population history and conservation (Brumfield et al. 2003)

\section{9- Chimpanzee phylogeographic and parasitological studies: an overview}

This section follows a chronological approach in order to demonstrate the close relationship between the technical advanves of molecular biology and the chimpanzee nonivasive genetic studies. The first noninvasive molecular studies with non-human primates had only appeared in the beginning of the 1990'. According to Goossens et al. (2003), this fact is due to, contrarily to other animal orders, primate populations have complex social systems, long generations and the obtainance of genetic samples before non-invasive genotyping was logistically and ethically impossible. The molecular studies with non-human primates can be grouped in what is currently called 'Molecular Primatology'.

Molecular Primatology can be defined as the application of techniques from Molecular Genetics to Primatology (Di Fiori and Gagneux 2007).

This recent denomination emerged with the need to group a series of ecologic, genetic, behavioural or population studies where nonhuman primates were used as systems. Its denomination was proposed by Morris Goodman (Wildman et al. 2003). In 2006 Anthony Di Fiori organized an international conference (i.e. Molecular Primatology: Progress and Promise, 2006), under the auspices of the Centre for the Study of Human Origins from New York University, where he gatehered the support of the scientific community for the designation of this subdiscipline of Primatology.

Despite the proliferation of these studies in the last decades, there are some classical works that announce the emergence of Molecular Primatology. Nuttal 
(1904), in his serologic monography:" Blood Immunity and Blood Relationship", suggested that human beings are intimately related to chimpanzees and gorillas because, besides owning the same blood type/groups ( $A B O)$, they produce the same antigens.

In the 1960's, the idea that it could be possible to rebuild organism's evolutionary history started to gain strength. This research path started, therefore to be applied to non-human primates (Buettner-Janush et al. 1961; Goodman 1962; Zuckerkandl 1963). In the 1970's appeared the first studies on the amino acid sequences and this novel technique was applied to studies of non-human primates phylogenies, and to unravel their molecular socio-ecology (Duggleby 1977). It is, however, in the 1980's and 1990's that the first intensive studies on DNA sequencing in non-human primates were initiated, with the development of several molecular techniques.

According to Di Fiori (Di Fiori 2003; Di Fiori and Gagneux 2007) the main scientific areas of the Molecular Primatology study can be classified as:

Molecular Ecology: the use of molecular techniques that allow the examination of consanguinity, dispersal patterns, social organization in primates and phylogeography (vide Avise 1995; 1998; 2000; 2004; Avise and Hamrick 1996; Beebee and Rowe 2004; Melnick et al. 1992; Rosemblum et al. 1997; Shimada 2000; Goldberg and Ruvolo 1997; Morin et al. 1994a; Goldberg and Wrangham 1997; Idani 1991; White 1996; Gerloff et al. 1999).

Conservation Genetics: the application of molecular techniques to primate conservation biology. Most of the non-human primate species inhabit tropical regions that are threatened due to various endogenous and exogenous factors. By this reason it's important to alert all the "Global Communities" that there are less than 200.000 chimpanzees worldwide. In this sense, conservation genetics becomes relevant because it helps to the characterization of the genetic diversity of some species, or even the way it is geographically structured, estimating the populations' effective size or the information on captivity colonies mating (see for more details: 
Loeschcke et al. 1994; Frankham et al. 2005; Avise and Hamrick 1996; Smith and Wayne 1996; and more recently a new journal "Conservation Genetics" ${ }^{1}$, that provides excellent perspectives on the molecular applicabilities to conservation).

Molecular Diversity and Adaptation: the adaptive meaning of non-human primates' Intra and Inter molecular diversity rate. Also in here the molecular techniques offer an alternative method that allows the direct estimation of the consanguinity degree and the individuals' kinship, basing in the genetic markers sharing (Pamilo and Crozier 1982; Queller and Goodnight 1989; Lynch and Ritland 1999).

Behaviour Genetics: Genetic and behavioural variation among individuals. That is, the attempt to understand what is the genetic basis that leads one individual to have more agonistic behaviours than other individuals, the reason for the existence, in the same sympatric species, of individuals that migrate later than others, or even, why do some individuals show greater cognitive ability than others (Fairbanks 2001; Plomin et al. 2001; Lesch et al. 1996; Bennet et al. 2002).

Comparative Genomics: analysis and comparison of different species genomes. This term was coined by Thomas Roderick (1986) and, in the following year, the current director of the OMIM Project (Online Mendelian Inheritance in Man) Victor McKusick launched the credited scientific Journal, Genomics (Di Fiori and Gagneux 2007). It is also in this sense that the chimps genome sequencing and comparisons to humans are included (Consortium 2005).

In 1969, Hill revises Schwartz's taxonomy and classified chimpanzees into two species: Pan troglodytes and Pan paniscus. He also recognised that there are four subspecies in the common chimpanzees and a new subspecies of hybrid individuals between gorillas and chimps, which he called Pan troglodytes koolakamba. However, no study has, so far, confirmed the existence of this hypothethic subspecies (Hill 1969).

\footnotetext{
${ }^{1}$ http://www.springer.com/life+sciences/ecology/journal/10592
} 
Excluding this last subspecies Hill's classification remained identical till 1997, when Gonder and colleagues (1999), by recurring to non-invasive genetic techniques, conducted a mitochondrial diversity survey among the chimpanzees from Nigeria and Cameroon. The study of these reserachers showed the existence of a fourth subspecies, endemic of that area. Based on Gray's attribution (1862) this subspecies was named Pan troglodytes vellerosus (Gonder et al. 1997).

This controversy around the number of chimpanzee subspecies demonstrates that there is a great genetic, morphologic, behavioural and ecological diversity among different chimpanzee communities (Gonder et al. 2006). In this sense, it's not surprising that many of the genetic studies that have been conducted in chimpanzees were focused on their systematics, phylogeography, evolutionary history and sociogenetics.

Morin and Woodruff (1992) used shed hairs as an innovative DNA source, mostly from wild chimpanzee communities. Their results suggested that there were 3 great lineages and that chimpanzees' evolutionary history should be revised (Morin et al. 1993; 1994a; 1994b; 2001; Morin and Woodruff 1992; Woodruff 1993).

Takenaka and colleagues (1993) successively applied paternity tests in captivity, recurring to non-invasive samples, opening the way, not only to future studies on wild communities but also to a better understanding of their social dynamics.

In 1994, based on mitochondrial DNA samples, Ruvolo and colleagues (1994) carried out a study on the hominoid' phylogeny and conclude that the genus Homo and the genus Pan form a separate lineage from gorillas. This study also revealed that both intra-population variability is higher to the one observed between the species of chimpanzees which, consequently, can have important effects in the genetic management of these species in captivity and also, that the little mitochondrial diversity in humans can be put in perspective when compared to other humanoids' diversity. 
In order to maximise the genetic variability of a chimpanzee colony in Taronga Zoo, Houlden and colleagues (1997) performed a maternity and paternity analyses of several chimpanzees members and proved that, effectively, the alpha male had the highest reproductive success, confirming the idea of a correlation between hierarchy and reproductive success. They also claim that microsatelites are good markers to the distinction of the individuals' origin and provenience and, consequently, an election marker for management measures and genetic maintenance in captivity (Houlden, et al. 1997).

Additionally, Goldberg and Ruvolo (1997) conducted an extensive study on the phylogeography and sociogenetics of western African chimpanzees. This study demonstrated that they didn't show a classic phylogeographic pattern, with a low overall variability and little clustering similar to the studies done with human populations. In biogeographic terms these scientists verified that rivers didn't prevent the genes' flow between eastern chimpanzees, since no discontinuities were observed in the haplotypical trees, confirming $P$. troglodytes schweinfurthii as a subspecies with a great mobility, capable of moving in wide corridors and forest fragments (Goldberg and Ruvolo 1997; Goldberg and Wrangham 1997).

Gagneux and colleagues (1997) refer the technical difficulties intrinsically bounded to non-invasive methods, mostly referring false alleles and allelic dropout. They also warn that, if circumstances are more favourable, it is preferable to collect plucked hair in detriment of shed hair.

Gagneux and colleagues (1999a), in a study reflecting African hominoids' evolutionary history, presented a new date for the split between humans and chimps situated around 2.5 million years ago. In the same way, by comparing mtDNA phylogenetic sequences, they verifyed that there are profound subclades in gorillas and chimps and that chimpanzee' clades show a higher number of ramifications, suggesting that gorillas and chimpanzees had a very different evolutionary history from humans. 
Another study, from a sociogenetics perspective, revealed that female chimpanzees in Taï Forest furtively seek males that don't belong to their social unit, increasing the genic flow of males among communities, even though they are phylopatric. This reproductive strategy allows females to choose a larger number of males, without loosing the resources previously owned, as well as the protection conferred to them by their mates (Gagneux et al. 1999b).

In the same year, Taberlet et al. (1999) published an article about the advantages and disadvantages of the application of non-invasive methods, granting a major theoretical contribution through their model to the reliability in these kind of studies (Taberlet et al. 1999).

In 2000, Katherine Gonder presented a new extensive phylogeographic study about chimpanzees from Nigeria and Cameroon (Gonder 2000). New technical improvements appear in the microsatellites use (Goossens et al. 2000), and Meier et al. (2000) reconfirmed the relevance of microsatellites application in the genetic characterization of captivity chimpanzee communities. They also verified that there was not a correlation amid the position of males in the social hierarchy and the short-term reproductive success (Meier et al. 2000). A year later, Linda Vigilant (2001) published an article about "Paternity and relatedness in wild chimpanzee communities", in agreement with the study performed by Constable et al (2001) about the paternity of Gombe's Chimpanzees: " Noninvasive paternity assignment in Gombe chimpanzees" (Constable et al. 2001). An important phylogeographic study also emerged in this year, assembling four of the researchers that contributed the most to the comprehension of the chimpanzees' evolutionary history: "Gene flow in wild chimpanzee populations: what genetic data tell us about chimpanzee movement over space and time" (Gagneux et al. 2001).

Another relevant contribution was the publication of a study by Stone et al. (2002) based on the non-codificant region of $Y$ chromosome. This study concluded that chimpanzees and bonobos have, from six to seven times, more variation than 
humans and that their population effective size was big or relatively constant when compared to the former (Stone et al. 2002).

Nevertheless, Yu et al (2003) launched, once again, the controversy on the dating of the chimps and human beings' common ancestor by declaring that there is "Low nucleotide diversity in chimpanzees and bonobos". These authors pointed to a later dating of chimps and bonobos split (ca. 1,8 MYA), advancing the formation of the Congo River as hypothesis (Yu et al. 2003). Expectadly, in the following year, new studies appeared showing alternative results, like the case of Fischer et al. (2004), that stated that chimpsanzee evolutionary history might have been more complex than previously thought, that in spite of a clear decrease trend in the number of chimpanzee wild populations, they exhibit a high genetic diversity. The authors also advance that this observation can be due to a sudden population reduction followed by a fast recovering. They also attributed a split time amid central and western chimps of about 430.000 and 650.000 years (Fischer et al. 2004). McGrew et al. in the same year (2004), demonstrated, in the Mont Assirik chimpanzees communities, Senegal, that non-invasive techniques could effectively be of a great contribution to the deep socioecologic knowledge and biology os the species (McGrew et al. 2004). Moreover, a phylogeographic study on the Bossou chimps' mitochondrial diversity was published, demonstrating that there is little genic flow among the communities of chimpanzees from the south of Guinea (Shimada et al. 2004).

2005 was certainly the "International Year of the Chimpanzee", given the fact that the chimpanzee genome was sequenced by one international consortium, allowing an effective "Comparative Genomics" (Consortium 2005) and the publication of a vast number of papers (see volume 437 of Nature).

An opinion article about the challenges placed to population genetics' research in a "post genomic era" is presented by Stone and Verrelli (2006). In this same year, Gonder et al. (2006) grant another important contribution to the understanding of the biogeography of chimpanzees from Nigeria-Cameroon, gradually strengthening the existence of the fourth species (Gonder and Disotell 
2006, Gonder et al. 2006). Fischer et al. (2006) in the other hand, pointed out the isolation by distance model as a possible explanation for the complex demographic and evolutionary chimpanzee histories and disagree with the notion that subspecies are genetically distinct entities (Fischer et al. 2006). See as well Mitani's work about the demographic influences on the behavior of chimpanzees (Mitani 2006).

More recently, Becquet et al. (2007) by analysing 310 autosomatic microsatellites from 78 chimpanzees (41 western, 16 central, 7 eastern, 3 hybrids and 11 unknown) and 6 bonobos, obtained the following results:

(i) The high mutation rate from the microsatellite data allowed more information about historical/demographical events by locus. In terms of cluster analysis, the authors recurred to the program STRUCTURE that demonstrated the existence of four major clusters (i.e. discontinuous populations). This result, together with the map of haplotypes of the $Y$ chromosome and the mtDNA, confirmed that there are few evidences for the existence of a fourth subspecies.

(ii) Concerning the principal components analysis (PCA), it also demonstrated a high level of population structure giving a statistical meaning to the chimpanzee populations' subdivisions: four discontinuous populations, four very significant eigenvectors.

(iii) The authors also tested for possible additional populations admitting, however, that the sample size is limited, i.e. there is little variation in the $P$. $t$. vellerosus samples and that a more systematic survey is necessary.

(iv) In terms of inbreeding evidence the authors found a reduced number of heterozygous genotypes, especially in western and central chimpanzees, and in terms of allele variation the difference between bonobos and western chimpanzees is bigger than central or eastern chimps. This fact derives on the effects of the genetic drift (i.e. bottleneck) on western chimpanzees. The first diverging population was $P$. t. verus, pointing out as a possible result, a diminished population effective size.

The main conclusions of this study were: 
1. The three different chimpanzee subspecies denominations match to individuals clusters with similar allelic frequencies that can be defined from genetic data without considering the geographic "label";

2. There are low evidence of mixture between wild groups. Eastern and central populations are more related in time among themselves than western chimpanzee populations;

3. The PCA suggests something about the western population. Still, more data, more samples, more genetic markers and information about the geographic origin is required in order to clearly understand this structure;

4. No support for the existence of a fourth common chimpanzee population was found.

5. Despite of trying to include the biggest number possible of samples from the African continent, the geographic sample selection procedure wasn't random.

6. Chimpanzees from other regions, including those regions where chimpanzees are extinct, may give us the impression of discontinuity. Future studies that include chimps through more African populations may, in principle, identify intermediate populations and demonstrate more variation patterns (Becquet et al. 2007).

Caswell et al. (2008) presented new dating for the splits among chimpanzees and bonobos populations: 1.290 .000 years ago for bonobos and chimpanzees; 510.000 for western and central chimps and at least 50.000 between eastern and central chimpanzees. They also estimate that the effective size of the central chimpanzee population is of 100.000 individuals, more than once thought, and that the River Congo formation may have been in the origin of the chimps and bonobos split, seeing that this date is consistent with this hypothesis (Caswell et al. 2008) (Fig. 1.4). 


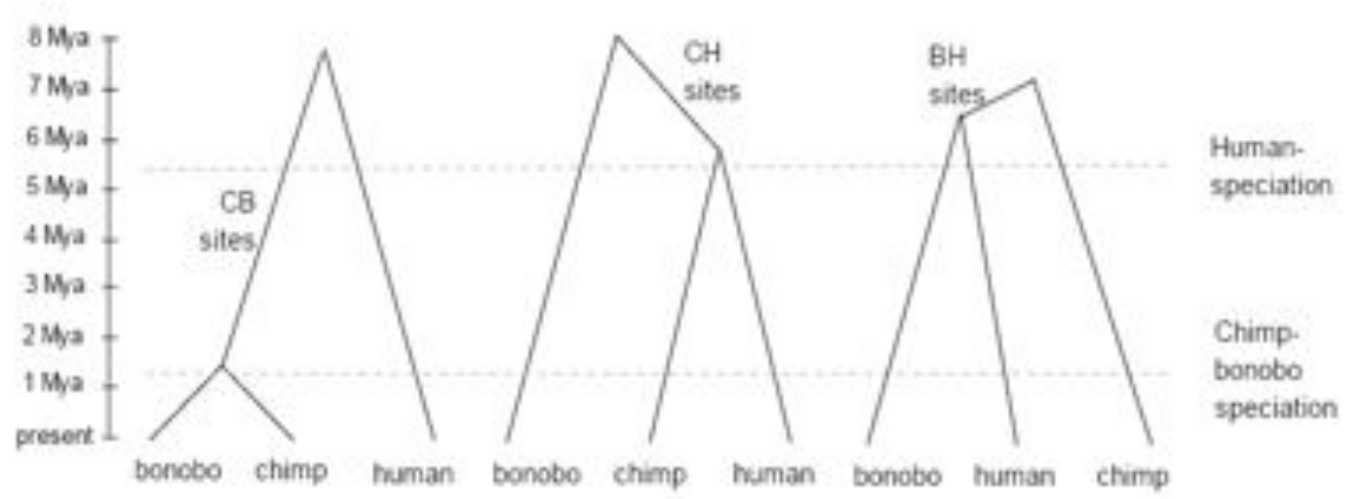

Figure 1.4: Split dates between chimpanzees, bonobos and humans (from Caswell et al. 2008:10).

Another recent study suggests that chimps and humans speciation process was complex, with the possibility of gene flow among both species after an initial period of separation (Patterson et al. 2006). Finally, Gonder et al (2011), by using genotypes of 94 chimpanzees, demonstrated that the species fall into three major populations: (i) Upper Guinea in western Africa (P. t. verus); (ii) the Gulf of Guinea region ( $P$. t. ellioti); and (iii) equatorial Africa ( $P$. t. troglodytes and $P$. $t$. schweinfurthii). This study also suggests that the chimpanzees from NigeriaCameroon occasionally hybridize (Gonder et al. 2011). Chimpanzee evolutionary history remains open and covered in controversy. Research in this area will surely contribute to shed light in certain chimpanzee phylogeographic hypothesis and time estimations.

In another perspective, the interaction between parasites and hosts can play a very important role in natural and wild populations' diversity (Nunn et al. 2004). According to Esch and Fernandez (1993) parasites can affect ecology and the hosts' evolution, as well as their growth and regulation (Hochachka and Dhondt 2000). They can also affect the whole community's biodiversity (Hudson et al. 1998; 2002), besides having a direct impact in the hosts' survival and reproduction and an indirect one by affecting their health conditions (Boyce 1990; Chandra and Newberne 1977; 
Coop and Holmes 1996; Dobson and Hudson 1992; Hudson et al. 1992). A severe parasitosis can cause haemorrhages, tissue and organs damage, spontaneous abortions, congenital malformations and, in some cases, even the host's death (Chandra and Newberne 1977).

The very close phylogenetic relation amid humans and chimpanzees can also result in the parasite exchange (Ott-Joslin 1993; Wolfe et al. 1998). Recent studies have shown that many of the emerging infectious diseases (HIV/AIDS, Ebola, etc) have chimpanzees as a reservoir (Gao et al. 1999; Leroy et al. 2004). In the same way, many human diseases (poliomyelitis, respiratory diseases, etc) had their impact on chimpanzee and gorilla populations (Hill et al. 2001; Kalema-Zikusoka et al. 2002). Even though some studies about intestinal parasites have been performed in primate populations, such as the baboons (Appleton et al. 1986; Eley et al. 1989; Müller-Graf et al. 1997) and howler monkeys (Stoner 1996), the parasitological studies on chimpanzees are still insufficient (Ashford et al. 2000; Lilly et. al. 2002; McGrew et al. 1989). As the chimpanzee's habitat is being fragmented, contact with humans is also being accented, increasing the risk of parasite transmission (Gillespie 2004). For this very reason it's important to maintain a current and updated record on their health conditions.

\subsection{0- Research questions, hypothesis and predictions}

The most recent genetic studies suggest the evolutionary history of West African chimpanzees as a very complex matter (Gagneux et al. 2001; Fischer et al. 2004; Fischer et al. 2006; Gonder and Disotell 2006; Gonder et al. 2006; Becquet et al. 2007; Caswell et al. 2008; Gonder 2011). Thus I set the question: Which were the demographic events that could have influenced the current mitochondrial genetic diversity in Guinea-Bissau's chimpanzees?

How do Guinea-Bissau chimpanzees relate with other members of the Pan troglodytes verus subspecies? Studies by Gonder (2006) suggest that there is a 
different lineage in Nigeria and Cameroon and that there was not any significant gene flow exchange with other western chimpanzees. More up-to-date studies conducted with western chimpanzees can confirm this idea. In the same way, what's the relation that these chimpanzees have with the neighbouring communities of Guinea? Considering the study by Shimada et al. (2004) I hypothesize that chimpanzees in Guinea-Bissau share haplotypes with Guinea.

From another point of view, what sorts of symbionts colonize the chimpanzee gastrointestinal tract ecosystem in Guinea-Bissau?

I would expect to find a high level of gastrointestinal symbiont diversity consequence of a disturbed habitat, a higher infection of parasites with direct cycles as contact intra and interspecific increases, and no differences in parasite prevalence between subpopulations.

\subsection{1- Aims and objectives}

This research addresses a gap in the current knowledge about the evolutionary and demographic history of chimpanzees in Guinea-Bissau. Similarly, it establishes baseline ecological information regarding their symbiontism patterns and how they are affected by habitat fragmentation.

To accomplish these aims I conducted extensive non-invasive surveys across the species distribution in the country. My objectives were:

1- $\quad$ To report on the use and trade of chimpanzee body parts in Guinea-Bissau for traditional practices (e.g. for nutritional, medicinal or ritual purposes, or "animistic myths").

2- $\quad$ To revisit the chimpanzee West African phylogeography;

3- $\quad$ To analyse and interpret their genetic diversity and differenciation;

4- $\quad$ To assess their genetic structure;

5- To reflect about their demographic history and to infer their lineage split divergences in a palecoclimate context; 
6- $\quad$ To monitor their gastrointestinal symbiont fauna and health status;

7- To contribute to their conservation by aporting genetic and parasitological recommendations.

\subsection{2- Thesis structure}

This thesis is organized into self-contained chapters. The data chapters of this thesis (Chapters 3-5) were written as separate manuscripts. Each one of these chapters includes an abstract, introduction, specific questions and hypotheses, methods, results, discussion, acknowledgements, and references. Formatting follows the rules and guidance for the particular journal.

Chapter 2 describes the study areas, the non-invasive sampling strategy, laboratory procedures (i.e genetic and parasitological) and general data analyses.

Chapter 3 reports the use and trade of chimpanzee body parts in GuineaBissau for traditional practices (e.g. for nutritional, medicinal or ritual purposes, or "animistic myths"). Informal ethnographic interviews were conducted and observations made with a view to providing insight into how these human traditions and myths might pose an additional threat. This chapter has been submitted to Traffic Bulletin as: Rui M. Sá, Maria Ferreira da Silva, Fernando Sousa and Tânia Minhós. "The trade and ethnobiological use of Chimpanzee body parts in GuineaBissau: implications for conservation". After peer review was published and is included in Appendix L.

Chapter 4 revisits the chimpanzee West African phylogeography with special focus on chimpanzees from Guinea-Bissau. It investigates their evolutionary history and unveils their demographic history. Based on a 261bp from the HVR1 mtDNA, their genetic structure was assessed and conservation genetics implications discussed. This chapter is in preparation for submission to Evolutionary Anthropology as: Rui M. Sá, Kathljine Koops, Annaria Marra, Tânia Minhós, Maria Ferreira da Silva, Joost Van Schinjdel, Cláudia Sousa and Michael W. Bruford. 
"Inferring the evolutionary history of a peripheral and endangered ape population: the chimpanzees of Guinea Bissau".

In Chapter 5 I present the results of the parasitological survey of the chimpanzee population inhabiting Cantanhez National Park, in the south of GuineaBissau. I compared three chimpanzee subpopulations living within the Park in the areas with different levels of anthropogenic fragmentation. This chapter was submitted and is currently under review to the American Journal of Primatology as: Rui M. Sá, Jana Petrášová, Kateřina Pomajbíková, Ilona Profousová, Klára J. Petrželková, Cláudia Sousa, Joanne Cable, Michael W. Bruford and David Modrý. "Gastrointestinal symbionts of chimpanzees in Cantanhez National Park, GuineaBissau with respect to habitat fragmentation" and is currently under revision.

Chapter 6 summarize the major findings of this research, its limitations and future directions. It also provides recommendations and considerations for chimpanzee conservation in Guinea-Bissau.

Finally, from Appendix I to $\mathrm{M}, \mathrm{I}$ attached five manuscripts that are either in preparation (Appendixes I and J) or published (Appendix K-M). These manuscripts were produced during the course of $\mathrm{my} \mathrm{PhD}$ and they fall under the Molecular Primatology research scope. I share first authorship with the first four (Appendix I-L) and the last one I am co-author (Appendix M).

\subsection{3- References}

Ancrenaz M, Dabek L, and O' Neill S. 2007. The costs of exclusion: recognizing a role for local communities in biodiversity conservation. PLOS Biol 5: e289.

Andresen E. 2000. Ecological roles of mammals: the case of seed dispersal. In: Entwistle, Abigail and Nigel D. (Eds.) Future priorities for the conservation of mammalian diversity: Has the panda had its day? pp. 12-25. Cambridge University Press, Cambridge. 
Anthony N, Johnson-Bawe M, Jefffery J. et al. 2007. The role of Pleistocene refugia and rivers in shaping gorilla genetic diversity in central Africa. PNAS 104: 2043220436.

Appleton C, Henzi S, Whitten A, et al. 1986. The gastro-intestinal parasites of Papio ursinus from the Drakensberg Mountains, Republic of South Africa. International Journal of Primatology 7: 449-456.

Arnold K, and Whiten A. 2003. Grooming dynamics of male chimpanzees of the Budongo Forest, Uganda: tests of five explanatory models. Behaviour 140: 519- 552.

Ashford R, Reid G, and Wrangham R. 2000. Intestinal parasites of the chimpanzee Pan troglodytes, in Kibale Forest, Uganda Annals of Tropical Medicine and Parasitology 94: 173-179.

Avise J. 1995. Mitochondrial DNA polymorphism and a connection between genetics and demography of relevance to conservation. Conservation Biology 9: 686-690.

Avise J. 1998. The history and purview of phylogeography: a personal reflection. Molecular Ecology 7: 371-379.

Avise J. 2000. Phylogeography. The history and formation of species. London, Harvard University Press.

Avise J. 2004. Molecular Markers, Natural History and Evolution. Sunderland, Massachusetts, Sinaeur Associates.

Avise J. 2009. Phylogeography: retrospect and prospect. Journal of Biogeography 36: 3-15. 
Avise J, and Arnold J. et al. 1987. Intraspecific phylogeography: the mitochondrial DNA bridge between population genetics and systematics. Annual Review of Ecology and Systematics 18: 489-522.

Avise J, and Hamrick J. 1996. Conservation genetics: ca se histories from nature. New York, Chapman and Hall.

Becquet C, Patterson N, Stone A, et al. 2007. Genetic structure of chimpanzee populations. PLoS Genetics 3: e66.

Beebee T, and Rowe G. 2004. An Introduction to Molecular Ecology. Oxford University Press, Oxford.

Bennet A, Lesch K, Heils L, et al. 2002. Early experience and serotonin transporter gene variation interact to influence primate CNS function. Molecular Psychiatry 7: 118-122.

Berg| R, Bradley B, Nsubuga A, et al. 2008. Effects of Habitat Fragmentation, Population Size and Demographic History on Genetic Diversity: The Cross River Gorilla in a Comparative Context. American Journal of Primatology 70: 848-859.

Bermejo MJ, Rodríguez-Teijeiro G, Illera A, et al. 2006. Ebola outbreak kills 5000 gorillas. Science 314:1564.

Blom A, Alers MPT, Feistner ATC, et al. 1992. Primates in Gabon-current status and distribution. Oryx 26: 223-234. 
Boesch C, and Boesch H. 1989. Hunting behavior of wild chimpanzees in the Taï National Park. American Journal of Physical Anthropology 78: 547-573.

Boesch C, and Tomasello M. 1998. Chimpanzee and human cultures. Current Anthropology 39: 591-614.

Boesch C, Gnakouri C, Marques L, et al. 2008. Chimpanzee conservation and theatre: a case study of an awareness project around the Taï National Park, Côte d'Ivoire. In Stoinski T, Steklis D and Mehlman P (Eds). Conservation in the 21st Century: Gorillas as a Case Study. New York: Springer Science and Business Media.

Boyce M. 1990. The red queen visits sage grouse leks. Animal Zoolology 30: 263-270.

Brownell A. 2003. Benin. In Kormos R, Boesch C, Bakarr M, and Butynski T.West African Chimpanzees: Status Survey and Conservation Action Plan. IUCN, Gland, Switzerland.

Bruford M, and Wayne R. 1993. Microsatellites and their application to population genetics. Current Opinion Genetic Developments 3: 939-943.

Brumfield R, Beerli P, et al. 2003. The utility of single nucleotide polymorphisms in inferences of population history. Trends in Ecology and Evolution 18: 249-256.

Buettner-Janush J, Twichell J. Wong B, et al. 1961. Multiple haemoglobins and transferrins in a macaque sibship. Nature 192: 948-950.

Butynski T. 2003. The robust chimpanzee (Pan troglodytes: taxonomy, distribution, abundance and conservation status. In Kormos R, Boesch C, Bakarr M and Butynski T 
(Eds.). West african chimpanzees: status survey and conservation action plan. IUCN, Gland, Switzerland.

Call J, Agnetta B, and Tomasello M. 2000. Social cues that chimpanzees do and do not use to find hidden objects. Animal Cognition 3: 23-34.

Caldecott J, and Miles L. 2005. World Atlas of Great Apes and their Conservation, University of California Press.

Caldecott J, and Kapos V. 2005 Great ape habitats: tropical moist forests of the Old World. In Caldecott J, and Miles, L. (Eds.) The World Atlas of Great Apes and their Conservation. pp. 31-42. California University Press (Berkeley, California and London).

Caldwell C, and Whiten A. 2007. Social learning in monkeys and apes. In Campbell C, Fuentes A, Mackinnon K, Panger M, and Bearder S (Eds.). Primates in perspective. Oxford University Press, New York.

Campbell C, Fuentes A, Mackinnon K, Panger M, and Bearder S. 2008. Primates in Perspective. London, Oxford University Press.

Carvalho S, Cunha E, Sousa C. et al. 2008. Chaines opératoires and resourse exploitation in chimpanzee (Pan troglodytes) nut cracking. Journal of Human Evolution 55: 148-163.

Casanova C. 2006. Introdução à Antropologia Biológica: princípios evolutivos, genetica e primatologia. Universidade Técnica de Lisboa, ISCSP, Lisboa.

Caspary H-U, Koné I, Prouot C, et al. 2001. La chasse et la filière viande de 
broussedans l'espace Tai, Côte d'Ivoire. Tropenbos Côte d'Ivoire Série 2, Wageningen, Netherlands.

Caswell J, Mallick L, Richter D et al. 2008. Analysis of chimpanzee history based on genome sequence alignments. PLoS Genetics 4: e1000057.

Chandra R, and Newberne P. 1977. Nutrition, Immunity, and Infection. Plenum Press, New York.

Chapman CA, and Russo SE. 2007. Primate seed dispersal: Linking behavioural ecology and forest community structure. In: Campbell CJ, Fuentes AF, MacKinnon KC, Panger M, and Bearder S. (Eds.). Primates in Perspective. pp.510-525. Oxford University Press, Oxford.

Chapman C, Gillespie T, and Goldberg T. 2005. Primates and the Ecology of their infectious diseases: how anthropogenic change affects host-parasite interactions? Evolutionary Anthropology 14: 134-144.

Chapman CA, Wrangham RW, Chapman U. 1995. Ecological constraints on group size: an analysis of spider monkey and chimpanzee subgroups. Behavioural Ecology and Sociobiology 32: 199-209.

CITES. 2008. Conservation of and trade in great apes. Resolution Conference No 13.4. http://www.cites.org/eng/res/13/13-04.php [Accessed 27/10/2008].

Consortium. 2005. Initial sequence of the chimpanzee genome and comparison with the human genome. The Chimpanzee Sequencing and Analysis Consortium. Nature 437:69-87. 
Constable J, Asley M, Goodall J, et al. 2001. Noninvasive paternity assignment in Gombe chimpanzees. Molecular Ecology 10: 1279-1300.

Coop R, and Holmes P. 1996. Nutrition and parasite interaction. International Journal of Parasitology 26:951-962.

Coote T, and Bruford M. 1996. Human microsatellites applicable for analysis of genetic variation in apes and old world monkeys. The Journal of Heredity 87: 406410.

Costa S, Lee P, Casanova C, et al. 2007. Social perceptions of nonhumans in Tombali (Guinea-Bissau, West Africa); Gender variances. Iberian Primatology: Present and Future Challenges, Peniche, APP.

Cowling A, Cox P, Maslin M et al. 2008. Simulated glacial and interglacial vegetation across Africa: implications for species phylogenies and trans-African migration of plants and animals. Global Change Biology 14: 827-840.

Cox CB, and Moore PD. 2005. Biogeography. An Ecological and Evolutionary Approach. Blackwell Publishing, Oxford.

Dalén L, Gotherstrom A, and Angerbjorn A. 2004. Identifying species from pieces of faeces. Conservation Genetics 5: 109-111.

Daszak P, Cunningham A, and Hyatt A. 2001. Anthropogenic environmental change and the emergence of infectious diseases in wildlife. Acta Tropica 78: 103-116.

Deagle B, Tollit D, Jarman S, et al. 2005. Molecular scatology as a tool to study diet of prey DNA in scats from captive Steller sea lions. Molecular Ecology 14:1831-1842. 
deMenocal P. 2004. African climate change and faunal evolution during the PliocenePleistocene. Earth and Planetary Science Letters 220:3-24.

Despommier D, Gwazda R, and Hotez PJ. 1995. Parasitic Diseases. Springer-Verlag, New York.

Di Fiori A. 2003. Molecular genetic approaches to the study of primate behavior, social organization, and reproduction. Yearbook of Physical Anthropology 46: 62-99.

Di Fiori A, and Gagneux P. 2007. Molecular Primatology. In Campbell C, Fuentes A, Mackinnon K, Panger M, and Bearder S. Primates in Perspective. Edited Oxford University Press, London.

Dobson A, and Foufopoulos J. 2001. Emerging infectious pathogens of wildlife. Philosophical Transactions of the Royal Society of London Biological Sciences 356: 1001-1012.

Dobson A, and Hudson P. 1992. Regulation and stability of a free-living host parasite system: Trychostrongylus tenuis in red grouse: 2 population models. Journal of Animal Ecology 61:487-498.

Doran DM. 1997. Comparative positional behavior of the African apes. In: McGrew WC, Marchant LF, Nishida T (Eds.). Great ape societies. Cambridge University Press , Cambridge, pp. 213-24.

Draulans D, and Van Krunkelsven E. 2002. The impact of war on forest areas in the Democratic Republic of Congo. Oryx 36:35-40. 
Dudley JJ, Ginsberg A, Plumptre J, et al. 2002. Effects of war and civil strife on wildlife and wildlife habitats. Conservation Biology 16:319-329.

Duggleby C, 1977. Blood group antigens and the population genetics of Macaca mulatta on Cayo Santiago. II. Effects of social group division. Yearbook of Physical Anthropology 20: 263-271.

Duran C, Appleby N, et al. 2009. Molecular genetic markers: discovery, applications, data storage and visualisation. Current Bioinformatics 4: 16-27.

Eggert L, Eggert J, and Woodruff D. 2003. Estimating population size for elusive animals: the forest elephants of Kakum National Park, Ghana. Molecular Ecology 12: 1389-1402.

Eley R, Strum S, Muchemi G, et al. 1989. Nutrition, body condition, activity patterns and parasitism of free-ranging baboons (Papio anubis) in Kenya. American Jounal of Primatology 18: 209-219.

Endler JA. 1982. Pleistocene forest refuges: fact or fancy? In Prance GT. (Ed.) Biological diversification in the tropics. Columbia University Press, New York.

Eriksson, J., G. Hohmann, and C. L. Boesch. 2003. Phylogeography and genetic diversity of wild bonobos (Pan paniscus). American Journal of Physical Anthropology 68: 68.

Eriksson, J., G. Hohmann, C. Boesch, and L. Vigilant. 2004. Rivers influence the population genetic structure of bonobos (Pan paniscus). Molecular Ecology 13: $3425-3435$. 
Esch GW, and Fernández JC. 1993. A functional biology of parasitism: Ecological and evolutionary implications., Chapman \& Hall, Cambridge.

Fa J, Juste J, Val, J. et al. 1995. Impact of market hunting on mammal species in Equatorial Guinea. Conservation Biology 9: 1107-1115.

Fairbanks L. 2001. Individual differences in response to a stranger: social impulsivity as a dimension of temperament in vervet monkeys (Chlorocebus aethiops sabaeus). Journal of Complementary Psychology 115: 22-28.

Fischer $\mathrm{H}$, Wahlen $\mathrm{M}$, Smith J. et al. 1999. Ice core records of athmospheric CO2 around the last three glacial terminations. Science 283: 1712-1714.

Fischer A, Pollack J, Thalmann O, et al. 2006. Demographic History and Genetic Differentiation in Apes. Current Biology 16: 1133-1138.

Fischer A, Wiebe V, Pääbo S et al. 2004. Evidence for a Complex Demographic History of Chimpanzees. Molecular Biology and Evolution 21: 799-808.

Fragaszy D, and Perry S. 2003. The Biology of Traditions: Models and Evidence. Cambridge University Press, Cambridge.

Frankham R, Ballou J, and Briscoe D. 2005. Introduction to Conservation Genetics: Cambridge University Press, Cambridge.

Gagneux P. 1998. Population Genetics of West African Chimpanzees (Pan troglodytes verus). PhD Dissertation. Basel University. 
Gagneux P, Boesch C, and Woodruff D. 1997. Microsatellite scoring errors associated with noninvasive genotyping based on nuclear DNA amplified from shed hair. Molecular Ecology 6: 861-868.

Gagneux P, Wills C, Gerloff U, et al. 1999a. Mitochondrial sequences show diverse evolutionary histories of African hominoids. PNAS 96: 5077-5082.

Gagneux P, Boesch C, and Woodruff D. 1999b. Female reproductive strategies, paternity and community structures in wild West African chimpanzees. Animal Behaviour 57: 19-32.

Gagneux P, Gonder K, Goldberg T, and Morin P. 2001. Gene flow in wild chimpanzee populations: what genetic data tell us about chimpanzee movement over space and time. Philosophical Transactions of the Royal Society of London B 356: 889-897.

Galtier N, Nabholz B, Glémin S, et al. 2009. Mitochondrial DNA as a marker of molecular diversity: a reappraisal. Molecular Ecology 18: 4541-4550.

Gao F, Bailes F, Robertson D, et al. 1999. Origins of HIV-1 in the chimpanzee Pan troglodytes troglodytes. Nature 397: 436-441.

Gibbard P, and van Kolfschoten T. 2004. The Pleistocene and Holocene Epochs. In Gradstein F, Ogg F, James G, Smith G and Gilbert A. (Eds.). A Geologic Time Scale 2004. Cambridge University Press, Cambridge.

Gerloff U, Hartung B, Fruth B, et al. 1999. Intracommunity relationships, dispersal pattern, and paternity success in a wild living community of bonobos (Pan paniscus) determined from DNA analysis of feacal samples. Proceedings of the Royal Society of London Biology 266: 1189-1195. 
Gillespie T. 2004. Noninvasive Assessment of Gastrointestinal Parasite Infections in Free-Ranging Primates. International Journal of Primatology 27: 1129-1143.

Gippoliti S, Embalo D, and Sousa, C. 2003. Guinea-Bissau. In: West African chimpanzees: Status Survey and Conservation Action Plan. Kormos R, Boesch C, Bakarr M, and Butynski T. (Eds.). IUCN, Gland, Switzerland.

Goldberg TL, and Ruvolo M. 1997. Molecular phylogenetics and historical biogeography of east African chimpanzees. Biological Journal of the Linnean Society 61: 301-324.

Goldberg TL, and Wrangham R. 1997. Genetic correlates of social behavior in wild chimpanzees: evidence from mitocondrial DNA. Animal Behavior 54: 559-570.

Goldsmith ML. 1999. Ecological constraints on the foraging effort of western gorillas (Gorilla gorilla gorilla) at Bai Hokou, Central African Republic. International Journal of Primatology 20: 1-23.

Gómez-Moliner B, Cabria M, Rubines J, et al. 2004. PCR-RFLP identification of mustelid species: European mink (Mustella lutreola), American mink (Mustella vison) and polecat (Mustella putorius) by analysis of excremental DNA. Journal of Zoology of London 262: 311-316.

Gonder MK, Oates, JF, Disotell DR. et al. 1997. A new West African chimpanzee subspecies? Nature 388: 337.

Gonder K. 2000. Evolutionary Genetics of Chimpanzees (Pan troglodytes) in Nigeria and Cameroon. PhD Dissertation. The City University of New York. 
Gonder K, and Disotell T. 2006. Contrasting Phylogeographic Histories of Chimpanzees in Nigeria and Cameroon: A Multi-Locus Genetic Analysis. In Lehman S, and Fleagle J. (Eds.). Primate Biogeography. Progress and Prospects. pp. 135-168. Springer Science, New York.

Gonder MK, Disotell TR, and Oates JF. 2006. New genetic evidence on the evolution of chimpanzee populations, and implications for taxonomy. International Journal of Primatolology 27: 1103-1127.

Gonder MK, Locatelli S, Ghobrial L, et al. 2011. Evidence from Cameroon reveals differences in the genetic structure and histories of chimpanzee populations. Proceedings of the National Academy of Sciences USA 108: 4766-4771.

Goodall J. 1986. The chimpanzees of Gombe: patterns of behavior. Harvard University Press, Cambridge, Massachusetts.

Goodman M. 1999. The genomic record of Humankind's evolutionary roots. American journal of human genetics 64:31-9.

Goodman M. 1962. Immunochemistry of the primates and primate evolution. Annals of the New York Academy of Sciences 102:219-234.

Goossens B, Waits L. et al. 1998. Plucked hair samples as a source of DNA: reliability of dinucleotide microsatellite genotyping. Molecular Ecology 7: 1237-1241.

Goossens B, Latour S, Vidal C, et al. 2000. Twenty new microsatellite loci for use with hair and faecal samples in the chimpanzee (Pan troglodytes troglodytes). Folia Primatologica 71: 177. 
Goossens B, Anthony N, Jeffery K, et al. 2003. Collection, storage and analysis of noninvasive genetic material in primate biology. In Setchell J, and Curtis D. (Eds.). Field and Laboratory Methods in Primatology. pp. 295-308. Cambridge University Press, Cambridge.

Groves CP. 2001. Primate Taxonomy. Washington, DC., Smithsonian Institution Press.

Grubb P. 1982. Refuges and dispersal in the speciation of African forest mammals. In Prance GT. (Ed.) Biological diversification in the tropics. pp. 537-53. Columbia University Press, New York.

Grubb P. 1990. Primate geography in the Afro-tropical forest biome In: Peters G, and Hutterer R. (Eds.). Vertebrates in the tropics. pp. 187-214. Museum Alexander Koenig, Bonn.

Grubb P, Butynski TM, Oates JF et al. 2003. Assessment of the Diversity of African Primates. International Journal of Primatology 24: 1301-1357.

Haig, S. 1998. Molecular contributions to conservation. Ecology 79: 413- 425.

Hamilton AC. 1982. Environmental History of Africa: A Study of the Quaternary. Academic Press, London.

Haffer J. 1982. General aspects of the refuge theory. In Prance GT. (Ed.). Biological Diversification in the Tropics. Columbia University Press, New York. 
Hanamura S, Kiyono M, Lukasik-Braum M, et al. 2008. Chimpanzee deaths at Mahale caused by a flu-like disease. Primates 49: 77-80.

Hedmark E, Flagstad O, Segerstrom P, et al. 2004. DNA-based individual and sex identification from wolverine (Gulo gulo) faeces and urine. Conservation Genetics 5: 405-410.

Hill W. 1969. The nomenclature, taxonomy, and distribution of chimpanzees. In Bourne P. (Ed.). The chimpanzee. pp. 22-49. Karger, Basel.

Hill K, Boesch C, Goodall J, et al. 2001. Mortality rates among wild chimpanzees. Journal of Human Evolution 40: 437-450.

Hochachka V, and Dhondt A. 2000. Density-dependent decline of host abundance resulting from a new infectious disease. PNAS 97: 5303-5306.

Hockings K, and Humble T. 2009. Best Practice Guidelines for the Prevention and Mitigation of Conflict Between Humans and Great Apes. I. S. P. S. G. (PSG). Switzerland.

Houlden B, Woodworth L, and Humphrey K. 1997. Captive breeding, paternity determination, and genetic variation in chimpanzees (Pan troglodytes) in the Australasian Region. Primates 38: 341-347.

Hudson R. 1990. Gene genealogies and the colalescent process. Oxford Surveys in Evolutionary Biology 7: 1-44.

Hudson P, Dobson A, and Newborn D. 1992. Do parasites make prey vulnerable to predation: Red grouse and parasites. Journal of Animal Ecology 61: 661-692. 
Hudson P, Dobson A, and Newborn D. 1998. Prevention of population cycles by parasite removal. Science 282:2256-2258.

Hudson P, Rizzoli A, Grenfell B, Heesterbeek H, et al. 2002. The Ecology of Wildlife Diseases. Oxford University Press, Oxford.

Huffman MA, and Wrangham RW. Diversity of medicinal plant use in wild chimpanzees. In Wrangham RW, McGrew WC, de Waal FB, and Heltne PG (Eds.). Chimpanzee Cultures. pp. 1-18. Harvard University Press, Cambridge MA.

Huijbregts BP, de Wachter L, Obiang M et al. 2003. Ebola and the decline of gorilla Gorilla gorilla and chimpanzee Pan troglodytes populations in Minkebe Forest, northeastern Gabon. Oryx 37:437-443.

Idaghdour Y, Broderick D, and Korrida A. 2003. Faeces as a source of DNA for molecular studies in a threatened population of great bustards. Conservation Genetics 4: 789-792.

Idani G. 1991. Social relationships between immigrant and resident bonobo (Pan paniscus) females at Wamba. Folia Primatologica 57: 83-95.

Imbrie J. 1985. A theoretical framework for the Pleistocene ice ages. Journal of the Geological Society of London 142: 417-432.

Imbrie J, Boyle S, Clemens A. et al. 1992. On the structure and origin of major glacial cycles. Linear responses to Milankovitch forcing. Palaeooceanography 7: 701-738.

Inoue S, and Matzuzawa T. 2007. Working memory of numerals in chimpanzees. Current Biology 17:R1004. 
Inskipp T. 2005. Chimpanzee (Pan troglodytes). In Caldecott J. and Miles L (Eds.). World Atlas of Great Apes and their Conservation. University of California Press, London.

IUCN, 1992. Guinea-Bissau. In Sayer JA, Harcourt CS, and Collins NN. (Eds.), The conservation atlas of the world, Macmillan, Basingstoke.

IUCN. 2007. 2007 IUCN Red List of Threatened Species. Available at: http://www.iucnredlist.org. [Accessed: 5/10/2008].

IUCN. 2009. 2009 IUCN Red List of Threatened Species. Available at: http://www.iucnredlist.org. [Accessed: 7/12/ 2009].

IUCN. 2011. 2011 IUCN Red List of Threatened Species. Available at: http://www.iucnredlist.org. [Accessed: 17/12/2011].

Jobling M, Hurles M et al. 2004. Human Evolutionary Genetics: Origins, Peoples and Disease, Garland Publishing.

Jones KE, Patel NG, Levy MA, et al. 2007a. Global trends in emerging infectious diseases. Nature 451, 990-993.

Kalema-Zikusoka G, Kock R, and Macfie E. 2002. Scabies in free-ranging mountain gorillas (Gorilla beringei beringei) in Bwindi Impenetrable National Park, Uganda. Veterinary Records 150: 12-15.

Kohn M, and Wayne R. 1997. Facts from feces revisited. Trends in Ecology and Evolution 12: 223-227. 
Kormos R. and Boesch C. 2003. Regional Action Plan for the Conservation of Chimpanzees in West Africa, IUCN.

Kortlandt A. 1983. Marginal habitats of chimpanzees. Journal of Human Evolution 12: 231-278.

Kukla G. 2005. Saalian supercycle, Mindel/Riss interglacial and Milankovitch's dating. Quaternary Science Reviews 24: 1573-1583.

Lahm SM, Kombila R, Swanepoel R, et al. 2006. Morbidity and mortality of wild animals in relation to outbreaks of Ebola haemorrhagic fever in Gabon, 1994-2003. Transactions of the Royal Society of Tropical Medicine and Hygiene 101:64-78.

Laland KN, and Hoppitt WJE 2003. Do animals have culture? Evolutionary Anthropology 12: 150-159

Laurance WF, Useche DC, Rendeiro J, et al. 2012. Averting biodiversity collapse in tropical forest protected areas. Nature 489: 290-294.

Lee P, Thornback J, and Bennet EL. 1988. Threatened Primates of Africa. Gland, Switzerland.

Lehman S, and Fleagle J. 2006. Primate Biogeography. Progress and prospects. Springer Science, New York.

Leroy $E$, Rouquet $P$, Formenty $P$, et al. 2004. Multiple Ebola virus transmission events and rapid decline of central African wildlife. Science 303: 387-390. 
Lesch K, Bengel D, Heils A, et al. 1996. Association of anxiety-related traits with a polymorphism in the serotonin transporter gene regulatory region. Science 271: 1527-1531.

Lewis DJ, and Wu J.2005. Optimal Landscape Conservation with Habitat Fragmentation Effects. Working Paper, Department of Agricultural and Applied Economics, University of Wisconsin-Madison.

Lilly A, Mehlman P, and Doran D. 2002. Intestinal parasites in gorillas, chimpanzees and humans at Mondika Research Site, Dzanga-Ndoki National Park, Central African Republic. International Journal of Primatology 23: 555-573.

Livingstone D. 1993. Evolution of African climate. In Goldblatt P. Biological Relationships between Africa and South America. Yale University Press, New Haven.

Loeschcke V, Tomiuk J, and Jain S. 1994. Conservation Genetics. Birkhäuser Verlag, Basel.

Lomolino MV, Sax DF, and Brown JH. 2004. Foundations of Biogeography. University of Chicago Press, Chicago.

Lovejoy T, Bierregaard R, Rylands AB, et al. 1986. Edge and other effects of isolation on Amazon forest fragments. In Soulé ME. (Ed.). Conservation Biology: The Science of Scarcity and Diversity. Sinauer Association. Sunderland, MA.

Lutz S, Weisser H-J, Heizmann J, and Pollak S. 1998. Location and frequency of polymorphic positions in the mtDNA control region of individuals from Germany. International Journal of Legal Medicine 111: 67-77. 
Lynch M, and Ritland K. 1999. Estimation of pairwise relatedness with molecular markers. Genetics 152: 1753-1766.

Maley J. 1996. The African rain forest-main characteristics of change in vegetation and climate from the Upper Cretaceous to the Quaternary. Proceedings of the Royal Society of Edinburgh 140: 31-73.

Margulis L. 1992. Symbiosis in Cell Evolution: Microbial communities in the Archean and Proterozoic eons. W. H. Freeman \& Company.

Marsh L. 2003. The Nature of Fragmentation. In Marsh LK (Ed.). Primates in Fragments: Ecology and Conservation. Kluwer Academic/ Plenum Publishers, Los Alamos, New Mexico.

Mayr E, O'Hara RJ. 1986. The biogeographic evidence supporting the Pleistocene forest refuge hypothesis. Evolution 40: 55-67.

McGrew WC. 1998. Culture in nonhuman primates? Annual Review of Anthropology, 27: 301-328.

McGrew WC. 2004. The Cultured Chimpanzee: Reflections on Cultural Primatology. Cambridge Univeristy Press, Cambridge.

McGrew W, Tutin C, Collins D, et al. 1989. Intestinal parasites of sympatric Pan troglodytes and Papio spp. at two sites: Gombe (Tanzania) and Mt. Assirik (Senegal). American Journal of Primatology 17: 147-155.

McGrew W, Ensminger A, Marchant L, et al. 2004. Genotyping aids field study of unhabituated wild chimpanzees. American Journal of Primatology 63: 87-93. 
McLennan M. 2008. Beleaguered chimpanzees in the agricultural district of Hoima, western Uganda. Primate Conservation 23: 45-54.

Meier C, Hemelrijk C, and Martin R. 2000. Paternity determination, genetic characterization, and social correlates in a captive group of chimpanzees (Pan troglodytes). Primates 41: 175-183.

Melnick D, Hoelzer G, and Honeycutt R. 1992. Mitochondrial DNA: its uses in anthropological research. In Dover E. (Ed.). Molecular applications in Biological Anthropology. pp. 179-233. Cambridge University Press, Cambridge.

Mesoudi A, and Whiten A. 2004. The hierarchical transformation of event knowledge in human cultural transmission. Journal of Cognition and Culture 4: 1-24.

Miles L, Caldecott J, and Nellemann C. 2005. Chalenges to great ape survival. In Caldecott J, and Miles L. (Eds.). World Atlas of Great Apes and their Conservation. University of California Press, London.

Mitani J, Merriwether DA, and Zhang C. 2000. Male affiliation, cooperation, and kinship in wild chimpanzees. Animal Behaviour 59: 885-893.

Morin P, and Woodruff D. 1992. Paternity exclusion using multiple hypervariable microsatellite loci amplified from nuclear DNA of hair cells. In Martin R, Dixson A, and Wickings E. (Eds.). pp. 63-81. Paternity in Primates: Genetic Tests and Theories. Karger, Basel. 
Morin P, Wallis J, Moore J, et al. 1993. Non-invasive sampling and DNA amplification for paternity exclusion, community structure, and phylogeography in wild chimpanzees. Primates 34: 347-356.

Morin P, Moore J, Chakraborty R, et al. 1994a. Kin selection, social structure, gene flow, and the evolution of chimpanzees. Science 265: 1193-1201.

Morin P, Wallis J, et al. 1994b. Paternity exclusion in a community of wild chimpanzees. Molecular Ecology 3: 469-478.

Morin P, Chambers A, Boesch C, et al. 2001. Quantitative polymerase chain reaction analysis of DNA from noninvasive samples for accurate microsatellite genotyping of wild chimpanzees (Pan troglodytes verus). Molecular Ecology 10: 1835-1844.

Moritz C. 1994. Applications of mitochondrial DNA analysis in conservation: a critical review. Molecular Ecology 3: 401-411.

Moritz C, Dowling TE, and Brown WM. 1987. Evolution of animal mitochondrial DNA: relevance for population biology and systematics. Annual Review of Ecology Systematics and Evolution 18: 269-292.

Morovvati S, Modarresi M, Habibi, G. et al. 2007. Sequence analysis of mitochondrial DNA Hypervariable regions: An Approach to Personal Identification. Archives of Medical Research 38: 5.

Müller-Graf C, Collins D, Packer C, et al. 1997. Schistosoma mansion infection in a natural population of olive baboons (Papio cynocephalus anubis) in Gombe Stream National Park, Tanzania. Parasitology 15: 621-627. 
Newton-Fisher NE. 2002. Relationships of male chimpanzees in the Budongo Forest, Uganda. In: Boesch C, Hohmann G, Marchant LF (Eds.) Behavioural diversity in chimpanzees and bonobos. Cambridge University Press, Cambridge, pp. 125-137.

Newton-Fisher NE, Reynolds V and Pumptre AJ. 2000. Food supply and chimpanzee (Pan troglodytes schweinfurthii) party size in the Budongo Forest Reserve, Uganda. International Journal of Primatology 21: 613-628.

Nichol JE. 1991. The extent of desert dunes in Northern Nigeria as shown by image enhancement. The Geographical Journal 157: 13-24.

Nishida T. 1979. The Social Structure of Chimpanzees of the Mahale Mountains. In Hamburg DA, and McCown ER (Eds.). The Great Apes. Benjamin/Cummings, London.

Nishida T, and Hiraiwa-Hasegawa M. 1987. Chimpanzees and Bonobos: Cooperative Relationships among Males. In Smuts BB, Cheney DL, Seyfart RM, Wrangham RW, and Struhsaker TT (Eds.). Primate Societies. University of Chicago Press, Chicago.

Nishida T, and Hosaka K. 1996. Coalition strategies among adult male chimpanzees of Mahale Mountains, Tanzania. In McGrew WC, Marchant LF, and Nishida T (Eds.). Great Ape Societies, pp. 114-134. Cambridge University Press, Cambridge.

Nishida T, Corp N, Hamai M, et al. 2003. Demography, female life history and reproductive profiles among the chimpanzees of Mahale. American Journal of Primatology 59: 99-121.

Nishida T, and Mwinuka C. 2005. Introduction of seasonal park fee system to Mahale Mountains National Park: a proposal. Pan African News 12: 17-19. 
Nunn C, Altizer S, Sechrest W, et al. 2004. Parasites and the Evolutionary Diversification of Primate Clades. The American Naturalist 164: 90-103.

Nuttal G. 1904. Blood Immunity and Blood Relationship. Cambridge University Press Cambridge.

Oates J, Gadsby L, Jenkins P. 2003. Nigeria. In Kormos R, Boesch C, Bakarr MI, and Butynski TM (Eds.) West African Chimpanzees. Status Survey and Action Plan. IUCN, Gland, Switzerland.

Ott-Joslin J. 1993. Zoonotic diseases of nonhuman primates. In Fowler M. (Ed.). Zoo and Wild Animal Medicine. W. B. Saunders, Philadelphia.

Palomares F, Godoi J, Piriz A, et al. 2002. Fecal genetic analysis to determinate the presence and distribution of elusive carnivores: design and feasibility for the Iberian Iynx. Molecular Ecology 11: 2171-2182.

Pamilo P, and Crozier R. 1982. Measuring genetic relatedness in natural populations: methodology. Theoretical Populations Biology 21: 171-193.

Parker P, Snow A, Schung M, et al. 1998. What molecules can tell us about populations: choosing and using a molecular marker. Ecology 79: 361-382.

Patterson N, Richter D, Gnerre S, et al. 2006. Genetic evidence for complex speciation of humans and chimpanzees. Nature 441: 1103-1108.

Pires A, and Fernandes M. 2003. Last lynxes in Portugal? Molecular approaches in a pre-extinction. Conservation genetics. 4: 525-532. 
Plomin R, DeFries J, McClearn G, et al. 2001. Behavioral Genetics. Worth Publishers, New York.

Prescott J, Rapley WA, and Joseph MM. 1994. Status and conservation of chimpanzee and gorilla in Cameroon. Primate Conservation 14-15: 7-12.

Poulsen JR, and Clark CJ. 2004. Densities, distributions, and seasonal movements of gorillas and chimpanzees in swamp forest in northern Congo. International Journal of Primatolology 25:285-306.

Queller D, and Goodnight K. 1989. Estimating relatedness using genetic markers. Evolution 43: 258-275.

Reynolds V. 2005. The chimpanzees of the Budongo Forest: Ecology, Behaviour and Conservation. Oxford University Press, Oxford.

Reynolds V, Kyamanywa R, and Wallis J. 2000. Fragments, Sugar, and Chimpanzees in Masindi District, Western Uganda. In Marsh L. (Ed.). Primates in Fragments: Ecology and Conservation. Kluwer Academic /Plenum Publishers, Los Alamos, New Mexico.

Riddle A, Pilgrim K, Mills L, et al. 2003. Identification of mustelids using mitochondrial DNA and non-invasive sampling. Conservation Genetics 4: 241-243.

Rosemblum L, Supriatna J, and Melnick D. 1997. Phylogeographic analysis of pigtail macaque populations (Macaca nemestrina) infered from mitochondrial DNA. American Journal of Physical Anthropology 104: 35-45.

Russell C, and Russell WMS. 1990 Cultural Evolution of Behaviour. Netherlands Journal of Zoolology 40:745-762. 
Ruvolo M, Pan D, Goldberg T, et al. 1994. Gene trees and hominoid phylogeny. PNAS 91: 8900-8904.

Sayers K, Lovejoy O. 2008. The chimpanzee has no clothes. Current Anthropolology 49: 87-113.

Schlotterer C. 2000. Evolutionary dynamics of microsatellite DNA. Chromosoma 109: 365-371.

Sherwin W, and Moritz C. 2000. Managing and monitoring genetic erosion. In Young AG, and Clarke GM (Eds.). Genetics, Demography and Viability of Fragmented Populations. Cambridge University Press.Cambridge, UK.

Shimada M. 2000. Geographic distribution of mitochondrial DNA variations among grivet (Cercopithecus aethiops aethiops) populations in central Ethiopia. International Journal of Primatolology 21: 113-129.

Shimada M, Hayakawa S, Humle T, et al. 2004. Mitochondrial DNA genealogy of chimpanzees in the Nimba Mountains and Bossou, West Africa. American Journal of Primatology 64: 261-275.

Sillero-Zubiri C, and Switzer D. 2001. Crop raiding primates: Searching for alternative, humane ways to resolve conflict with farmers in Africa. People and Wildlife Initiative. Wildlife Conservation Research Unit, Oxford University.

Smith T, and Wayne R. 1996. Molecular genetic approaches in conservation. Oxford University Press, New York. 
Sousa C, and Casanova C. 2004. Chimpanzee distribution and relation with local human communities in coastal area of Guinea-Bissau. Available at: http://www.fct.mctes.pt/projectos/pub/2004/painel_result/vglobal_projecto.asp?id Projecto $=57434 \&$ idElemConcurso $=56$ [Accessed: 23/05/2008].

Sterck EHM, Watts DP, and van Schaick C. 1997. The evolution of female social relationships in nonhuman primates. Behavioural Ecology and Sociobiology 41: 291309.

Stone A, Griffiths R, Zegura L, et al. 2002. High levels of Y-chromosome nucleotide diversity in the genus Pan. PNAS 99: 43-48.

Stone A, and Verrelli B. 2006. Focusing on comparative ape population genetics in the post-genomic age. Current Opinion in Genetics and Development 16: 586-591.

Stoneking M. 2000. Hypervariable sites in the mtDNA control region are mutational hotspots. American Journal of Human Genetics 67: 1029-1032.

Stoner K. 1996. Prevalence and intensity of intestinal parasites in mantled howling monkeys (Allouatta palliata) in northeastern Costa Rica: Implications for conservation biology. Conservation Biology 10: 539-546.

Strier KB. 1989. Effects of patch size on grouping associations in muriquis. Folia Primatologica 52:70-77.

Stuart M, and Strier S. 1995. Primates and parasites: a case of a multidisciplinary approach. International Journal of Primatology 16: 577-593. 
Stumpf R. 2007. Chimpanzees and Bonobos. Diversity within and between species. In Campbell C, Fuentes A, Mackinnon K, Panger M, and Bearder S. (Eds.) Primates in Perspective. Oxford University Press, New York.

Sugiyama Y. 1999 : Socioecological factors of male chimpanzee migration at Bossou, Guinea. Primates $40: 61-68$.

Symington MM. 1988. Food competition and foraging party size in the black spider monkey (Ateles paniscus chamek). Behaviour 105: 117-134.

Taberlet P, Waits L, and Luikart G. 1999. Noninvasive genetic sampling: look before you leap. Trends in Ecology and Evolution 14: 323-327.

Takahata Y. 1990. Social relationships among male chimpanzees. In Nishida T (Ed.). The chimpanzees of the Mahale Mountain, pp. 133-148. University of Tokyo Press, Tokyo.

Takenaka O, Kawamoto S, Udono T, et al. 1993. Chimpanzee microsatellite PCR primers apllied to paternity testing in a captive colony. Primates 34: 357-363.

Tautz D, and Schlotterer C. 1994. Concerted Evolution, Molecular Drive and NaturalSelection-Reply. Current Biology 4: 1166-1166.

Tomasello M. 1999. The Cultural Origins of Human Cognition. Harvard University Press, Cambridge MA.

Tomasello M, and Call J. 1997. Primate Cognition. Oxford University Press, Oxford. Tutin C. 1999. Fragmented living: behavioural ecology of primates in a forest fragment in the Lopé Reserve, Gabon. Primates 40: 249-265. 
Toth G, Gaspari Z, et al. 2000. Microsatellites in different eukaryotic genomes: Survey and analysis. Genome Research 10: 967-981.

van Schaik CP. 1983. Why are diurnal primates living in groups? Behaviour 87: 120144.

Wallis J. 2000. Prevention of disease transmission in primate conservation. Annals of the New York Academy of Sciences 916: 691-693.

Walsh PD, Abernethy KA, Bermejo M, et al. 2003 Catastrophic ape decline in western equatorial Africa. Nature 422:611-614.

Walsh P, Breuer T, Sanz C. et al. 2007. Potential for Ebola Transmission between Gorilla and Chimpanzee Social Groups. The American Naturalist 169: 684-689.

Wasser S, Houston G, Cadd G, et al. 1997. Techniques for application of fecal DNA methods to field studies of Ursids. Molecular Ecology 6: 1091-1097.

Watts D. 2000a. Grooming between male chimpanzees at Ngogo, Kibale National Park. I. Partner number and diversity and grooming reciprocity. International Journal of Primatology 21: 189-210.

Watts D. 2000b. Grooming between male chimpanzees at Ngogo, Kibale National Park. II. Influence of male rank and possible competirion for partners. International Journal of Primatology 21: 210- 238. 
Wildman D, Uddin M, Liu G, et al. 2003. Implications of natural selection in shaping 99,4\% nonsynonymous DNA identity between humans and chimpanzees: enlarging genus Homo. PNAS 100: 7181-7188.

White F. 1993. Refuge theory, ice-age aridity and the theory of tropical biotas: an essay in plant geography. Fragmenta Floristica et Geobotanica 2: 385-409.

White F. 1996. Comparative socio-ecology of Pan paniscus. In McGrew W, Marchant L, and Nishida T. (Eds.). Great Ape Societies. pp. 29-41. Cambridge University Press, Cambridge.

Whiten A. 2005. The second inheritance system of chimapnzees and humans. Nature 437: 52-55.

Whiten A, Goodall K, McGrew WC, et al. 1999. Cultures in chimpanzees. Nature 399: 682-685.

Whiten A, Goodall K, McGrew WC, et al. 2001. Charting cultural variation in chimpanzees. Behaviour 138: 1481-1516.

Whiten AA, Spiteri V, Horner K et al. 2007. Transmission of multiple traditions within and between chimpanzee groups. Current Biology 17:1038-1043.

Wilkie DS, and Carpenter JF. 1999. Bushmeat hunting in the Congo Basin: an assessment of impacts and options for mitigation. Biodiversity and Conservation 8: 927-955. 
Wolfe N, Escalante A, Karesh W, et al. 1998. Wild primate populations in emerging infectious disease research: The missing link? Emerging Infecious Diseases 4: 149158.

Wrangham RW. Feeding behavior of chimpanzees in Gombe National Park Tanzania. 1977. In Clutton-Brock TH. (Ed.) Primate Ecology, Academic Press, London.

Wrangham RW. 1980. Sociobiology: modification with dissent. Biological Journal of the Linnean Society 13:171-177.

Wrangham RW. 1986. Ecology and social evolution in two species of chimpanzees. In Rubenstein DI and Wrangham RW (Eds.). Ecology and Social Evolution: Birds and Mammals, pp. 352-378. Princeton University Press, Princeton.

Wrangham RW. 1994. Overview - ecology, diversity and culture. In Wrangham RW, McGrew WC, de Waal FB, and Heltne PG. (Eds.). Chimpanzee Cultures. pp. 21-23. Harvard University Press, Cambridge MA.

Wrangham RW, Conklin-Brittain NL, and Hunt KD. 1998. Dietary response of chimpanzees and cercopithecines to seasonal variation in fruit abundance: I. Antifeedants. International Journal of Primatology 19: 949-970.

WWF 2009. Endangered Species: Chimpanzees. http://wwf.panda.org/what_we_do/endangered_species/great_apes/chimpanzees/ [Accessed: 28/11/2008].

Yu N, Jensen-Seaman M, Chemnick L, et al. 2003. Low Nucleotide Diversity in Chimpanzees and Bonobos. Genetics 164: 1511-1518. 
Zachos JC, Pagani M, Sloan L, et al. 2001. Cenozoic Global Deep-Sea Stable Isotope Data. Paleoceanography 292: 686- 693.

Zuckerkandl E. 1963. Perpectives in molecular anthropology. In Washburn S. (Ed.). Classification and Human Evolution. pp. 243-272. Aldine, Chicago. 


\section{CHAPTER 2}

"O meu grito de revolta fez vibrar os peitos de todos os Homens..."

"My scream of revolt thrilled the hearts of men..."

- Amílcar Cabral, Liberation Africanist leader

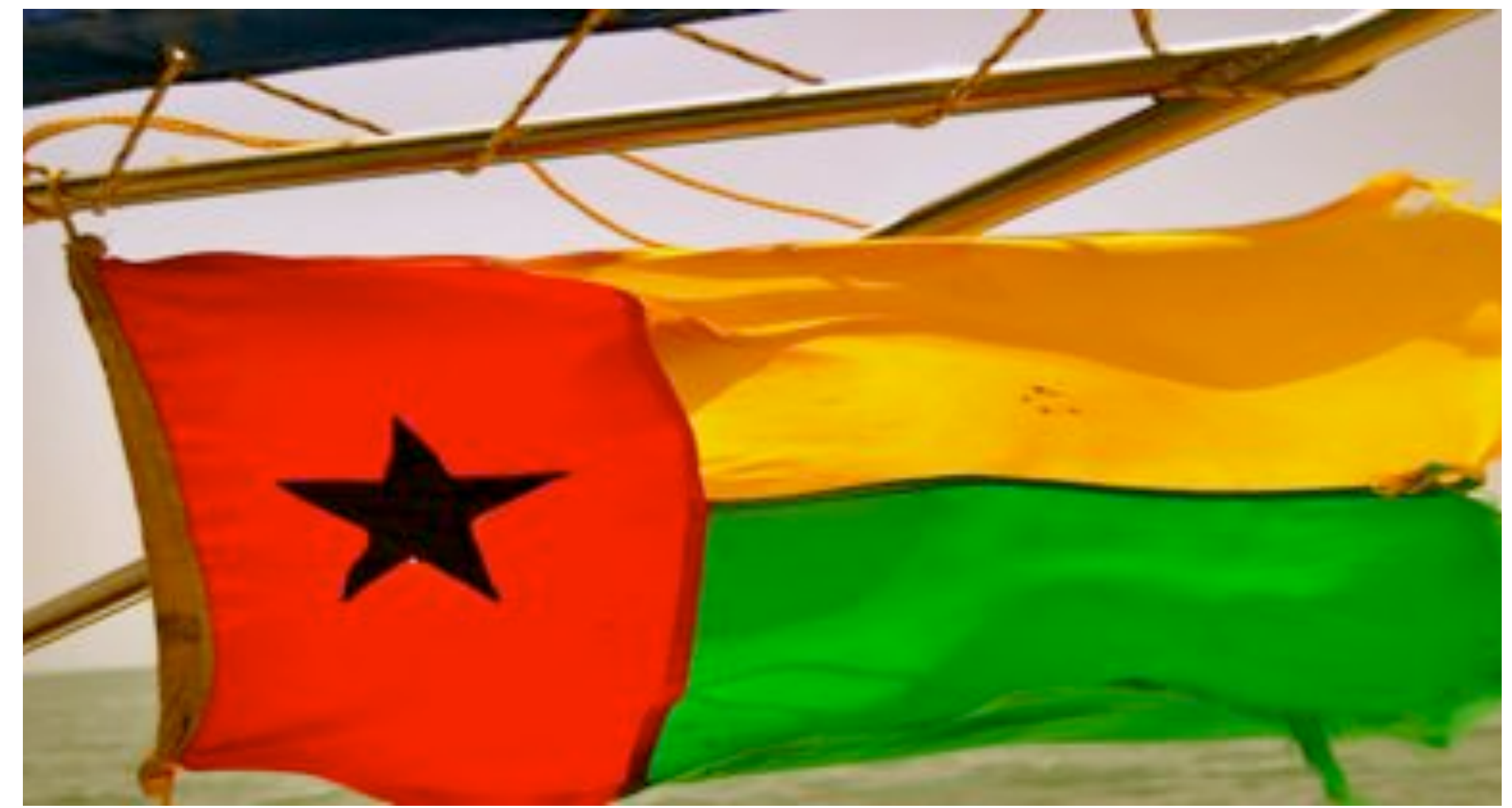




\section{CHAPTER 2}

\section{GENERAL MATERIAL AND METHODS}

\section{1- Fieldwork}

I performed the fieldwork in two missions to the Republic of Guinea-Bissau. The first field mission was during September-November of 2008, during the wet season in Cantanhez National Park, and the second mission was from January-June 2010 , in different surveys during the dry season across the country.

\section{2- Republic of Guinea-Bissau}

The Republic of Guinea-Bissau is located in the Western coast of Africa, between Senegal, in the north, and the Republic of Guinea in the south and east. In georeferencial terms, this country is located between the latitude $10 \div 55^{\prime}-12 \circ 40^{\prime} \mathrm{N}$ and the longitude 1338'-16043'W (Fig. 2.1).

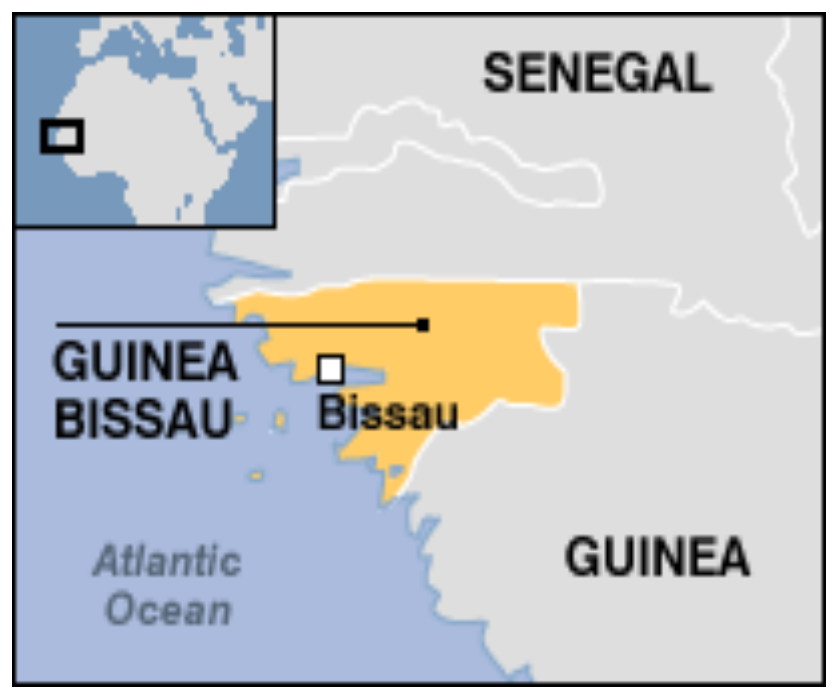

Figure 2.1: Guinea-Bissau location (BBC 2011). 
A continental and an insular part, the Bijago Archipelago, compose GuineaBissau's territory. The total surface of the country is $36125 \mathrm{~km}^{2}$. (PNUD 2010).

In administrative terms, Guinea-Bissau is organised into 8 regions and one autonomous sector.

Guinea-Bissau's climate is, generally, tropical humid with two clear distinct seasons. The wet season, starts from May to November, and the dry season occurs from December to April. The mean annual temperature, under the influence of the trade winds, varies from 24 to 27 으. The average relative humidity level is accented (about $70 \%$ ) and is, essentially, influenced by the winds, rainfall and the coastal proximity.

The relief comprehends rather little accented altitude zones, being the maximum reached values of about 300 m (PNUD 2010).

Of all West African countries, Guinea-Bissau is the one that possesses the highest surface of mangrove areas (Sousa et al. 2005). Mangrove vegetation shows a special adaptation due to its tolerance to the influence of salt seawater and to the settling sediments (PNUD 2010). Besides its physical function (e.g. anti-erosion, protection from storms, etc.), mangroves or 'tarrafes' [Creoule] have an ecological function of utmost importance to this country's economy. These areas become preferable for reproduction for the marine, terrestrial, and bird species. Human communities use frequently mangrove molluscs and crustaceans on their diet (PNUD 2010).

On the other hand, sub-humid forests show a heterogenic vegetal coverage with a great diversity and density, with vegetal stratums composed of large and medium trees and bushes (Cassamá 2006). Deep inside the forest we can find a fresh microclimate with low temperature oscillations. In function of the climate conditions, especially of a higher rainfall levels, recorded there, the main and representative spots of this formation are located in the south of Guinea-Bissau, occupying vast areas in the south of Quinara and in the region of Tombali (Cassamá 2006). 
There is a clear reduction of the vegetal formations, in quantitative and qualitative terms, in almost all regions of the country, probably because of "slash and burn", itinerant agriculture, lumber exploration with trading purposes, the creation of big and significant crop fields (monocultures), mostly of cashew nuts, the appearing of new populations in dense forest density areas searching for new arable lands and the occupation of mangrove areas in order to cultivate rice, groundnuts, sweet potatoes among others crops (Catarino 2004; Cassamá 2006).

The deforestation is caused by itinerant agriculture, also called as "pam-pam" [Creoule]. In the limits of the sub-humid forest there is a transition forest with a surface of 24000 ha in the region of Gabú and of 24418,59 ha (0,99\%) in the coastal area (Catarino 2004).

Several studies confirm that, biogeographically, Guinea-Bissau is located in a Guinean-Congolean and Sudanian transition zone (Catarino et al. 2001). Zaire Guinean floristic elements, reach their most northern extension limits in Cantanhez (Malaisse 1996). These elements are in the origin of the formations of the Guinean and sub-Guinean humid sectors, where dense, dry and semi-dry forests prevail, as well as sub-humid (deciduous) forests and natural palm trees. On the contrary, the Sudan-Sahelian zone, where wide forests and arboreal savannahs constitute the main formations (Catarino 2004). Its location in this transition zone also influences its fauna elements (PNUD 2010). Guinea-Bissau is no exception in relation to the greater radiations that characterise the African fauna, especially concerning primate presence (Gippoliti and Dell'Omo 2003).

According to Casanova and Sousa (2007) there are, at least, twelve families of mammals (18 Artiodactyla, including the Hippopotamus amphibious, 20 species of Carnivores, 25 Cetacean, 24 Chiropteran, 5 Insectivore, 1 Lagomorphs, 1 Pholidota, 11 Primates, 1 Proboscid, 19 Rodents, 1 Sirenia, and 1 Tubulidentata).

Eleven species of primates are present in the country, and nine of them are inscribed in the Appendix II of CITES (please see table 5) (Casanova and Sousa 2007, Gippoliti and Dell'Omo 2003, Gippoliti et al. 2003) (Table 2.1). 
Table 2.1: Non-human primates of Guinea-Bissau (from Casanova and Sousa 2007:9)

\begin{tabular}{lll}
\hline Common Name & Scientific Name & IUCN Conservation Status \\
& (Groves 2001) & \\
Northern Lesser Bush Baby & Galago senegalensis & Lower Risk \\
& senegalensis & \\
Sooty Mangabey & Cercocebus torquatus atys & Endangered \\
Patas Monkey & Erythrocebus patas & Endangered \\
Vervet Monkey & Chlorocebus sabaeus & Lower Risk \\
Mona Monkey & Cercopithecus campbelli & Lower Risk \\
Diana Monkey & Cercopithecus diana & Endangered \\
Lesser Spot-nosed Guenon & Cercopithecus petaurista & Lower Risk \\
& buettikoferi & \\
Guinea Baboon & Papio papio & Lower Risk \\
Western Red Colobus & Procolobus badius temmincki & Endangered \\
Western Black and White & Colobus polykomos & Lower Risk \\
Colobus & Pan troglodytes verus & \\
Chimpanzee & & Endangered \\
\hline
\end{tabular}

Guinea-Bissau has a population of 1520830 (INE 2009). It is a multi ethnic and multi religious society (Table 2.2) (INE 2009). It has a density, per $\mathrm{Km}^{2}$ of 37.5 and, $64 \%$ of its population live in rural areas. It has a demographic growth rate of $2 \%$, an average life expectancy of 44.7 years and an infant mortality rate of 138 per 1000 children (INE 2009).

If we consider the projections made to the year 2050, the Guinean population will be of 2,900,000 individuals (INE 2009). For a more detailed description about the main socio-demographic indicators, please see Table 2.3).

In economical terms, this country has a gross domestic product of 301 million US dollars; its main wealth comes from the primary sector with $85 \%$, where the cashew nuts (Anacardium occidentale) are the main exporting product (INE 2009). 
Among the main exporting countries there's India, Thailand, Uruguay, Portugal and South Korea. It's a dependent country relating the funds for international aid, like the United Nations, European Union, World Bank, FMI and frequently depends on the international food assistance (CIA 2008).

The Republic of Guinea-Bissau was formerly a Portuguese colony. Thirteen years after the struggle against Portuguese colonialism, Guinea-Bissau proclaimed, in 1973, its independence. In 1974 it was recognised the right to self-determination. The first presidential elections happened in 1994. However, the transition to democracy was difficult, especially after the end of the civil war, that took place from 1998 to 1999, and the following political instability established, that the country has been feeling until today (PNUD 2010).

In environmental terms Guinea-Bissau has signed several conventions favouring the protection of natural resources, forests and biodiversity. However, the absence of effective judicial and law enforcement systems doesn't allow the application of the commitments that once had assumed (PNUD 2010; Casanova and Sousa 2007).

According to the last report from the United Nations Development Plan (PNUD 2010), the Republic of Guinea-Bissau has a poverty index of 44.8 and a human development index of 0.374 , making it the third poorest country in the world, engaging the $175^{\text {th }}$ position worldwide (PNUD 2010). Corruption and bureaucracy, human rights violation, disrespect for the sovereignty organs, political instability, its major external debt and its weak production ability strongly weaken human empowerment (PNUD 2010). 
Table 2.2: Major ethnic groups and beliefs of Guinea-Bissau (INEC 2007).

\begin{tabular}{ll}
\hline Ethnic groups & $\%$ \\
\hline Balante & 27 \\
Fulani & 23 \\
Mandinka & 13 \\
Mandyako & 11 \\
Pepel & 10 \\
Beafada & 3 \\
Mancanha & 3 \\
Bijago & 3 \\
Nalu & 1,5 \\
Others & 3 \\
\hline Religious affiliations & $\%$ \\
\hline Indigenous beliefs/ Animism & 45 \\
Muslim & 40 \\
Christian & 13 \\
Other & 2 \\
\hline
\end{tabular}

Table 2.3: Major socio-economical and demographic indicators (INEC 2007).

\begin{tabular}{ll}
\hline Indicator & Value \\
\hline Population & $1,520,830$ \\
Population density & $37,5 \%$ \\
Life expectancy & 44,7 (Total) \\
Infant mortality rate & $138 / 1000$ \\
Literacy rate & $44.8 \%$ \\
Armed forces & 9,250 \\
Agriculture, forestry, fishing & $85 \%$ \\
Industry & $2 \%$ \\
Number of telephones & $7 / 1000$ \\
Paved road as a share of total roads & 10 \\
\hline
\end{tabular}




\section{2- Study Areas}

\subsection{1- Study Area 1: Tombali Region}

Surveys were conducted in Cantanhez and Catió Peninsulas (2008 and 2010 missions) from the Tombali region. Cantanhez National Park (CNP) is located in this region (Fig. 2.2) and comprises a total area of $1068 \mathrm{~km}^{2}$. The Cacine and Cumbidjã Rivers act as natural boundaries and form the Cubucaré Peninsula. The park was formally established in 2008 but since the mid-1980's was considered a forest hunting reserve (IBAP 2008). The climate is tropical humid with two annual seasons: the rainy season from June to October and the dry season from November to May with little or no rainfall. Mean annual rainfall is $2000 \mathrm{~mm}$ (SD \pm 500 ) and the temperature varies between 280 and 31으 (Simão 1997).

CNP is $\pm 70 \mathrm{~m}$ above sea level and consists of a patchy environment of small rivers; mangroves, arborous and grassland savannahs; agriculture fields, human settlements and sub-humid forests characterize the landscape. Forest fragments consist of a mixture of evergreen and semi deciduous vegetation cover (Catarino 2004). Native fauna include seven species of non-human primates: the lesser bush baby (Galago senegalensis), the western red colobus (Procolobus badius temmincki), the king colobus (Colobus polykomus), the vervet monkey (Chlorocebus aethiops sabaeus), the Campbell's monkey (Cercopithecus campbelli), the Guinean baboon (Papio papio) and the western chimpanzee (Pan troglodytes verus) (Gippoliti and Dell'Omo 2003; Casanova and Sousa 2007).

The World Wide Fund for Nature (WWF) has recognized the Cantanhez forests as one of the 200 most important ecoregions in the world, with the last vestigial segments of humid forest in West Africa. However, through satellite images, Oom et al. (2009) identified a trend of forest loss with a conversion from closed humid forests to savanna-woodlands. The amount of land for crops is continually expanding due to increasing numbers of people (Hockings and Sousa 2011) (Fig. 2.2). 
The name itself "Cantanhez" comes from, according to personal information, a herbaceous plant that grows in the high regions of the Cubucaré [specifically in the Amidara and São Francisco woods] used by men during the three years that they had to spend in the woods for the animist ceremony of "fanado"

According to an overall tradition, recognized by all the others, the first ethnicity that settled and occupied the lands were the Nalús and they are considered, by this fact, as the "owners of the land" (Frazão-Moreira 2001).

The Cantanhez Forests are an archetype of the Guinea-Bissau's collective consciousness, that is, they are perceived as the place of independence and resistance and as the cradle of the foundation of the main movement and political party of Guinea-Bissau - The PAIGC (African Party for the Independence of Guinea and Cape Verde).

Due to that, Cantanhez was a reference site in the armed rebellion against the Portuguese colonization and, from the natives' point of view, an icon on the "Liberation War" ${ }^{3}$. The guerilla's success, as well as the PAIGC's, is intimately associated to these woodlands. This fact is a result of two main reasons: one of real or material order and other of spiritual and symbolic character. On the one hand the isolation, their forest resources diversity and their dense and closed surroundings allowed local communities to renew unique knowledges, acquired by ancestral experience. In the other hand, the conviction and hope on the spiritual support and on the protection of the "Nhinte Camatchol" or of the "Irãs" strengthened their

\footnotetext{
2 "Fanado" [Creole] is an animist religious ceremony that is practised by several ethnicities (Nalús, Balanta, Fulas, Sosso, etc) and generally involves a crossing ritual to adulthood, culminating with circumcision. This cultural expression is part of the Guineans culture and it is still practised nowadays, involving however a more reduced presence in the "Sacred Woods" (about three months). It's a collective ceremony and aims at the transmission of reserved knowledge, fortifying, as well, the cohesion and community unity (Campredon 1997).

${ }^{3}$ The armed conflict begun in the south, in January of 1963 (Simpósio 2008).

4 "Nhinte Camatchol" is a Nalu sculpture used at fanado. It represents a bird's head with a human face, being the main message of this ritual to the participants that they must consider true brotherhood, a collective interest affirmation, above individual or familiar interest. This mask couldn't be seen by the non-initiated, under the penalty of death (Campredon 1997).
} 
self-determination, self-esteem and identity, inciting the rebellion's progression and concretization (Brito 2007).

This park also sheltered not only some important headquarters to the Portuguese troops, but also several guerrilla "barrakas" ${ }^{6}$.

This entire area had become known among the Portuguese troops as the "Death Corridor", due to the intensity of the attacks (Simpósio 2008). These were key moments of war that are inserted in an environmental frame of dense forest.

It is still possible to find today traces of that conflict, namely land mines, inactivated bombs, and many buildings totally ruined, in several places of Cantanhez (Rui Sá pers. observation 2008).

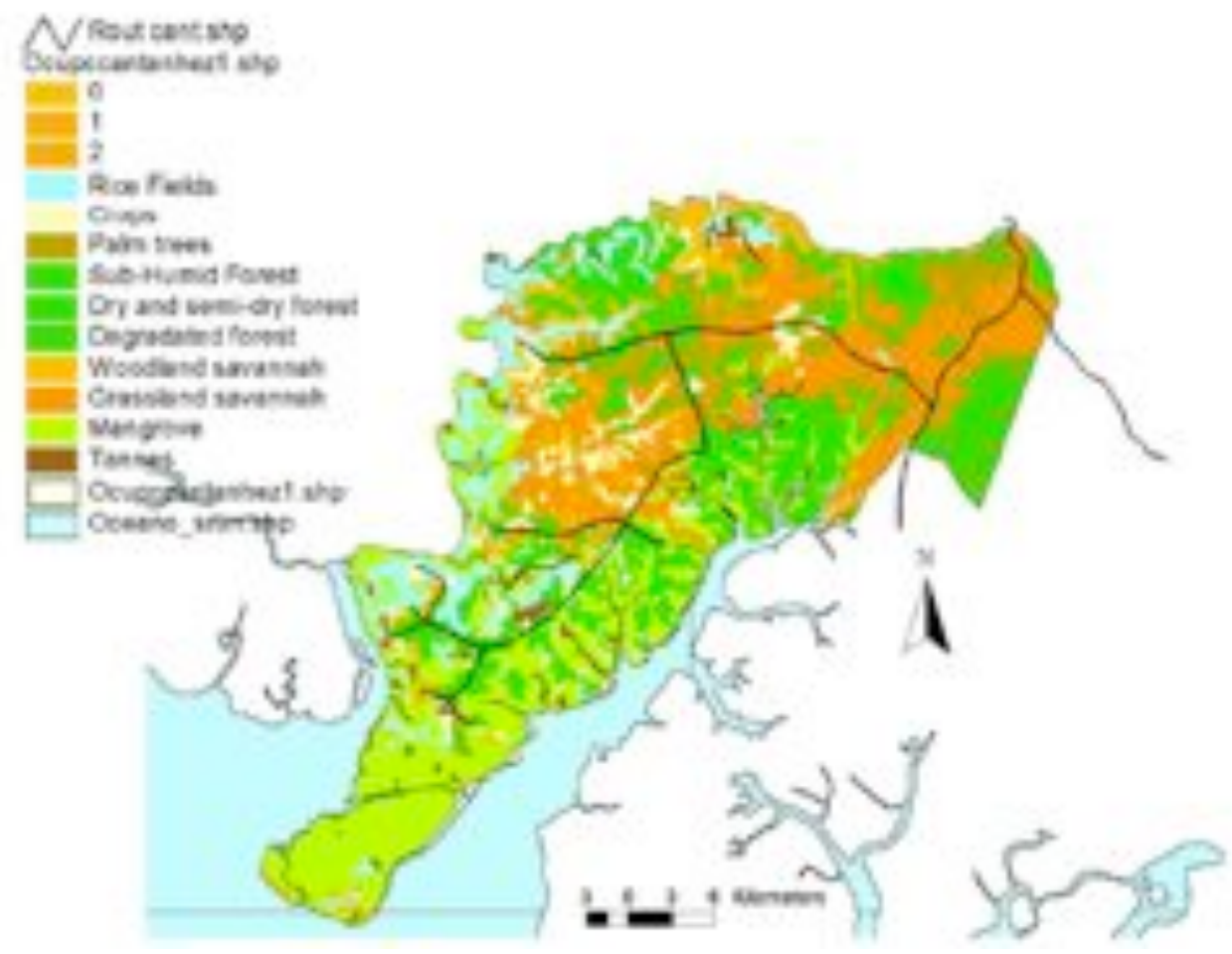

Figure 2.2: Map of land use in Cantanhez National Park, Guinea-Bissau (INEP 2010).

\footnotetext{
5 "Irãs" means spirits of the forests.

6 "Barrakas" [Creole] military lodgings from the PAIGC's guerrilla.
} 


\subsection{2- Study Area 2: Quínara Region}

Surveys were performed in Buba, Fulacunda and Empada sectors, which belong to the Quínara administrative region. Cufada Lagoons Natural Park (CLNP) is located in this region, and was created by presidential decree on 2000 . This park has long been considered as an area of high importance for biodiversity. CLNP covers an area of $700 \mathrm{~km}^{2}$. Is bounded by the Rio Corubal at north, and the road to Fulacunda at northwest, and the Buba River at south. The soils are most common brownish, yellow and red (Catarino 2006).

The dominant vegetation type is semi-dry forest and dry forest areas with patches of sub-humid and moist savannas. The park area is recognized as 'wetland of international importance' and is therefore recognized by the Ramsar Convention. In addition to chimpanzees (Pan troglodytes verus), baboons (Papio papio) and patas monkeys (Erytrocebus patas), it is possible to observe white pelicans (Pelecanus onocrotalus) and other attractive birds: Phalacrocorax africanus, Platalea alba, Phalacrocorax africanus, Glareola pratincola, Egretta garzetta, Sarkidiomis melanotos, etc. (Araújo 1994).

The resident human population is spread over 33 villages concentrated mostly in the north of the park along the river Corubal (Fig. 2.3).

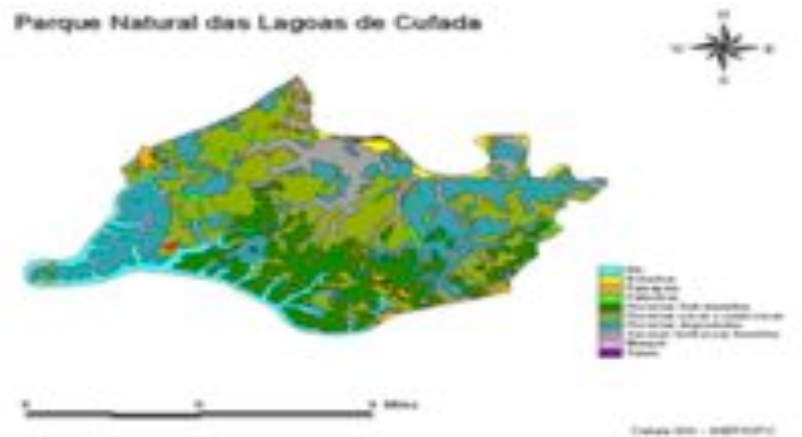

Figure 2.3: Map of land use in Cufada Lagoons Natural Park, Guinea-Bissau (INEP 2010). 


\subsection{3- Study Area 3: Gabú Region}

A chimpanzee survey was performed in the Boé sector during April-May 2010. This sector is located in the Gabú region at approximately $12^{\circ} \mathrm{N}$ by $14^{\circ} \mathrm{W}$. The Northern border of the Boé sector is the Corubal River, while to the South and East lays the border with Guinea. The totally area of the sector is $3287.8 \mathrm{~km}^{2}$ (Reintjes and Wit 1986). The sector has a population of approximately 12,000 largely subsistence agriculturalists and pastoralists. The majority of the population is of the Fulani ethnicity. There are no recent meteorological data for the Boé sector. The annual rainy season is typically from June until September, with little to no rainfall in the dry season. The Féfinê River is permanent and crosses the Boé from South to North, forming a tributary to the Corubal. There are a large number of small permanent and seasonal streams in the sector. The lake at Vendu Cham is an important site for avifauna. The sector is dominated by savannah vegetation on poor laterite soils, where Parkia biglobosa is a common tree species. The local population frequently burns the savannah. Where the laterite cap is broken, species rich gallery forests can be found. Many forest patches are being cleared by slash-and-burn methods to be replaced with subsistence agriculture and seasonal settlements. This land use results in potentially frequent contact between chimpanzees and humans or domestic animals and their faeces.

The chimpanzee population in the Boé is very poorly studied. Serra et al. (2006) estimated a population of 710 individuals for the sector, based mainly on interviews with villagers. Other than chimpanzees, seven other species of primates are present in the Boé: Galago senegalensis senegalensis, Papio papio, Cercopithecus aethiops sabeus, Erythrocebus patas, Cercocebus atys, Colobus polykomos and Piliocolobus badius. Other large mammals include Hippopotamus amphibius, Tragelaphus scriptus scriptus, Syncerus caffer nanus, Phacochoeurus africanus, Kobus ellipsiprymnus defassa, Crocuta crocuta and Panthera pardus. 
The World Bank and the United Nations Environment Program are in the process of creating the new protected area: Dulombi-Boé National Park (World Bank 2011) (Fig. 2.4). 


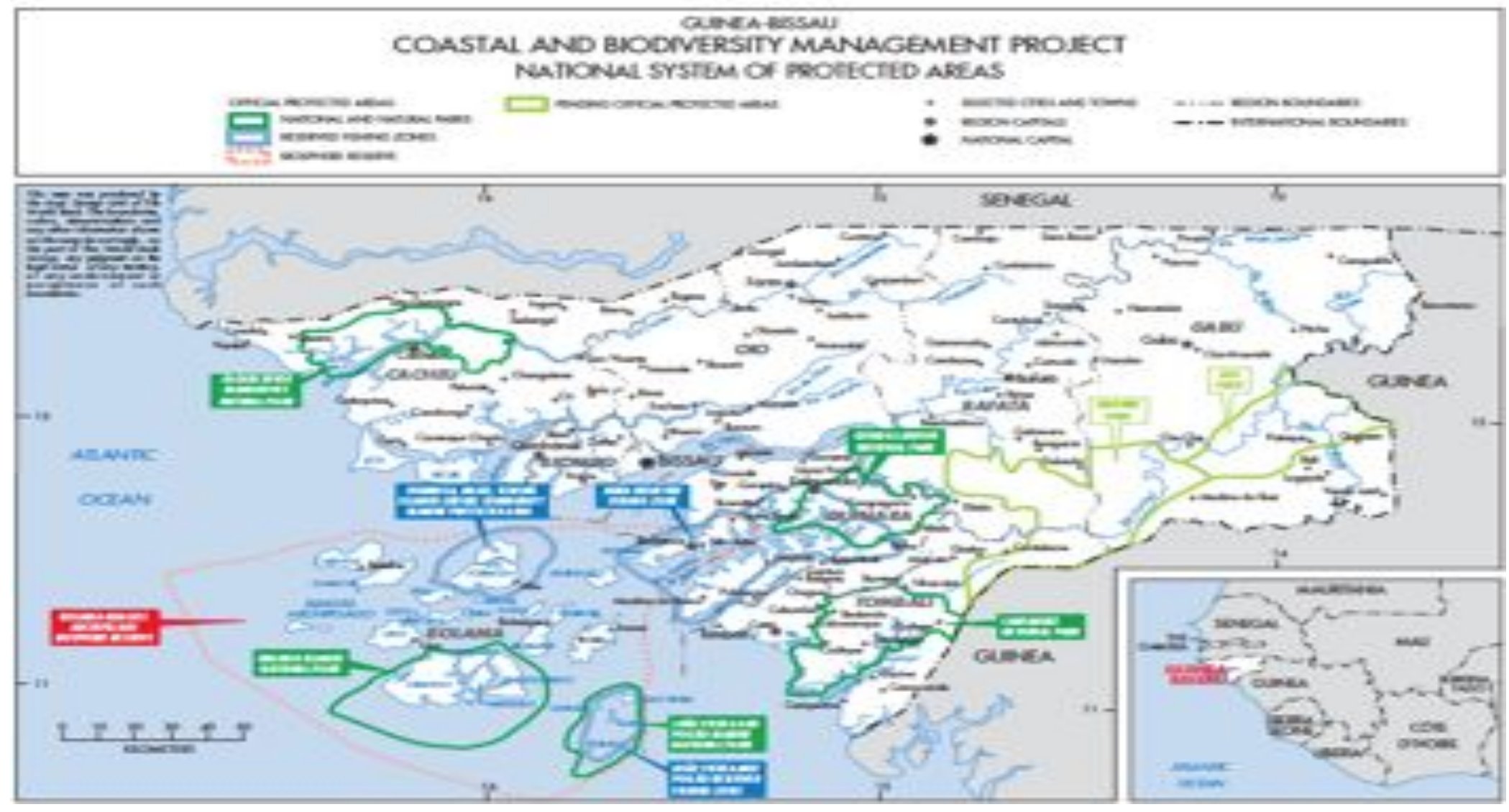

Figure 2.5: Guinea-Bissau Protected Areas and future National Park of Dulombi-Boé (World Bank 2011). 


\section{3- Non-invasive sampling strategy}

Data were collected from wild populations of $P$. troglodytes verus across Guinea-Bissau. Approximatelly 500 fecal samples (Table 2.4) were collected from: Tombali, Quínara and Gabú regions (Fig. 2.5). These samples were taken from free ranging chimpanzees. Cantanhez region was sampled extensively. Communities ranged in size from 2 to 23 animals when it was possible to see and count them. For each sample collected, and individual code, region, place, GPS coordinates, status, sex and age (i.e. if known) and morphometric measures were recorded. Approximately $5 \mathrm{~g}$ of the outer layer of fecal material were stored at room temperature in absolute ethanol for $24 \mathrm{~h}$ and then transferred to a second tube with silica gel type III (Sigma Alrich) and maintained at room temperature until DNA was extracted according with "Two steps" protocol suggested by Roeder et al. (2004).

For the parasitological survey, each sample was immediately fixed in PROTOfixTM CLR (Alpha-tech-Systems, Inc.) according with the fabricant instructions and stored at room temperature until futher analysis.

Permits to transport samples were obtained near the official institutions of Guinea-Bissau, Portugal and UK (IBAP, ICNB and DEFRA). 
Table 2.4: Chimpanzee non-invasive sampling, Guinea-Bissau, for this study.

\begin{tabular}{|c|c|c|c|c|c|c|}
\hline Regions & Areas & Sampling Site & $\mathbf{N}$ & Lat. & Lon. & $\begin{array}{c}\text { Sample } \\
\text { site } \\
\text { Number }\end{array}$ \\
\hline Tombali & Cantanhez & Madina & 25 & $11^{\circ} 12^{\prime} 47.64^{\prime \prime} \mathrm{N}$ & $15^{\circ} 2^{\prime} 12.72^{\prime \prime} \mathrm{W}$ & 1 \\
\hline Tombali & Cantanhez & Farim & 20 & $11^{\circ} 12^{\prime} 31.02^{\prime \prime} \mathrm{N}$ & $15^{\circ} 4^{\prime} 25.80^{\prime \prime} \mathrm{W}$ & 2 \\
\hline Tombali & Cantanhez & Caiquéne & 25 & $11^{\circ} 13^{\prime} 30.93^{\prime \prime} \mathrm{N}$ & $15^{\circ} 5^{\prime} 47.73^{\prime \prime} \mathrm{W}$ & 3 \\
\hline Tombali & Cantanhez & Canghode & 27 & $11^{\circ} 9^{\prime} 40.68^{\prime \prime} \mathrm{N}$ & $15^{\circ} 7^{\prime} 35.46^{\prime \prime} \mathrm{W}$ & 4 \\
\hline Tombali & Cantanhez & Catomboi & 15 & $11^{\circ} 11^{\prime} 38.28^{\prime \prime} \mathrm{N}$ & $15^{\circ} 4^{\prime} 36.36^{\prime \prime} \mathrm{W}$ & 5 \\
\hline Tombali & Cantanhez & Amidara & 15 & $11^{\circ} 16^{\prime} 52.38^{\prime \prime} \mathrm{N}$ & $14^{\circ} 58^{\prime} 34.02^{\prime \prime} \mathrm{W}$ & 6 \\
\hline Tombali & Cantanhez & Cambéque & 10 & $11^{\circ} 11^{\prime} 30.18^{\prime \prime N}$ & $15^{\circ} 0{ }^{\prime} 49.74 " \mathrm{~W}$ & 7 \\
\hline Tombali & Cantanhez & São Francisco & 15 & $11^{\circ} 19^{\prime} 18.96^{\prime \prime} \mathrm{N}$ & $14^{\circ} 59^{\prime} 29.22^{\prime \prime} \mathrm{W}$ & 8 \\
\hline Tombali & Cantanhez & Ponta Nova & 15 & $11^{\circ} 18^{\prime} 41.64^{\prime \prime} \mathrm{N}$ & $14^{\circ} 58^{\prime} 51.36^{\prime \prime} \mathrm{W}$ & 9 \\
\hline Tombali & Cantanhez & Cadique & 60 & $11^{\circ} 14^{\prime} 19.92^{\prime \prime N}$ & $15^{\circ} 6^{\prime} 51.30^{\prime \prime} \mathrm{W}$ & 10 \\
\hline Tombali & Cantanhez & Muna & 25 & $11^{\circ} 10^{\prime} 2.46^{\prime \prime} \mathrm{N}$ & $15^{\circ} 8^{\prime} 36.00^{\prime \prime} \mathrm{W}$ & 11 \\
\hline Tombali & Cantanhez & Mejo & 15 & $11^{\circ} 22^{\prime} 48.45^{\prime \prime} \mathrm{N}$ & $14^{\circ} 54^{\prime} 51.00^{\prime \prime} \mathrm{W}$ & 12 \\
\hline Tombali & Cantanhez & Quebo Sutuba & 10 & $11^{\circ} 9^{\prime} 34.51^{\prime \prime} \mathrm{N}$ & $14^{\circ} 54^{\prime} 41.12^{\prime \prime} \mathrm{W}$ & 13 \\
\hline Tombali & Cantanhez & Lautchande & 25 & $11^{\circ} 14^{\prime} 55.14^{\prime \prime} \mathrm{N}$ & $15^{\circ} 4^{\prime} 20.40^{\prime \prime W}$ & 14 \\
\hline Tombali & Cantanhez & Cambafre & 15 & $11^{\circ} 18^{\prime} 1.74^{\prime \prime} \mathrm{N}$ & $14^{\circ} 56^{\prime} 22.20^{\prime \prime} \mathrm{W}$ & 15 \\
\hline Tombali & Cantanhez & Cancira & 11 & $11^{\circ} 22^{\prime} 48.45^{\prime \prime} \mathrm{N}$ & $14^{\circ} 54^{\prime} 51.00^{\prime \prime} \mathrm{W}$ & 16 \\
\hline Tombali & Cantanhez & Bagriel & 4 & $11^{\circ} 20^{\prime} 22.44^{\prime \prime} \mathrm{N}$ & $15^{\circ} 0^{\prime} 50.94^{\prime \prime} \mathrm{W}$ & 17 \\
\hline Quínara & Cufada & Buba Itchinque & 27 & $11^{\circ} 45^{\prime} 11.58^{\prime \prime} \mathrm{N}$ & $15^{\circ} 5^{\prime} 18.36^{\prime \prime} \mathrm{W}$ & 18 \\
\hline Quínara & Cufada & Tira Camisa & 5 & $11^{\circ} 41^{\prime} 25.56^{\prime \prime} \mathrm{N}$ & $15^{\circ} 4^{\prime} 2.94^{\prime \prime} \mathrm{W}$ & 19 \\
\hline Quínara & Cufada & Bani & 5 & $11^{\circ} 43^{\prime} 42.54^{\prime \prime} \mathrm{N}$ & $15^{\circ} 5^{\prime} 31.20^{\prime \prime} \mathrm{W}$ & 20 \\
\hline Quínara & Cufada & Injassane & 5 & $11^{\circ} 44^{\prime} 29.88^{\prime \prime N}$ & $14^{\circ} 59^{\prime} 4.74^{\prime \prime} \mathrm{W}$ & 21 \\
\hline Quínara & Cufada & Nhala-Molha Pé & 10 & $11^{\circ} 37^{\prime} 45.72^{\prime \prime} \mathrm{N}$ & $14^{\circ} 53^{\prime} 55.08^{\prime \prime} \mathrm{W}$ & 22 \\
\hline Quínara & Cufada & Buba Tumbo & 5 & $11^{\circ} 38^{\prime} 37.92^{\prime \prime} \mathrm{N}$ & $15^{\circ} 0^{\prime} 19.80^{\prime \prime} \mathrm{W}$ & 23 \\
\hline Quínara & Empada & Dois Rios & 20 & $11^{\circ} 37^{\prime} 56.22^{\prime \prime} \mathrm{N}$ & $15^{\circ} 9^{\prime} 18.66^{\prime \prime} \mathrm{W}$ & 24 \\
\hline Tombali & Catió & Briame & 18 & $11^{\circ} 17^{\prime} 19.92^{\prime \prime N}$ & $15^{\circ} 14^{\prime} 28.86^{\prime \prime} \mathrm{W}$ & 25 \\
\hline Gabú & Boé & Dinguirai & 12 & $11^{\circ} 45^{\prime} 18.72^{\prime \prime} \mathrm{N}$ & $13^{\circ} 51^{\prime} 55.38^{\prime \prime} \mathrm{W}$ & 26 \\
\hline Gabú & Boé & Pataque & 8 & $11^{\circ} 53^{\prime} 04.9^{\prime \prime} \mathrm{N}$ & $13^{\circ} 57^{\prime} 32.5^{\prime \prime} \mathrm{W}$ & 27 \\
\hline Gabú & Boé & Aicum & 6 & $11^{\circ} 56^{\prime} 29.22^{\prime \prime N}$ & $13^{\circ} 52^{\prime} 37.38^{\prime \prime} \mathrm{W}$ & 28 \\
\hline Gabú & Boé & Béli North & 18 & $11^{\circ} 52^{\prime} 04.7^{\prime \prime} \mathrm{N}$ & $\begin{array}{l}13^{\circ} 57^{\prime} 31.9^{\prime \prime} \\
W\end{array}$ & 29 \\
\hline Gabú & Boé & Béli & 14 & $11^{\circ} 51^{\prime} 10.80^{\prime \prime} \mathrm{N}$ & $13^{\circ} 54^{\prime} 39.66^{\prime \prime} \mathrm{W}$ & 30 \\
\hline Gabú & Boé & Vendu Leidi & 10 & $11^{\circ} 44^{\prime} 33.00^{\prime \prime} \mathrm{N}$ & $13^{\circ} 43^{\prime} 22.44^{\prime \prime} \mathrm{W}$ & 31 \\
\hline Gabú & Boé & Munhini & 5 & $11^{\circ} 45^{\prime} 9.84^{\prime \prime} \mathrm{N}$ & $13^{\circ} 55^{\prime} 27.66^{\prime \prime} \mathrm{W}$ & 32 \\
\hline
\end{tabular}




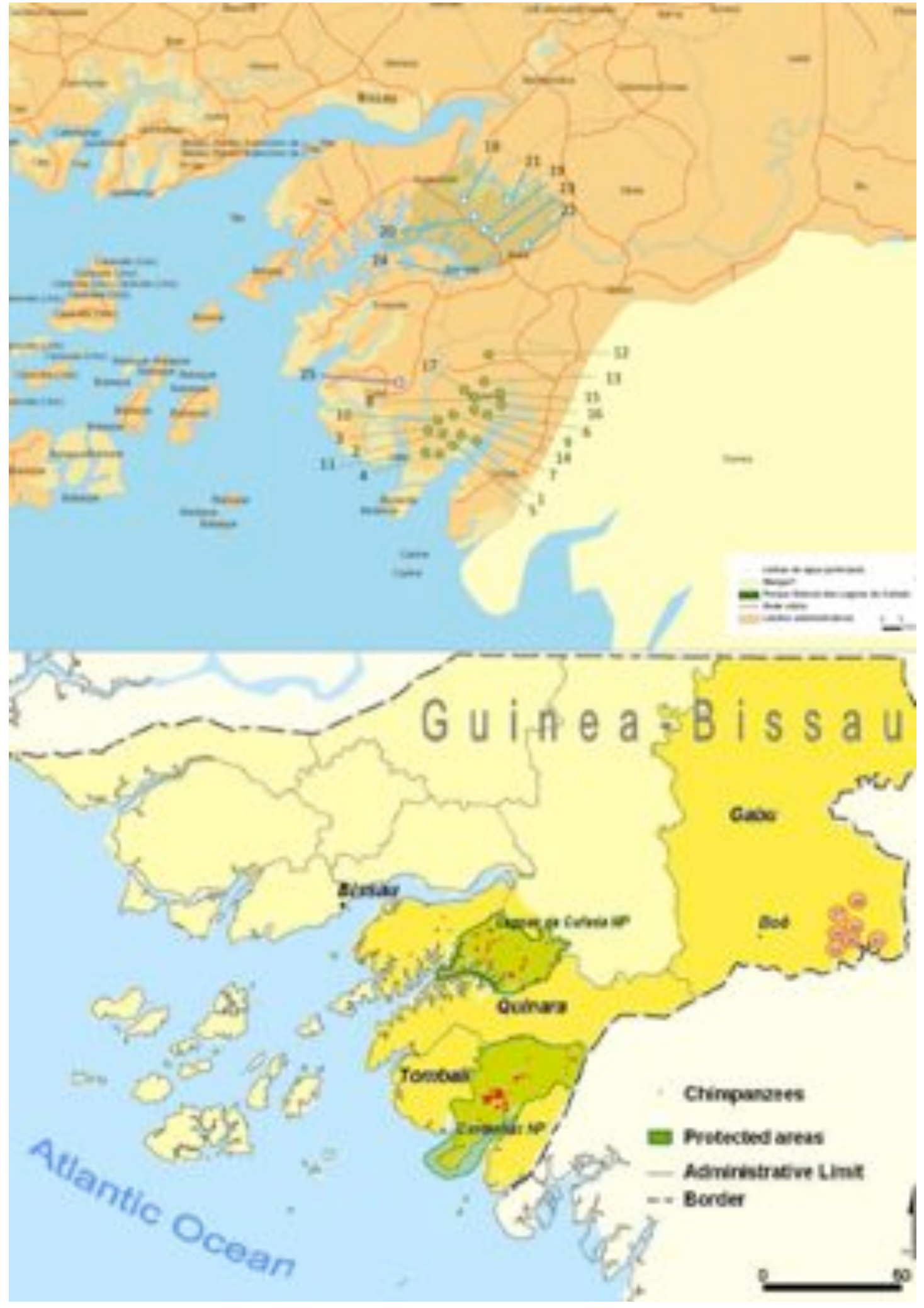

Figure 2.5: Guinea-Bissau sampling sites for this study. Numbers represent sampling sites indicated in Table 2.4. 


\section{4- Ethnographic observations}

Visits were made to Bandim market, the largest market in Bissau, the capital, during two weeks in September 2008 and a similar period in June 2010. Some men were found to be offering wild animal body parts for sale (e.g. skin, bones, teeth, horns and scales). When possible, morphological identification of the specimens viewed was made and photographs taken.

Five urban vendors in Bandim and 17 rural informants in villages in the CNP and the Boé region were informally interviewed following an unstructured script, in order to document the geographical origin and use of Chimpanzee body parts, prices and the scale of the trade, i.e. whether at a national, regional, or transnational level. Direct observations of the trade were conducted in the market and field notes were taken. Informants were ensured that the purpose of the work was not to condemn or report their practices to the local authorities. Every observation was recorded and notes/interviews organized into social demographic categories (e.g. urban traders, local villagers, gender, ethnic group). Only information relevant to the research topic was assigned to these categories (Rubin and Rubin 1995).

\section{5- Genetic procedures}

All molecular procedures were performed in MWB laboratory (aka G10), at Cardiff School of Biosciences.

\subsection{1- DNA extraction}

To test the best preservation method to storage the samples, a pilot study was conducted during the 2008 mission in CNP. The samples were stored at room temperature in Silica Gel (SIGMA ALDRICH, type III), absolute ethanol, or according the 'Two Steps method' (Roeder et al. 2004). A set of 16 fresh chimpanzee samples was collected, and the same sample was divided and stored in those preservation methods. The "two steps" proved to be be the most reliable to preserve the chimpanzee DNA and was therefore subsequently used in the next genetic surveys 
(Fig. 2.6).

A separate and dedicated fume hood was used during all the faecal extraction process. Before the start of the process all the areas (hood, bench, and centrifuge) were decontaminated with bleach (20\%) and DNA Away (DUTSCHER, France, catalogue number 038188). Tweezers, $2 \mathrm{~mL}$ and 1,5mL Eppendorf tubes were previously autoclaved, and all the 5 dedicated equipment was exposed to UV-light overnight inside the hood. Each sample was extracted in duplicate and two negative controls were included to monitor possible contamination. The extraction procedure was divided in two consecutive days by using the QIAmp DNA Stool Mini Kit ${ }^{\circledR}$ (QIAGEN, Germany) according to the manufacturer instructions with the following modifications: Day 1- To each faecal sample (approximately $0.1 \mathrm{~g}$ ) $1.7 \mathrm{~mL}$ ASL buffer was added, vortexed 10 minutes and then allowed to soak at room temperature in an orbital shaker overnight. Day 2- The centrifuge and incubating times were increased to 3-10 min and immediately before the precipitation step with $100 \%$ ethanol, $4 \mu \mathrm{L} 1350 \mu \mathrm{g} / \mathrm{mL}$ poly-A Carrier RNA (QIAGEN, Germany, catalogue number 1017647) was added. The poly-A increases the efficiency of binding and elution when the expected DNA yield is $\leq 10 \mathrm{ng}$. The elution time with AE buffer was also increased to $30 \mathrm{~min}$ and the final volume reduced to $150 \mu \mathrm{L}$.

\section{"Wash" protocol}

I also tried one alternative faecal extraction protocol developed by (Flagstad et al. 1999) and (Palomares et al. 2002) with the following modifications: 0,70g of faecal material (desiccated in Silica Gel) was placed in a $50 \mathrm{~mL}$ sterile tube and washed (10 to $30 \mathrm{X}$ with a disposable Pasteur pipette) with $600 \mu \mathrm{L}$ of phosphate buffered saline (PBS) ( $\mathrm{pH}$ 7.4). After the wash step all the solution was taken into a $2 \mathrm{~mL}$ tube and centrifuged at full speed (approx. $13000 \mathrm{rpm}$ ) and the supernatant was poured off. $1 \mathrm{~mL}$ of ASL buffer was added to the pellet and let soak overnight. The next steps were the same as above.

Two blank extraction negatives and several PCR's were included to monitor possible contaminations. 


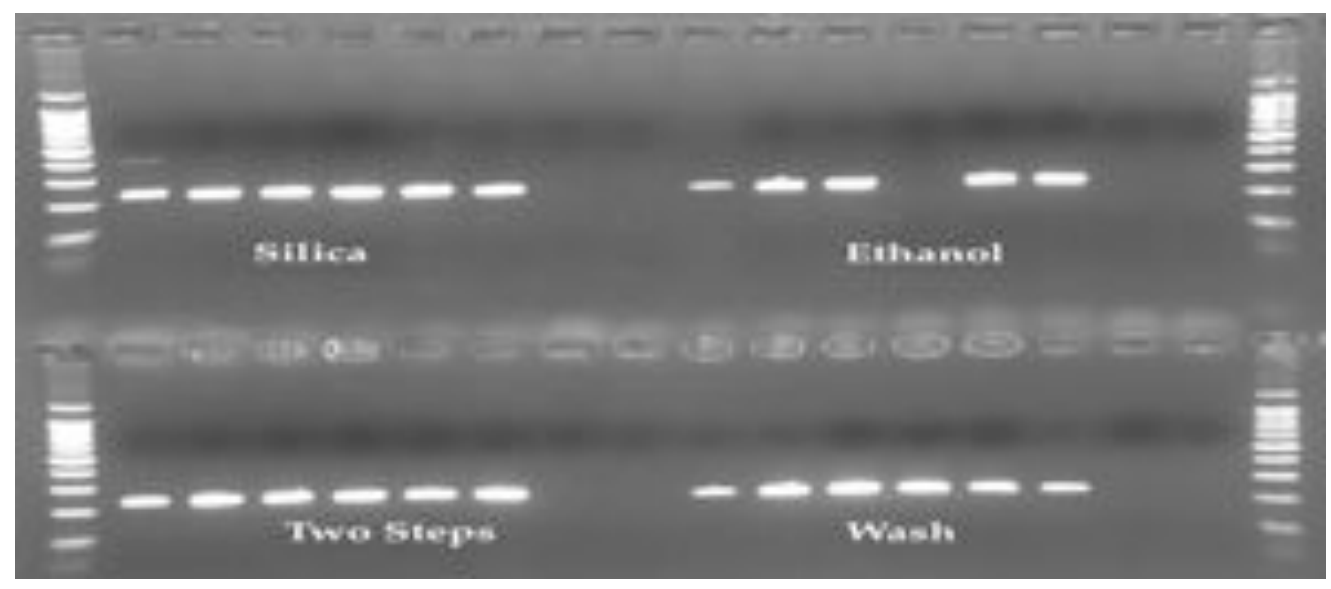

Figure 2.6: PCR results of the best preservation DNA reagent after electrophoresis. The "Two Steps" presented the most convincing results.

\subsection{2- DNA amplification and sequencing}

To test the extraction success, a mtDNA HVRI PCR was performed on a Applied Biosystems Gene Amp ${ }^{\oplus}$ PCR System 9700 using $200 \mu$ l PCR tubes in a total volume of $20 \mu \mathrm{L}$ PCR reaction mixture consisting of: $9 \mu \mathrm{L}$ of QIAGEN Multiplex PCR kit containing buffer, DNTP's, Taq polymerase and $3 \mathrm{mM} \mathrm{MgCl} 2$ (final concentration), $0.1 \mu \mathrm{L} 1 \times \mathrm{BSA}, 0.1 \mu \mathrm{L} 1 \times \mathrm{Q}$ solution, $6.8 \mu \mathrm{L}$ ultrapure water and $0.2 \mu \mathrm{M}$ primers and 2 $\mu \mathrm{L}$ DNA template. PCR profile were as follows: 95_C for $15 \mathrm{~min}$, then amplified for 45 cycles of 94_C for $30 \mathrm{~s}, 51$ _C for $60 \mathrm{~s}$, and 72_C for $60 \mathrm{~s}$, and finally extended at 72_C for 10 min. Primers L15926 (5'-TAC ACT GGT CTT GTA AAC C-3', corresponding to positions 15326-15344 of the complete chimpanzee mtDNA genome [EMBL/GenBank accession No. D38113) and H16555 (5'-TGA TCC ATC GTG ATG TCT TA-3', corresponding to positions 15971-15990 of D38113) were used because they amplify the HVRI mtDNA region of chimpanzees. These primers have been reported to reliably amplify a $600 \mathrm{bp}$ of the mitochondrial control region fragment (also known as D-loop) in chimpanzees (Shimada et al. 2004) (Table 2.5). Reactions were visualized on a $2 \%$ agarose gel stained with ethidium bromide and DNA was quantified based on the intensity of the band when compared to the ladder scale 
intensity (Fig. 2.7). Samples with less than $5 \mathrm{ng} / \mu \mathrm{L}$ were not used because they rarely work both for sequencing and microsatellite analyses.

Table 2.5: HVR1 chimpanzee primers.

\begin{tabular}{lll}
\hline Primer & Sequence & Reference \\
\hline L15926 & 5'-TACACTGGTCTTGTAAACC-3' & Shimada et al. 2004 \\
H16555 & 5'-TGATCCATCGTGATGTCT-3' & Shimada et al. 2004 \\
\hline
\end{tabular}

PCR products were purified with Exonuclease I and Shrimp Alkaline Phosphatase (SAP) enzymes (New England Biolabs, UK) at 37_C for 60 min and inactivated at 80_C for $15 \mathrm{~min}$ and send for sequencing to MACROGEN EUROPE using the same amplification primers (Table 2.5). Chromatograms were inspected and sequences were edited, assembled and aligned using the program SEQUENCHER (Gene Codes Corporation). The consensus sequences were BLASTed to confirm chimpanzee species.

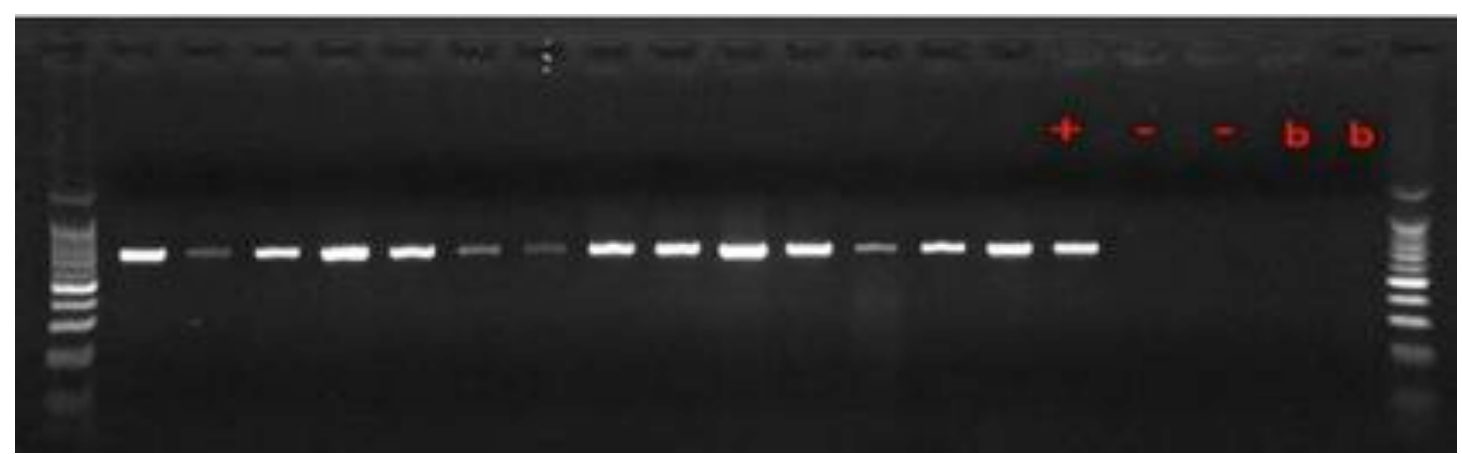

Figure 2.7: MtDNA gel picture. Positive amplifications indicated by bright band around 700bp. + positive control; - DNA isolation controls; b blank PCR control.

\subsection{3- Sequences authenticity}

In order to effectively ensure that the sequences of this study were not contaminated with "numts" all PCR products were carefully inspected both in 
agarose gels (for dual bands in the presence of the expected size of fragment), and for double peaks in the sequencing electropherograms. Furthermore, a great degree of variation was found in the dataset, and all the sequences aligned in accordance with the reference sequence of the mitochondrial genome of HVR1 Pan troglodytes troglodytes [GenBank Access No.: X93335] (Arnasson et al. 1996).

Complementary, the sequences produced by this study were also compared with the sequences deposited in chimpanzee numts database MITOMAP (http://www.mitomap.org/MITOMAP). No evidence was found for the presence of "numts" in the dataset of this study.

\subsection{4- Microsatellites and molecular sexing}

I tested 9 microsatellite loci initially developed for humans but that cross amplify great apes. All primers were previously used in chimpanzee population genetic studies by Gusmão et al (2002) and Roeder et al (2006). The 9 loci were designed, optimized and combined in two multiplexes by using the software Multiplex Manager 1.0 (Holleley and Geerts 2009): M1 (Amelogenin, D16S2624, D1S550, D10S1432, and D2S1326) and M2 (D5S1457, HUMFIBRA, D4S1627, and DYS439). Multiplex 1 includes the amelogenin sexing system that allows an accurate DNA-based sex identification of chimpanzees using non-invasive samples (Bradley et al. 2001). PCR amplification mixture was carried using a QIAGEN Multiplex PCR kit according to the manufacturer's instructions. Final reaction volume was $8 \mu \mathrm{L}$. Primers were 5'-fluorolabelled and their final concentration in the PCR mixture was $0.2 \mu \mathrm{M}$. PCR profile on a Applied Biosystems Gene Amp PCR System 9700 were: 95_C for 15 min, 45 cycles of 94_C for $30 \mathrm{~s}, 57$ _C (M1) or 58_C (M2) for 1, 40 min, 72_C for 1, $30 \mathrm{~min}$ and a final extension of 72_C for $20 \mathrm{~min}$. Loci used, ranges, dyes, primer sequences and multiplex combinations are shown in Table 2.6. Samples were sent to MACROGEN KOREA where they were electrophoresed on an automated genetic analyzer using $1 \mu \mathrm{L}$ PCR product and the internal size standard ROX 400 . Alleles were scored using GeneMapper v. 3.2 software (Applied Biosystems). 
From these multiplexes (M1 and M2) two loci are not working properly specially the locus D1S550 and therefore a new multiplex combination (M3) with 5 additionally loci was created and optimized (Table 2.7). 
Table 2.6: Multiplex composition, primer information and allelic size ranges.

\begin{tabular}{|c|c|c|c|c|}
\hline Locus & Multiplex & Label & $\begin{array}{l}\text { Allele size range } \\
\text { (bp) }\end{array}$ & Primers \\
\hline Amelogenin & \multirow{5}{*}{ M1 } & FAM & $104-110$ & $\begin{array}{l}\text { F-5'- CCTGGGCTCTGTAAAGAATAGTG-3' } \\
\text { R-5'-ATCAGAGCTTAAACTGGGAAGCTG-3' }\end{array}$ \\
\hline D16S2624 & & NED & $119-139$ & $\begin{array}{l}\text { F- 5'-TGAGGCAATTTGTTACAGAGC-3' } \\
\text { R- 5'-TAATGTACCTGGTACCAAAAACA-3' }\end{array}$ \\
\hline D1S550 & & HEX & $147-177$ & $\begin{array}{l}\text { F- 5'-CCTGTTGCCACCTACAAAAG-3' } \\
\text { R-5'-TAAGTTAGTTCAAATTCATCAGTGC-3' }\end{array}$ \\
\hline D10S1432 & & FAM & $162-182$ & $\begin{array}{l}\text { F-5'- CAGTGGACACTAAACACAATCC-3' } \\
\text { R-5'-TAGATTATCTAAATGGTGGATTTCC-3 }\end{array}$ \\
\hline D2S1326 & & FAM & $210-282$ & $\begin{array}{l}\text { F-5'-AGACAGTCAAGAATAACTGCCC-3' } \\
\text { R-5'-CTGTGGCTCAAAAGCTGAAT-3' }\end{array}$ \\
\hline D5S1457 & \multirow{4}{*}{ M2 } & FAM & 101-133 & $\begin{array}{l}\text { F- 5'-TAGGTTCTGGGCATGTCTGT-3' } \\
\text { R- 5'-TGCTTGGCACACTTCAGG-3' }\end{array}$ \\
\hline HUMFIBRA & & HEX & 171-203 & $\begin{array}{l}\text { F-5'-GCCCCATAGGTTTTGAAACTCA-3' } \\
\text { R-5'-TGATTTGTCTGTAATTGCCAGC-3' }\end{array}$ \\
\hline D4S1627 & & FAM & $214-250$ & $\begin{array}{l}\text { F-5'AGCATTAGCATTTGTCCTGG-3' } \\
\text { R-5'-GACTAACCTGACTCCCCCTC-3' }\end{array}$ \\
\hline DYS439 & & HEX & $230-258$ & $\begin{array}{l}\text { F- 5'-TCCTGAATGGTACTTCCTAGGTTT-3' } \\
\text { R- 5'-GCCTGGCTTGGAATTCTTTT-3' }\end{array}$ \\
\hline
\end{tabular}

Table 2.7: Multiplex 3 composition, primer information and allelic size ranges.

\begin{tabular}{|c|c|c|c|c|}
\hline Locus & Multiplex & Label & $\begin{array}{l}\text { Allele size } \\
\text { range (bp) }\end{array}$ & Primers \\
\hline DQCAR & \multirow{5}{*}{ M3 } & FAM & $99-119$ & $\begin{array}{l}\text { F- 5'-GAAACATATATTAACAGAGACAGACAAA-3' } \\
\text { R- 5'-CATTTCTCTTCCTTATCACTTCATA-3' }\end{array}$ \\
\hline D1S207 & & HEX & $128-160$ & $\begin{array}{l}\text { F- 5'-CACTTCTCCTTGAATCGCTT-3' } \\
\text { R- 5'-GCAAGTCCTGTTCCAAGTCT-3' }\end{array}$ \\
\hline D13S159 & & TAMRA & $154-190$ & $\begin{array}{l}\text { F- 5'-AGGCTGTGACTTTTAGGCCA-3' } \\
\text { R- 5'- CCAGGCCACTTTTGATCTGT-3' }\end{array}$ \\
\hline D14S306 & & FAM & $196-248$ & $\begin{array}{l}\text { F- 5'- AAAGCTACATCCAAATTAGGTAGG-3' } \\
\text { R- 5'- TGACAAAGAAACTAAAATGTCCC-3' }\end{array}$ \\
\hline D6S311 & & HEX & $208-248$ & $\begin{array}{l}\text { F-5'-ATGTCCTCATTGGTGTTGTG-3' } \\
\text { R- 5'- GATTCAGAGCCCAGGAAGAT-3' }\end{array}$ \\
\hline
\end{tabular}




\subsection{5- Data analysis}

The haplotypes were defined by analyzing the sequences in the program DNASP v. 4.01 (Rozas et al. 2003). The haplotype diversity (h) nucleotide ( $\pi$ ) and Watterson $\left(\theta_{\mathrm{w}}\right)$ were estimated in the program ARLEQUIN v.3.01 (Excoffier et al. 2005) as well as the estimator $\mathrm{F}_{\mathrm{ST}}$ in the analysis of their genetic differentiation. The haplotype richness $(\mathrm{Hr})$ was calculated using the method implemented in the software CONTRIB v.1.02 (Petit et al. 1998). The analysis of molecular variance (AMOVA) using the pairwise differences were also held in the program ARLEQUIN and the most likely pattern of population subdivision was estimated using the spatial analysis of molecular variance in the program SAMOVA 1.0 (Dupanloup et al. 2002).

In order to evaluate a possible pattern of insolation by distance a Mantel test and a RMA were applied in the program IBDWS v 3.16 (Jensen et al. 2005). Similarly, to assess whether there are vicariant barriers that may prevent gene flow, the program BARRIER v. 2.2 was used (Manni et al. 2004).

The phylogenetic reconstruction of the Network was made in the program NETWORK v. 4.6, which uses the algorithm of median-joining (Bandelt et al. 1999).

For the phylogenetic analysis, the best model of evolution and replacement of nucleotides was asseed through the Akaike Information Criterion implemented in the program jMODELTEST v.0.1.1 (Posada 2008). Using the methods of neighbor joining and the Bayesian inference program MRBAYES v. 3.1 (Ronquist and Huelsenbeck 2003) for phylogenetic trees reconstruction. The posterior probabilities were inferred using the Metropolis-Coupled Markov Chain Monte Carlo algorithm (MC-MCMC) from one million generations, with sampling every 100, 4 chains, 2 runs and an initial burn-in $25 \%$. Stationarity of the chains was established from $\rho<0.01$ split frequencies. The convergence of the MCMC Bayesian inferences was evaluated in the program Tracer v.1.5 (Rambaut and Drummond 2007). All trees obtained were viewed and edited in Figtree software v.1.3.1 (Rambaut 2006) and in the program TREEGraph v. 2.0 (Stöver and Müller 2010).

With the aim of analyzing their divergence times, a relaxed molecular clock and a coalescent approach, implemented in the program BEAST v. 1.6.2, was used (Drummond and Rambaut 2007). Three independent runs were performed using the 
same mutation rate; the same optimized parameters and the model suggested by jMODELTEST. The convergence of the runs was also evaluated in the program TRACER after the combining of logs and trees in LogCombiner and TreeAnnotator respectively (Drummond and Rambaut 2007). The analysis of demographic history and the chance of sudden expansion and space were tested using: mismatch distributions (Rogers and Harpending 1992) and tests of neutrality (Tajima D and Fu Fs) and the program ARLEQUIN; tests Fu and Li F* and $D *$ in the program DNASP v.4.01.

For genotyping criteria the "multi-tubes" approach (Taberlet et al. 1996) was initially considered (up to seven positive PCR repeats to confirm homozygosity). However, due to the high number of extracted DNA samples, time and financial constraints prevented that each individual was genotyped as many times as recommended by the protocol. The number of replicates was therefore estimated by using a maximum likelihood approach implemented in the software GEMINI v. 1.4.1 (Valière et al. 2002) that uses a priori information about the error rates (i.e. allelic dropout and false alleles), which were determined in the software PEDANT v. 1.0 (Johnson and Haydon 2007, 2009). General parameters in the software GEMINI included 100 simulation replicates and the range of repetition number was set from 2-12. This test revealed that four PCR repetitions were appropriate to achieve a high probability of identity assuring a 95\% confidence of the genotypes, and the per locus consensus threshold revealed that for a sample to be included in the final dataset must have at least two positive PCR results for nine of the 14 loci. For molecular sexing the result was considered as true when observed three times out of the four repetitions.

Allelic dropout, null alleles and stutter peaks were assessed using MICROCHECKER, v. 2.2.3 (van Oosterhout et al. 2004). Moreover, a quality index (QI) for all loci was determined according to Miquel et al. (2006) and samples with a QI below 0.50 were removed from the dataset, as they are genotypes with poor quality.

To detect repeated individuals the software GIMLET v. 1.3.3 (Valière 2002) was used, and duplicated genotypes were removed. This software was also used to calculate the Probability of Identity (PI) and the Probability of Identity between 
siblings ( $\left(\mathrm{I}_{\text {sibs }}\right.$ ) (Waits et al. 2001). Finally, GenAIEx v. 6.4.1 (Peakall and Smouse 2006) was used to conduct all standard population genetic analyses.

\section{6- Parasitological screening}

All parasitological analyses were performed in the Department of Parasitology of the Veterinary and Pharmaceutical Sciences University, Brno, Czech Republic.

\subsection{1- Laboratory techniques}

About half of each sample was kept in the original flask for possible further analyses/repetitions. The other half was diluted 1.1 with $\mathrm{H} 2 \mathrm{O}$ and filtered through standard sieves ( $100 \mu \mathrm{m})$ for macroscopic examination. The filtered material of each fecal sample was prepared for coprological examination by combining a modified Sheather's solution flotation (s.g. 1.33) and a MIF (Merthiolate lodine Formaldeyde) sedimentation techniques and then stained with Lugol's iodine. Direct smears were performed during fieldwork. Several drops were examined for each technique from each sample in a compound microscope at 100x-1000x magnifications. Symbionts were identified on the basis of egg, cyst, trophozoite and larvae stages, color, shape, content and size by using identification keys. Measurements were made to the nearest $0.1 \mu \mathrm{m} \pm \mathrm{SD}$, using a calibrated ocular micrometer. Representatives were photographed using Nomarski interference contrast. Mean egg/cysts sizes are based on measurements of 10 eggs/cysts from 10 different samples.

\subsection{2- Statistical analyses}

Chi square or Fisher's exact tests with subsequent Bonferroni correction were performed in order to compare sample prevalence in chimpanzees inhabiting North, Central and South CNP areas for each parasite taxa separately. Differences in symbiont richness among areas were investigated using Kruskal-Wallis ANOVA, with LSD post hoc tests used for pairwise comparisons. The value of $\rho<0.05$ was set as 
significant. SPSS, version 17 (SPSS Inc., Chicago, IL) and SISA (http://www.quantitativeskills.com/sisa/) were used for all statistical analyses.

\section{7- References}

Araújo A. 1994. A importância ornitológica da região da Cufada na Guiné-Bissau. Estudos de Biologia e Conservação da Natureza 13. ICN-CEMPA. Lisboa pp. 71.

Arnasson U, Xu X, and Gullberg A. 1996. Comparison between the complete mitochondrial DNA sequences between Homo and the common chimpanzee based on nonchimerich sequences. Journal of Molecular Evolution 42: 145-152.

Bandelt H, Forster P, Röhl H. 1999. Median-joining networks for inferring intraspecifics phylogenies. Mol Biol Evol 16: 37- 48.

BBC 2011. http://www.bbc.co.uk/news/world-africa-13443186 [Accessed: $12 / 08 / 2011]$.

Brito BR. 2007. Estudos das potencialidades e dos constrangimentos do Ecoturismo na região de Tomabali. Acção para o Desenvolvimento.

CIA 2008. Central Intelligence Agency. The World factbook: Guiea-Bissau. https://www.cia.gov/library/publications/the-world-factbook/geos/pu.html [Acessed: 24/11/2008].

Campredon P. 1997. Cantanhez: forêts sacrées de Guinée-Bissau. Tiniguena. pp. 47.

Casanova C, and Sousa C. 2007. Action Plan for the Conservation of Chimpanzees, red western colobus and king colobus in Guinea-Bissau Republic. IBAP, Guiné-Bissau.

Cassamá V. 2006. Alterações do coberto do solo na mata do Cantanhez (GuinéBissau) de 1953 a 2003. MSc Dissertation. 
Catarino LMF. 2004, Fitogeografia da Guiné-Bissau. PhD Dissertation. Instituto Superior de Agronomia, Universidade Técnica de Lisboa.

Catarino L, Martins E, and Moreira I. 2001. Influence of environmental features in the phytogeographic framework of Guinea-Bissau. Systematics and Geography of Plant 71: 197-208.

Catarino L, Martins E, Pinto-Basto MF, and Diniz MA. 2006 Plantas vasculares e Briófitos da Guiné-Bissau. IICT / IPAD, Lisboa. pp. 340.

Dupanloup I, Schneider S, Excoffier L. 2002. A simulated annealing approach to define the genetic structure of populations. Mol Ecol 11: 2571-2581.

Excoffier L, Laval G, Schneider S. 2005. ARLEQUIN ver. 3.0: An integrated software package for population genetics data analysis. Evolutionary Bioinformatics Online 1: 47-50.

Flagstad O, Roed K, et al. 1999. Reliable noninvasive genotyping based on excremental PCR of nuclear DNA purified with a magnetic bead protocol. Molecular Ecology 8: 879-883.

Frazão-Moreira A. 2001. As classificações botânicas Nalu (Guiné-Bissau): Consensos e variabilidades. Etnográfica 5: 131-151.

Gippoliti S, and Dell'Omo G. 2003. Primates of Guinea-Bissau, West Africa: Distribution and Conservation Status. Primate Conservation 19: 73-77.

Gippoliti S, Embalo D, and Sousa C. 2003. Guinea-Bissau. In: Kormos R, Boesch C, Bakarr M, and Butynski T. (Eds) West African chimpanzees: Status Survey and Conservation Action Plan. IUCN, Gland, Switzerland. Pp.55-61. 
Gusmão L, Gonzalez-Neira A, Alves C, et al. 2002. Genetic diversity of Y-specific STRs in chimpanzees (Pan troglodytes). American Journal of Primatology 57: 21-29.

Hockings K, Sousa C. 2011. Human-chimpanzee sympatry and interactions in Cantanhez National Park, Guinea-Bissau: Current Research and future directions. Primate Conservation 26.

Holleley CA, and Geertz PG. 2009. Multiplex Manager 1.0: a crossplatform computer program that plans and optimizes multiplex PCR. BioTecnhniques 46: 511-517.

IBAP. 2008. Estratégia nacional para as áeras protegidas e a conservação da biodiversidade da Guiné-Bissau 2007-2011. Bissau. República da Guiné-Bissau.

INE 2009. Instituto Nacional de Estatística da República da Guiné-Bissau. http://www.stat-guinebissau.com/ [Accesssed: 17/04/2009].

INEP. 2010. http://www.inep-bissau.org/ [Acessed 23/11/2010].

Jensen J, Bohonak J, Kelley S. 2005. Isolation by distance, web service BMC Genetics 6:13.

Johnson PC, Haydon DT. 2007. Maximum-likelihood estimation of allelic dropout and false allele error rates from microsatellite genotypes in the absence of reference 
data. Genetics 175: 827-842.

Johnson PC, Haydon DT. 2009. Software for quantifying and simulating microsatellite genotyping error. Bioinformatics and Biology Insights 1: 71-75.

Malaisse F. 1996. Caractérisations phytogéographique et écologique des forêts de Cantanhez (Région de Tombali, Guinée-Bissau). Aç̧ão para o Desenvolvimento, Bissau.

Manni F, Guérard E, Heyer E. 2004. Geographic patterns of (genetic, morphologic, linguistic) variation: how barriers can be detected by 'Monmonier algorithm. Hum Biol 76: 173-190.

Miquel C, Bellemain E, Poillot C, Bessiére J, Durand A and Taberlet P. 2006. Quality indexes to assess the reliability of genotypes in studies using noninvasive sampling and multiple-tube approach. Molecular Ecology Notes 6: 985-988.

Oom D, Lourenço P, Cabral AIR, Vasconcelos MJP, Catarino L, Cassamá V, Moreira J. 2009. Quantification of deforestation rates in Guinea-Bissau- a baseline carbon trading under REDD. $33^{\text {rd }}$ International Symposium on Remote Sensing of Environment, 4-8 May 2009, Stresa, Italy.

Palomares F, Godoi J, et al. 2002. Fecal genetic analysis to determinate the presence and distribution of elusive carnivores: design and feasibility for the Iberian lynx. Molecular Ecology 11: 2171-2182.

Peakall R, and Smouse PE. 2006. GENALEX 6: Genetic analysis in Excel. Population genetic software for teaching and research. Molecular Ecolology Notes 6:288-295. 
Petit R, Mousadik E, Pons O. 1998. Identifying populations for conservation on the basis of genetic markers. Conserv Biol 12: 844-855.

PNUD 2010. United Nations Development Plan. Guinea-Bissau Profile. http://hdrstats.undp.org/en/countries/profiles/GNB.html. [Accessed: 15/05/2010].

Posada D. 2008. jMODELTEST: Phylogenetic model averaging. Mol Biol Evol 25: 12531256.

Rambaud A. 2006. FiggTree v.1.3.1. Available from http://tree.bio.ed.ac.uk/software/figgtree.

Rambaud A, Drummond A. 2007. TRACER v.1.5. Available from http://www.beast.bio.edu.ac.uk/Tracer.

Reintjes S, and Wiet P. 1986. Gabú region in Guinea-Bissau. IUCN. pp.32.

Roeder A, Archer F, et al. 2004. A novel method for collection and preservation of faeces for genetic studies."Molecular Ecology 4: 761-764.

Roeder A, Jeffery $\mathrm{K}$, et al. 2006. A universal microsatellite multiplex kit for genetic analysis of great apes. Folia Primatologica 77: 240-245.

Rogers A, Harpending C. 1992. Population growth makes waves in the distribution of pairwise genetic differences. Mol Biol Evol 9: 552-569.

Ronquist F, Huelsenbeck J. 2003. MRBAYES 3: Bayesian phylogenetic inference under mixed models. Bioinformatics 19: 1572-1574.

Rozas J, Sánchez-DelBarrio JC, Messeguer X, et al. 2003. DnaSP, DNA polymorphism 
analyses by the coalescent and other methods. Bioinformatics 19: 2496-2497.

Rubin HJ, and Rubin IS. 1995. Qualitative interview: the art of hearing data. Thousand Oaks: Sage Publications.

Shimada M, Hayakawa S, et al. 2009. Skewed Matrilineal Genetic Composition in a Small Wild Chimpanzee Community. Folia Primatologica 80: 19-32.

Shimada M, Hayakawa S, et al. 2004. Mitochondrial DNA Genealogy of Chimpanzees in the Nimba Mountains and Bossou, West Africa. American Journal of Primatology 64: 261- 275.

Simão A. 1997. Identificação e delimitação cartográfica dos grandes maciços florestais de Cantanhez. Relatório de missão. Acção para o Desenvolvimento.

Simpósio 2008. http://www.guiledje.org/ [Acessed: 19/12/2008].

Sousa, C., Gippoliti, S., and Akhlas, M. (2005). Republic of Guinea-Bissau. In: World Atlas of Great Apes and their Conservation, Caldecott J, Miles L (Eds). University of California Press, London. pp.362-365.

Stöver B, Müller K. 2010. TreeGraph 2: Combining and visualizing evidence from different phylogenetic analyses. BMC Informatics 11:7.

Taberlet P, Griffin S, Goossens B, Questiau S, Manceau V, Escaravage N, Waits LP, Bouvet J. 1996. Reliable genotyping of samples with very low DNA quantities using PCR. Nucleic Acids Research 24: 3189-3194. 
Valière N. 2002. GIMLET: a computer program for analysing genetic individual identification data. Molecular Ecology Notes 2: 377-379.

Valière N, Berthier P, Mouchiroud D, Pontier D. 2002. Gemini: Software for Testing the Effects of Genotyping Errors and Multitubes Approach for Individual Identification. Molecular Ecology Notes 2: 83-86.

van Oosterhout C, Hutchinson WF, Wills DP, Shipley P. 2004. Micro-checker: software for identifying and correcting genotyping errors in microsatellite data. Molecular Ecology Notes 4: 535-538.

Waits LP, Luikart G, and Taberlet P. 2001. Estimating the probability of identity among genotypes in natural populations: cautions and guidelines Molecular Ecology 10: $249-256$.

World Bank Report. 2011. Implementation and results report. http://www wds.worldbank.org/external/default/WDSContentServer/WDSP/IB/2011/11/03/000 386194_20111103005507/Rendered/PDF/ICR16840P083450COdisclosed011010110. pdf. [Accessed 25/07/2011]. 


\section{CHAPTER 3}

"The purpose of anthropology is to make the world safe for human differences."

- Ruth Benedict, Anthropologist

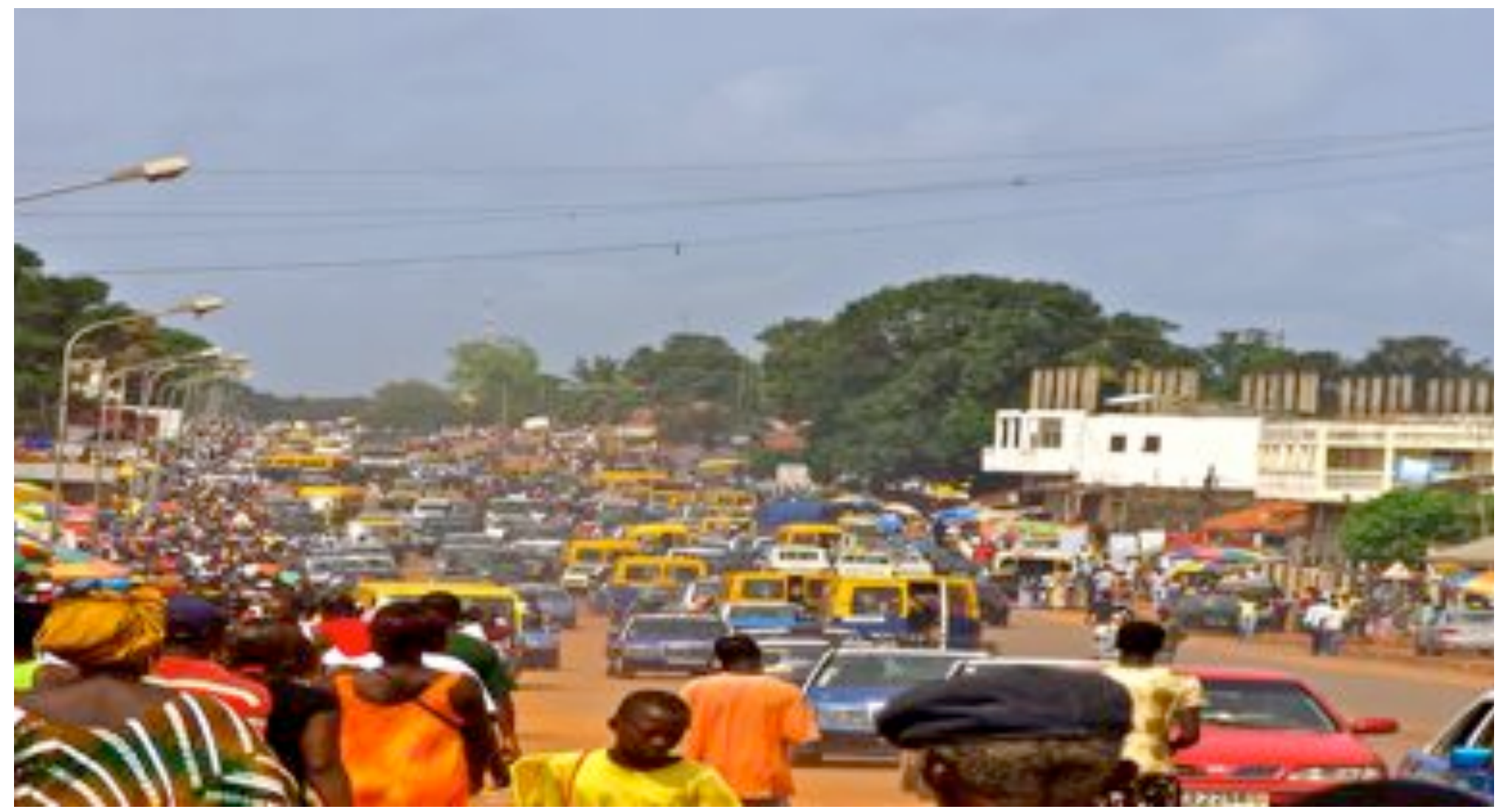




\section{CHAPTER 3}

\section{THE TRADE AND ETHNOBIOLOGICAL USE OF CHIMPANZEE BODY PARTS IN GUINEA-BISSAU: IMPLICATIONS FOR CONSERVATION}

$\underline{\text { Rui M. Sá }}{ }^{1,2,3}$, Maria Ferreira da Silva ${ }^{2,5}$, Fernando Sousa ${ }^{4}$ \& Tânia Minhós ${ }^{2,4}$

1.Departamento de Antropologia, Faculdade de Ciências Sociais e Humanas, Universidade Nova de Lisboa

${ }^{2}$ School of Biosciences, Cardiff University, UK

${ }^{3}$ CRIA-Centre for Research in Anthropology, Portugal

4. Centre for Environmental Biology, University of Lisbon, Portugal

${ }^{5} \mathrm{CIBIO}$ - University of Porto, Portugal.

*Author for correspondence:

Rui M. Sá

Cardiff School of Biosciences, Biomedical Sciences Building, Museum Avenue,

Cardiff, CF10 3AX

Wales, UK

Phone: +44 (0) 29208 75776; Mobile: +351 917092241

Fax: +44 (0) 2920874116

Email: ruimoutinhosa@gmail.com 


\section{1- ABSTRACT}

Anthropogenic disturbances such as habitat loss, fragmentation and hunting for pet trade are reported to be the main threats to chimpanzee survival in the wild. Here we report for the first time the use of chimpanzee body parts for traditional medicine purposes in Guinea Bissau as an additional anthropogenic threat and discuss the impact that this activity might have in its populations. Chimpanzee skins along with other mammal and reptile body parts were found in the main Bissau market as well as in a market in Dakar (Senegal). Traders and local people were interviewed using an ethnoprimatological approach in order to access the use and origin of the animals' body parts. All interviews confirmed the use of these animal by-products for folk medicine purposes. Moreover, evidences of a transnational trade were also found. This phenomenon seems to be a common practice in West African countries and might constitute an important additional factor contributing to the decline of wild populations of several threatened species. It is urgent to better understand the extent and impact of such practices, which can be accomplished by combining ethnography, and molecular approaches in order to suggest adequate conservation measures and law enforcement.

Keywords: Body parts, Chimpanzees, Conflict, Conservation, Ethnoprimatology, Folk medicine, Guinea-Bissau, Trade 


\section{2- INTRODUCTION}

Guinea-Bissau represents the western-most limit of the endangered West African Chimpanzee Pan troglodytes verus (Sousa et al., 2005). During the 1980s, Chimpanzees were erroneously considered extinct in the country due to a total absence of information owing largely to political and civil unrests-(Lee et al., 1988). In 1994, a preliminary survey was conducted and the presence of Chimpanzees was reconfirmed (Gippoliti and Dell' Omo, 1995; 1996). More recently, research has been carried out in co-operation with national and local authorities, establishing a system for the systematic monitoring and management of this great ape (Casanova and Sousa, 2007). Within the country, Chimpanzees are distributed across the south of the Corubal River. Their presence is confirmed in two protected areas Cantanhez National Park (CNP) and Cufada Lagoons Natural Park (CLNP) in the southwestern region, and in the eastern region of Boé (Casanova and Sousa 2007; Brugiere et al., 2009).

Due to high levels of exploitation, loss of habitat and habitat quality as a result of human activities, this subspecies is estimated to have experienced a significant population reduction in the past 20 to 30 years (IUCN, 2011). However, no recent data are available to allow for an estimation of rates of decline (IUCN, 2011). The most recent figures available, from 1996 (Gippoliti et al., 2003), estimate that the number of Chimpanzees in Guinea-Bissau ranges from between 600 and 1000 individuals. It is estimated that Chimpanzee density in the southern area of CNP is of 2.34 nest builders $/ \mathrm{km}^{2}$ in a total area of $17.225 \mathrm{~km}^{2}$ corresponding to 40 individuals (Sousa et al., 2011), while in the neighbouring east area of Gadamael, just 
outside the CNP area, this value decreases to 0.89 nest builders $/ \mathrm{km}^{2}$ in a total area of $36.513 \mathrm{~km}^{2}$, which corresponds to 33 individuals (Sousa, 2009). However, the exact number of individuals and communities for the whole CNP and the rest of the country remain unclear; with the aid of a molecular census, however, it will be possible to infer its effective population size (Sá et al., 2009).

Anthropogenic disturbances such as habitat loss and fragmentation (e.g. logging activities and shifting land occupation for the purposes of agriculture and food production, e.g. cashew nuts, the hunting of infant animals for the pet trade, and casual deaths from crop raiding allied to extrinsic factors such as disease are the main threats, not only to Chimpanzees but to all non-human primates in GuineaBissau (Gippoliti et al., 2003; Casanova and Sousa, 2007; Brugiere et al., 2009). The species is classified by IUCN as Endangered, and listed in CITES Appendix I, being also protected at national level. Even though most primate species in Guinea-Bissau are traded for meat consumption, there is no evidence that this is the case for Chimpanzees (Minhos et al., in prep.).

The following paper reports on the use and trade of Chimpanzee body parts in Guinea-Bissau for traditional practices (e.g. for nutritional, medicinal or ritual purposes, or "animistic myths"). Informal interviews were conducted and observations made with a view to providing insight into how these human traditions and myths might pose an additional threat. 


\section{3- METHODS}

Visits were made to Bandim market, the largest market in Bissau, the capital, during two weeks in September 2008 and a similar period in June 2010. Some 10-15 men were found to be offering wild animal body parts for sale (e.g. skin, bones, teeth, horns and scales). Where possible, morphological identification of the specimens viewed was made and photographs taken.

An ethnoprimatological approach (i.e. the study of human and non-human primate interactions) aims to understand the incorporation of non-human primates into folklore, myths, the hunting of non-human primates for food, keeping nonhuman primates as pets, indigenous knowledge of non-human primate behaviour, among others (Wolfe and Fuentes, 2007; Fuentes and Hockings, 2010). In this study, the authors were interested in understanding and placing into context the social inclusion of Chimpanzee body parts for human traditional practices using informal interviews and ethnographic observations, although not enough data were collected to provide an in-depth analysis for such an approach.

Most of the vendors encountered were male. Five urban vendors in Bandim and 17 rural informants in villages in the CNP and the Boé region were informally interviewed following an unstructured script, in order to document the geographical origin and use of Chimpanzee body parts, prices and the scale of the trade, i.e. whether at a national, regional, or transnational level. Direct observations of the trade were conducted in the market and field notes were taken. Informants were ensured that the purpose of the work was not to condemn or report their practices to the local authorities. Every observation heard and/or seen was recorded and 
notes/interviews organized into social demographic categories (e.g. urban traders, local villagers, gender, ethnic group). Only information relevant to the research topic was assigned to these categories (Rubin and Rubin, 1995).

\section{4- RESULTS AND DISCUSSION}

\subsection{1- Traded species}

During market visits (seven visits of approximately four hours each) morphologically identified dried Chimpanzee skins were found being sold for traditional medicinal purposes. Additionally, dried skins from Temminck's Red Colobus monkeys Procolobus badius temminckii, Guinea Baboons Papio hamadryas papio and Olive Baboons Papio hamadryas anubis were also found. The authors also detected trade of dried skins of several non-primate species such as Leopard Panthera pardus, Nile Crocodile Crocodylus niloticus, African Civet Civettictis civetta, Elephant Loxodonta sp., Hare Lepus sp., African Buffalo Syncerus caffer, Spotted Hyaena Crocuta crocuta and several species of antelopes, snakes and lizards, as well as skins alleged to be of Wild Dog Lycaon pictus and Lion Panthera leo (Fig. 3.1).

Other animal body parts observed included bones, spines of Crested Porcupine Hystrix cristata, teeth, antelope horns, scales of Pangolin Manis sp., mollusc shells, fish bones and feathers. Morphologically specific identification was not possible in most cases due to the similarity of those body parts to other species, as well as to their condition. A few sellers mentioned that some of the bones being offered for sale were from primates. 
All the species mentioned above are reported as occurring in Guinea Bissau except for Olive Baboons, whose western limit of their distribution is reported to be in Mali and Republic of Guinea (IUCN, 2011). The observed olive baboon skin was morphologically quite different to the other baboon skins found at the market. While Guinea Baboon skins presented red/brownish coloration, the Olive Baboon (Papio anubis) skin was more grey-greenish, typical of what has been described for the subspecies (Groves 2001).

\subsection{2- Costs, origin and scale}

Interviews with urban traders revealed that the cost of a piece of Chimpanzee skin (Fig.3.1) was relatively high, ranging from 1500 CFA Francs (XOF) to XOF90 000 (USD2.9 to USD173.96, based on an exchange rate in 2008 of XOF460.77 to USD1). The average monthly wage in 2008 was XOF40 000 (approximately USD88.00) (UNDP, 2010).

All urban vendors reported that the Chimpanzee and other animal body parts originated from the "southern part" (with the exception of the elephant hide seen which, the authors were told, came from Senegal), and they frequently mentioned the regions of Cantanhez and Gabú. Vendors considered south of the country every location south of Bissau. It should be noted that elephants have not been seen in Senegal for 15 years. Furthermore, most vendors said that consumers were of both sexes, different ethnic groups and social status.

It was apparent to the authors that witchdoctors are not the only people to buy animal-derived products for traditional medicine or protection fetishes. For example, according to statements from three vendors: 
"All sort of people buy. Men and women, poor or rich... Fulas, Pepel, Balanta, even Europeans. Every kind. Not only djamba kuss [witchdoctors] to please the irans [magical and religious entities]."

According to Robillard in litt., July 2011, it is common practice in Africa for people who are unwell to buy their own products based on a list provided by the traditional doctor.

Two of the vendors also mentioned that individuals from neighbouring countries such as Senegal, Guinea or Gambia are involved in the trade within in the country: "Other foreigners also buy and sell their own plants, shells or skins".

\subsection{3- Symbolic and medicinal use}

Most male informants in rural CNP and Boé villages associated the use of Chimpanzee-derived products with the needs of women, as revealed by one elder Fula respondent in Béli, Boé:

"Dári [chimpanzee] is mezinho [traditional medicine] of women."

Three Balanta women in CNP confirmed that Chimpanzee skin is used to: "prepare a cleansing mixture against hideousness when they are pregnant or their children are still babies in the event they see a lonely chimpanzee cross their way". Likewise, another woman said that "the leaves of the nest where a menstruated female chimpanzee sleeps can be applied to heal mental problems".

One informant admitted that he uses a stitched amulet made of chimpanzee body parts to help provide awareness to protect him and his friends while in the bush (Rui Sá, personal observation 2008). 
One informant admitted that he uses a stitched amulet made of chimpanzee body parts to help provide awareness to protect him and his friends while in the bush (Rui Sá, personal observation 2008).

\subsection{4- Guinea-Bissau in the context of previous studies}

One possible explanation for the lack of information on magic practices and traditional-medicines using animal body parts in Guinea-Bissau is the difficulty in collecting information on such an undisclosed subject and also the lack of interest and in-depth studies undertaken. As a result, the authors' observations are opportunistic. However, the use of animals' body parts for medicinal purpose could seriously threaten the biodiversity of Guinea-Bissau and, in particular, constitutes an additional and significant threat to Chimpanzee populations already menaced by habitat lost and fragmentation, the pet trade and crop raiding conflicts. Therefore, this phenomenon deserves to be thoroughly investigated (Cá 2008). Although previously not reported for Guinea Bissau, the use of non-human primate body parts in traditional medicine is not unusual elsewhere in the world (Alves et al., 2010; Leypey and Fomine, 2010). In a recent review, Alves et al., 2010, reported the use of 101 species of primates in folk/magic-religious practices, most frequently in Africa, Latin America and Asia. Although Cercopithecidae species are the most affected, Chimpanzees are also referred to as a remedy for diseases and for use in folk medicine (Alves et al., 2010).

In Nigeria, Mali, Sierra Leone, Congo and Guinea, Chimpanzee body parts are used to cure male impotency, epilepsy, bone fractures and infertility in women 
forested areas, people use Chimpanzee body parts in birth and circumcision rituals (Mallart Guimera, 1981). The Yoruba people of south-western Nigeria believe in the magical properties of Chimpanzee body parts in appeasing witches and fortune tellers (Dedeke and Aboyami, 2006). However, it is not easy for people to obtain these remedies or to gain access to these animals. In Central Africa, the consumption of Chimpanzee meat is taboo for young men, pregnant women and children (Robillard in litt., July 2011).

The presence in Bandim market of the skin of an Olive Baboon suggests a foreign origin for some of the animal body parts being offered for sale. While the distribution area for this species (Papio anubis) includes neighbouring Guinea and Mali, it does not occur in Guinea-Bissau (Soewu 2008). The Guinean Baboon, Papio papio is the only baboon subspecies reported and observed in the country (IUCN, 2011). There are striking differences in morphology between both baboons species (namely coat coloration, Grooves 2001), which enables distinction based on its skins. Furthermore, in Colobane and Boucotte markets at Senegal (in Dakar and Ziguinchor, respectively), several species of reptiles and mammals, including primate species (data not shown) were found in trade for use in traditional medicinal practices and/or magical ceremonies [Fernando Sousa, personal observation 2008]. According to information provided by the sellers, those animal body parts were brought from Niger, Nigeria, Ivory Coast and Mali. Chimpanzee skins were also found in these Senegalese markets [Fernando Sousa, personal observation 2008]. The respondents pinpointed Cassamance (on the border between Senegal and Guinea-Bissau) as the putative origin of Boucotte market Chimpanzee skins and Guinea-Bissau and Republic of Guinea as the possible origin of the Chimpanzee skins being sold at 
pinpointed Cassamance (on the border between Senegal and Guinea-Bissau) as the putative origin of Boucotte market Chimpanzee skins and Guinea-Bissau and Republic of Guinea as the possible origin of the Chimpanzee skins being sold at Colobane market. The possibility that the Chimpanzee skins found in Bandim market could also be from the Republic of Guinea cannot be excluded since sellers mentioned the "south" as the origin but not specifically the south of Guinea-Bissau.

\subsection{5- Implications for conservation}

The suggested transnational interest for Guinea-Bissau Chimpanzee skins may constitute an even bigger threat for the conservation of this population. Since Chimpanzee populations are declining in West African countries (IUCN, 2010), foreign hunters could be attracted to Guinea-Bissau and the hunting of Chimpanzees could therefore increase in the near future. Biodiversity management authorities in Guinea-Bissau (IBAP and Direcção Geral de Florestas e Fauna) have introduced new laws to regulate the trade in wild meat (e.g. recently, the hunting of primates throughout the country was prohibited (Angola Press, 2011). However, the lack of resources and lack of awareness of management authorities and politicians are hindering law enforcements in the country. At the international level, conservation agencies should re-examine their strategies to mitigate this trade, and, at the national level, specific programmes should be designed and applied to empower all actors involved (e.g. park rangers, Customs officers, the military, police, etc.), complemented at the same time by provision of environmental education for the local communities. 
Further work by the authors will include the molecular determination of the origin of the skins observed in the markets and of the species involved. This will assist in evaluating the scale of the trade. Finally, an ethnographic study specifically centred on the use of non-human primate body parts by traditional medicine using more in-depth techniques such as participant observation or long-term observation will allow the authors to draw up possible differences in the use of distinct animal parts and determine how such practices are disseminated.

\section{5- ACKNOWLEDGEMENTS}

The authors are enormously thankful to the Institute of Biodiversity and Protected Areas (IBAP) in Guinea-Bissau for facilitating their research in GuineaBissau, and for providing logistical support. Particular thanks go to Milza Nanqui whose help was determinant in obtaining information in the Guinea-Bissau market whose assistance facilitated the gathering of information at the market in Bissau and to all the informants for agreeing to and trusting the authors to talk about sensitive issues. The authors are also very grateful to M.W. Bruford, C. Sousa and C. Casanova. The authors are also very thankful to Marine Robillard, Expert into conservation, Natural History Museum, Paris, France, and David Greer, WWF's African Great Ape Programme co-ordinator for their helpful discussion and comments that improved the quality of the manuscript.

\section{6- REFERENCES}

Alves, R.R., Souto, W.M., and Barboza, R.R. (2010) Primates in traditional folk medicine: a world overview. Mammal Review. 40(2):155-180. 
Brugiere, D., Badjinca, I., Silva, C., and Serra, A. (2009). Distribution of chimpanzees and interactions with humans in Guinea-Bissau and Western Guinea, West Africa. Folia Primatologica 80:353-358.

Cá, Augusto. (2008). Estudos sobre a caça e mercado de primatas em Tombali, Sul da Guiné-Bissau. MSc thesis. Universidade Federal de Minas Gerais.

Casanova, C., and Sousa, C. (2007). Action Plan for the Conservation of Chimpanzees, red western colobus and king colobus in Guinea-Bissau Republic. IBAP, Guiné-Bissau.

CITES (2011). http://www.cites.org/. Viewed on 30 September 2011.

Dedeke, G.A., and Aboyami, F. (2006). Ethnozoological trade and practices among the ljebu people of southwestern Nigeria and the impact on some mammalian species. Indilinga 5(2):175-187.

Drummond A, Rambaud A. 2007. BEAST: Bayesian evolutionary analysis by sampling trees. BMC Evol Biol 7:214.

Fuentes, A., and Hockings, K. (2010). The ethnoprimatological approach in Primatology. American Journal of Primatology 72:841-847.

Gippoliti, S., and Dell'Omo, G. (1996). Primates of the Cantanhez Forest and the Cacine Basin, Guinea-Bissau. Oryx 30:74-80. 
Gippoliti, S., and Dell'Omo, G. (1995). Status and conservation of the chimpanzee Pan troglodytes verus in Guinea-Bissau. African Primates 1:3-5.

Gippoliti, S., Embalo, D., and Sousa, C. (2003). Guinea-Bissau. In: West African chimpanzees: Status Survey and Conservation Action Plan. Kormos, R., Boesch, C., Bakarr, M., and Butynski, T. (Eds), IUCN, Gland, Switzerland. Pp.55-61.

Groves, C. (2001). Primate Taxonomy. Smithsonian Institution Press, Washington, DC.

Guinea-Bissau prohibits the hunting of primates and other large animals (2011). http://sicnoticias.sapo.pt/vida/2011/02/14/governo-da-guine-bissau-proibe-abatede-primatas-e animais-de-grande-porte3. Viewed on 21 April 2011.

IUCN (2010). IUCN Red List of Threatened Species. Version 2010.4. www.iucnredlist.org. Viewed on 21 April 2011.

Lee, P.C., Thornback, J. and Bennet, E.L. (1988). Threatened Primates of Africa. Gland, Switzerland.

Leypey F, Fomine M (2010). Edible Wild Animals as Source of Medication in Cameroon. Petits Propos Culinaires. 90:99-117. 
Mallart Guimera, L. (1981). Ni dos ni ventre. Religion, magie et sorcellerie Evuzok. Paris: Société d'ethnographie.

Minhos, T., Sá, R., Ferreira da Silva, M. Wallace, E., Barata, A., Carmo, M. and Bruford, M.W. (In prep.). Characterization of the urban primate bushmeat trade in Guinea Bissau using molecular tools for species identification.

Rubin, H.J. and Rubin I.S. (1995). Qualitative interview: the art of hearing data. Thousand Oaks: Sage Publications.

Sá, R., Sousa, C., and Bruford, M.W. (2009). (Abstract) Conservation genetics and phylogeography of the chimpanzees in Guinea-Bissau. Folia Primatologica 80(2):172.

Sousa, F.M. (2009). Pan troglodytes verus densities and the use of natural resources in Gadamael área, Guinea-Bissau. MSc thesis. Lisbon University. Lisbon, Portugal.

Sousa, J., Barata, A.V., Sousa, C., Casanova, C., and Vicente, L. (2011). Chimpanzee oil-palm use in southern Cantanhez National Park, Guinea-Bissau. American Journal of Primatology 73:1-13.

Sousa, C., Gippoliti, S., and Akhlas, M. (2005). Republic of Guinea-Bissau. In: World Atlas of Great Apes and their Conservation, Caldecott J, Miles L (Eds). University of California Press, London. pp.362-365. 
Soewu, D.A. (2008). Wild animals in ethnozoological practices among the Yorubas of southwestern Nigeria and the implications for biodiversity conservation. African Journal of Agricultural Research. 3(6):421-427.

Wolfe, L.D., and Fuentes, A. (2007). Ethnoprimatology. In: Primates in perspective, Campbell, C.J., Fuentes, A., Mackinnon, K.C., Panger, M., and Bearder, S.K. (Eds). Oxford University Press, Oxford, Pp.691-705.

United Nations Development Programme (2010). Human Development Report 2010. UNDP, New York. 


\section{7- FIGURES}



Foure 1: Trade of animal body

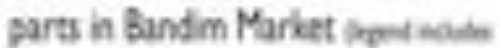

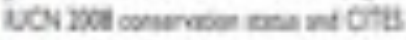
growenon lenet)

I - Leoper Podes podel flaconglest| - Near Tratabl OTES Apsenda 1

2- Chinguroee fon bophosers at

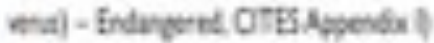

3-Crocodili (Gxadyla nlobeat). Lewr Raltws concent. CTES Apeonds land

4- Guines baboon pepel - Lover louk Lur Concers, CrTES Aponda in 5 - Pouby Lon Rocles ibol -

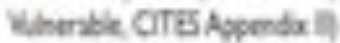

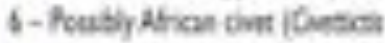

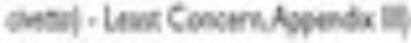

7-Antriopés horn

Figure 3.1. All animal-derived products for human traditional purposes in Bandim market, Bissau, Guinea-Bissau. 


\section{CHAPTER 4}

"By comparing the human and chimp genomes, we can see the process of evolution clearly in the DNA changes since we diverged from our common ancestor."

- Robert Waterston, Geneticist

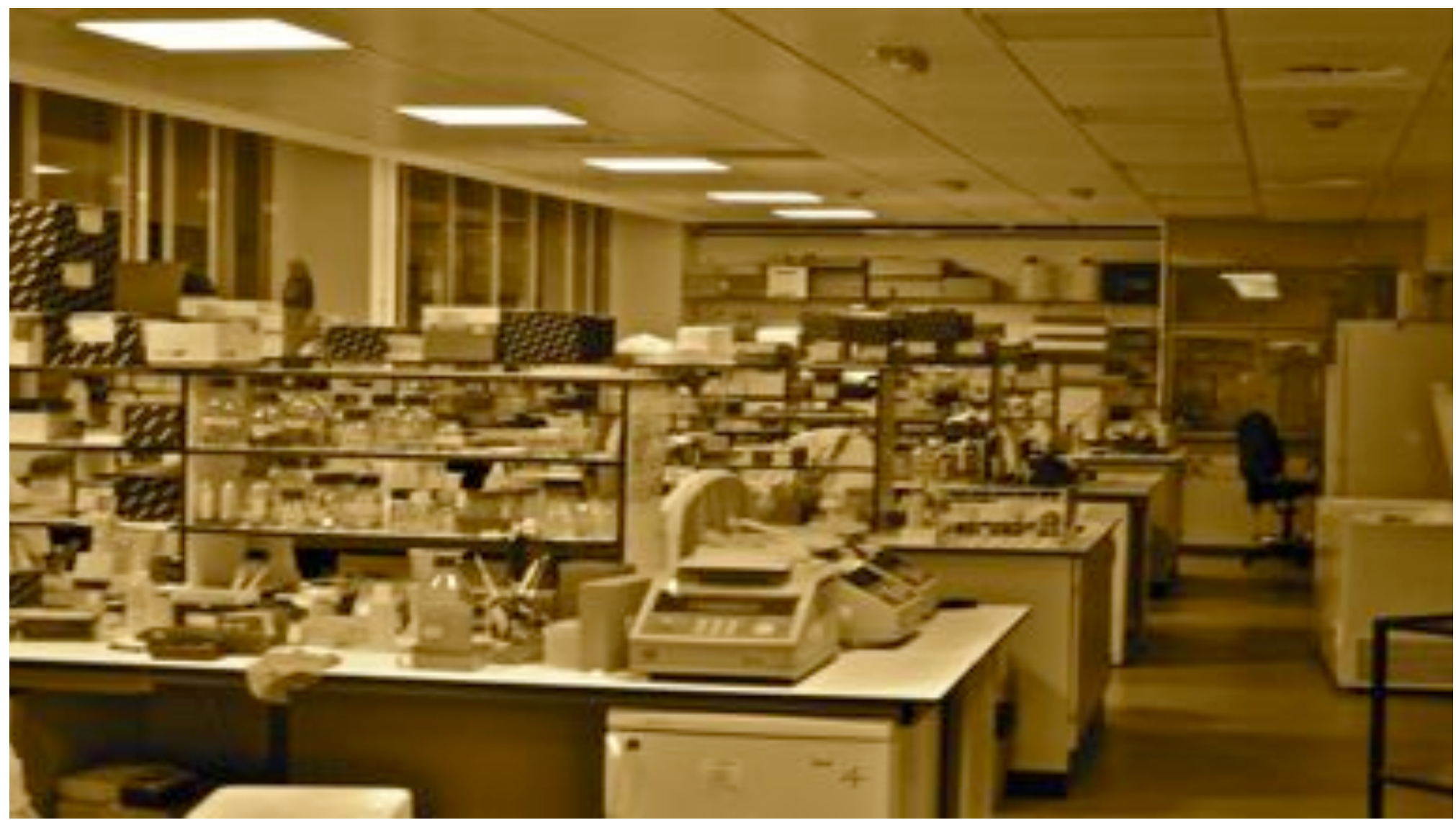




\section{CHAPTER 4}

\section{INFERRING THE EVOLUTIONARY HISTORY OF A PERIPHERAL AND ENDANGERED APE POPULATION: THE CHIMPANZEES OF GUINEA-BISSAU}

Rui M. Sá ${ }^{1,2,3 *}$, Kathelijne Koops ${ }^{4}$, Annamaria Marra ${ }^{5}$, Tânia Minhós ${ }^{1,6}$, Maria Ferreira da Silva ${ }^{1,7}$, Joost Van Schinjdel ${ }^{8}$, Cláudia Sousa ${ }^{2,3}$, Joanne Cable ${ }^{1}$ \& Michael W. Bruford $^{1}$

${ }^{1}$ School of Biosciences, Cardiff University, Cardiff, UK

${ }^{2}$ Departamento de Antropologia, Faculdade de Ciências Sociais e Humanas, Universidade Nova de Lisboa, Lisbon, Portugal

${ }^{3}$ CRIA-Centre for Research in Anthropology, Lisbon, Portugal

${ }^{4}$ Department of Archaeology and Anthropology, Division of Biological Anthropology, University of Cambridge, Cambridge, UK

${ }^{5}$ Department of Biology, University of Bari, Bari, Italy

${ }^{6}$ Centre for Environmental Biology, University of Lisbon, Lisbon, Portugal

${ }^{7} \mathrm{CIBIO}-$ University of Porto, Porto, Portugal

${ }^{8} \mathrm{CHIMBO}$ Foundation, Kesteren, The Netherlands

*Author for correspondence:

Rui M. Sá

Cardiff School of Biosciences, Biomedical Sciences Building, Museum Avenue, Cardiff, CF10 3AX

Wales, UK

Phone: +44 (0) 29208 75776; Mobile: +351 917092241

Fax: +44 (0) 2920874116

Email: ruimoutinhosa@gmail.com 


\section{1- ABSTRACT}

The phylogeography of West African chimpanzees has been intensively studied yet remarkably none have included the relict and peripheral population of Guinea-Bissau. Guinea-Bissau represents the most western limit of the species distribution, with known populations in the Quínara, Tombali and Gabú regions. We investigated the diversity, phylogeographic structure and demographic history of this region by analyzing it alongside existing Pan troglodytes verus data from the hypervariable mitochondrial region. We included 334 individuals from 28 locations, including chimpanzees from Guinea Bissau $(n=189)$ and the Nimba Mountains (Guinea, $\mathrm{n}=145$ ). From the 51 haplotypes detected, haplotype $(h)$ and nucleotide diversity was high (94\% and $0.05325 \pm 0.00116)$ and phylogenetic analyses revealed the existence of two deep evolutionary lineages. In addition we describe eleven subclades, where subclade B1 presented a star shaped pattern that was observed in the median joining network suggesting a demographic expansion. The bimodal mismatch distribution and the neutrality tests imply that an expansion has occurred promoting secondary contact between the two lineages. Analysis of molecular variance revealed $74 \%$ of the genetic variation is partitioned within individuals $\left(^{\Phi}\right.$ $\mathrm{ST}=0.25956, \mathrm{p}<0.0001)$. Barrier analysis identified three major genetic discontinuities and the estimated divergence times point to vicariance events in the Middle Pleistocene and the recurrence of past climatic oscillations in the African forests. We suggest that the two phylogeographic groups should be considered as distinct management units. We also indicate priority areas for conservation based on the genetic diversity of the populations.

\section{Keywords}

West Africa, evolutionary history, genetic diversity, chimpanzee, Pan troglodytes verus, Guinea-Bissau, Nimba, phylogeography 


\section{2- INTRODUCTION}

The evolutionary history of the genus Pan (i.e. chimpanzees and bonobos) has been a permanent topic of interest due to their close affinity with humans ${ }^{1}$. Studies on wild chimpanzees began in the 1960s and since then they have become reference models, providing unique insights for our understanding of human biology and evolution ${ }^{2}$. Chimpanzees are frequently used for comparison in human genetic studies and they were among the first species when non-invasive molecular techniques were applied ${ }^{3,4}$. Several efforts have been made to unravel their complex evolutionary history, but even now debate continues concerning the exact number of chimpanzee subspecies ${ }^{5-7}$.

Chimpanzees are usually divided into four subspecies ${ }^{11-13}$, but this classification is contested ${ }^{1,14}$. The subspecies $P$. $t$. troglodytes has a range that extends throughout Central Africa. P. t. schweinfurthii is located essentially in Eastern Africa, and based on morphometric variation some taxonomists argue that this subspecies can de further divided in two: $P$. $t$. schweinfurthii and $P$. $t$. marungensis ${ }^{15}$. The chimpanzees from southern Nigeria and western Cameroon, previously known as $P$. t. vellerosus ${ }^{17}$, have been reclassified as $P$. t. ellioti ${ }^{16,18-19}$.

The fourth subspecies P. t. verus is located in the Upper Guinea regions of West Africa and spans the region from southern Senegal to Liberia and Sierra Leone $^{11}$. West African chimpanzees are extinct in the wild in Gambia, Togo and Benin and may be present in Burkina Faso ${ }^{11,20-22}$. They inhabit a broad range of habitats including wooded savannahs, savannah forest mosaics, mountain forests and moist lowland forests ${ }^{23}$. Recent studies of chimpanzee genetic diversity suggest that $P$. $t$. verus shared a last common ancestor with P. t. troglodytes between 0.38 and 0.55 mya and the Niger River and the Dahomey Gap have been proposed as a geographic barrier that facilitated the split ${ }^{1,5-7,27-32}$. Central and eastern chimpanzees share a more recent ancestry ${ }^{33-36}$. The contrast between low genetic diversity and lack of subdivision in humans, and the high diversity with geographical subdivision in chimpanzees has led to the hypothesis that the chimpanzee belongs to a single population with a continuous exchange of gene flow and some authors even propose that chimpanzees should not be classified into subspecies ${ }^{1,3,36}$. However, 
Morin et al. (1994) argue that the West African chimpanzee mtDNA sequences are more divergent than those from the other subspecies. The average genetic distance among $P$. t. ssp. verus and the other subspecies is two-thirds the genetic distance between chimpanzees and bonobos, suggesting that they could be elevated to species level ${ }^{4}$.

Evolution and environment interact to shape a species' biogeography, population structure, and the flow of genes within its current range ${ }^{37}$. For chimpanzees four factors are recognized: i) geographical or physical barriers; ii) mating systems and social structure; iii) anthropogenic disruption, and; iv) paleoclimate and vegetation ${ }^{38}$. Geographic barriers such as deserts, mountains and large rivers impact on the dispersal between populations ${ }^{39}$. Chimpanzees do not seem to be affected in their movements by mountains or rock formations, however large watercourses do appear to form effective barriers, at least in the case of bonobos $^{9}$ and in the Nigeria-Cameroon chimpanzees where the Sanaga River was identified as a barrier ${ }^{1,6}$. The operational sex ratio (i.e. the number of breeding males per breeding females) and differential fitness have a large impact on the genetic constitution of chimpanzee populations, by potentially lowering the effective population size and rendering populations more prone to genetic $\mathrm{drift}^{40-41}$. In the small chimpanzee community of Bossou for example, Shimada et al. (2004) demonstrated a skewed matrilineal genetic composition ${ }^{42}$.

Anthropogenic disruption caused by fragmentation and severe hunting is known to have a strong impact on the demography of wild primate populations and on their genetic constitution ${ }^{37,43}$. In the long term, fragmentation leads to a decline in genetic diversity, thus increasing genetic differentiation due to a decrease of gene flow between breeding groups combined with random genetic drift and inbreeding ${ }^{44-45}$. Lastly, the temperature oscillations during the Plio-Pleistocene (ca. 5 mya) have caused rapid changes in forest distribution, thereby fragmenting them into small refugia. During the drought periods the Upper Guinean forests in West Africa contracted and expanded substantially in interglacials ${ }^{46}$. Based on current floristic and faunal biodiversity, four Pleistocene forest refuges have been proposed in Upper Guinea: the Grabo Hills region in Liberia, Cape Three Points in Ghana, the Nimba Mountains in the eastern part of the Guinean highlands, and the northern 
limit of the Guinean sub-humid forests in Cantanhez, Guinea-Bissau ${ }^{47-50}$. It is still not clear to what extent western chimpanzee populations followed the distribution of forests and how their demography and distribution were affected by such historical changes $^{1,6,38}$. Yet, the extent to which such paleoclimatic changes caused subdivision in the region remains an open question, since any disconnections could have been followed by re-connections of the disrupted chimpanzee populations after expansion of the forests ${ }^{3}$.

The phylogeographic history of West African chimpanzees remains debated, yet remarkably no previous studies have included individuals from the peripheral relictual population in Guinea-Bissau. This country represents the most western limit of the species distribution where chimpanzee survival is considered very precarious ${ }^{51-52}$. Major threats to their survival include the pet trade, hunting for traditional medicine practices and habitat destruction caused by logging and agriculture ${ }^{53-54}$. Due to the absence of information regarding their status, chimpanzees have been erroneously considered extinct in Guinea-Bissau ${ }^{55}$. However, in 1994 a survey reconfirmed their presence and made a preliminary evaluation of their conservation status ${ }^{56-57}$. The most recent national survey estimates $600-1000$ chimpanzees in Guinea-Bissau ${ }^{51,58}$ but the exact number of chimpanzee communities remains unclear. Little is known about their ecological, social and behavioural characteristics, and the extent of their genetic diversity at the population level and structure has never been evaluated.

Here, we reanalysed western chimpanzee phylogeography by further exploring their mitochondrial diversity, structure and demographic history in GuineaBissau and the Nimba Mountains (Guinea) using hypervariable control region mtDNA sequences. Specifically, we addressed the question: what influence did the Pleistocene historical events have on the current genetic diversity and structure of $P$. t. verus in Guinea and Guinea-Bissau? Population genetic theories predict that populations located on the periphery of a species' range should be smaller and more fragmented, displaying a greater genetic structure among populations and lower genetic diversities within populations due to genetic drift and inbreeding ${ }^{43}$. These forces can drive peripheral populations close to extinction and a concern for conservation ${ }^{37,44}$. We expected that chimpanzees in Guinea-Bissau: 1)- experience a 
higher genetic structure, and 2)- a lower genetic diversity, as they are located at the species' range edge. Furthermore, we compared our data with those from Bossou and other West African study sites to shed light on the evolutionary history of the subspecies. Finally, conservation insights are discussed in order to contribute towards a genetic management for this endangered and relatively unprotected ape in Guinea-Bissau.

\section{3- MATERIALS AND METHODS}

\subsection{1- Study areas}

Within Guinea-Bissau, chimpanzees are distributed south of the Corubal River. Their presence has been confirmed in two protected areas (i) Cantanhez National Park (CNP) and Cufada Lagoons Natural Park (CLNP) in the southwestern region, and (ii) the eastern region of Boé ${ }^{53,59}$. Extensive sampling surveys during 2008 and 2010 were performed at 27 sites in Tombali, Quínara and Gabú regions, and non-invasive samples were collected (see Table 4.1 and Fig. 4.1). The samples from Nimba region were collected by KK around the area of the coordinates $7^{\circ} 37^{\prime} 23.04^{\prime \prime} \mathrm{N}$ Latitude and $8^{\circ} 26^{\prime} 10.62^{\prime \prime} \mathrm{W}$.

CNP is located in the Tombali region and comprises a total area of $1068 \mathrm{~km}^{2}$ and comprises a patchy environment of small rivers; mangroves, wooded and grassland savannahs; agriculture fields, human settlements and sub-humid forests characterize the landscape ${ }^{61}$. The World Wide Fund for Nature has recognized the Cantanhez forests as one of the 200 most important ecoregions in the world, and one of the last segments of humid forest in West Africa ${ }^{62}$. CLPN is located in the Quínara region, created by presidential decree in $2000^{63}$. It covers an area of 700 $\mathrm{km}^{2}$ and is bounded in the North by the Corubal River in the Northwest by the road to Fulacunda, and in the South by the Buba River. The dominant vegetation type is semi-dry forest and dry forest areas with patches of sub-humid and moist savannas. The park area is recognized as 'wetland of international importance' and is therefore recognized by the Ramsar Convention ${ }^{64}$. 
The Boé sector is located in the Gabú region and is approximately $3288 \mathrm{~km}^{2}$, having a population of approximately 12,000 largely subsistence agriculturalists and pastoralists. The sector is dominated by savannah vegetation on poor laterite soils, where Parkia biglobosa is a common tree species. The World Bank and the United Nations Development Program are in the process of creating a new protected area, the future: Dulombi-Boé National Park ${ }^{65}$.

Lastly, the Nimba Mountains and particularly the Seringbara study site near the village with the same name, in south-eastern Guinea, which is only $6 \mathrm{~km}$ southeast of the Bossou research site (Fig. 4.1). The Nimba Mountains form a natural boundary between Guinea, Ivory Coast and Liberia and are protected as the Réserve Naturelle Intégrale du Mont-Nimba, in Guinea and Ivory Coast. On the Guinean side, the reserve extends over $12.7 \mathrm{~km}^{2}$. The reserve forms a UNESCO World Heritage Site covering in total approximately 22,000 ha $^{66}$.

\subsection{2- Non-invasive populations sampling strategy}

Fecal samples from chimpanzees were collected at 28 sites (Table 4.1). Approximately $5 \mathrm{~g}$ of the outer layer of faecal material was stored at room temperature in absolute ethanol for $24 \mathrm{~h}$ and then transferred to a second tube with silica gel type III (Sigma Alrich) and maintained at room temperature until DNA was extracted following the "Two Step" protocol suggested by Roeder et al. ${ }^{67-68}$. Permits to transport the Guinean-Bissau samples were obtained near the official institutions of Guinea-Bissau, Portugal and UK (IBAP, ICNB and DEFRA).

\subsection{4- DNA extraction, amplification and sequencing}

DNA was extracted using the QIAmp DNA Stool Mini Kit ${ }^{\circledR}$ (QIAGEN, Germany) according to the manufacturer's instructions with the following modifications: Day 1 - $1.7 \mathrm{ml}$ ASL buffer was added to each faecal sample (approximately $0.1 \mathrm{~g}$ ), vortexed for $10 \mathrm{~min}$ and then allowed to soak in an orbital shaker overnight at room temperature. Day 2 - The centrifuge and incubating times were increased to 3-10 
min and $4 \mu \mathrm{l}$ of $1350 \mu \mathrm{g} / \mathrm{ml}$ poly-A Carrier RNA (QIAGEN, Germany) was added immediately before the ethanol precipitation step with $100 \%$. The elution time with AE buffer was also increased to $30 \mathrm{~min}$ and the final volume reduced to $150 \mu \mathrm{l}$. Each sample was extracted in duplicate and two negative controls were included to monitor possible contamination.

The mitochondrial (mt)DNA hypervariable region I was amplified in $20 \mu \mathrm{l}$ volumes comprising: $9 \mu$ l of QIAGEN Multiplex PCR kit containing buffer, DNTP's, Taq polymerase and $3 \mathrm{mM} \mathrm{MgCl}_{2}$ (final concentration), $0.1 \mu \mathrm{l} 1 \times \mathrm{BSA}, 0.1 \mu \mathrm{l} 1 \times \mathrm{Q}$ solution, $6.8 \mu \mathrm{l}$ ultrapure water and $0.2 \mu \mathrm{M}$ primers and $2 \mu \mathrm{l}$ DNA template. The PCR profile was as follows: $95^{\circ} \mathrm{C}$ for $15 \mathrm{~min} ; 45$ cycles of $94^{\circ} \mathrm{C}$ for $30 \mathrm{~s}, 51^{\circ} \mathrm{C}$ for $60 \mathrm{~s}$, and $72^{\circ}{ }_{-} \mathrm{C}$ for $60 \mathrm{~s}$, and $72{ }^{\circ} \mathrm{C}$ for $10 \mathrm{~min}$. Primers L15926 (5'-TAC ACT GGT CTT GTA AAC C-3', corresponding to positions $15326-15344$ of the complete chimpanzee mtDNA genome [GenBank Accession No. D38113] and H16555 (5'-TGA TCC ATC GTG ATG TCT TA-3', corresponding to positions 15971-15990 of D38113) were used because they amplify the HVRI mtDNA region of chimpanzees which reliably amplify a $600 \mathrm{bp}$ of the control region in chimpanzees ${ }^{70}$. PCR products were purified with Exonuclease I and Shrimp Alkaline Phosphatase (SAP) (New England Biolabs, UK) at $37^{\circ} \mathrm{C}$ for 60 min, were inactivated at $80^{\circ} \mathrm{C}$ for $15 \mathrm{~min}$ and sequenced using Macrogen Europe's service using the same forward and reverse amplification primers. Sequences were edited, assembled and aligned using the program SEQUENCHER 3.1.2 (Gene Codes Corporation). The consensus sequences were submitted to a BLAST search to confirm chimpanzee origin.

\subsection{4- Sequence authenticity}

In order to ensure that the sequences of this study were not contaminated with 'Numts' (Nuclear Copies of Mitochondrial DNA ${ }^{98}$ ), which would provide nonhomologous data, all PCR products were inspected both for dual bands in agarose gels and for double peaks in sequencing chromatograms. Furthermore, all sequences aligned with the reference Pan troglodytes HVR1 sequence [GenBank Access No.: X93335 $]^{71}$ and were compared with sequences reported to be chimpanzee Numts 
from GenBank. No evidence was found for the presence of nuclear copies in this study.

To determine the individuality of each sample, those that exhibited the same haplotype and were of the same molecular sex and geographical location were genotyped using 6 nuclear microsatellite loci (D16S2624, D10S1432, D2S1326, D5S1457, HUMFIBRA, and D4S1627). When tested using a random subset of individuals $(\mathrm{N}=20)$ each microsatellite marker was found to be highly polymorphic based on the polymorphic information content (PIC) (D16S2624, PIC=0.6979; D10S1432, PIC= 0.7127; D2S1326, PIC= 0.8096; D5S1457, PIC=0.7273; HUMFIBRA, $\mathrm{PIC}=0.5824 ; \mathrm{D} 4 \mathrm{~S} 1627, \mathrm{PIC}=0.7713)$. Sequences from specimens with the same haplotype and of the same sex from the same location but with differing genotypes, were considered to represent different individuals.

For genotyping criteria the number of replicates was estimated by using a maximum likelihood approach implemented in the software GEMINI v. 1.4.1 ${ }^{72}$ that uses a priori information about the error rates (i.e. allelic dropout and false alleles), which were determined in the software PEDANT v. $1.0^{73-74}$. General parameters in the software GEMINI included 100 simulation replicates and the range of repetition number was set from 2-12. This test revealed that four PCR repetitions were appropriate to achieve a high probability of identity assuring a 95\% confidence of the genotypes, and the per locus consensus threshold revealed that for a sample to be included in the final dataset must have at least two positive PCR results for nine of the 14 loci. For molecular sexing the result was considered as true when observed three times out of the four repetitions.

Allelic dropout, null alleles and stutter peaks were assessed using MICROCHECKER, v. 2.2.3 $3^{75}$. Moreover, a quality index (QI) for all loci was determined according to Miquel et al. (2006) $)^{76}$ and samples with a QI below 0.50 were removed from the dataset, as they are genotypes with poor quality.

To detect repeated individuals the software GIMLET v. 1.3.3 ${ }^{77}$ was used, and duplicated genotypes were removed. This software was also used to calculate the Probability of Identity (PI) and the Probability of Identity between siblings $\left(\mathrm{PI}_{\text {sibs }}\right)^{78}$. Finally, GenAlEx v. $6.4 .1^{79}$ was used to conduct all standard population genetic analyses. 


\subsection{5- Phylogenetic and population genetic analyses}

The HVR1 haplotypes were defined by analyzing the sequences in the program DNASP v. $4.01^{77}$. The haplotype diversity $(h)$ nucleotide $(\pi)$ and Watterson $\left(\theta_{W}\right)$ were estimated in the program ARLEQUIN v.3.01 ${ }^{78}$ as well as the estimator $F_{S T}$ in the analysis of their genetic differentiation. $\theta_{\mathrm{W}}$ summarizes the rate by which the evolutionary processes of mutation and genetic drift create and eliminate variation, and assumes neutrality. It is based on the number of polymorphic sites, but is independent of their frequency in contrast to $\pi^{91}$. The contributions of each population to the total haplotypic diversity (CT) and total haplotypic richness (CRT) were calculated using the software CONTRIB v.1.02 and partitioned into two components: the contribution due to a population's own level of diversity (CS and CRS), and its differentiation from other populations (CD and CRD), respectively ${ }^{79}$.

For phylogenetic analyses, West African HVR1 chimpanzee sequences were included from the neighboring country of Guinea (i.e. Bossou, Yeale, Seringbara) ${ }^{42,69,}$ ${ }^{72}$, and from Nigeria and Cameroon ${ }^{73}$. A median-joining haplotype network was constructed using the program NETWORK v. $4.6^{83}$. For phylogenetic analysis, the best evolutionary model was the $H K Y+G$ substitution model with a gamma shape parameter of 0.2250 (-InL=1566.0998), determined using the Akaike Information Criterion, implemented in the program jMODELTEST v.0.1.1 ${ }^{84}$. Phylogenetic trees were constructed using: (i) maximum parsimony (MP) with 1000 replicates of bootstraps; (ii) neighbor joining (NJ) with the Kimura 2-Parameter factor of correction and 10000 bootstrap replacements in MEGA, and (iii) the Bayesian inference (BI) program MRBAYES v. 3.1 $1^{85}$. The BI posterior probabilities were inferred using the Metropolis-Coupled Markov Chain Monte Carlo algorithm (MC-MCMC) from six million generations, with sampling every 100, 4 chains, 2 runs and an initial burn-in of $25 \%$. Stationarity of the chains was established from $\rho<0.01$ split frequencies. The convergence of the MCMC BI chains was evaluated in the program Tracer v.1.5 $5^{86}$ where ESS $>200$ confirmed a good convergence. All trees obtained were viewed and edited in Figtree software v.1.3.1 ${ }^{87}$ and concatenated by the three 
methods in a consensus tree in the program TREEGraph v. $2.0^{88}$.

Analysis of molecular variance (AMOVA) using pairwise nucleotide differences were also calculated in the program ARLEQUIN and the most likely pattern of population subdivision was estimated using spatial analysis of molecular variance in SAMOVA $1.0^{80}$ using 10,000 iterations from each of 100 random initial conditions, and testing all grouping options (predefined number of groups $(K)$ ranging from 2 to 18$)$.

In order to evaluate the relationship between genetic and geographic distance, a Mantel test and a linear regression by reduction of major axis (RMA) were applied in the program IBDWS $\vee 3.16^{81}$. Euclidean geographic distances were estimated using the ruler tool in the software Google Earth. To evaluate the existence of vicariant barriers that may prevent gene flow between the geographical regions, the program BARRIER v. 2.2 was used ${ }^{82}$. This method employs a geometric network connecting all sampled populations. Delaunay triangulation was computed from the intersections of the medians of each triangle, and a Voronoi tessellation obtained. Genetic distances are calculated for all neighboring populations and associated to each network edge. We used $\mathrm{F}_{\text {ST }}$ pairwise distances as a measure of genetic differentiation among populations. Then a number of barriers were identified (defined a priori) through the Monmonier's algorithm associated with higher values of genetic distance between populations ${ }^{81}$. Only barriers showing values of pairwise genetic differentiation higher than the average for all populations were represented on a map.

The analysis of demographic history and the likelihood of sudden expansion were tested using: mismatch distributions ${ }^{90}$ in ARLEQUIN; and tests of neutrality (Tajima D and Fu $F_{s}$ ) in the same software, and the tests Fu and $\mathrm{Li} \mathrm{F}^{*}$ and $\mathrm{D}$ * in the program DNASP v.4.01.

Finnaly, to analyze divergence times, a relaxed molecular clock and a coalescent approach was implemented in the program BEAST v. 1.6.2 ${ }^{89}$. The molecular clock was calibrated based on fossils from human-chimpanzee, humanNeanderthal and chimpanzee-bonobo divergence. Three independent runs were performed using the same mutation rate; optimized parameters and the substitution model suggested by jMODELTEST, and the Yule speciation process was used. The 
convergence of the runs was also evaluated in the program TRACER after combining logs and trees in LogCombiner and TreeAnnotator, respectively ${ }^{89}$.

\section{4- RESULTS}

\subsection{1- mtDNA HVR1 diversity}

We obtained a $261 \mathrm{bp}$ sequence for the mitochondrial HVR1 from 334 west African chimpanzee fecal samples (189 from Guinea-Bissau, and 145 from the Nimba Mountains, Guinea). We found 55 polymorphic sites comprising 52 transitions (ti) and three transversions (tv) with an overall ti/tv ratio of 31.04 following the maximum likelihood estimate. The nucleotide composition was as follows: A (37.67\%), T (17.10\%), C (6.73\%), and G (38.51\%).

Fifty-one haplotypes were identified, found in 1 - 3 populations (Table 2) with 19 shared, including the haplotypes $\mathrm{H} 1, \mathrm{H} 13$ and $\mathrm{H} 35$ that were distributed between the two countries. Nimba possessed the highest number of exclusive haplotypes $(n=12)$, followed by Cadique $(n=8)$ and Vendu Leidi $(n=8)$ in Guinea-Bissau. H13 was the most common haplotype, present in 46 individuals. $\mathrm{H} 3$ and $\mathrm{H} 4$ occured only in Guinea-Bissau and were widespread across all study areas. Cantanhez possessed the highest number of private haplotypes $(n=11)$ followed by Nimba and Boé (with 9 each), Cufada ( $n=5)$, Catió $(n=3)$ and Empada with one (H5). Three haplotypes are communal between CNP and CLNP (i.e. H2, H6, H9), and five between Boé and Cantanhez (i.e. $\mathrm{H} 14, \mathrm{H} 18, \mathrm{H} 19, \mathrm{H} 21, \mathrm{H} 24$ ). Within $\mathrm{CNP}, \mathrm{H} 15$ is the most frequent haplotype occurring in seven localities $(n=21)$ (Table 4.2).

The haplotype diversity $(h)$ for each study area ranged from 0.836 in Nimba to 0.929 in Gabú. The highest values of the nucleotide diversity $(\pi)$ also occurred in Gabú $(\pi=0.05516)$ and the lowest in Nimba $(\pi=0.0429)$. The total haplotype and nucleotide diversities were $h=0.935$ and $\pi=0.05325$, respectively. An alternative measure to $\pi$ is Watterson's theta estimator $\left(\theta_{w}\right)$. The average high $\theta_{w}$ for all population was 0.03058 with a variation between 0.02804 and 0.03620 in Nimba and Quínara, respectively. Estimates of the molecular diversity indexes are given in Table 
4.3.

The $P$. troglodytes verus populations contributed differently to the total genetic diversity and differentiation inferred for the study areas. The contributions from the diversity (CS and CRS) and differentiation (CD and CRD) components of each population are shown in Fig. 4.2. The highest CS and CRS values were observed in Aicum, Béli, Béli North and Vendu Leidi populations, all belonging to the Gabú region. In contrast, the highest $C D$ and $C R D$ values were seen in Bani, and Injassane from Quínara region and in general from the Cantanhez populations. These contributions to genetic differentiation were probably due to exclusive haplotypes found in medium to high frequencies in this region (see haplotypes $\mathrm{H} 15, \mathrm{H} 16, \mathrm{H} 17$, $\mathrm{H} 25, \mathrm{H} 26, \mathrm{H} 27, \mathrm{H} 28, \mathrm{H} 29, \mathrm{H} 40, \mathrm{H} 41$, and H42 in Table 4.2).

\subsection{2- Phylogenetic analysis}

The chimpanzees from Nigeria Cameroon (P. t. ellioti) formed a monophyletic unit statistically well supported by posterior probabilities $(\mathrm{BI}=1)$. The 51 P. t. verus haplotypes from Guinea-Bissau and Nimba Mountains clustered in two main clades, named Lineage A and B (Fig. 4.3).

The median-joining phylogenetic network confirmed the results of the phylogenetic tree analysis, but it provided more resolution on relationships among haplotypes and within subclades where it was possible to observe a clear star-shape pattern in Lineage B (Fig. 4.4). The haplotype distribution within Guinea-Bissau is presented in Figure 5.

\subsection{3- Phylogeographic structure}

Pairwise $F_{S T}$ values calculated from haplotype frequencies of the 28 populations sampled indicate significant differentiation (Table 4.4). However, when the populations were grouped together the $\mathrm{F}_{\mathrm{ST}}$ values varied from 0.00334 (TombaliQuínara) to 0.21095 (Quínara-Nimba) and only the Nimba differed significantly from zero (Table 4.4). Pairwise Phist calculated from Kimura's two parameter genetic 
distances revealed similar results demonstrating that the three regions within Guinea-Bissau are not significantly differentiated.

In order to reveal the partitioning of genetic diversity a hierarchical AMOVA was conducted showing a strong differentiation among all chimpanzee populations $\left(\varphi_{\mathrm{ST}}=0.25956, p<0.0001\right)$. AMOVA revealed $74.04 \%$ of overall genetic variance partitioned among individuals within populations whereas differences among populations within regions accounted for $23.74 \%\left(\varphi_{\mathrm{sc}}=0.24274, \mathrm{p}<0.0001\right)$. Only $2.22 \%$ of the genetic variation is partitioned among regions and this was not significant (AMOVA $\left.\varphi_{\mathrm{CT}}=0.2221, \mathrm{p}>0.05\right)$ (Table 4.5).

The SAMOVA demonstrated that the strongest partitioning of genetic diversity was obtained when samples were assigned to 2 - 10 groups. The best grouping scheme divided the distribution range of $P$. troglodytes verus in GuineaBissau and Nimba into two main geographical groups $\left(K=2 ; F_{C T}=0.34253, p<0.0001\right)$. When the number of groups exceeded three, SAMOVA showed lower $\mathrm{F}_{\mathrm{CT}}$ values. With $\mathrm{K}=2$ a partition between the south Cantanhez populations and all the others corresponded to the two main HVR1 haplotype lineages. The populations from south Cantanhez (i.e. Farim, Catomboi, Cafatche and Canghode) comprised only haplotypes from Lineage A while the rest of the populations in Guinea Bissau and Nimba have haplotypes from both lineages. Table 4.6 summarizes the SAMOVA analysis and the components of genetic variance explained for each cluster.

Mantel tests performed to assess isolation by distance revealed no correlation when all the populations were considered $(Z=5.999555 .85, r=-0.0822$, one sided $p=0.8370$ from 30000 permutations). However, when considering Cantanhez only (i.e. excluding Nimba and Gabú) to take into account the long-term historical divergence among populations as recommended by Telles and Diniz-Filho, $(2005)^{93}$ this correlation was significant $(Z=159.8819, r=0.5661$, one-sided $p=0.0080$ from 30000 permutations). The isolation by distance among Cantanhez populations was confirmed by the RMA ( $\left.y=-0.08010 x=0.03709, r^{2}=0.320\right)$.

The Monmonier algorithm (BARRIER software) suggested three main barriers $(\alpha, \beta, \gamma)$ to gene flow in the Guinea-Bissau chimpanzee distribution range: $(\alpha)$ the most significant barrier is located approximately in the south of the CNP in the 
Cubucaré Peninsula, thus isolating the populations of Catomboi, Cafatche and Canghode (11 $\left.11^{\circ} 19.26^{\prime \prime} \mathrm{N}-15^{\circ} 6^{\prime} 32.49 " \mathrm{~W}\right) ;(\beta)$ another barrier located south of the Rio Grande de Buba in the Quínara region causing genetic discontinuity between the CLNP and the Empada and Catió chimpanzees $\left(11^{\circ} 37^{\prime} 47.19^{\prime \prime} \mathrm{N}-15^{\circ} 10^{\prime} 23.11^{\prime \prime} \mathrm{W}\right)$, and $(\gamma)$ one barrier that separates Aicum and Vendu Leidi populations from the others in the Boé sector and in the Tombali region, located in the southeast of the country between the geographic coordinates $\left(11^{\circ} 44^{\prime} 19.79^{\prime \prime} \mathrm{N}-13^{\circ} 44^{\prime} 3.80^{\prime \prime} \mathrm{W}\right)$ and $\left(11^{\circ} 56^{\prime} 39.19^{\prime \prime} \mathrm{N}-13^{\circ} 53^{\prime} 0.34^{\prime \prime} \mathrm{W}\right)$. These barriers are represented in Figure 4.5.

\subsection{4- Demographic history and divergence time}

Historical demography was analysed by estimating parameters for neutrality tests and by conducting mismatch distribution analyses. Tajima's D tests were positive but not statistically significant for each region or for all populations grouped together. Similarly, the Fu's $F_{s}$ values were not significant, although presenting a negative value for all populations (Fu's $\left.F_{s}=-93294\right)$. The test Fu and Li's and $D^{\prime}$ is based on the differences between the number of singletons and the total number of mutations, whereas the test $\mathrm{Fu}$ and Li's $\mathrm{F}^{\prime}$ is based on differences between the number of singletons and the average number of differences between pairs of sequences $^{94}$. These two tests presented positive values and were statistical significant in each region and in all populations, with the exception of the test Fu and Li's D' for the Tombali region that was not significant suggesting a deviation from neutrality (see Table 4.3).

Considered altogether, the mismatch distributions for all populations were bimodal and they fitted with their distributions under the sudden and spatial expansion models and this may be due to their peripheral nature. The tests for the goodness-of-fit confirmed both demographic models $(S S D=0.00621, p>0.05 ; S S D=$ $0.00710, p>0.05$ for the sudden and spatial expansion models, respectively). However, when considering only the sequences from Lineage A and Lineage B defined by the phylogenetic and network inferences, the patterns were unimodal fitting with the distributions expected under the sudden and spatial expansion 
models. Furthermore, the model parameters $\Theta_{0}$ and $\Theta_{1}$ calculated for Linage $A$ and Lineage B separately, showed values expected under a model of rapid growth in both cases (Fig. 4.6). Tests for the goodness-of-fit for the observed data support similarly the expansion model revealed by the SSD values for both lineages ( $S S D=0.037, P=0.046$; and $S S D=0.0155, P=0.192$, respectively). Aditionally, the small raggedness index values supported a smooth distribution ( $R$-Index $=0.044 ; P=0.237$; R-Index=0.0189, $P=0.055$ ).

Considering a divergence rate of $22.5 \%$ per million years ${ }^{6,95}$, and a split time between humans and chimpanzees of 7-5 mya ${ }^{96}$, and between chimpanzees and bonobos of 2.1-1.5 mya ${ }^{96}$, the two major mitochondrial lineages are estimated to have diverged at 1 mya (95\% HPD: 0.34-2.11). The most recent common ancestor (mrca) of Lineage A is estimated at 0.67 mya, while the TMRCA of Lineage $B$ is estimated at 0.43 mya (95\% HPD: 0.34 to 2.11 mya). The divergence time among the Lineage A haplogroups varied between 0.32 mya (95\% HPD: 0.03 to 0.95 ) for haplogroup A3 and 0.47 mya (95\% HPD: 0.9 to 1.22 ) and between 0.07 mya (95\% HPD: 0-47-0.97) for haplogroup B2 and 0.29 mya (95\% HPD: 0.04 to 0.81) for haplogroup B2.

\section{5- DISCUSSION}

This study is the first to investigate the mitochondrial genetic structure and demographic history of the Guinea-Bissau chimpanzees, and for that purpose Nimba chimpanzees were incorporated. It revisits West African chimpanzee phylogeography by including individuals from these areas. The high genetic diversity observed for all populations in the current study ( $h=94 \%, \pi=5.3 \%$ and $\theta_{W}=3.1 \%$ ) is in agreement with previous reports for Upper Guinea chimpanzees ${ }^{5}$ 35, 38. The nucleotide diversities fall within the range reported by Gagneux et al. (2009) for the subspecies $(\pi=0.07 \text {, range } 0-16 \%)^{5}$ and when compared with other populations ${ }^{38}$ : Tai, Ivory Coast $(\pi=5.2 \%)$, Bossématié Forest, Liberia $(\pi=4.81 \%)$, Tenkere, Sierra Leone $(\pi=4.73 \%)$ and Solo, Mali $(\pi=4.47 \%)$. The chimpanzees from the Tombali and Gabú regions in Guinea-Bissau exhibit a similar nucleotide diversity $(\pi=5.4 \%$ and $\pi=$ $5.5 \%$, respectively). When compared with the eastern chimpanzees ( $\pi=2.5 \%$, range 
$0-9 \%)^{97}$ the nucleotide diversities reported in this study are higher, but in the same range of central chimpanzees $(\pi=5.6 \%)^{98}$. Nevertheless, the genetic diversities wre consistently greater in the peripheral chimpanzees of Guinea-Bissau when compared to Nimba.

Fifty-one haplotypes were detected from which 39 are exclusive to GuineaBissau. The Tombali region, where CNP lies, possessed the highest number of haplotypes $(n=26)$ and five $(H 44, H 46, H 48, H 49, H 50)$ are newly reported for the Nimba Mountains population when compared to previous studies ${ }^{70,72}$. Three haplotypes were shared between the two countries ( $\mathrm{H} 1, \mathrm{H} 13, \mathrm{H} 35)$ over $800 \mathrm{~km}$ apart indicating that female gene flow must have been substantial until fairly recently. The Niger River has been proposed as a natural barrier to gene flow $^{73}$, but our findings suggest that this river has not been a substantial boundary between Guinea and Guinea-Bissau chimpanzees, or they have used the Liberia and Sierra Leone as a preferred route (Fig. 1).

Bayesian Inference phylogenetic reconstruction revealed two deep clades (Lineage A and Lineage B). The existence of these two evolutionary lineages in the western chimpanzees had been previously reported ${ }^{4,6,9}$.

Our analyses indicated a high level of genetic structure $\left(F_{S T}=0.25956\right.$, $\mathrm{p}<0.0001$ ), with $74.04 \%$ of the total genetic diversity due to differences within populations among individuals (Table 5). The same pattern of genetic variation apportionment was found for the Nigeria-Cameroon chimpanzees ${ }^{27}$ and bonobos ${ }^{9}$. In the current study, two major phylogeographical groups were identified by the SAMOVA algorithm ( $\mathrm{K}=2)$ : one restricted to the south of the CNP encompassing the populations of Farim, Catomboi, Cafatche and Canghode, and a second cluster constituted by all the other populations (Table 7). The chimpanzees from south Cantanhez detain exclusively haplotypes from Lineage A, whereas the second group have haplotypes from both lineages.

The genetic structure of the Guinea-Bissau chimpanzees can be predicted either via isolation by distance or by vicariance. The Mantel test $(Z=159.8819, r 2=$ $0.5661, \rho<0.05)$ showed that there is a positive correlation between the genetic distance and the geographic distance. As the latter increases the former decreases causing a divergence between the haplotype frequencies promoted by the genetic 
drift, thus establishing an isolation-by-distance pattern. This pattern explains that Cantanhez female chimpanzees prefer to migrate to a neighbouring population rather than travel long distances, hence following a stepping-stone model of dispersal. This pattern also occurs in other chimpanzee population's elsewhere ${ }^{14,73}$.

The genetic discontinuity analyses conducted in the BARRIER program, which combines fundamentals of statistical geometry (Voronoi Tesselation and Delaunay triangulations) with the maximum difference algorithm of Monmonnier ${ }^{83}$ revealed the existence of three main barriers to gene flow. The most significant barrier (1) is located in the south of the CNP isolating the populations of Farim-Canghode. This barrier coincides with the best clustering of groups revealed by the SAMOVA analyses. This group is isolated in the very end of the Cubucaré Pensinsula limited by the Cumbijã and Cacine Rivers. Nowadays there are no apparent physical boundaries in the area. The second significant barrier (2) is located approximately at the 110 $37^{\prime} \mathrm{N}-15010^{\prime}$ causing a genetic discontinuity between the CLNP and the Empada and Catió chimpanzees. These Peninsulas are clearly separated by the Rio Grande de Buba at north and the Catió River at west, but its connectivity is linked with the CNP at southeast via the Nhala corridor. Lastly, a third genetic disjunction (3) was identified in the Gabú region, isolating the remote chimpanzees from Vendu Leidi and Aicum. The Féfine River could have been a natural barrier for these populations as they are located on the east side of the river.

Signatures of recent demographic and spatial expansion were revealed by: (i) the Fu and Li's D' and F' neutrality tests, (ii) the star shape pattern in the network and (iii) the bimodal pattern of the mismatch distributions. In addition, both nucleotide and haplotype diversities were high and according to Grant and Bowen (1998) this can reflect a secondary contact between different lineages ${ }^{99}$. The bimodal pattern in both mismatch distributions suggests population subdivision, several demographic expansions in the past, various waves of migration among different populations or a combination of these ${ }^{100}$. The same pattern was observed for the P. t. ssp. ellioti ${ }^{27,73}$. However, this pattern contrasts with the eastern and central chimpanzee subspecies characterized by an unimodal pattern ${ }^{5,33}$. Based on the mismatch analyses of the peripheral chimpanzees in Guinea-Bissau it appears that historical isolation and subsequent secondary contact has produced the 
patterns of genetic diversity and mismatch distribution detected here, contrary to expectations.

The two mtDNA lineages emerged, according to this study around 1 mya after the divergence between the Central/Western chimpanzees around 1.6-1.3 mya ${ }^{4}$. Historically, they fall into the Upper Pleistocene (1-0.78 mya) and the haplogroup divergence within each lineage dates back to the Middle Pleistocene $(0.78-0.12$ mya). In paleoclimate terms these divergence estimates occurred during the Gunz (0.68-0.62) and Mindel (0.45-0.30) glaciations with a Last Glacial Maximum around 27 500-14 500 years ago. Several evidences and recent studies have demonstrated that during the glaciation periods the climate in Africa was cooler and drier than today ${ }^{46}$. The recurrence of climatic changes during the Pleistocene periods in West Africa, with cycles of forest expansion and contraction ${ }^{101}$, likely led to repeated vicariance events that can explain the genetic structure and diversity observed for the chimpanzees in Guinea-Bissau and Nimba. Moreover, the concepts of endemism and diversity can be translated into genetic terms to make statements about the locations of the refuges and of lineage expansions out of those areas during the interglacial periods of the forest re-expansion ${ }^{73}$. Populations with high levels of haplotypic diversity may have been protected within Pleistocene refuges during the periods of maximum glaciation ${ }^{1,27,33-34,73,79}$. The distribution of the genetic diversity appears to follow that hypothesis.

\subsection{1- Conservation considerations}

Several studies have demonstrated that anthropogenic effects such as fragmentation and deforestation can promote changes in the diversity and genetic structure of species, usually decreasing the genetic diversity within populations and increasing differentiation among populations ${ }^{44-45,102-103}$. Further research is needed to uncover contemporary changes, because mtDNA is not a powerful marker to detect contemporary alterations in the genetic structure of fragmented populations as more polymorphic nuclear markers such as microsatellites, could result in a modification of the phylogeographical patterns obtained in this study. However, 
taking into account that $P$. $t$. verus is an endangered hominid we considered relevant to use mtDNA to inform conservation strategies for this species in Guinea-Bissau. Petit et al. (1998) pointed out that the criteria for the selection of priority populations to be conserved must include its differentiation and its diversity levels ${ }^{79}$. Additionally, Moritz (1994) propose the use of "management units (MU)" to recognize the management units with a significant divergence of alleles (at nuclear or organelle loci) ${ }^{104}$. Therefore, the chimpanzee populations containing representative genetic diversity from the two major phylogeographic groups should be identified. The group in south Cantanhez constituted by the Farim-Canghode populations warrants special attention, as it is isolated in the very south of the CNP and under intense pressure from habitat fragmentation and loss (Rui Sá pers. observation). Hunting practices must be forbidden totally, with appropriate law enforcement in order to mitigate its deleterious effects. The guards of the CNP should be more present and active, supervising more frequently areas in the park where hunting is more frequent. Alternatives to chimpanzee crop-raiding attacks in this area must be developed in order to prevent locals to kill them during emergent conflicts. Canghode and Cafatche populations should be carefully protected, as they are the units that most contribute to the genetic diversity within this group. Among the second group the populations of the northern area of CNP (i.e. Amidara, São Francico, Mejo, Cancira), Buba Inthingue and Injassane in CLNP and the populations of Béli, Vendu Leidi, Dinguirai and Aicum in the Gabú region are recognized as the units that contribute most to maintaining genetic diversity. Special attention should be given to the populations of Vendu Leidi and Dinguirai as mining activities are planned for these areas. In addition, special attention should be also given to the population of Briame in the Catió Peninsula as they are living in an intense anthropogenic area and if the forest connectivity in the northern part between the Empada and Buba sectors is lost they will become isolated.

In conclusion, the results of the present study show that palaeoecological history and rivers have a role in shaping the genetic variability and structure of the chimpanzees in Guinea-Bissau and Nimba and they can be used for conservation purposes. 


\section{6- ACKNOWLEDGMENTS}

We thank the Instituto da Biodiversidade e das Áreas Protegidas of GuineaBissau and Direcção Geral de Florestas e Caça for providing licences for the collection of samples and logistical support. We thank all the Cantanhez National Park and Cufada Lagoons Natural Park rangers and guides for their invaluable support. We thank Chimbo Foundation for support during fieldwork in the Boé sector. We thank Catarina Casanova, Marta Carmo, André Barata, Joana Roque de Pinho and Fernando Sousa for assistance with the field work. We thank Silke Waap and Raquel Xavier with the data analyses. This study was supported by a PhD grant from FCT, Portugal (SFRH/BD/35797/2007) and by the Great Ape Fund (GA-0678).

\section{7- REFERENCES}

1 Gonder MK, Locatelli S, Ghobrial L, et al. 2011. Evidence from Cameroon reveals differences in the genetic structure and histories of chimpanzee populations. Proc Natl Acad Sci USA 108: 4766-4771.

2 Sayers K, Lovejoy O. 2008. The chimpanzee has no clothes. Curr Anthropol 49: 87113.

3 Gagneux P. 2002. The genus Pan: population genetics of an endangered outgroup. Trends Genet 18: 327-330.

4 Morin PA, Moore JJ, Chakraborty, R. et al. 1994. Kin selection, social structure, gene flow, and the evolution of chimpanzees. Science 265: 1193-1201.

5 Gagneux P, Wills C, Gerloff U, et al. 1999. Mitochondrial sequences show diverse evolutionary histories of African hominoids. Proc Natl Acad Sci USA 96: 5077-5082. 
6 Gonder MK, Disotell TR, Oates JF. 2006. New genetic evidence on the evolution of chimpanzee populations, and implications for taxonomy. Int J Primatol 27: 11031127.

7 Becquet C, Patterson N, Stone AC, et al. 2007. Genetic structure of chimpanzee populations. PLoS Genet 3: e66.

8 Groves CP. 2001. Primate taxonomy. Smithsonian Institution. Washington, DC.

9 Eriksson J, Hohmann G, Boesch C, Vigilant L. 2004. Rivers influence the population genetic structure of bonobos (Pan paniscus). Mol Ecol 13: 3425-3435.

10 Prüfer K, Munch K, Hellmann I, et al. 2012. The bonobo genome compared with the chimpanzee and human genomes. Nature 000:1-5.

11 Kormos R, Boesch C. 2003. Regional Action Plan for the Conservation of Chimpanzees in West Africa. IUCN.

12 Caldecott J, Miles L. (eds.) 2005. World Atlas of Great Apes and their Conservation. London. University of California Press.

13 Oates JF, Tutin CEG, Humle T, et al. 2012. Pan troglodytes. IUCN Red List of Threatened Species. Version 2012.1. IUCN, Gland, Switzerland. Available at www.iucnredlist.org. Accessed July 20, 2012.

14 Fischer A, Pollack J, Thalmann O, et al. 2006. Demographic history and genetic differentiation in apes. Curr Biol 16: 1133-1138.

15 Groves CP. 2005. Geographic variation within eastern chimpanzees. Australas Primatol 17: 19-46. 
16 Oates JF, Groves, CP, Jenkins PD. 2009. The type locality of Pan troglodytes vellerosus (Gray, 1862), and implications for the nomenclature of West African chimpanzees. Primates 50: 78-80.

17 Gonder MK, Oates, JF, Disotell DR. et al. 1997. A new west African chimpanzee subspecies? Nature 388: 337.

18 Oates JF, Bergl R, Linder J. 2004. Africa's Gulf of Guinea forests: Biodiversity patterns and conservation priorities. Advances in Applied Biodiversity Science 6: 195.

19 Morgan B, Adeleke A, Bassey T. et al. 2011. 2011. Regional action plan for the conservation of the Nigeria-Cameroon chimpanzee (Pan troglodytes ellioti). Gland, Switzerland and San Diego, CA, USA: IUCN/SSC Primate Specialist Group and Zoological Society of San Diego, CA, USA.

20 Humle T, Boesch C, Duvall C. et al. 2012. Pan troglodytes ssp. verus. IUCN Red List of Threatened species. Version 2012.1. Available at: www.iucnredlist.org. Accessed July 20, 2012.

21 Brownell, A. 2003a. Benin. In West African Chimpanzees: Status Survey and Conservation Action Plan. Edited by R. Kormos, C. Boesch, M. Bakarr, and T. Butynski, pp. 121-122: IUCN, Gland, Switzerland.

22 Brownell, A. 2003b. Burkina Faso. In West African Chimpanzees : Status Survey and Conservation Action Plan Edited by R. Kormos, C. Boesch, M. Bakarr, and T. Butynski, pp. 121-122: IUCN, Gland. Switzerland.

23 Inskipp T. 2005. Chimpanzee (Pan troglodytes). In World Atlas of Great Apes and their Conservation, Edited by J. Caldecott and L. Miles. London. University of California Press. 
24 Sugiyama Y, Koman J. 1979. Social structure and dynamics of wild chimpanzees at Bossou, Guinea. Primates 20: 323-339.

25 Boesch C, Boesch H. 1981. Sex differences in the use of natural hammers by wild chimpanzees: A preliminary report. J Hum Evol 10: 585-593.

26 Haslam M, Hernadez-Aguílar A, Ling V. et al. 2009. Primate archaeology. Nature 460: 339-444.

27 Gonder MK, Disotell TR. 2006. Contrasting phylogeographic histories of chimpanzees in Nigeria and Cameroon: A multilocus analysis. Primate Biogeography. Lehman and Fleagle (eds.). Plenun/Kluwer Press, New York.

28 Won YJ, Hey J. 2005. Divergence population genetics of chimpanzees. Mol Biol Evol 22: 297-307.

29 Caswell JL, Mallick S, Richter DJ. Et al. 2008. Analysis of chimpanzee history based on genome sequence alignments. PLoS Genet 4:e1000057.

30 Hey J. 2010. The divergence of chimpanzees species and subspecies as revealed in multipopulation isolation-with-migration analyses. Mol Biol Evol 27: 921-933.

31 Stone AC, Battistuzzi FU, Perry Jr GH. et al. 2010. More reliable estimates of divergence times in Pan using complete mtDNA sequences and accounting for population structure. Philos Trans R Soc Lond B Biol Sci 365: 3277-3288.

32 Wegmann D, Excoffier L. 2010. Bayesian inference of the demographic history of chimpanzees. Mol Biol Evol 27: 1425-1435.

33 Goldberg TL, Ruvolo M. 1997a. The geographic apportionment of mitochondrial genetic diversity in east African chimpanzees, Pan troglodytes schweinfurthii. Mol Biol Evol 14: 976-984. 
34 Goldberg TL, Ruvolo M. 1997b. Molecular phylogenetics and historical biogeography of east African chimpanzees. Biol J Linn Soc 61: 301-324.

35 Gagneux P, Gonder MK, Goldberg TL, Morin PA. 2001. Gene flow in wild chimpanzee populations: what genetic data tell us about chimpanzee movement over space and time. Phil Trans R Soc Lond B 356: 889-897.

36 Fischer A, Pollack J, Thalmann O, et al. 2006. Demographic history and genetic differentiation in apes. Curr Biol 16: 1133-1138.

37 Frankham R, Ballou J, Briscoe D. 2005. Introduction to Conservation Genetics. Cambridge. Cambridge University Press.

38 Gagneux P. 1998. Population genetics of West African chimpanzees (Pan troglodytes verus). PhD Dissertation. Basel University. Basel, Switzerland.

39 Croteau EK. 2010. Causes and consequences of dispersal in plants and animals. Nature Education Knowledge 1:12.

40 Wright S. 1978. Evolution and genetics of populations. Chicago: University of Chicago Press.

41 Kvarnemo C, Ahnesjo I. 2002 Operational sex ratios and mating competition. In: Sex ratios. Concepts and research methods, by Hardy, ICW (ed.). Cambridge: Cambridge University Press.

42 Shimada MK, Hayakawa S, Fujita S, et al. 2009. Skewed matrilineal genetic composition in a small wild chimpanzee community. Folia Primatol 80: 19-32.

43 Lowe A, Harris S, Ashton P. (eds.). 2004. Ecological genetics: Design, analysis and application. Oxford, Blackwell Publishing. 
44 Bergl R, Bradley BJ, Nsubuga AM, Vigilant L. 2008. Genetic effects of habitat fragmentation, population size and demographic history on primate populations: the Cross River gorilla in a comparative context. Am J Primatol 70: 848-859.

45 da Silva MJ, Minhos T, Sa RM, Bruford MW. 2012. Using genetics as a tool in primate conservation. Nature Education Knowledge 3:10.

46 Maley J. 1991. The African rain forest vegetation and paleoenvironments during late Quaternary. Climate Change 19:79-98.

47 Guillaumet JL. 1967. Recherches sur la vegetation et la flore de la région du BasCavally (Côte d'Ivoire). Mémoires ORSTOM 20: 249.

48 Mayr E, O'Hara RJ. 1986. The biogeographic evidence supporting the Pleistocene forest refuge hypothesis. Evolution 40: 55-67.

49 Rompaey RSAR. 1993. Forest gradients in West Africa. Department of Forestry, Wageningen Agricultural University.

50 Catarino L, Martins ES, Moreira I. 2001. Influence of environmental features in the phytogeographic framework of Guinea-Bissau. In: Robbrecht E, Degreef J, Friis I. (eds.). Plant systematics and phytogeography for the understanding of African biodiversity. Proceedings of the XVIth AETFAT Congress, Belgium.

51 Sousa C, Gippoliti S, Akhlas M. 2005. Republic of Guinea-Bissau. In: Caldecott J, Miles L. (eds.).World atlas of great apes and their conservation. Berkeley: University of California Press. 362-365 pp.

52 Torres J, Brito JC, Vasconcelos MJ, Catarino L, Gonçalves J. Honrado J. 2010. Ensemble models of habitat suitability relate chimpanzee (Pan troglodytes) conservation to forest and landscape dynamics in Western Africa. Biol Conserv 143: 
416-425.

53 Casanova C, Sousa C. 2007. Plano de aç̧ão nacional para a conservação das populações de chimpanzés, cólobus vermelhos ocidentais e cólobos brancos e pretos ocidentais na República da Guiné-Bissau. Bissau. IBAP. Ministério do Desenvolvimento Rural, Agricultura, Recursos Naturais e Ambiente, Bissau. 101 p.

54 Sá RM, Ferreira da Silva M, Sousa F, Minhos T. 2012. The trade and ethnobiological use of chimpanzee body parts in Guinea-Bissau: Implications for Conservation. Traffic Bulletin 24: 31-34.

55 Lee PC, Thornback J, Bennett EL. 1988. Threatened primates of Africa: The IUCN red data book. IUCN, Gland, Switzerland and Cambridge.

56 Gippoliti S, Dell'Omo G. 1995. Status and conservation of the chimpanzee Pan troglodytes verus in Guinea-Bissau. African Primates 1: 3-5.

57 Gippoliti S, Dell'Omo G. 1996. Primates of the Cantanhez Forest and the Cacine Basin, Guinea-Bissau. Oryx 30: 74-80.

58 Gippoliti S, Dell'Omo G. 2003. Primates of Guinea-Bissau, West Africa: Distribution and Conservation Status. Primate Conserv 19: 73-77.

59 Brugière D, Badjinca I, Silva C, Serra A. 2009. Distribution of chimpanzees and interactions with humans in Guinea-Bissau and Western Guinea, West Africa. Folia Primatol 80:353-358. 
60 Simão A. 1997. Identificação e delimitação cartográfica dos grandes maciços florestais de Cantanhez. Bissau: Relatório de missão. IBAP. 64 p.

61 Catarino L. 2004. Fitogeografia da Guiné-Bissau. PhD dissertation. Lisboa, Portugal: Instituto Superior de Agronomia. Universidade Técnica de Lisboa. 420 p.

62 Hockings K, Sousa C. 2011. Human-chimpanzee sympatry and interactions in Cantanhez National Park, Guinea-Bissau: Current Research and future directions. Primate Conserv 26.

63 IBAP. 2010. http://www.ibap-gbissau.org/. (Accessed on 16 March 2010).

64 RAMSAR Convention. 2012. http://www.wetlands.org/. (Accessed on 20 July 2012).

65 UNDP. 2012. http://www.gw.undp.org/ (Accessed 20 July 2012).

66 Lamotte M. 1998. Le Mont Nimba, Réserve de Biosphère et Site du Patrimoine Mondial (Guinée - Côte d'Ivoire) - Initiation à la Géomorphologie et Biogéographie. Paris: UNESCO.

67 Roeder AD, Archer FI, Poinar HN, Morin PA. 2004. A novel method for collection and preservation of faeces for genetic studies. Molecular Ecology Notes 4: 761-764. 
68 Nsubuga AM, Robbins MM, Roeder A, et al. 2004 Factors affecting the amount of genomic DNA extracted from ape feces and the identification of an improved sample storage method. Mol Ecol 13: 2089-2094.

69 Kishore R, Hardy WR, Anderson VJ, et al. 2006. Optimization of DNA Extraction from Low-Yield and Degraded Samples Using the BioRobot ${ }^{\circledR}$ EZ1 and BioRobot ${ }^{\circledR}$ M49. J Forensic Sci 51: 1005-1061.

70 Shimada MK, Hayakawa S, Humle T, et al. 2004. Mitochondrial DNA genealogy of chimpanzees in the Nimba Mountains and Bossou, West Africa. Am J Primatol 64: $261-275$.

71 Arnason U, Xu X, Gullberg A, et al. 1996. Comparison between the complete mitochondrial DNA sequences of Homo and the common chimpanzee based on nonchimeric sequences. J Mol Evol 42: 145-152.

72 Valière N, Berthier P, Mouchiroud D, Pontier D. 2002. Gemini: Software for Testing the Effects of Genotyping Errors and Multitubes Approach for Individual Identification. Molecular Ecology Notes 2: 83-86.

73 Johnson PC, Haydon DT. 2007. Maximum-likelihood estimation of allelic dropout and false allele error rates from microsatellite genotypes in the absence of reference data. Genetics 175: 827-842. 
74 Johnson PC, Haydon DT. 2009. Software for quantifying and simulating microsatellite genotyping error. Bioinformatics and Biology Insights,1: 71-75.

75 van Oosterhout C, Hutchinson WF, Wills DP, Shipley P. 2004. Micro-checker: software for identifying and correcting genotyping errors in microsatellite data. Molecular Ecology Notes 4: 535-538.

76 Miquel C, Bellemain E, Poillot C, Bessiére J, Durand A and Taberlet P. 2006. Quality indexes to assess the reliability of genotypes in studies using noninvasive sampling and multiple-tube approach. Molecular Ecology Notes 6: 985-988.

77 Valière N. 2002. GIMLET: a computer program for analysing genetic individual identification data. Molecular Ecology Notes 2: 377-379.

78 Waits LP, Luikart G, and Taberlet P. 2001. Estimating the probability of identity among genotypes in natural populations: cautions and guidelines Molecular Ecology 10: $249-256$.

79 Peakall R, and Smouse PE. 2006. GENALEX 6: Genetic analysis in Excel. Population genetic software for teaching and research. Molecular Ecolology Notes 6:288-295.

80 Koops, K, McGrew WC, Matsuzawa T, Knapp LA. 2012. Terrestrial nest-building by wild chimpanzees (Pan troglodytes): Implications for the tree-to-ground sleep transition in early hominins. Am J Phys Anthropol 148: 351-361.

81 Gonder K. 2000. Evolutionary genetics of chimpanzees (Pan troglodytes) in Nigeria and Cameroon. PhD dissertation. New York. The City University of New York. 
82 Zsurka G, Kudina T, Peeva V. et al. 2010. Distinct patterns of mitochondrial genome diversity in bonobos (Pan paniscus) and humans. BMC Evol Biol 10: 270.

83 Fehren-Schmitz L, Reindel M, Cagigao ET, et al. 2010. Pre-Columbian population dynamics in coastal southern Peru: A diachronic investigation of mtDNA patterns in the Palpa region by ancient DNA analysis. Am J Phys Anthropol 141: 208-221.

84 Krause J, Orlando L, Serre D, et al. 2007. Neanderthals in Central Asia and Siberia. Nature 449: 902-904.

85 Rozas J, Sánchez-DelBarrio JC, Messeguer X, et al. 2003. DnaSP, DNA polymorphism analyses by the coalescent and other methods. Bioinformatics 19: 2496-2497.

86 Excoffier L, Laval G, Schneider S. 2005. ARLEQUIN ver. 3.0: An integrated software package for population genetics data analysis. Evolutionary Bioinformatics Online 1: 47-50.

87 Petit R, Mousadik E, Pons O. 1998. Identifying populations for conservation on the basis of genetic markers. Conserv Biol 12: 844-855.

88 Dupanloup I, Schneider S, Excoffier L. 2002. A simulated annealing approach to define the genetic structure of populations. Mol Ecol 11: 2571-2581. 
89 Jensen J, Bohonak J, Kelley S. 2005. Isolation by distance, web service BMC Genetics 6:13.

90 Manni F, Guérard E, Heyer E. 2004. Geographic patterns of (genetic, morphologic, linguistic) variation: how barriers can be detected by 'Monmonier algorithm. Hum Biol 76: 173-190.

91 Bandelt H, Forster P, Röhl H. 1999. Median-joining networks for inferring intraspecifics phylogenies. Mol Biol Evol 16: 37- 48.

92 Posada D. 2008. jMODELTEST: Phylogenetic model averaging. Mol Biol Evol 25: $1253-1256$.

93 Ronquist F, Huelsenbeck J. 2003. MRBAYES 3: Bayesian phylogenetic inference under mixed models. Bioinformatics 19: 1572-1574.

94 Rambaut A, Drummond A. 2007. TRACER v.1.5. Available from http://www.beast.bio.edu.ac.uk/Tracer.

95 Rambaud A. 2006. FiggTree v.1.3.1. Available from http://tree.bio.ed.ac.uk/software/figgtree. 
96 Stöver B, Müller K. 2010. TreeGraph 2: Combining and visualizing evidence from different phylogenetic analyses. BMC Informatics 11:7.

97 Drummond A, Rambaud A. 2007. BEAST: Bayesian evolutionary analysis by sampling trees. BMC Evol Biol 7:214.

98 Rogers A, Harpending C. 1992. Population growth makes waves in the distribution of pairwise genetic differences. Mol Biol Evol 9: 552-569.

99 Watterson GA. 1975. On the number of segregating sites in genetic models without recombination. Theoretical Population Biology 7: 256-276.

100 Telles MPC, Diniz-Filho JAF. 2005. Multiple mantel tests and isolation-bydistance, taking into account long-term historical divergence. Genet Mol Res 4, 742748.

101 Fu YX, Li WH. 1993. Statistical tests of neutrality mutations. Genetics 133, 693709.

102 Jensen-Seaman MI, Kidd KK. 2001. Mitochondrial DNA variation and biogeography of eastern gorillas. Mol Ecol 10, 2241-2247.

103 Stone AC, Battistuzi FU, Kubatko LS et al. 2010. More reliable estimates of divergence times in Pan using the complete mtDNA sequences abd accounting for population structure. Phill Trans R Soc B 365, 3277-3288.

104 Goldberg T. 1998. Biogeographic predictors of genetic diversity in popultions of eastern African chimpanzees (Pan troglodytes schweinfurthii). I J Primatol 19, 237- 
$105 \mathrm{Yu} \mathrm{N}$, Jensen-Seaman M, Kidd L et al. 2003. Low nucleotide diversities in chimpanzees and bonobos. Genetics 164, 1511-1518.

106 Grant WS, Bowen BW. 1998. Shallow population histories in deep evolutionary lineages of marine fishes: insights from sardines and anchovies and lessons for conservation. Heredity 89, 415-426.

107 Rogers AR, Jorde LB. 1995. Genetic evidence on modern human origins. Hum Biol 67, 1-36.

108 Cowling A, Cox P, Maslin M et al. 2008. Simulated glacial and interglacial vegetation across Africa: implications for species phylogenies and trans-African migration of plants and animals. Global Change Biol 14, 827-840.

109 Ribeiro RA, Lemos-Filho JP, Ramos ACS, Lovato MB. 2011. Phylogeography of the endangered rosewood Dalbergia nigra (Fabaceae) insights into the evolutionary history and conservation of the Brazilian Atlantic Forest. Heredity 106, 46-57.

110 Bertorelle G, Bruford MW, Hauffe HC et al. 2009. Population genetics for animal conservation. Cambridge: Cambridge University Press.

111 Moritz C. 1994. Defining 'Evolutionary Significant Units' for conservation. Trends Ecol Evol. 9, 373-375. 


\section{8- TABLES}

Table 4.1: Chimpanzee non-invasive sampling, in Guinea-Bissau and Guinea, for this study. Number of chimpanzees sequenced $(\mathrm{N})$, geographic coordinates: latitude (Lat.), longitude (Lon.).

\begin{tabular}{|c|c|c|c|c|c|}
\hline Region & Locality & $\mathbf{N}$ & Lat. & Lon. & $\begin{array}{c}\text { Sample site } \\
\text { Number }\end{array}$ \\
\hline A Tombali-Cantanhez & Madina & 1 & $11^{\circ} 12^{\prime} 47.64^{\prime \prime} \mathrm{N}$ & $15^{\circ} 2^{\prime} 12.72^{\prime \prime} \mathrm{W}$ & 1 \\
\hline A Tombali-Cantanhez & Farim & 4 & $11^{\circ} 12^{\prime} 31.02^{\prime \prime N}$ & $15^{\circ} 4^{\prime} 25.80^{\prime \prime} \mathrm{W}$ & 2 \\
\hline A Tombali-Cantanhez & Caiquéne & 8 & $11^{\circ} 13^{\prime} 30.93^{\prime \prime N}$ & $15^{\circ} 5^{\prime} 47.73^{\prime \prime} \mathrm{W}$ & 3 \\
\hline A Tombali-Cantanhez & Canghode & 12 & $11^{\circ} 9^{\prime} 40.68^{\prime \prime} \mathrm{N}$ & $15^{\circ} 7^{\prime} 35.46^{\prime \prime} \mathrm{W}$ & 4 \\
\hline A Tombali-Cantanhez & Cafatche & 8 & $11^{\circ} 19^{\prime} 15.60^{\prime \prime N}$ & $15^{\circ} 6^{\prime} 31.98^{\prime \prime} \mathrm{W}$ & 5 \\
\hline A Tombali-Cantanhez & Catomboi & 5 & $11^{\circ} 11^{\prime} 38.28^{\prime \prime N}$ & $15^{\circ} 4^{\prime} 36.36^{\prime \prime} \mathrm{W}$ & 6 \\
\hline A Tombali-Cantanhez & Amidara & 10 & $11^{\circ} 16^{\prime} 52.38^{\prime \prime} \mathrm{N}$ & $14^{\circ} 58^{\prime} 34.02^{\prime \prime} \mathrm{W}$ & 7 \\
\hline A Tombali-Cantanhez & Cambéque & 3 & $11^{\circ} 11^{\prime} 30.18^{\prime \prime N}$ & $15^{\circ} 0^{\prime} 49.74 " \mathrm{~W}$ & 8 \\
\hline A Tombali-Cantanhez & São Francisco & 5 & $11^{\circ} 19^{\prime} 18.96^{\prime \prime N}$ & $14^{\circ} 59^{\prime} 29.22^{\prime \prime} \mathrm{W}$ & 9 \\
\hline A Tombali-Cantanhez & Ponta Nova & 5 & $11^{\circ} 18^{\prime} 41.64^{\prime \prime} \mathrm{N}$ & $14^{\circ} 58^{\prime} 51.36^{\prime \prime} \mathrm{W}$ & 10 \\
\hline A Tombali-Cantanhez & Cadique & 16 & $11^{\circ} 14^{\prime} 19.92^{\prime \prime N}$ & $15^{\circ} 6^{\prime} 51.30^{\prime \prime} \mathrm{W}$ & 11 \\
\hline A Tombali-Cantanhez & Mejo & 10 & $11^{\circ} 22^{\prime} 48.45^{\prime \prime N}$ & $14^{\circ} 54^{\prime} 51.00^{\prime \prime} \mathrm{W}$ & 12 \\
\hline A Tombali-Cantanhez & Quebo Sutuba & 3 & $11^{\circ} 9^{\prime} 34.51 " \mathrm{~N}$ & $14^{\circ} 54^{\prime} 41.12^{\prime \prime} \mathrm{W}$ & 13 \\
\hline A Tombali-Cantanhez & Lautchande & 16 & $11^{\circ} 14^{\prime} 55.14^{\prime \prime} \mathrm{N}$ & $15^{\circ} 4^{\prime} 20.40^{\prime \prime} \mathrm{W}$ & 14 \\
\hline A Tombali-Cantanhez & Cancira & 8 & $11^{\circ} 22^{\prime} 48.45^{\prime \prime N}$ & $14^{\circ} 54^{\prime} 51.00^{\prime \prime} \mathrm{W}$ & 15 \\
\hline B Quínara-Cufada & Buba Itchinque & 10 & $11^{\circ} 45^{\prime} 11.58^{\prime \prime} \mathrm{N}$ & $15^{\circ} 5^{\prime} 18.36^{\prime \prime} \mathrm{W}$ & 16 \\
\hline B Quínara-Cufada & Bani & 2 & $11^{\circ} 43^{\prime} 42.54^{\prime \prime} \mathrm{N}$ & $15^{\circ} 5^{\prime} 31.20^{\prime \prime} \mathrm{W}$ & 17 \\
\hline B Quínara-Cufada & Injassane & 2 & $11^{\circ} 44^{\prime} 29.88^{\prime \prime} \mathrm{N}$ & $14^{\circ} 59^{\prime} 4.74^{\prime \prime} \mathrm{W}$ & 18 \\
\hline B Quínara-Cufada & Nhala-Molha Pé & 3 & $11^{\circ} 37^{\prime} 45.72 " \mathrm{~N}$ & $14^{\circ} 53^{\prime} 55.08^{\prime \prime W}$ & 19 \\
\hline B Quínara-Empada & Dois Rios & 13 & $11^{\circ} 37^{\prime} 56.22^{\prime \prime N}$ & $15^{\circ} 9^{\prime} 18.66^{\prime \prime} \mathrm{W}$ & 20 \\
\hline A Tombali-Catió & Briame & 10 & $11^{\circ} 17^{\prime} 19.92^{\prime \prime N}$ & $15^{\circ} 14^{\prime} 28.86^{\prime \prime} \mathrm{W}$ & 21 \\
\hline C Gabú-Boé & Dinguirai & 5 & $11^{\circ} 45^{\prime} 18.72 " \mathrm{~N}$ & $13^{\circ} 51^{\prime} 55.38^{\prime \prime} \mathrm{W}$ & 22 \\
\hline C Gabú-Boé & Pataque & 4 & $11^{\circ} 53^{\prime} 04.9^{\prime \prime} \mathrm{N}$ & $13^{\circ} 57^{\prime} 32.5^{\prime \prime} \mathrm{W}$ & 23 \\
\hline C Gabú-Boé & Aicum & 3 & $11^{\circ} 56^{\prime} 29.22^{\prime \prime} \mathrm{N}$ & $13^{\circ} 52^{\prime} 37.38^{\prime \prime} \mathrm{W}$ & 24 \\
\hline C Gabú-Boé & Béli North & 7 & $11^{\circ} 52^{\prime} 04.7^{\prime \prime} \mathrm{N}$ & $13^{\circ} 57^{\prime} 31.9^{\prime \prime} \mathrm{W}$ & 25 \\
\hline C Gabú-Boé & Béli & 7 & $11^{\circ} 51^{\prime} 10.80^{\prime \prime} \mathrm{N}$ & $13^{\circ} 54^{\prime} 39.66^{\prime \prime} \mathrm{W}$ & 26 \\
\hline C Gabú-Boé & Vendu Leidi & 9 & $11^{\circ} 44^{\prime} 33.00^{\prime \prime} \mathrm{N}$ & $13^{\circ} 43^{\prime} 22.44^{\prime \prime W}$ & 27 \\
\hline D Nimba Mountains & Area of Seringbara & 145 & $7^{\circ} 37^{\prime} 23.04^{\prime \prime} \mathrm{N}$ & $8^{\circ} 26^{\prime} 10.62^{\prime \prime W}$ & 28 \\
\hline
\end{tabular}


Table 4.2: Distribution of 51 HVR1 haplotypes found in 334 chimpanzees in Guinea-Bissau and Nimba (i.e. Guinea) from 28 populations (Sites 1-28)a. Haplotype number (H), total number of animals sequenced (NA), total number of haplotypes (NHT).

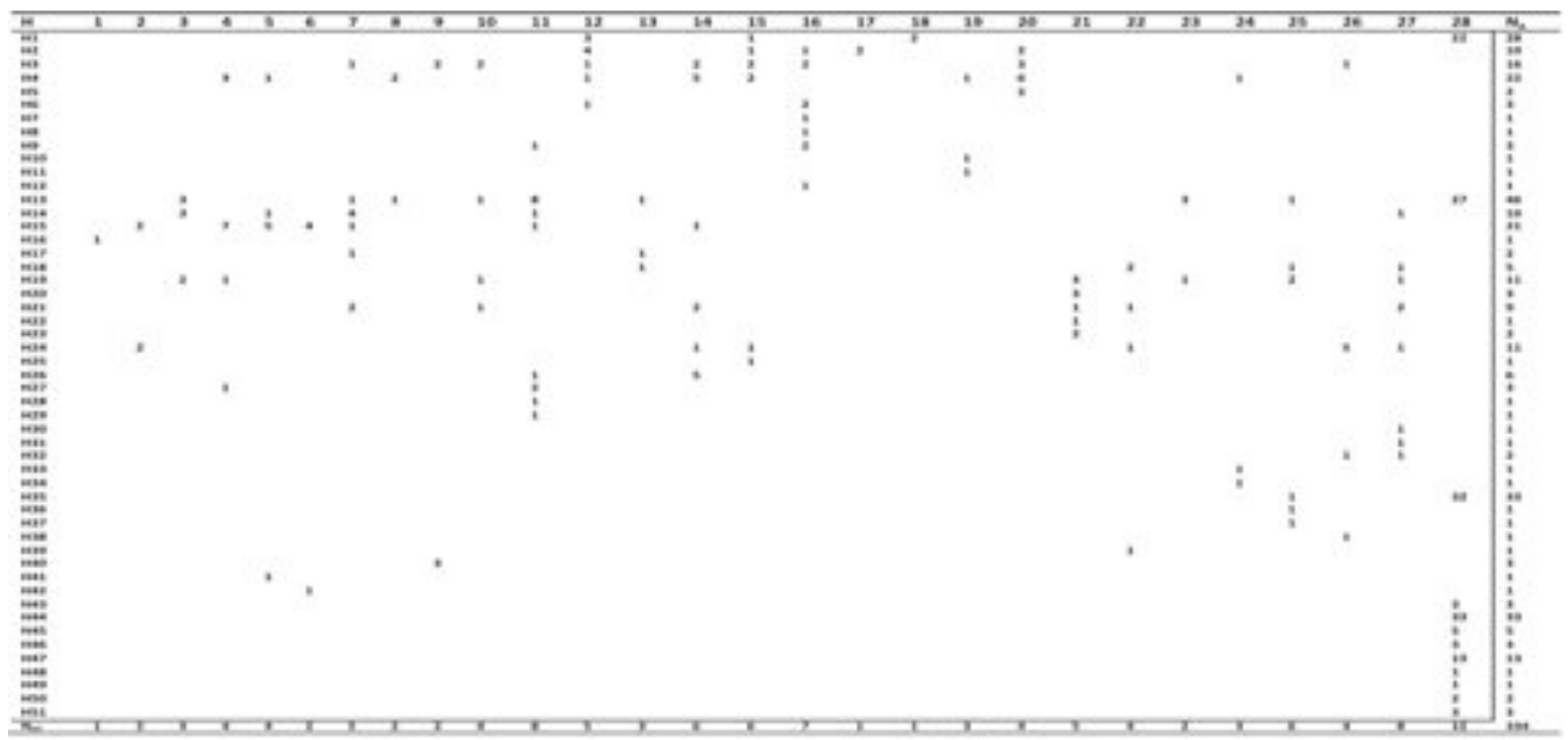

${ }^{\mathrm{a}}$ For each site number and locality see Table 4.1. 
Table 4.3: Summary statistics and demographic expansion tests observed in the study areas and in all populations, including the mean number of pairwise differences $(k)$, and the theta per site from $S\left(\theta_{w}\right)$ according to Watterson (1975).

\begin{tabular}{|c|c|c|c|c|c|}
\hline Parameters & Tombali & Quínara & Gabú & Nimba & All populations \\
\hline Sample size & 124 & 30 & 35 & 145 & 334 \\
\hline Number of populations & 16 & 6 & 5 & 1 & 28 \\
\hline Number of polymorphic sites & 45 & 39 & 42 & 44 & 55 \\
\hline Number of haplotypes & 26 & 12 & 18 & 12 & 51 \\
\hline Haplotype diversity (SD) & $0.9251( \pm 0.100)$ & $0.897( \pm 0.031)$ & $0.929( \pm 0.021)$ & $0.836( \pm 0.012)$ & $0.935( \pm 0.005)$ \\
\hline Nucleotide diversity (SD) & $0.05355( \pm 0.00129)$ & $0.04839( \pm 0.00322)$ & $0.05516( \pm 0.00311)$ & $0.04082( \pm 0.00307)$ & $0.05325( \pm 0.00116)$ \\
\hline$\theta_{\mathrm{w}}$ & 0.02958 & 0.03620 & 0.03510 & 0.02804 & 0.03058 \\
\hline k & 13.761 & 12.485 & 14.121 & 10.490 & 13.633 \\
\hline Tajima's D & 2.36727 & 1.17622 & 1.89567 & 1.36985 & 1.93048 \\
\hline Fu and Li's F' & $2.14021^{* *}$ & $1.73893 *$ & $2.23514 * *$ & $1.98212 *$ & $2.53128 * *$ \\
\hline Fu and Li's D' & 1.29726 & $1.59058 * *$ & $1.81072 * *$ & $1.84959 * *$ & $2.08803 * *$ \\
\hline $\mathrm{Fu}^{\prime} \mathrm{s} \mathrm{F}_{\mathrm{s}}$ & 3.62642 & 3.30846 & 0.64391 & 13.64252 & -93294 \\
\hline Mismatch distribution & Bimodal & Bimodal & Unimodal & Multimodal & Bimodal \\
\hline
\end{tabular}

$* \mathrm{P}<0.05 ; * \mathrm{P}<0.02$ 
Table 4.4: Pairwise $\mathrm{F}_{\mathrm{ST}}$ values between chimpanzee study areas in Guinea-Bissau and Nimba Mountains.

\begin{tabular}{lcccc}
\hline & Tombali & Quínara & Gabú & Nimba \\
\hline Tombali & - & & & \\
Quínara & 0.00334 & - & & \\
Gabú & 0.01178 & 0.00984 & - & \\
Nimba & $\mathbf{0 . 1 9 2 1 1}$ & $\mathbf{0 . 2 1 0 9 5}$ & $\mathbf{0 . 1 9 9 9 2}$ & - \\
\hline \multicolumn{6}{c}{} & & & & \\
\hline
\end{tabular}

Table 4.5: Hierarchical analysis of molecular variance (AMOVA) for chimpanzee HVR1 mtDNA sequences from Guinea-Bissau and Nimba.

\begin{tabular}{|c|c|c|c|c|c|c|}
\hline Variance component & Variance & $\begin{array}{c}\% \\
\text { Total }\end{array}$ & d.f. & SSD & $\Phi$ statistics & $\mathbf{P}$ \\
\hline Among regions $\sigma_{\mathrm{a}}^{2}$ & 0.17410 & 2.22 & 5 & 298.867 & $\begin{array}{l}\text { ФCT }= \\
0.02221\end{array}$ & 0.52590 \\
\hline $\begin{array}{l}\text { Among populations within } \\
\text { regions } \sigma_{b}^{2}\end{array}$ & 1.86041 & 23.74 & 22 & 394.057 & $\begin{array}{l}\text { D SC }= \\
0.24274\end{array}$ & $<0.0001$ \\
\hline Within populations $\sigma_{\mathrm{c}}^{2}$ & 5.80365 & 74.04 & 307 & 1781.721 & $\begin{array}{l}\text { (1) S }= \\
0.25956\end{array}$ & $<0.0001$ \\
\hline
\end{tabular}


Table 4.6: Results from SAMOVA analysis with different clusters defined a priori. Number of groups (K), group composition and fixation indexes are reported.

\begin{tabular}{|c|c|c|c|c|}
\hline K & Group composition & $\mathrm{F}_{\mathrm{CT}} *$ & $\mathbf{F}_{\mathrm{SC}^{*}}$ & $\mathbf{F}_{\mathrm{ST}^{*}}$ \\
\hline 2 & $\begin{array}{l}(2,4,5,6)(1,3,7,8,9,10,11,12,13,14,15,16,17,18,19,20, \\
21,22,23,24,25,26,27,28)\end{array}$ & 0.34253 & 0.17112 & 0.45503 \\
\hline 3 & $\begin{array}{l}(2,4,5,6)(24)(1,3,7,8,9,10,11,12,13,14,15,16,17,18,19, \\
20,21,22,23,25,26,27,28)\end{array}$ & 0.33889 & 0.16451 & 0.44765 \\
\hline 4 & $\begin{array}{l}\text { (1) }(2,4,5,6)(7,8,9,10,11,12,13,14,15,16,17,18,19,20,21, \\
22,23,25,27,28)(24,26)\end{array}$ & 0.33661 & 0.14285 & 0.43137 \\
\hline 5 & $\begin{array}{l}(7,8,9,10,11,12,13,14,15,16,17,19,20,21,22,23,25,27, \\
28)(1,2,3,4,5)(26)(24)\end{array}$ & 0.33159 & 0.14037 & 0.42542 \\
\hline 6 & $\begin{array}{l}(2,3,4,5)(24)(1)(18)(7,8,9,10,11,12,13,14,15,16,17,19, \\
20,21,22,23,25,27,28)(26)\end{array}$ & 0.32997 & 0.14092 & 0.42439 \\
\hline 7 & $\begin{array}{l}(1)(5)(7,8,9,10,11,12,13,14,15,17,19,20,21,22,23,25, \\
27,28)(16,26)(18)(2,3,4)(24)\end{array}$ & 0.31821 & 0.12368 & 0.40253 \\
\hline 8 & $\begin{array}{l}(1)(16,26)(5)(2,3,4)(24)(19)(18)(7,8,9,10,11,12,13,14, \\
15,17,20,21,22,23,25,27,28)\end{array}$ & 0.30858 & 0.12287 & 0.39353 \\
\hline 9 & $\begin{array}{l}\text { (1) }(16)(2,3,4)(7,8,9,10,11,12,13,14,15,17,19,20,21,22, \\
23,25,27,28)(5)(24)(19)(18)(26)\end{array}$ & 0.29791 & 0.12851 & 0.38814 \\
\hline 10 & $\begin{array}{l}(8)(1)(24,26)(2)(3,4)(5)(21)(7,9,10,11,12,13,14,15,17, \\
19,20,22,23,25,27,28)(18)(19)\end{array}$ & 0.28449 & 0.11777 & 0.36876 \\
\hline
\end{tabular}

${ }^{a}$ See Table 4.1 for locality and sample site number. 


\section{9- FIGURES}

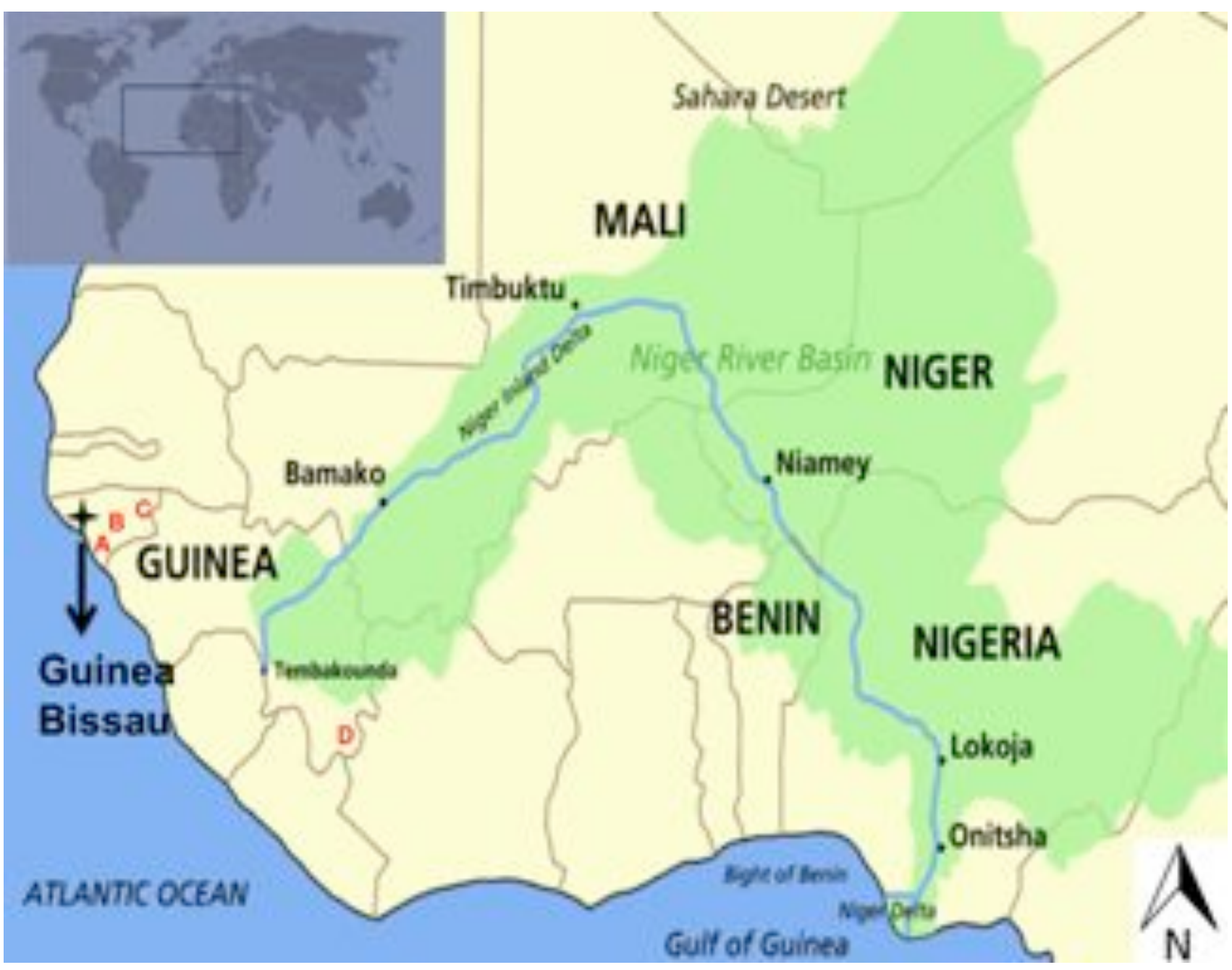

Figure 4.1: Study areas: A (Guinea-Bissau, Tombali region including the peninsulas of Cantanhez and Catió); B (Guinea-Bissau, Quínara region including the Cufada Lagoons Natural Park and the Empada peninsula); C (Guinea-Bissau, Gabú region across the Boé sector) and D (Guinea, Seringbara and Nimba Mountains). 

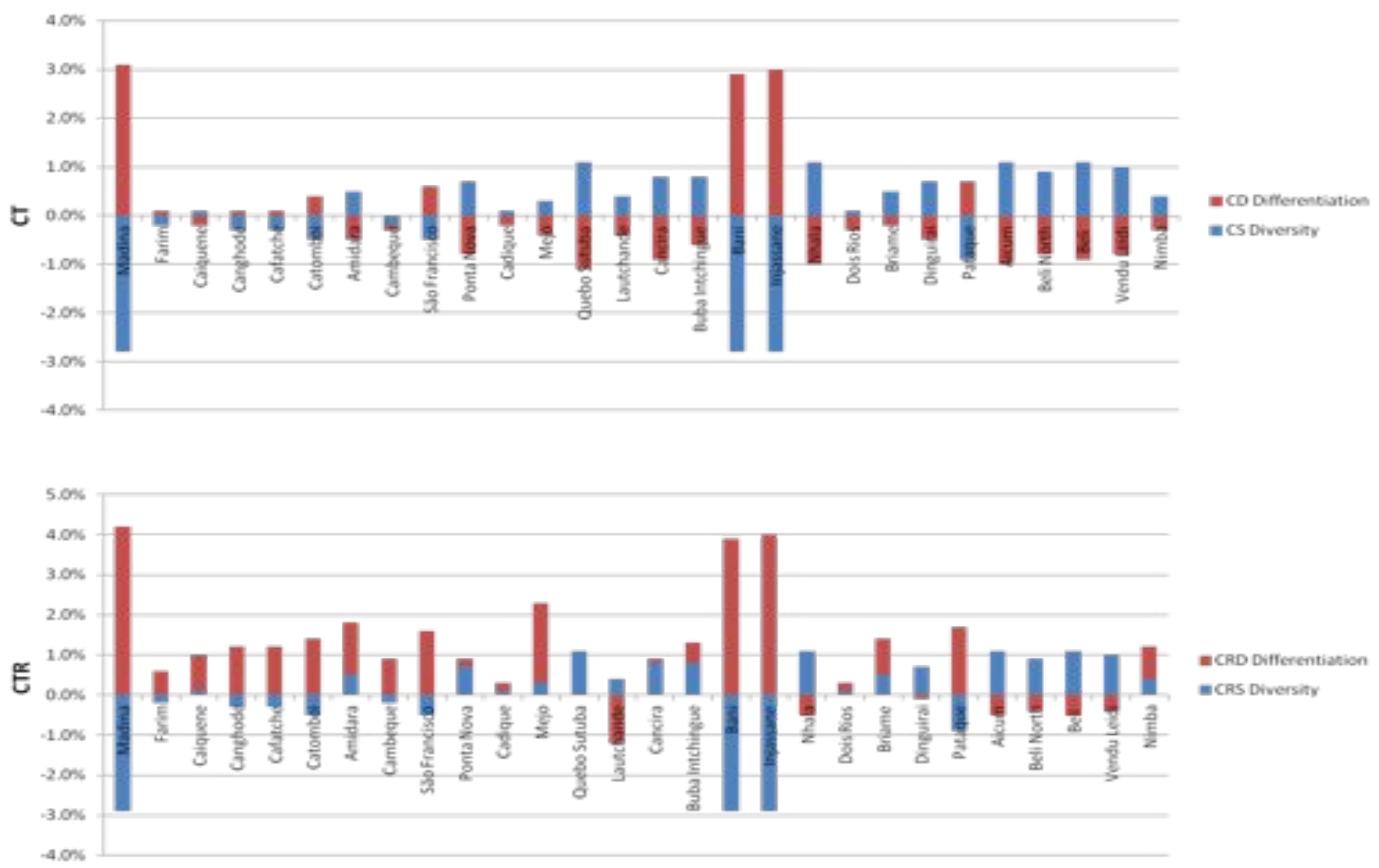

Figure 4.2: The contribution to the total haplotype diversity (CT) and haplotypic richness (CTR) of each population of chimpanzees using the HVR1 haplotypes. The blue and red bars represent the contribution of diversity (CS and CRS) and differentiation (CD and CRD), respectively. 


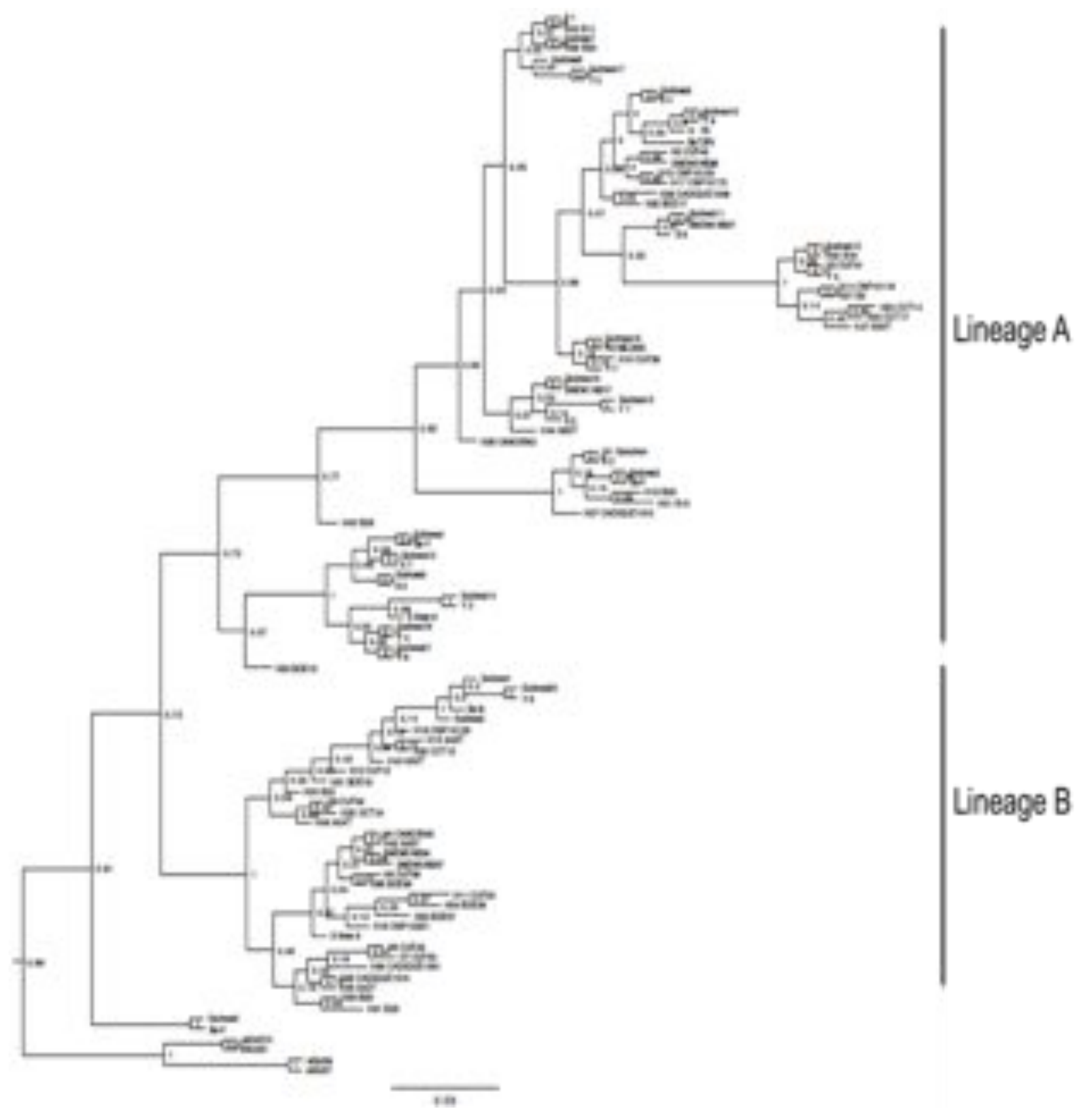

Figure 4.3: Phylogenetic relationships among haplotypes of Guinea and Guinea-Bissau chimpanzees according to Bayesian inference. The numbers, in each node, refer to the posterior probabilities. 


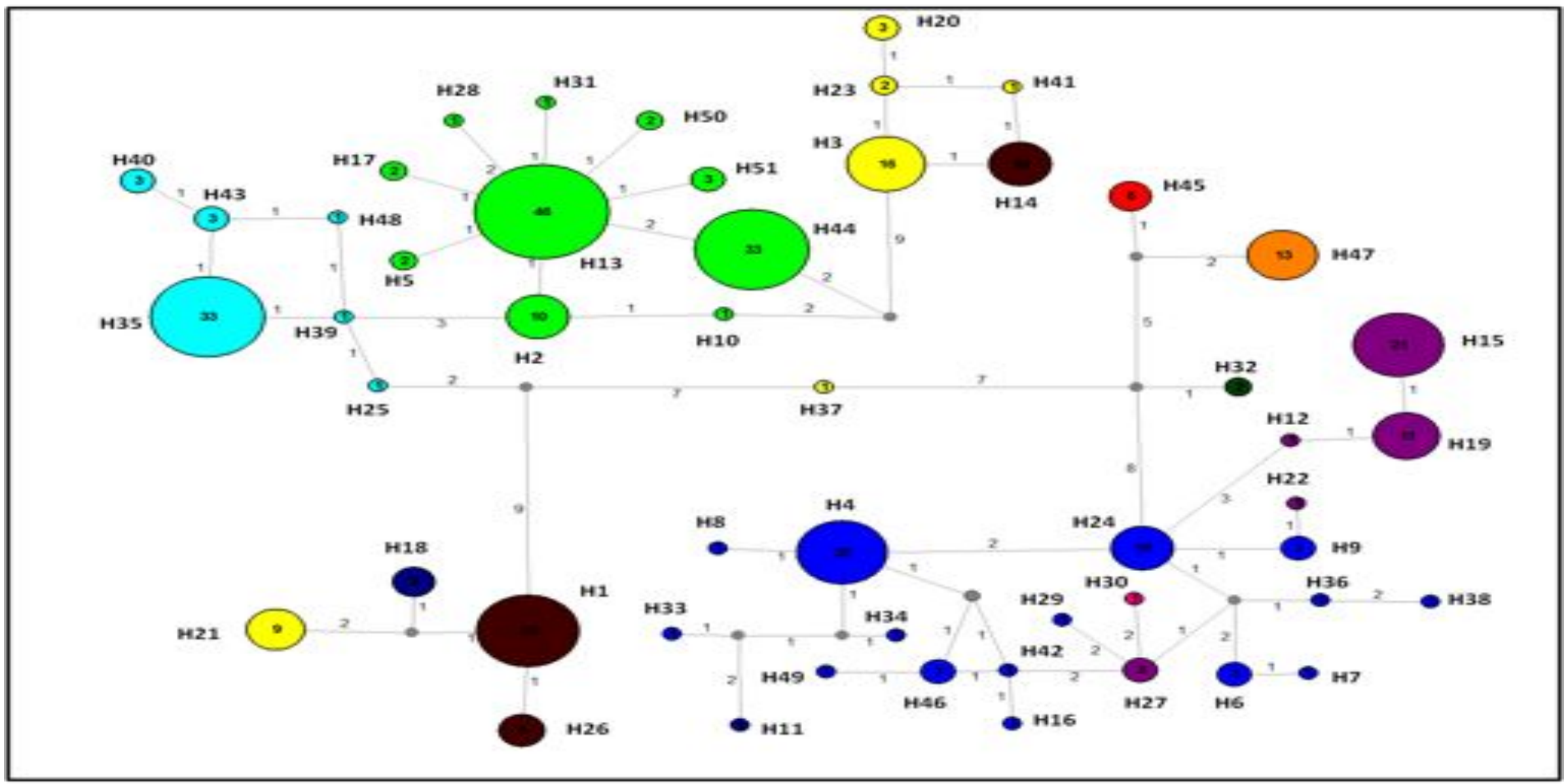

Figure 4.4: Haplotype network recovered by median joining analysis. Haplotypes are represented by circles with size proportional to their frequencies and coloured according to subclades recovered in the phylogenetic analyses. Numbers outside the circles represent the mutational steps, and inside the circles the number of individuals for each haplotype. Grey circles represent missing haplotypes, extinct or not sampled. 


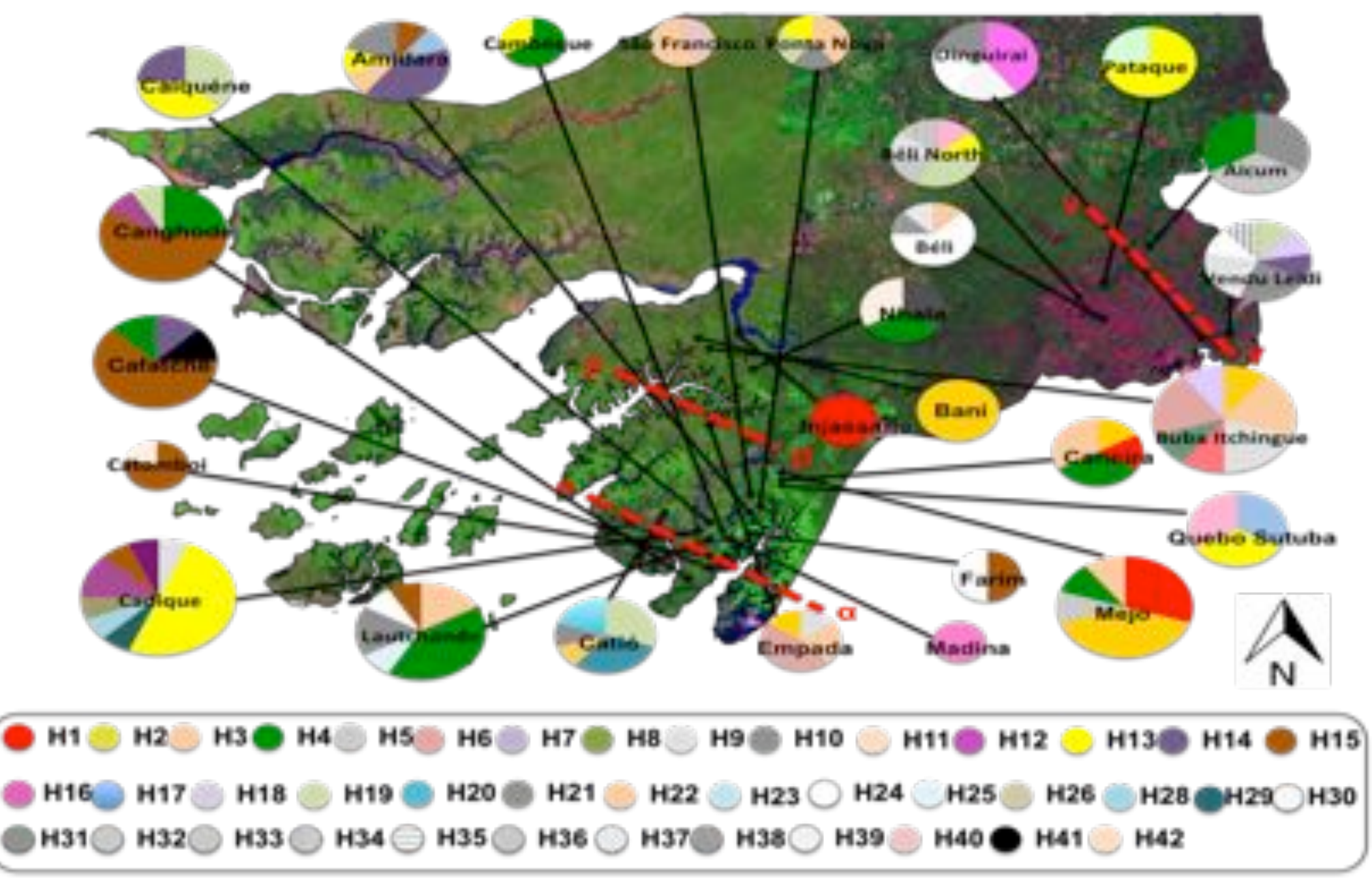

Figure 4.5: Map showing the geographic distribution of the HVR1 haplotypes in the P. troglodytes verus populations in Guinea-Bissau. The haplotypes are identified in the legend. The broken lines in red indicate the genetic barriers $(\alpha, \beta, \gamma)$ as defined by the Monmonier algorithm. 


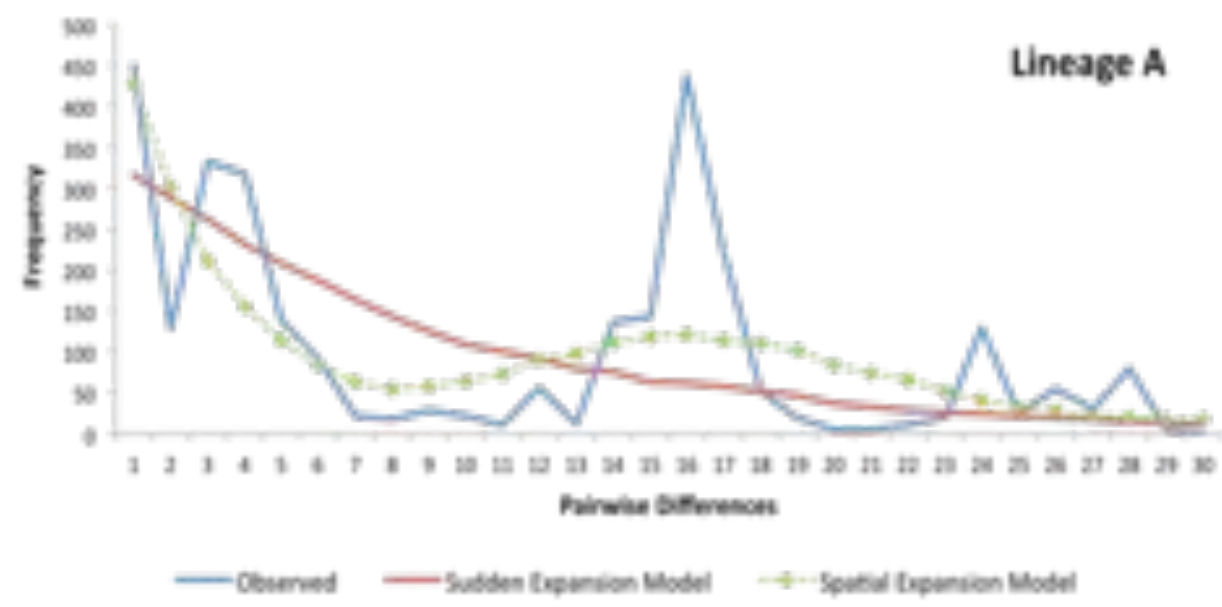

$k=9.429$

$0,0.8387$

$t=0.000$

0.8 .397

$\$ S 0=0.037$

Pn 0.459

Rindex: 0.044

Pn 0.237

M. 0.999

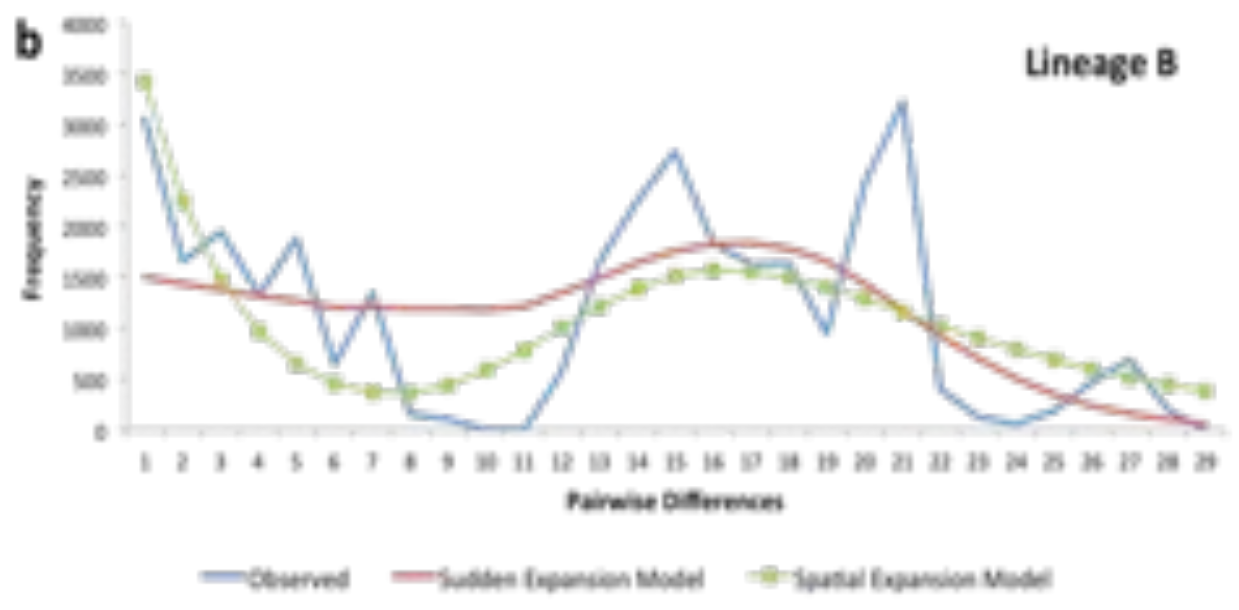

$k=11.605$

$0_{0}=0.000$

$y=17,635$

$0,121.046$

$S S D=0.0155$

$P=0.192$

$R$ index $=0.018$

$P=0.055$

$M=2.337$

Figure 4.6: Mismatch distributions for the Guinea-Bissau and Nimba chimpanzees and respective associated parameters. Mismatch distribution according with the sudden expansion model and with the spatial expansion model for Lineage $A(A)$ and Lineage $B$ (B), respectively. Mean pairwise differences between pairs of haplotypes (k), mismatch derived parameters $\left(\Theta_{0}, \tau, \Theta_{1}\right)$. Sum of squared differences (SSD) and Harpending Raggedness Index with respective P values. Number of female migrants (M). 


\section{CHAPTER 5}

"Parasites are in general, actors that play in the shadows..."

- Claude Combes, Parasitologist

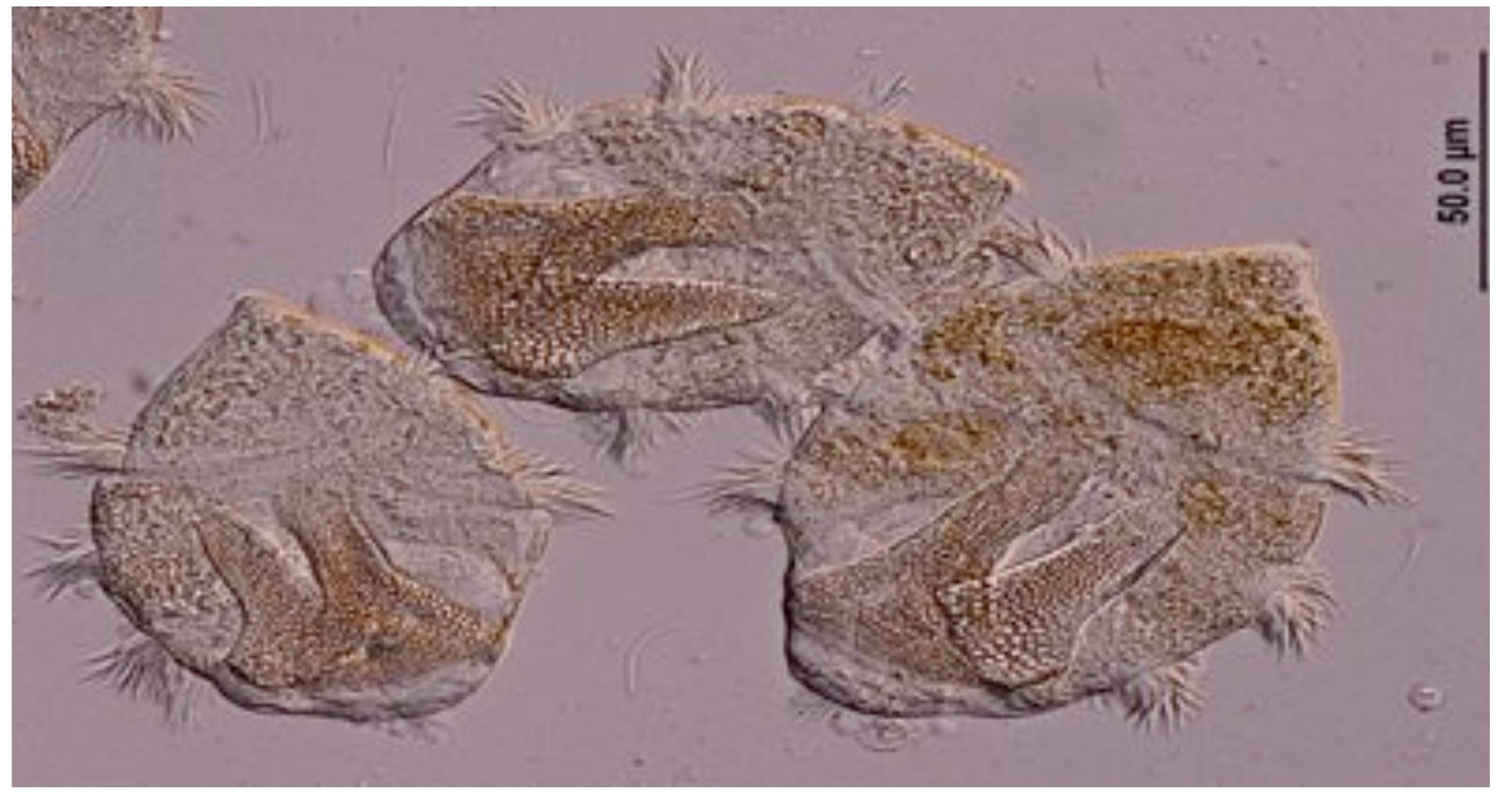




\section{CHAPTER 5}

\section{GASTROINTESTINAL SYMBIONTS OF CHIMPANZEES IN CANTANHEZ NATIONAL PARK, GUINEA-BISSAU WITH RESPECT TO HABITAT FRAGMENTATION}

Rui M. Sá ${ }^{1,2,3} *$, Jana Petrášová ${ }^{4}$, Kateřina Pomajbíková ${ }^{4}$, Ilona Profousová ${ }^{4}$, Klára J. Petrželková ${ }^{5,6}$, Cláudia Sousa $^{2,3}$, Joanne Cable ${ }^{1}$, Michael W. Bruford ${ }^{1}$ and David Modrý ${ }^{4,7}$

${ }^{1}$ School of Biosciences, Cardiff University, Cardiff, United Kingdom

${ }^{2}$ Deparatmento de Antropologia, Faculdade de Ciências Sociais e Humanas, Universidade Nova de Lisboa, Lisbon, Portugal

${ }^{3}$ CRIA-Centre for Research in Anthropology, Lisbon, Portugal

${ }^{4}$ Department of Pathology and Parasitology, University of Veterinary and Pharmaceutical Sciences Brno, Czech Republic

${ }^{5}$ Department of Mammal Ecology, Institute of Vertebrate Biology, Academy of Sciences of Czech Republic, Brno, Czech Republic

${ }^{6}$ Liberec Zoo, Liberec, Czech Republic

${ }^{7}$ Biology Center, Institute of Parasitology, Academy of Sciences of the Czech Republic, České Budějovice, Czech Republic

*Author for correspondence:

Rui M. Sá

Cardiff School of Biosciences, Biomedical Sciences Building, Museum Avenue, Cardiff, CF10 3AX

Wales, UK

Phone: +44 (0) 29208 75776; Mobile: +351 917092241

Fax: +44 (0) 2920874116

Email: ruimoutinhosa@gmail.com 


\section{1- ABSTRACT}

One of the major factors threatening chimpanzees (Pan troglodytes verus) in GuineaBissau is habitat fragmentation. Such fragmentation may cause changes in symbiont dynamics resulting in increased susceptibility to infection, changes in host specificity and virulence. We monitored gastrointestinal symbiotic fauna of three chimpanzee subpopulations living within in Cantanhez National Park (CNP) in Guinea Bissau in the areas with different levels of anthropogenic fragmentation. Using standard coproscopical methods (merthiolate-iodine formalin concentration and Sheather's flotation) we examined 102 fecal samples and identified at least 13 different symbiotic genera (Troglodytella abrassarti, Troglocorys cava, Blastocystis spp., Entamoeba spp., lodamoeba butschlii, Giardia intestinalis, Chilomastix mesnili, Bertiella sp., Probstmayria gombensis, unidentified strongylids, Strongyloides stercoralis, Strongyloides fuelleborni and Trichuris sp.). The symbiotic fauna of the CNP chimpanzees is comparable to that reported for other wild chimpanzee populations, although CNP chimpanzees have a higher prevalence of Trichuris sp. Symbiont richness was higher in chimpanzee subpopulations living in fragmented forests compared to the community inhabiting continuous forest area. We reported significantly higher prevalence of $G$. intestinalis in chimpanzees from fragmented areas, which could be attributed to increased contact with humans and livestock.

Key Words: Cantanhez National Park; Fragmentation; Pan troglodytes verus; Parasites; Symbionts; Trichuris sp. 


\section{2- INTRODUCTION}

The gastrointestinal tract of primates is colonized by broad range of organisms with a variety of relationships with their host. Although most of them are traditionally referred to as parasites, term "symbionts" is more appropriate to describe the community in its complexity [Combes, 2001; Douglas, 2010]. Then, symbionts can be further defined as (i) mutualists (in reciprocally positive interactions) (ii) commensals (neither benefit nor harm their facilitators) and (iii) parasites (occur in a win-lose relation when one species benefits while the other species is harmed) [Bronstein, 2009].

Some parasites can constitute a risk for nonhuman primate conservation by affecting health, behaviour and survival of their hosts, especially in cases when they are already threatened by other factors [Daszak et al., 2000; McCallum \& Dobson, 2002; Goldberg et al., 2005]. Most primate populations nowadays live in more or less disturbed landscapes [e.g. Cowlishaw \& Dunbar, 2000; Marsh, 2003; Gillespie et al., 2005a; Hopkins \& Nunn, 2007]. Anthropogenic disruptions such as habitat loss and fragmentation, overexploitation and climate change are regularly listed as extinction drivers at global and local scales [Coop \& Holmes, 1996; Caldecott \& Miles, 2005; Smith et al., 2009]. These factors may modify symbiont host ranges, vector dynamics, parasite virulence and transmission rates and consequently may lead to changes in infection risks and clinical outcomes of the infections, finally leading to host population decline [Gillespie et al., 2005a; Pedersen et al., 2007]. 
Habitat loss reduces not only species movement and dispersal, but also resource availability and as a consequence animals suffer the effects of overcrowding [Gillespie \& Chapman, 2008]. As the contact and conflict among individuals increases, their stress levels rise and immunological competence starts to weaken and therefore their infection resistance can decrease, eventually promoting the spread of diseases and symbiont transmission [Scott, 1988; Eley et al., 1989; Coe, 1993; Ashford et al., 1996, Sleeman et al., 2000; Nunn \& Altizer; 2006]. Several studies on primate symbiont ecology reported higher prevalence and richness of gastrointestinal symbionts in non-human primates living in forest fragments assuming positive correlation between pathogen prevalence and richness and host density [Gillespie \& Chapman, 2006; Gillespie \& Chapman, 2008; Mbora et al., 2009; Kowalewski et al., 2011] while other studies recorded the opposite or no effect [Cristóbal-Azkarate et al., 2010; Lane et al., 2011].

Endangered species, such as chimpanzees, have usually limited geographic ranges and irregular distributions within their ranges [Fahrig, 2003; Chapman et al., 2005]. Many studies have reported the gastrointestinal symbionts of several populations of the common chimpanzee (Pan troglodytes) in different types of habitats [e.g. Huffman et al., 1997; Ashford et al., 2000, Muehlenbein, 2005; Howells et al., 2010; Petrášová et al., 2010]. However, there is a paucity of information about the symbionts of chimpanzees in Guinea-Bissau, West Africa, which represents the most western limit of the species distribution where its survival is considered very precarious [Sousa et al., 2005; Torres et al. 2010]. Major threats to their survival include the pet trade, hunting for 
animistic/traditional medicine practices and importantly also habitat fragmentation caused by logging and agriculture [Casanova \& Sousa, 2007; Sá et al., 2009].

We present the results of the parasitological survey of chimpanzee population inhabiting Cantanhez National Park (CNP), in the south of Guinea-Bissau. We compared three chimpanzee subpopulations living within the Park in the areas with different levels of anthropogenic fragmentation.

\section{3- METHODS}

\subsection{1- Study Site}

Cantanhez National Park (CNP) (Fig. 5.1) is located in Tombali Region, in southern GuineaBissau and comprises a total area of $1068 \mathrm{~km}^{2}$. The Cacine and Cumbidjã Rivers act as natural boundaries and form the Cubucaré Peninsula. The park was formally established in 2008 but since the mid-1980's was considered a forest hunting reserve [IBAP, 2008]. The climate is tropical humid with two annual seasons: the rainy season from June to October and the dry season from November to May with little or no rainfall. Mean annual rainfall is $2000 \mathrm{~mm}(\mathrm{SD} \pm 500)$ and the temperature varies between 28ㅇ and 31ㅇ C [Simão, 1997].

CNP is approximately $70 \mathrm{~m}$ above sea level and consists of a patchy environment of small rivers; mangroves, arborous and grassland savannahs; agriculture fields, human settlements and sub-humid forests characterize the landscape. Forest fragments consist of a mixture of evergreen and semi-deciduous vegetation cover [Catarino, 2004]. Native fauna include seven species of non-human primates: the lesser bush baby (Galago senegalensis), the western red colobus (Procolobus badius temmincki), the king colobus (Colobus polykomus), the vervet monkey (Chlorocebus aethiops sabaeus), the Campbell's monkey (Cercopithecus campbelli), the Guinean baboon (Papio papio) and the western 
chimpanzee (Pan troglodytes verus) [Gippoliti \& Dell'Omo, 2003; Casanova \& Sousa, 2007].

The World Wide Fund for Nature (WWF) has recognized the Cantanhez forests as one of the 200 most important ecoregions in the world, and ones of the last vestigial segments of humid forest in West Africa. However, through satellite images Oom et al. [2009] identified a trend of forest loss with a conversion from closed humid forests to savannawoodlands. This loss has been caused by 'slash and burn' agriculture. The amount of land for crops is continually expanding due to increasing numbers of people [Hockings \& Sousa, 2011]. Consequently, the encounters of humans and domestic animals with wildlife occur with increased frequency [Hockings \& Sousa, 2011].

Permission to carry out research in the CNP was conceded by the Instituto da Biodiversidade e das Áreas Protegidas as well as by the consent of the traditional leaders.

\subsection{2- Study Population}

Formerly, chimpanzees were erroneously considered extinct in Guinea-Bissau [Lee et al., 1988]. However a survey in 1994 reconfirmed chimpanzee presence in the study area and a preliminary evaluation of their conservation status was carried out [Gippoliti \& Dell'Omo, 1995; Gippoliti \& Dell'Omo, 1996].According to the most recent national estimate there are 600-1000 chimpanzees in Guinea-Bissau with approximately 400 individuals occurring in CNP [Gippoliti \& Dell'Omo, 2003; Sousa et al., 2005]. More recently, Torres et al. [2011] have demonstrated that suitable forest habitat for chimpanzees in the park declined by approximately 11\% (270 km²) from 1986 to 2003, resulted in a decrease of chimpanzee population. However, the exact number of chimpanzee communities remains unclear.

Within CNP, chimpanzees live in three principal areas (i.e. North, Central and South) (Table 1, Fig. 2). Recent phylogeographic studies have shown that there are three chimpanzee genetic subpopulations in CNP corresponding to the areas. The three subpopulations are 
significantly genetically different from each other. It was shown that $39.18 \%$ of the genetic variation occurs between subpopulations and the largest fraction of the variation (56.24\%) is partitioned among individuals within populations [R. Sá, unpubl. data].

The Northern area has more available forested habitat (3.55\%) than in the Central (1.24\%) or South (1.84\%) and can be perceived as a more continuous forest block. The central area is under a high anthropogenic pressure where chimpanzees are encroached at a very high density of 3 individuals $/ \mathrm{km}^{2}$ [Hockings \& Sousa, 2011]. The southern and central areas possess the higher number of forest fragments in comparison to the northern one (Table 5.1) and with continuing habitat degradation (Fig. 5.2).

\subsection{3- Sampling Strategy}

The current field study was conducted from September to November 2008, during the rainy season (mean annual rainfall ca. $2000 \mathrm{~mm}$ ). Fresh faecal samples were collected opportunistically during the day, near the nests or on the trails in all three areas (North, Central and South). In total, 14 fragmented forest patches were surveyed from north, central and south CNP areas (Table 5.1). The samples could not be attributed to specific individuals and to avoid sampling the same individual only one sample was collected from the same nest. On the following days we moved to a different forest fragment where the connectivity with the previous nest site was limited or absent. However, we cannot exclude the possibility that the same individual was sampled more than once. Only fresh samples were collected (from their inner part to avoid soil contamination), any potentially rain- "washed" or old (>12h) samples were discarded. Approximately $5 \mathrm{~g}$ of each sample was immediately fixed in a $13 \mathrm{ml}$ single vial tube of PROTOfix ${ }^{\mathrm{TM}}$ CLR (Alpha-tech-Systems, Inc., Vancouver, WA) according with the manufacturer's instructions [Jensen et al., 2000] and stored at room temperature until they were shipped under international permits to the Department of Pathology and Parasitology of the Veterinary and Pharmaceutical University, Brno, Czech Republic. 
All samples were collected non-invasively in conformity with the ASP-Principles for the Ethical Treatment of non-human Primates.

\subsection{4- Parasitological Screening}

About half of each sample was stored in the original vial for possible further repetitions. The remainder was homogenized with water and filtered thought a standard sieve $(\sim 100 \mu \mathrm{m})$ for macroscopic examination. This filtered material was processed using combined a modified Sheather's solution flotation (s.g. 1.33) [Sheater, 1923] and a Merthiolate-lodine-Formaldehyde Concentration (MIFC) sedimentation technique [Blagg et al., 1955]. A drop of Lugol's iodine was added to stain the preparations. Several drops were examined for each technique (Sheather's flotation and MIFC) from each sample in a compound microscope at 200x, 400x and 1000x magnification. Symbionts were identified on the basis of the morphology (i.e. size, wall structure, internal structures and shape), of their stages (e.g. eggs, cysts, trophozoites or larvae) using identification keys [Jessee et al., 1970; Ash \& Orihel, 2007; Hasegawa et al., 2009]. Measurements were made to the nearest $0.1 \mu \mathrm{m}$, using a calibrated ocular micrometer. Symbionts were microphotographed using Nomarski interference contrast on an Olympus AX70.

\subsection{5- Data analyses}

The terminology were defined according to Stuart and Strier [1995], Bush et al., [1997] and Gillespie [2006]; therefore prevalence refers to the percentage of samples with a given symbiont taxa and sample richness is the number of unique symbiont taxa recovered from a sample. Chi square or Fisher's exact tests with subsequent Bonferroni correction were performed in order to compare sample prevalence in chimpanzees inhabiting North, Central and South CNP areas for each symbiont taxa separately. Differences in symbiont richness among areas were investigated using Kruskal-Wallis ANOVA, with LSD post-hoc tests used for pairwise comparisons. The value of $\rho<0.05$ was 
set as significant. SPSS, version 17 [SPSS Inc., Chicago, IL] and SISA [http://www.quantitativeskills.com/sisa/] were used for all statistical analyses.

\section{4- RESULTS}

A total of 13 symbiont taxa were identified including three symbionts specific for chimpanzees [entodinomorphid ciliates Troglodytella abrassarti and Troglocorys cava and nematode Probstmayria gombensis]. Further we found ten symbionts with wider range of hosts and with more or less prominent zoonotic potential [Blastocystis spp., amoebas Entamoeba spp. and lodamoeba buestcshlii, flagellates Giardia intestinalis and Chilomastix mesnili; anoplocephalid tapeworm Bertiella sp., and several nematodes: unidentified strongylids, Strongyloides stercoralis, Strongyloides fuelleborni and Trichuris sp.] (Table 5.2). No flukes were observed. Neither tapeworm proglottids nor nematodes were macroscopically observed in fecal samples.

The median sample richness was 3 (range $=0-7$, mean $\pm S D=2.6 \pm 1.6$ ). Differences in prevalence among subpopulations were only detected for $G$. intestinalis (North, $n=0$; Central, $\mathrm{n}=4$; South, $\mathrm{n}=2$; Fisher exact test, $P=0.012$ ), Trichuris sp. (North, $\mathrm{n}=13$, Central, $\mathrm{n}=0$, South, $\mathrm{n}=2$; Fisher exact test, $P=0.001$ ) and Bertiella $\mathrm{sp}$. (North, $\mathrm{n}=0$, Central, $\mathrm{n}=1$, South, $n=4$; Fisher exact test, $P=0.025$ ) (Table 5.2). There was a significant difference in sample richness among the three subpopulations (Kruskal-Wallis ANOVA, $H=6.636$, $P=0.036$ ) with LSD post-hoc tests revealing that the north community has significantly lower sample richness than the central community $(P=0.013)$ but the differences were not 
significant between north and south $(P=0.131)$ and central and south $(P=0.301)$ communities.

\section{5- DISCUSSION}

To the best of our knowledge, this is the first study assessing the gastrointestinal symbionts of chimpanzees in Guinea-Bissau. Based on our results we can conclude that the symbiont fauna of chimpanzees inhabiting CNP is similar to that of other wild chimpanzee populations living in primary and secondary forest habitats, e.g.: Lopé, Gabon [Landsoud-Soukate et al., 1995]; Dzanga-Ndoki, Central African Republic [Lilly et al., 2002]; Mahale, Uganda [Huffman et al., 1997; Huffman et al., 2009]; Gombe, Tanzania [File et al., 1976; Murray et al., 2000; Bakuza \& Nkwengulila, 2009; Gillespie et al., 2010]; Kibale, Tanzania [Ashford et al., 2000; Krief et al., 2003]. We detected significant changes in symbiont fauna due to anthropogenic fragmentation. We demonstrate that fragmentation can have different impact on individual symbiont taxa and that both host ecology and symbiont characteristics must be taken in consideration to interpret the results.

Entodiniomorphid ciliate $T$. abrassarti was the most common symbiont species reaching the prevalence of $62 \%$; the other detected ciliate was $T$. cava found in $24.5 \%$ of samples. Both ciliates are currently considered chimpanzee specific commensals [Pomajbíková et al., 2010; Tokiwa et al., 2010; Profousová et al., 2011; Pomajbíková et al., 2012]. It was shown that at least $T$. abrassarti can actively participate in ape hindgut 
digestion, however its contribution to overall hydrolytic activities is low [Profousová et al., 2011]. Although reported prevalence of both ciliates greatly varies among the studied populations, they are probably present in all individuals in wild chimpanzee populations [Pomajbíková et al., 2010; Pomajbíková et al., 2012].

Group of detected commensals further includes amoebas Entamoeba spp. and I. buetschlii and flagellate $C$. mesnili. All three species were determined based on the cyst morphology, which is consistent with those described in humans [Ash \& Orihel, 2007]; however, molecular-phylogenetic analyses are necessary for precise identification and clarification of possible transmissions between humans and primates [Levecke, 2010]. Observed prevalence of both amoebas is similar to that reported e.g. in Gombe chimpanzees in Tanzania [Murray et al., 2000], but published data tend to vary significantly across study sites [Krief et al., 2005; Muehlebein, 2005]. Prevalence of $C$. mesnili (7\%) is comparable to that reported by Landsoud-Soukate et al. [1995] in chimpanzee population inhabiting Lope, Gabon.

The Giardia cysts were recovered only from samples originating from central and southern chimpanzee subpopulations inhabiting more fragmented habitats. This finding is in accordance with previous studies relating Giardia infections in wild primates to increased contact with humans and livestock [Wolfe et al., 1998; Nizeyi et al., 1999; Graczyk et al., 2002; Salzer et al., 2007; Johnston et al., 2010; Kowalewski et al., 2010; Lane et al., 2011]. G. intestinalis is typical of cross-species transmissions, including zoonotic transmissions and determination of particular assemblages by molecular 
techniques clarified this aspect of $G$. intestinalis ecology [Thompson, 2004; Hunter \& Thompson, 2005; Sprong et al., 2009; Johnston et al., 2010]. Undoubtedly, chimpanzees living in fragmented CNP areas are exposed to high contact with local inhabitants and livestock. Humans create trails and enter frequently in the forest fragments as well as other livestock like pigs, goats and cows. Chimpanzees also leave the fragments to crop raid in villages. Thus, humans and livestock share water sources with chimpanzees, shedding the Giardia cysts into water and increasing the chance for chimpanzees to get infected. Future studies should focus on determination of Giardia assemblages using molecular tools in order to detect the exact reservoir of infection for chimpanzees, and to determine if cross-species transmission is occurring.

Cysts of Blastocystis spp. were detected in $49 \%$ of samples; such high prevalence was recorded only in introduced chimpanzees of Rubondo Island, Tanzania [Petrášová et al., 2010]. However, cysts of Blastocystis can be easily overlooked due to their small size and we assume that this protist is rather common in also in populations of wild great apes as reported in captive ones [Stensvold et al., 2009].

Both the strongylids and Strongyloides infections are common in free-ranging great apes with strongylids being reported as the most prevalent parasites in several populations of wild chimpanzees reaching prevalence between $70-100 \%$ [e.g. Gombe, Tanzania: File et al., 1976; Mahale, Tanzania: Huffman et al., 1997; Kibale, Uganda: Muehlenbein, 2005; Gillespie et al., 2010]. Therefore the prevalence of strongylid nematodes in CNP chimpanzees (38\%) is lower in comparison with most studied sites, 
with exception of Lope Reserve in Gabon, where the prevalence reached only $21 \%$ [Landsoud-Soukate et al., 1995]. Absence or very low prevalence of strongylid nematodes was recorded also in savanna chimpanzees [McGrew et al., 1989; Howells et al., 2010] and introduced chimpanzees of Rubondo Island, Tanzania [Petrželková et al., 2010; Petrašová et al., 2010]. No impact of fragmentation/increased human contact on these nematodes was recorded in CNP chimpanzees. Without developing larvae using coprocultures, strongylid eggs cannot be reliably determined even to genera [Greiner \& McIntosh, 2009]. Both Strongyloides fuelleborni and S. stercoralis were found in CNP chimpanzees. Despite S. fuelleborni is known to predominantly infect chimpanzees whilst S. stercoralis is common in humans, mixed infections have been reported in both humans and chimpanzees [Hasegawa, 2010; Petrželková et al., 2010]. Future studies are warranted to clarify zoonotic potential of strongylids and Strongyloides occurring in chimpanzees and humans within CNP.

Probstmayria gombensis, enigmatic non-pathogenic nematode originally described from chimpanzee [File, 1976] was easily recognized by its characteristic L3 larvae. It has been found in several, but not all chimpanzee populations in similar or lower prevalence in comparison to CNP chimpanzees [e.g. Gombe NP, Tanzania: McGrew et al.,1989; Kibale NP, Uganda: Ashford et al., 2000; Muehlenbein, 2005].

Bertiella sp. (usually tentatively referred to as $B$. studeri) is so far the only tapeworm reported to occur in free-ranging chimpanzees, usually at low prevalence comparable to our study [Krief et al., 2005; Howells et al., 2010] or even lower [Kawabata 
\& Nishida, 1991; Ashford et al., 2000]. Transmission occurs when an intermediate host, usually an oribatid mite, containing the cystercercoid is accidently ingested by the primate. Surprisingly, prevalence of Bertiella sp. was higher in fragmented habitats. We speculate that fragmentation might have an effect on the intermediate hosts, oribatid mites; however, very little is known about life cycle and factors which affect this cestode and further research is warranted.

Probably the most striking difference in comparison to other free-ranging chimpanzee populations is a relatively high prevalence of Trichuris spp. (15\%) in CNP chimpanzees with most cases recorded in the northern community. Whipworms are regularly found in many primate species, including humans [McGrew et al., 1989; Ashford et al., 2000; Murray et al., 2000; Mbora \& Munene, 2006]. Most of the studies reported absence or low prevalence of Trichuris (less than 10\%) in wild chimpanzees [e.g. Krief et al., 2005; Gillespie et al., 2010] with exception of the chimpanzee community in Mahale, Tanzania where prevalence of Trichuris sp. reached up to $46 \%$ in certain periods [Huffman et al., 2009]. Whipworms found in non-human primates are usually considered as Trichuris trichiura [Ooi et al., 1993; Reichard et al., 2008; Liu et al., 2012] and several authors implied the zoonotic cross-transmission between non-human primates and humans [e.g. Munene et al., 1998; Chapman et al., 2007]. However, direct evidence for transmission between wild great apes and humans is lacking and unusually broad host range of $T$. trichiura rather implies underestimated diversity of Trichuris in non-human primates. Also morphometric variation observed in eggs suggests that species found in chimpanzees is 
probably divergent from human T. trichura; obviously, only molecular assessments can shed light on this uncertainty [Petrášová et al., 2010]. Significantly higher prevalence of Trichuris sp. in northern community in comparison to very low prevalence/total absence of Trichuris sp. in the central communities living in more fragmented habitats seems puzzling. In contrary to previous studies, habitat fragmentation does not result in higher prevalence of this nematode in CNP chimpanzees as it was shown e.g. in red colobus (Procolobus rufomitratus ssp. tephrosceles) and black-and-white colobus (Colobus guereza) in Kibale, Uganda [Gillespie \& Chapman, 2006; Gillespie \& Chapman, 2008]. High prevalence of Trichuris sp. is supposed to be associated with increased host density in the fragments [Gillespie \& Chapman, 2006; Gillespie \& Chapman, 2008]. To our knowledge there are no data on the effect of fragmentation on chimpanzee behavior and ecology. Based on personal observations [R. Sá, per. obs.] it seems that chimpanzees in fragmented areas tend to increase their travel distances by moving among the fragments probably in order to search for food. Thus the host density and range use intensity decreases leading to lower prevalence of Trichuris in fragmented biotopes in comparison to northern area with continuous forest. Additionally, we assume that crop raiding performed only by chimpanzees from fragmented habitats [R. Sá, pers. obs.] could improve their nutritional situation facilitating more effective immune response to parasites [Holmes, 1995] as suggested by Chapman et al. [2006], who reported less severe parasite infections in crop raiding black and white colobus in comparison to red colobus which did not crop raid. Similar situation was observed also in baboons [Eley et al.,1989; Hahn et al., 2003] 
The symbiont richness observed in this study shows a classic host-symbiont overdispersed distribution when most samples harbor few symbiont species while few others contain the largest proportion of multi-symbiont infections [Anderson and May, 1978; Shaw and Dobson, 1995; Morand \& Poulin, 1998; Shaw et al. 1998]. The symbiont richness pattern is an important variable to understand the population dynamics of the hostsymbiont relationship; it is assumed that the over dispersal pattern acts to increase density-dependent regulation of abundance in both hosts and symbionts, and to reduce the level of interspecific competition among symbionts [Tompkins et al., 2011]. Moreover, even individually benign infections can have a cumulative pathogenic effect [McCallum, 1994; McCallum \& Dobson, 1995]. Compared to 7.83 symbiont species per individual in Gombe [Gillespie et al., 2010], the CNP chimpanzees have a reduced incidence of coinfections, however the data are in agreement with the ranges reported for chimpanzees at Rubondo Island, Tanzania [Petrášová et al., 2010] and in Kibale NP, Uganda [Muehlenbein, 2005], giving the average richness of 2.0 and 4.75 symbiotic species per individual, respectively.

Symbiont richness was higher in chimpanzee subpopulations living in fragmented forests compared to the north community, which live in a more continuous forest area; however pairwise comparisons revealed that only central community had significantly higher symbiont richness in comparison to northern one. Epidemiological theory predicts that symbiont species richness should positively correlate with host population density [e.g. Nunn et al., 2003] expecting higher host densities in fragmented biotopes. Gillespie 
and Chapman [2008] recorded that the number of symbiont species infecting red colobus (Procolobus rufomitratus) in Kibale, Uganda was greater in forest fragments compared to unfragmented forest at higher densities in fragmented forests demonstrating a greater infection risk for those populations. Similarly, increased host density due to forest fragmentation and loss mediates increases in symbiont richness in Tana River red colobus (Procolobus rufomitratus) and mangabeys (Cercocebus galeritus) [Mbora et al., 2009]. The observed symbiont richness of this study is in agreement with the epidemiological theory suggesting that the forest fragmentation in the Central area is indicative of human disturbance, which is promoting a higher co-infection of symbionts in that chimpanzee subpopulation.

Oates [2006] argues that marginal populations are more prone to habitat destruction and vulnerable to demographic changes. Associated with these anthropogenic alterations, disease derived by parasite disturbance can enhance the extinction risk [Pedersen et al., 2007]. Under this complex scenario gastrointestinal symbiotic surveillance cannot be neglected for conservation purposes [Whiteman \& Parker, 2005]. Currently, there are no apparent parasite illness problems on CNP chimpanzees, nonetheless, further monitoring and epidemiological surveys not only on chimpanzees but also, on other primate sympatric species in the area are necessary. The results of this study should be considered in the conservation and management of this endangered ape especially when there are ecotourist development plans for the park [IBAP, 2010; AD, 2010; Hockings et al., 2011]. 


\section{6- ACKNOWLEDGEMENTS}

We thank to Zeca Dju, laia Camará, Djiby Injai, Momo Galissa, Djamba Injai, and Braima Camará for assisting with the sampling. We also thank the Guinea-Bissau environmental agency (IBAP) for permission to work in CNP and logistical support. We would like to acknowledge Maria Ferreira da Silva, Tânia Rodrigues, Kim Hockings, Joana Roque de Pinho and Sarah Perkins for invaluable suggestions. The research was supported by the Portuguese Science Foundation- FCT (grant SFRH/BD/35797/2007).

\section{7- REFERENCES}

AD. 2010. http://www.adbissau.org/ (accessed on 17 July 2010).

Anderson RM, May RM. 1978. Regulation and stability of host-parasite population interactions. I. Regulatory Processes. Journal of Animal Ecolology 47: 219-247.

Ash LR, Orihel, TC. 2007. Atlas of human parasitology. Chicago: American Society for Clinical Pathology Press. 525 p.

Ashford RW, Lawson H, Butynski T, Reid G. 1996. Patterns of intestinal parasitism in the mountain gorilla, Gorilla gorilla, in the Bwindi-Impenetrable Forest, Uganda. Journal of Zoolology 239: 507-514.

Ashford R, Reid GD, Wrangham RW. 2000. Intestinal parasites of the chimpanzee Pan troglodytes, in Kibale Forest, Uganda. Annals of Tropical Medicine and Parasitology 94: 173-179. 
Bakuza J, Nkwengulila G. 2009. Variation over time in parasite prevalence among freeranging chimpanzees at Gombe National Park, Tanzania. International Journal of Primatolology 30: 43-53.

Blagg W, Schloegel EL, Mansour NS, Khalaf, GI. 1955. A new concentration technique for the demonstration of protozoa and helminth eggs in feces. The American Journal of Tropical Medicine and Hygiene 4: 23-28.

Bronstein J. 2009. The evolution of facilitation and mutualism. Journal of Ecolology 97: $1160-1170$.

Bush AO, Lafferty KD, Lotz JM, Shostak AW. 1997. Parasitology meets ecology on tis own terms: Margolis et al. revisited. Journal of Parasitology 83: 575-583.

Caldecott C, Miles L. 2005. World atlas of great apes and their conservation, Berkeley: University of California Press. 456 p.

Casanova C. Sousa C. 2007. Plano de acção nacional para a conservação das populações de chimpanzés, cólobus vermelhos ocidentais e cólobos brancos e pretos ocidentais na República da Guiné-Bissau. Bissau. IBAP. Ministério do Desenvolvimento Rural, Agricultura, Recursos Naturais e Ambiente, Bissau. 101 p.

Catarino L. 2004. Fitogeografia da Guiné-Bissau [PhD dissertation] Lisboa, Portugal: Instituto Superior de Agronomia. Universidade Técnica de Lisboa. 420 p.

Chapman CA, Gillespie T, Goldberg TL. 2005. Primates and the ecology of their infectious diseases: How anthropogenic change affect host-parasite interactions? Evolutionary Anthropology 14: 134-144. 
Chapman CA, Wasserman MD, Gillespie TR, Speirs ML, Lawes MJ. Ziegler TE. 2006. Do nutrition, parasitism, and stress have synergistic effects on red colobus populations living in forest fragments? American Journal of Physical Anthropology 131: $525-534$.

Chapman CA, Naughton-Treves L, Lawes MJ, Wasserman MD, Gillespie TR. 2007. The conservation value of forest fragments: explanations for population decline of the colobus of western Uganda. International Journal of Primatology 28 :513-528.

Coe C. 1993. Psychosocial factors and immunity in nonhuman-primates-a review. Psychosomatic Medicine 55: 298-308.

Combes C. 2001. Parasitism: The ecology and evolution of intimate interactions. Chicago: University of Chicago Press. 552 p.

Coop RL, Holmes, PH. 1996. Nutrition and parasite interaction. International Journal of Parasitology 26: 951-962.

Cowlishaw G, Dunbar R. 2000. Primate conservation biology Chicago: University of Chicago Press. 498 p.

Cristóbal-Azkarate J, Hervier B, Vegas-Carillo S, Osorio-Sarabia D, Rodríguez-Luna E, Veà JJ. 2010. Parasitic infections of three Mexican howler monkey groups (Alouatta palliata mexicana) living in forest fragments in Mexico. Primates. 51: 231-239.

Daszak PA, Cunningham AA, Hyatt AD. 2000. Emerging infectious diseases of wildlifethreats to biodiversity and human health. Science. 287: 443-449.

Douglas AE. 2010. The symbiotic habit. New Jersey: Princeton University Press. 214 p. 
Eley RM, Strum SC, Muchemi G, Reid GDF. 1989. Nutrition, body condition, activity patterns and parasitism of free-ranging baboons (Papio anubis) in Kenya. American Journal of Primatolology 18: 209-219.

Fahrig L. 2003. Effects of habitat fragmentation on biodiversity. Annual Review of Ecology, Evolution and Systematics 34: 487-515.

File S. 1976. Probstmayria gombensis sp. n. (Nematoda: Atractidae) from the Chimpanzee. Journal of Parasitology 62: 256-258.

File SK, McGrew W, Tutin CEG. 1976. The intestinal parasites of a community of feral chimpanzees, Pan troglodytes schweinfurthii. Journal of Parasitology 62: 259-261.

Gillespie TR. 2006. Noninvasive assessment of gastrointestinal parasite infections in freeranging primates. International Journal of Primatology 27: 1129-1143.

Gillespie TR, Chapman CA. 2006. Prediction of parasite infection dynamics in primate metapopulations based on attributes of forest fragmentation. Conservation Biology 20: 441-448.

Gillespie T, Chapman C. 2008. Forest fragmentation, the decline of an endangered primate, and changes in host-parasite interactions relative to unfragmented forest. American Journal of Primatology 70: 222-230.

Gillespie TC, Chapman CA, Greiner EC. 2005a. Effects of logging on gastrointestinal parasite infections and infection risk in African primates. Journal of Applied Ecology 42: 699-707. 
Gillespie TR, Lonsdorf, EV, Canfield EP, Meyer DJ, Nadler Y, Raphael J, Pusey AE, Pond J, Pauley J, Mlengeya T, Travis DA. 2010. Demographic and ecological effects on patterns of parasitism in eastern chimpanzees (Pan troglodytes schweinfurthii) in Gombe National Park, Tanzania. American Journal of Physical Anthropology 143: $533-544$.

Gippoliti S, Dell'Omo G. 1995. Status and conservation of the chimpanzee Pan troglodytes verus in Guinea-Bissau. African Primates 1: 3-5.

Gippoliti S, Dell'Omo G. 1996. Primates of the Cantanhez Forest and the Cacine Basin, Guinea-Bissau. Oryx 30: 74-80.

Gippoliti S, Dell'Omo G. 2003. Primates of Guinea-Bissau, West Africa: Distribution and Conservation Status. Primate Conservation 19: 73-77.

Goldberg TE, Grant EC, Inendino KR, Kassler TW, Claussen JE, Philipp DP. 2005. Increased infectious disease susceptibility resulting from outbreeding depression. Conservation Biology 19: 455-462.

Graczyk TK, BoscoNizey J, Ssebide B, Thompson RCA, Read C, Cranfield MR. 2002. Anthropozoonotic Giardia duodenalis genotype (Assemblage A) infections in habitats of free-ranging human habituated gorillas, Uganda. Journal of Parasitology 88, 905-909.

Greiner EC, McIntosh A. 2009. Collection methods and diagnostic procedures for primate parasitology. In Huffman MA, Chapman C. (Eds.). Primate parasite ecology: the 
dynamics and study of host-parasite relationships Cambridge: Cambridge University Press. 3-28 p.

Hahn NE, Proulx D, Muruthi PM, Alberts S, Altmann J. 2003. Gastrointestinal parasites in free-ranging Kenyan baboons (Papio cynocephalus and P. anubis). International Journal of Primatology 24: 271-279.

Hasegawa H, Chapman CA, Huffman MA. 2009. Useful diagnostic refrences and images of protozoans, helminths, and nematodes commonly found in wild primates. In: Huffman MA, Chapman CA (Eds.). Primate parasite ecology: the dynamics and study of host-parasite relationships. Cambridge: Cambridge University Press. 507$514 \mathrm{p}$.

Hasegawa H, Sato H, Fujita S, Nguema PPM, Nobusue K, Miyagi K, Kooriyama T, Takenoshita, Y, Noda S, Sato A, Morimoto A, Ikeda I, Nishida T. 2010. Molecular identification of the causative agent of human strongyloidiasis acquired in Tanzania: Dispersal and diversity of Strongyloides spp. and their hosts. Parasitology International 59: 407-413.

Hockings K, Sousa C. 2011. Human-chimpanzee sympatry and interactions in Cantanhez National Park, Guinea-Bissau: Current Research and future directions. Primate Conservation 26.

Holmes JC. 1995. Population regulation: a dynamic complex of interactions. Wildlife Research 22:11-20. 
Hopkins ME, Nunn CL. 2007. A global gap analysis of infectious agents in wild primates.

Diversity and Distributions 13: 561-572.

Howells ME, Pruetz J, Gillespie TR. 2010. Patterns of gastro-intestinal parasites and commensals as an index of population and ecosystem health: the case of sympatric Western chimpanzees (Pan troglodytes verus) and Guinea baboons (Papio hamadryas papio) at Fongoli, Senegal. American Journal of Primatology 71: 173179.

Huffman MA, Gotoh S, Turner LA, Hamai M, Yoshida K. 1997. Seasonal trends in intestinal nematode infection and medicinal plant use among chimpanzees in the Mahale, Tanazania. Primates. 38: 111-125.

Huffman MA, Pebsworth P, Bakuneeta C, Gotoh S, Bardi M. 2009. Macro-habitat comparison of host-parasite ecology in two populations of chimpanzees in the Budongo forest, Uganda and the Mahale Moutains, Tanzania. In: Huffman MA, Chapman CA (Eds.) Primate parasite ecology: the dynamics of host-parasite relationships. Cambridge: Cambridge University Press. 311-330 p.

Hunter PR, Thompson RC. 2005. The zoonotic transmission of Giardia and Cryptosporidium. International Journal of Parasitology 35: 1181-1190.

IBAP. 2008. http://www.ibap-gbissau.org/. (accessed on 23 August 2008).

IBAP. 2010. http://www.ibap-gbissau.org/. (acessed on 16 March 2010).

Jensen B, Kepley W, Guarner J, Anderson K, Anderson D, Clairmont J, De L'Aune W, Austin E. H, Austin GE. 2000. Comparison of polyvinyl alcohol fixative with three less 
hazardous fixatives for detection and identification of intestinal parasites. Journal of Clinical Microbiology 38: 1592-1598.

Jessee MT, Schilling PW, Stunkard JA. 1970. Identification of intestinal helminth eggs in old world primates. Laboratory Animal Care 20: 83-87.

Johnston AR, Gillespie TR, Rwego IB, McLachlan TL, Kent AD, Golberg TL. 2010. Molecular epidemiology of cross-species Giardia duodenalis transmission in Western Uganda. PLoS Neglected Tropical Diseases 4: e683.

Kawabata M, Nishida T. 1991. A preliminary note on the intestinal parasites of wild chimpanzees in the Mahale Moutains, Tanzania. Primates. 32: 275-278.

Kowalewski M M, Salzer J S, Deutsch JC, Raño M, Kuhlenschmidt MS, Gillespie TR. 2011. Black and gold howler monkeys (Alouatta caraya) as sentinels of ecosystem health: patterns of zoonotic protozoa infection relative to degree of human-primate contact. American Journal of Primatology 73: 75-83.

Krief S, Huffman MA, Sévenet T, Guillot J, Bories C, Hladik CM, Wrangham RW. 2005. Noninvasive monitoring of the health of Pan troglodytes schweinfurthii in the Kibale National Park, Uganda. International Journal of Primatology 26: 467-490.

Krief S, Vermeulen B, Lafosse S, Kasenene JM, Nieguitsila A, Berthelemy M, L'Hostis M, Bain O, Guillot J. 2010. Nodular worm infection in wild chimpanzees in Western Uganda: A risk for human health? PloS Neglected Tropical Diseases 4: e630. 
Landsoud-Soukate J, Tutin CE, Fernandez M. 1995. Intestinal parasites of sympatric gorillas and chimpanzees in the Lopé Reserve, Gabon. Annals of Tropical Medicine and Parasitology 89: 73-79.

Lane K, Holley C, Hollocher H, Fuentes A. 2011. The anthropogenic environment lessens the intensity and prevalence of gastrointestinal parasites in Balinese long-tailed macaques (Macaca fascicularis). Primates 52: 117-128.

Lee PC, Thornback J, Bennett EL. 1988. Threatened primates of Africa: The IUCN red data book. IUCN, Gland, Switzerland and Cambridge.

Levecke B. 2010. The importance of gastroitestinal protozoa in captive non-human primates [PhD dissertation]. Ghent, Belgium: Faculty of Veterinary Medicine, Ghent University. 186 p.

Lilly, A. A., Mehlman, P. T., and Doran, D. 2002. Intestinal parasites in gorillas, chimpanzees and humans at Mondika Research Site, Dzanga-Ndoki National Park, Central African Republic. International Journal of Primatology 23: 555-573.

Liu G, Gasser R B, Su A, Nejsum P, Peng L, Lin R, Xu M, Zhu X. 2012. Clear genetic distinctiveness between human- and pig- derived Trichuris based on analyses of mitochondrial datasets. PloS Neglected Tropical Diseases 6: e1539.

Marsh LK. 2003. Primates in fragments: Ecology and Conservation New York: Kluwer Academic/ Plenum Publishers. 428 p. 
Mbora DNM, Munene E. 2006. Gastrointestinal parasites of critically endangered primates endemic to Tana River, Kenya: Tana River red colobus (Procolobus rufomitratus) and crested mangabey (Cercocebus galeritus). Journal of Parasitology 92: 928-932.

Mbora DN, Wieczkowski J, Munene E. 2009. Links between habitat degradation, and social group size, ranging, fecundity, and parasite prevalence in the Tana River mangabey (Cercocebus galeritus). American Journal of Physical Anthropology 140: 562-571.

McCallum H. 1994. Quantifying the effect of disease on threatened species. Pacific Conservation 1:107-117.

McCallum H, Dobson A. 2002. Disease, habitat fragmentation and conservation. Proceedings of the Royal Society: Biological Sciences 269: 2041-2049.

McGrew WC, Tutin CEG, Collins DA, File SK. 1989. Intestinal parasites of sympatric Pan troglodytes and Papio spp. at two sites: Gombe (Tanzania) and Mt. Assirik (Senegal). American Journal of Primatology 17: 147-155.

Morand S, Poulin R. 1998. Density, body mass and parasite species richness of terrestrial mammals. Evolutionary Ecology 12:717-27.

Muehlenbein M. 2005. Parasitological analysis of the male chimpanzees (Pan troglodytes schweinfurthii) at Ngogo, Kibale National Park, Uganda. American Journal of Primatology 65: 167-179.

Munene E, Otsyula M, Mbaabu D, Mutahi WT, Muriuki SMK. 1998. Helminth and protozoan gastro-intestinal (GIT) parasites in Captive and Wild-Trapped African non-humanprimates. Veterinary Parasitology 78: 195-201. 
Murray S, Stem C, Boudreau B, Goodall J. 2000. Intestinal parasites of baboons (Papio cynocephalus anubis) and chimpanzees (Pan troglodytes) in Gombe National Park. Journal of Zoo and Wildlife Medicine 31: 176-178.

Nizeyi JB, Cranfield MR, Graczyk TK. 2002. Cattle near the Bwindi Impenetrable National Park, Uganda, as a reservoir, of Cryptosporidium parvum and Giardia duodenalis for local community and free-ranging gorillas. Parasitology Research 88: 380- 385.

Nunn CL, Altizer S, Jones K, Sechrest W. 2003. Comparative tests of parasite species richness in primates. The American Naturalist 162: 597-614.

Nunn C L, Altizer SM. 2006. Infectious diseases in primates: Behavior, ecology and evolution. Oxford. Oxford University Press. 398 p.

Oates JF. 2006. Is the chimpanzee, Pan troglodytes, an endangered species? It depends on what "endangered" means. Primates. 47: 102-112.

Ooi HK, Tenora F, Itoh K, Kamiya M. 1993.Comparative study of Trichuris trichiura from non-human primates and from man and their difference with $T$. suis. The Journal of Veterinary Medical Science 55: 363-366.

Oom D, Lourenço P, Cabral AIR, Vasconcelos MJP, Catarino L, Cassamá V, Moreira J. 2009. Quantification of deforestation rates in Guinea-Bissau- a baseline carbon trading under REDD. $33^{\text {rd }}$ International Symposium on Remote Sensing of Environment, 4-8 May 2009, Stresa, Italy.

Pedersen AB, Jones KE, Nunn CL, Altizer S. 2007. Infectious diseases and extinction risk in wild animals. Conservation Biology 21: 1269-1279. 
Petrášová J, Modrý D, Huffman MA, Mapua MI, Bobáková L, Mazoch V, Singh J, Kaur T, Petrželková K. 2010. Gastrointestinal parasites of indigenous and introduced primate species of Rubondo Island National Park, Tanzania. International Journal of Primatology 5: 920-936.

Petrželková K, Hasegawa H, Appleton CC, Huffman MA, Archer CE, Moscovice, LR, Mapua M, Singh J, Kaur T. 2010. Gastrointestinal Parasites of the Chimpanzee Population Introduced onto Rubondo Island National Park, Tanzania. International Journal of Primatology 72: 307-316.

Pomajbíková K, Petrželková K, Petrašová J, Profousová I, Kalousová B, Jirků M, Sá RM, Modrý D. 2012. Distribution of the Entodiniomorphid ciliate Troglocorys cava Tokiwa, Modrý, Ito, Pomajbíková, Petrželková \& Imai, 2010, (Entodioniomorphida: Blepharocorythidae) in wild and captive chimpanzees. Journal of Eukaryotic Microbiology 59: 97-99.

Pomajbíková K, Petrželková K, Profousová I, Petrášová J, Kišidayová S, Váradyová Z, Modrý, D. 2010. A survey of entoniniomorphid ciliates in chimpanzees and bonobos. American Journal of Physical Anthropology 142: 42-48.

Profousová I, Mihaliková K, Laho T, Váradyová Z, Petrželková Modrý D, Kišidayová S. 2011. The ciliate, Troglodytella abrassarti, contributes to polysaccharide hydrolytic activities in the chimpanzee colon. Folia Microbiologica56: 339-343.

Reichard MV, Wolf RF, Carey DW, Garrett JJ, Briscoe HA. 2008. Efficacy of fenbendazole and milbemycin oxime for treating baboons (Papio cynocephalus anubis) infected 
with Trichuris trichiura. Journal of the American Association for Laboratory Animal Science 46: 42-45.

Sá R, Sousa C, Bruford MW. 2009. (Abstract) Conservation genetics and phylogeography of the chimpanzees in Guinea-Bissau. Folia Primatologica 80: 172.

Salzer JS, Rwego IB, Goldberg TL, Kuhlenschmidt MS, Gillespie TR. 2007. Giardia sp. and Cryptosporidium sp. infections in primates in fragmented and undisturbed forest in western Uganda. Journal of Parasitology 93:439440.

Scott ME. 1988. The impact of infection and disease on animal populations: implications for conservation biology. Conservation Biology 2: 40-56.

Shaw DJ, Dobson AP. 1995. Patterns of macroparasite abundance and aggregation in wildlife populations. A quantitative review. Parasitology. 111: S111-S133.

Shaw DJ, Grenfell BT, Dobson AP. 1998. Patterns of macroparasite aggregation in wildlife host populations. Parasitology. 117: 597-610.

Sheater AL. 1923. The detection of intestinal protozoa and mange parasites by a flotation technique. Journal of Comparative Pathology 36: 266-275.

Simão A. 1997. Identificação e delimitação cartográfica dos grandes maciços florestais de Cantanhez. Bissau: Relatório de missão. IBAP. 64 p.

Sleeman L, Meader L, Mudakikwa A, Foster J, Patton S. 2000. Gastrointestinal parasites of mountain gorillas (Gorilla gorilla beringei) in the Parc National des Volcans, Rwanda. Journal of Zoo and Wildlife Medicine 31: 322-328. 
Smith KK, Acevedo-Whitehouse K, Pedersen AB. 2009. The role of infectious diseases in biological conservation. Animal Conservation 12: 1-19.

Sousa C, Gippoliti S, Akhlas M. 2005. Republic of Guinea-Bissau. In Caldecott J, Miles L. (Eds.).World atlas of great apes and their conservation. Berkeley: University of California Press. 362-365 p.

Sprong H, Caccio SM, van der Giessen JW. 2009. Identification of Zoonotic Genotypes of Giardia duodenalis. PLoS Neglected Tropical Diseases 3: e558.

Stensvold CR, Arendrup M, Jespersgaard C, Mølback, Nielsen HV. 2007. Detecting Blastocystis using parasitologic and DNA-based methods: a comparastive study. Diagnostic Microbiology and Infectious Disease 59: 303-307.

Stuart MD, Strier KB. 1995. Primates and parasites: A case for a multidisciplinary approach. International Journal of Primatology 16: 577-593.

Thompson RCA. 2004. Epidemiology and zoonotic potential of Giardia infections. In: C. R. Sterling, R. D. Adam (Eds.). World class parasites, vol 8: the pathogenic enteric protozoa: Giardia, Entamoeba, Cryptosporidium and Cyclospora. Boston, USA: Kluwer Academic Publishers. 1-14 p.

Tompkins D, Dunn A, Smith M, Telfer S. 2011. Wildlife diseases: from individuals to ecosystems. Journal of Animal Ecology 80: 19-38.

Tokiwa T, Modrý D, Ito A, Pomajbíková K, Petrželková K, Imai S. 2010. A new entodiniomorphid ciliate, Troglocorys cava n. g., n. sp., from the wild eastern 
chimpanzee (Pan troglodytes schweinfurthii) from Uganda. Journal of Eukaryotic Microbiology 57: 115-120.

Torres J, Brito JC, Vasconcelos MJ, Catarino L, Gonçalves J. Honrado J. 2010. Ensemble models of habitat suitability relate chimpanzee (Pan troglodytes) conservation to forest and landscape dynamics in Western Africa. Biological Conservation 143: 416-425.

Whiteman NK, Parker PG. 2005. Using parasites to infer host population history: a new rationale for parasite conservation. Animal Conservation 8: 175-181.

Wolfe ND, Escalante AA, Karesh WB, Kilbourn A, Spielman A, Lal AA. 1998. Wild primate populations in emerging infectious disease research: The missing link? Emerging Infectious Diseases 4: 149-158. 
5.8- TABLES

TABLE 5.1: Characteristics of chimpanzee communities sampled in Cantanhez National Park, in Guinea-Bissau, West Africa.

\begin{tabular}{cccccc}
\hline Areas & № of & Size of & \% of & Distance to & No samples \\
& Fragments & Forested & Forest & nearest & collected \\
& 1 & 37.93 & 3.55 & 3,465 & 45 \\
\hline North & 5 & 13.20 & 1.24 & 67 & 25 \\
Central & 8 & 19.67 & 1.84 & 650 & 32 \\
\hline
\end{tabular}


TABLE 5.2: Symbiont prevalence (\%) of western chimpanzees (Pan troglodytes verus) at Cantanhez National Park, Republic of Guinea-Bissau.

\begin{tabular}{|c|c|c|c|c|}
\hline $\begin{array}{l}\text { Symbiont } \\
\text { Taxa }\end{array}$ & $\begin{array}{l}\text { North } \\
(n=45)\end{array}$ & $\begin{array}{l}\text { Central } \\
(n=25)\end{array}$ & $\begin{array}{l}\text { South } \\
(n=32)\end{array}$ & $\begin{array}{l}\text { Total } \\
(n=102)\end{array}$ \\
\hline \multicolumn{5}{|l|}{ Protozoa } \\
\hline Entamoeba spp. & 2 & 20 & 34 & 18 \\
\hline $\begin{array}{l}\text { lodamoeba } \\
\text { buetschlii }\end{array}$ & 4 & 4 & 3 & 4 \\
\hline Giardia duodenalis & 0 & 16 & 6 & 6 \\
\hline Chilomastix mesnili & 4 & 16 & 3 & 7 \\
\hline $\begin{array}{l}\text { Troglodytella } \\
\text { abrassarti }\end{array}$ & 42 & 80 & 69 & 62 \\
\hline Troglocorys cava & 22 & 36 & 19 & 25 \\
\hline Blastocystis sp. & 29 & 64 & 56 & 49 \\
\hline \multicolumn{5}{|l|}{ Cestoda } \\
\hline Bertiella sp. & 0 & 4 & 13 & 5 \\
\hline Nematoda & & & & \\
\hline $\begin{array}{cr}\text { Strongylida fam. } \\
\text { gen. sp. (Hookworms) }\end{array}$ & 27 & 48 & 16 & 38 \\
\hline $\begin{array}{l}\text { Strongyloides } \\
\text { fuelleborni }\end{array}$ & 27 & 16 & 16 & 22 \\
\hline $\begin{array}{l}\text { Strongyloides } \\
\text { stercoralis }\end{array}$ & 4 & 8 & 6 & 6 \\
\hline $\begin{array}{l}\text { Probstmayria } \\
\text { gombensis }\end{array}$ & 7 & 4 & 0 & 4 \\
\hline Trichuris sp. & 22 & 0 & 6 & 15 \\
\hline Overall \% & 87 & 100 & 91 & 91 \\
\hline
\end{tabular}




\section{9- FIGURES}

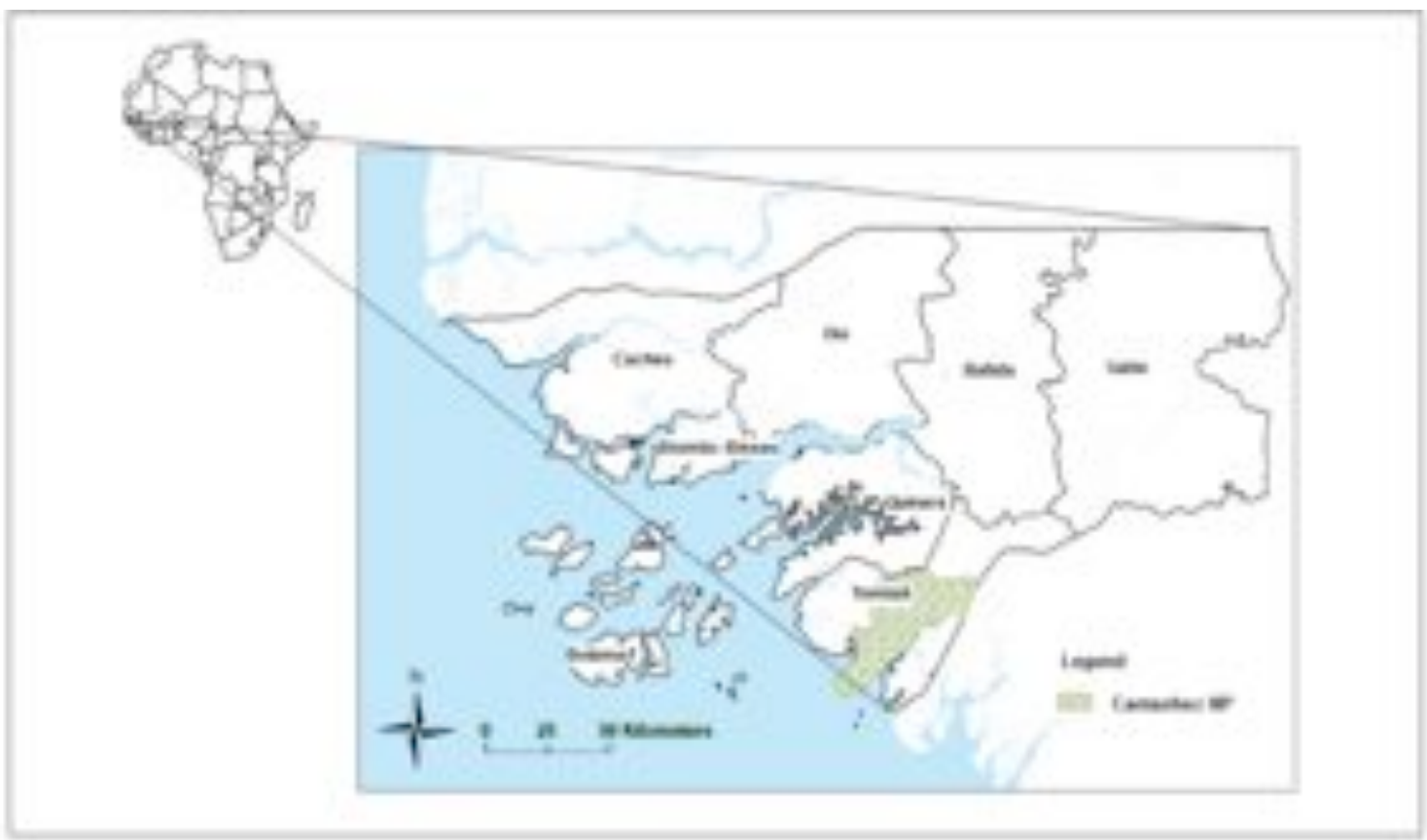

Figure 5.1: Location of Cantanhez National Park, Republic of Guinea-Bissau, West Africa (after Hockings and Sousa 2011). 


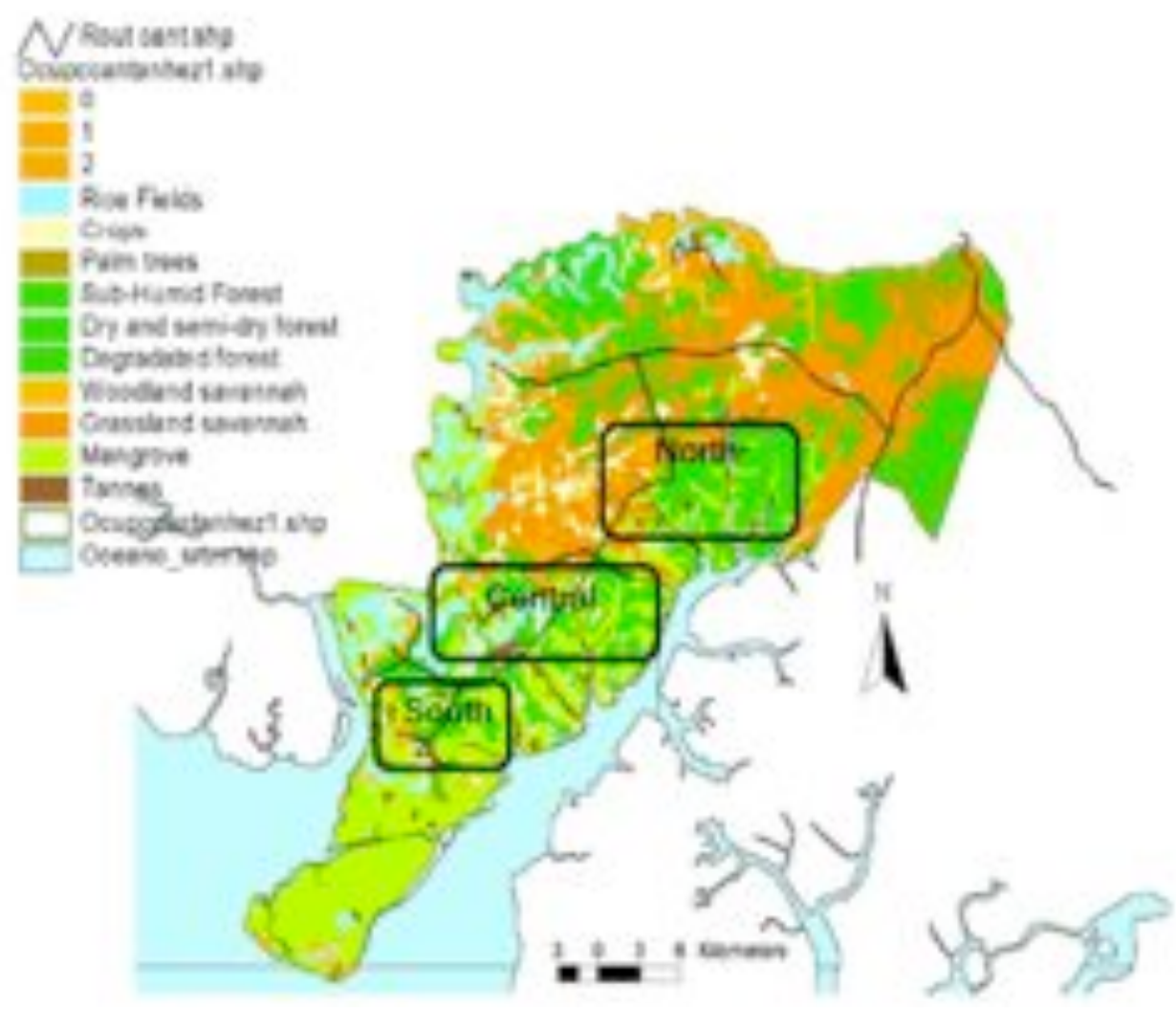

Figure 5.2: Chimpanzee distribution in three principal areas across Cantanhez National Park, Guinea-Bissau. 


\section{CHAPTER 6}

"The other's pain: the pain that hurts less."

- Susan Sontag, Essayist

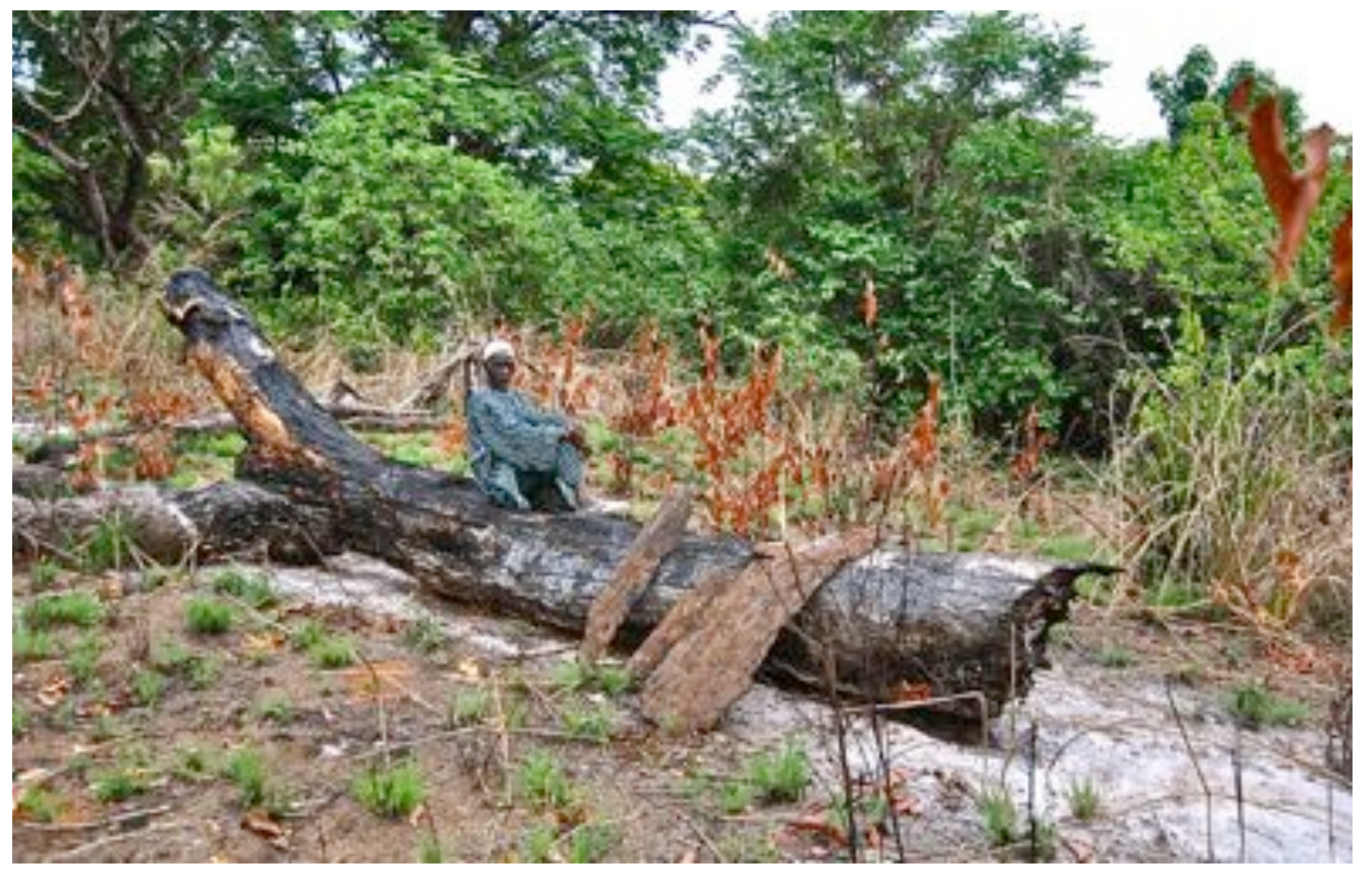




\section{CHAPTER 6}

\section{GENERAL DISCUSSION}

In this thesis I investigated concomitant threats that negatively impact on chimpanzee persistence in Guinea-Bissau. I also tested a set of hypotheses regarding their evolutionary history and examined the occurrence of gastrointestinal symbionts and how the observed parasitism patterns are influenced by habitat fragmentation. To achieve these goals I adopted a multidisciplinary approach that combined ethnography, non-invasive genetics and parasitology. Prior to this study, no research projects had assessed the Guinea-Bissau's chimpanzee mitochondrial diversity, structure and demographic history, and their gastrointestinal parasites were entirely unstudied. Overall, this set of studies has contributed to our understanding of the evolution and ecology of chimpanzees, specifically addressing a gap in knowledge regarding these apes in Guinea-Bissau. Moreover, this dissertation provides relevant considerations for the conservation of chimpanzees in Cantanhez, Quínara and Gabú regions.

\section{1- Overview of major findings, limitations, and further research}

Chapter 3, reports and examines one aspect of the illegal trade of chimpanzee and other non-human primate body parts in Guinea-Bissau. Such commerce can pose serious threats to wild populations. In this chapter I was interested to understand and place into context the social inclusion of chimpanzee and other animal body parts for human traditional practices. Morphologically identified chimpanzee skins were found in the market. Additionally, dried skins from Temminck's Red Colobus monkeys (Procolobus badius temminckii), Guinea baboons (Papio papio) and Olive baboons (Papio anubis) were identified, as well as from other mammals such as leopard (Panthera pardus) and lions (Panthera leo) among others. All the species are reported as occurring in Guinea-Bissau except for Olive baboons whose western limit of distribution is reported to be in Mali and the 
republic of Guinea (IUCN 2010). Furthermore, in Colobane and Boucotte markets in Senegal (Dakar and Ziguinchor, respectively) several species of reptiles and mammals, including primate species were also found for use in traditional medicinal and/or magical ceremonies. Two of the Guinea-Bissau vendors mentioned that citizens from Senegal, Guinea and Gambia are involved in the trade. All vendors mentioned that the animal body parts come from the "south of the country", particularly the regions of Cantanhez and Gabú. Most male informants in rural CNP and Boé villages associated the use of chimpanzee derived products with the female domain, and one informant admitted that he uses a stitched amulet made of chimpanzee body parts to help provide awareness and protect him. Although, not previously reported for Guinea-Bissau, the use of non-human primate body parts in traditional medicine is not unusual in Africa (Alves et al. 2010; Leypey and Fomine 2010). The suggested transnational trade of Guinea-Bissau chimpanzee skins may constitute an even bigger threat for the conservation of this population. Since chimpanzee populations are declining in West African countries (IUCN 2010), foreign hunters could be attracted to Guinea-Bissau and the hunting of chimpanzees could therefore increase in the near future. In addition, ethnographic observations and informal conversations with Guinea-Bissau immigrants in diaspora in Lisbon informed that usually the "esoteric professionals" import frequently animal body parts (including those from endangered species and CITES regulated) from GuineaBissau for their use in their customers that can buy those products paying high prices (personal information). If on one hand ethnic ecological knowledge can be a driver of protection for some species, some traditional practices can have negative impact for other animal populations (Colding and Folk 1997).

This study was limited to the capital, Bissau; however further studies in different regions of the country are necessary. It is urgent to identify and analyse the practices and social mechanisms of traditional societies, such as taboos, involving non-human primates throughout the country. An ethnobiological approach, more ethnoprimatological focused can be particularly appropriate as this field (i.e. the study of human and non-human primate interactions) aims to understand the incorporation of non-human primates as pets, food, indigenous knowledge of nonhuman primate behaviour, etc. (Wolfe and Fuentes 2007; Fuentes and Hockings 
2010). Further work must molecularly determine the origin of the skins and bushmeat in the markets in order to assess the frequency of the species traded (see Appendix I) and assign their geographical origin. Finally, cultural anthropological studies specifically centred on the use and symbolic incorporation and appropriation of non-human primate body parts by the Guinea-Bissau diaspora in Portugal will help to understand how such practices are disseminated.

In Chapter 4, I investigated for the first time the mitochondrial diversity, genetic structure and demographic history of the chimpanzees in Guinea-Bissau and Nimba Mountains, Guinea, thus revisiting the West African chimpanzee's phylogeography. Fifty-one haplotypes were detected and the genetic diversity was high. The phylogenetic analyses revealed the existence of two deep evolutionary lineages in consonance with previous reports (Morin et al. 1994, Gonder et al. 2006); and eleven haplogroups, some of them geographically associated. The bimodal mismatch distribution, the neutrality tests and the star shape pattern in the median joining network imply that a demographic expansion has occurred promoting secondary contact between the two lineages. The AMOVA revealed $74 \%$ of the genetic variation is partitioned within populations and a strong genetic structure $\left(F_{S T}=0.25956, \quad p<0.0001\right)$. Barrier analysis identified three major genetic discontinuities, two of them coinciding with the Rio Grande de Buba and the Féfine rivers and the estimates of divergence times pointed to vicariance events in the Middle Pleistocene where the recurrence of past climatic oscillations in the African forests, with cycles of forest expansion and contraction may have resulted in the genetic differentiation of the groups. Two phylogeographic clusters were identified based on the SAMOVA analyses and following the criteria pointed out by Petit et al. (1998) conservation units were identified in order to maintain the chimpanzee genetic diversity in Guinea-Bissau.

The dissimilar shapes of the mismatch distributions observed in this study and those from Nigeria-Cameroon (Gonder et al. 2006) suggest that these populations have experienced separate paleodemographic events and probably persisted in different refuges during the last glacial maximum. Gagneux et al. (1999) propose that the Upper Guinea chimpanzees may have persisted in a refuge around Liberia following the initial expansion of this subspecies into the forests of West 
Africa given that similar HVR1 sequences were detected in populations of GuineaBissau and Nimba spanning $800 \mathrm{~km}$. The population for the Upper Guinean chimpanzees may have occurred after the last glaciation or perhaps after an earlier glacial event. The mismatch patterns of this study clearly contrast with the unimodal mismatch distribution for the eastern chimpanzees suggesting that chimpanzees in East Africa have not undergone Pleistocene semi-isolated range of contractions and expansions and that these chimpanzees persisted during the glaciation periods by exploring more savanna like habitats (Goldberg and Ruvolo 1997).

Due to logistical constraints, during the sampling phase it was not possible to include specimens from the Dulombi and Cacine areas in Guinea-Bissau. Likewise, it would be important to include samples from Senegal, especially from the NiokoloKoba National Park where chimpanzees populations also occur, which are almost adjacent with the Gabú region in order to expand the phylogeographical results into a broader context. Other molecular markers should also be used in order to confirm the mtDNA patterns. By using nuclear markers, such as microsatellites it will be possible to assess the effects of habitat fragmentation to chimpanzee gene flow in Guinea-Bissau where the connectivity of some forests are clearly compromised. This study is being conducted by me and still ongoing. It will use a landscape genetics approach applied to chimpanzee conservation. Recent studies in landscape genetics demonstrate that the characterization of the geographical structure of genetic variation needs no prior knowledge about the number of populations or the possible landscape effects (Manel et al. 2003; Holderegger and Wagner 2006). Several statistical models have been used on other species (e.g. Bayesian clustering, Monmonier's algorithm) indicating that habitat and landscape traits can determine and predict geographical patterns related with limited gene flow, beyond the traditional models of isolation-by-distance (i.e. Mantel tests) (Manel et al. 2003; Holderegger and Wagner 2006; Hobbs et al. 2006; Manel and Segelbacher 2009). Results can be combined with GIS data and integrated maps can establish genetic patterns connected with the landscape).

Precise population size estimates are difficult to calculate (Arandjelovic et al 2010), nevertheless a molecular chimpanzee censusing is being carried out in Guinea-Bissau. This research is being undertaken under the scope of the project: 
"Guinea-Bissau endangered chimpanzee conservation genetics: biological anthropology contribution to biodiversity conservation" funded by FCT (PTDC/CSANT/099184/2008).

Finally the genetic findings of the different projects should be combined in order to conduct a PHVA (Population and Habitat Viability Assessment) to set up priorities, and to drive a positive conservation change in Guinea-Bissau (Carlsen et al. 2012). Such knowledge will allow the establishment of ecological corridors that will benefit not only the chimpanzees, but also the ecosystems and the Guinea-Bissau rich biodiversity.

Habitat fragmentation may cause changes in host-parasite dynamics resulting in increased susceptibility to infection, changes in host specificity and parasite virulence (Gillespie et al 2005; Pedersen et al. 2007). In Chapter 5, I report for the first time the symbiont-fauna of chimpanzees in Cantanhez National Park in areas with different levels of habitat fragmentation. Moreover, this is the first study to specifically address the effects of habitat fragmentation and gastrointestinal symbionts in chimpanzees, although previous studies have reported their prevalence and richness, none so far had specifically explored this association. Thirteen symbiotic genera (Troglodytella abrassarti, Troglocorys cava, Blastocystis spp., Entamoeba coli, lodamoeba butschlii, Giardia intestinalis, Chilomastix mesnili, Bertiella sp., Probstmayria gombensis, unidentified strongylids, Strongyloides stercoralis, Strongyloides fuelleborni and Trichuris sp.) were identified. The symbiotic fauna of the CNP chimpanzees is comparable to that reported for other wild chimpanzee populations, although CNP chimpanzees have a higher prevalence of Trichuris sp. Symbiont richness was higher in chimpanzee subpopulations living in fragmented forests compared to the community inhabiting continuous forest area. I reported significantly higher prevalence of $G$. intestinalis in chimpanzees from fragmented areas, which could be attributed to increased contact with humans and livestock confirming the hypothesis that CNP chimpanzees will exhibit a high level of gastrointestinal symbiont diversity consequence of a disturbed habitat, and a higher infection of parasites with direct cycles as contact intra and interspecific increases. Surprisingly, in fragmented areas chimpanzee density and range-use intensity decrease, which might contribute to low prevalence/total absence of Trichuris sp. in 
samples from chimpanzees in these areas when compared with those inhabiting continuous forest.

One limitation of this study is the geographical limitation to Cantanhez. Further studies should include a national survey across the different regions during both dry and rainy seasons in order to evaluate fluctuations in chimpanzee gastrointestinal parasite prevalence. Furthermore, studies involving other primates (humans inclusive) must be included to understand the possible risks of zoonotic transmission. The comparative parasitological study of five sympatric primates is ongoing and the prevalence tables are included in Appendixes A-E. Molecular screening should be applied to detect water-borne (i.e. Microsporidia phylum. or Cryptosporidium spp.) or vector-borne agents (e.g. Plasmodium spp.) difficult to detect by regular coproscopy techniques and usually associated with immunocompromised individuals (Hunter and Nichols 2002). Preliminary molecular trials revealed the presence for Encephalitozoon (putatively cuniculi) and Plasmodium spp. (data not shown). Similarly, other agents such as virus (i.e. SIV) and bacteria should also be considered in further health surveys.

Special attention should be given to the whipworm Trichuris spp. One third of the world's human population is at risk of infection from soil-transmitted geohelminths principal among them whipworms from this genus (Starr and Montgomery 2011). Presently, trichuriasis is listed in the Global Network for Neglected Tropical Diseases (GNNTD: http:/globalnetwork.org), yet few control programs have been consigned (Engels and Saviolli 2006; Hotez et al. 2007, 2009).

Aside from T. trichiura, T. lemuris and T. cynocephalus are the only Trichuris taxa described from primates (Kuntz and Meyers 1967). Notably, the low Trichuris spp. diversity observed in primates is inconsistent with the number of species described from other mammalian hosts. The vast majority of studies describe whipworm eggs as T. trichiura, as they are morphologically indistinguishable from $T$. suis (Ooi et al. 1993). Most likely, Trichuris spp. diversity and host specificity in nonhuman primates is underestimated. The taxonomic discrimination of species within the genus Trichuris remains controversial (Cutillas et al. 2009). Early studies based on the morphological species concept considered $T$. suis and $T$. trichiura as belonging to the same species (Soulsby 1982). More recently, phylogenetic studies 
proved that $T$. suis and $T$. trichiura are genetically distinct, arguing that only molecular approaches can shed light and discriminate between these closely related congeners. In contrast, morphometric distinctiveness should be interpreted with caution as the exact species determination of Trichuris spp. based solely on the egg and larvae morphological features is unreliable (Huffman and Chapman 2009). Nevertheless, several authors automatically imply the zoonotic cross-transmission between humans and nonhuman primates (Chapman et al. 2006). Further studies are necessary to clarify the host specificity of these parasites in primates studies conducted in Guinea-Bissau will certainly shed light on this uncertainty.

Finally, attention is warranted to chimpanzee specific ciliates (i.e. Troglodytella abrassarti and Troglocorys cava) that occur at high prevalence. Usually these symbionts are considered as commensals, but little is known about their biology, transmission or function. Troglocorys cava for example was only fully described in 2010 and the distribution of this entodinomorphid ciliate was recently clarified (see Appendix M).

\subsection{Reflection about the future of Guinea-Bissau forests}

According to a recent estimate, West Africa experienced an annual rate of forest loss of $1.17 \%$ between 1990 and 2005 (Fao 2007). The same trend was observed in Guinea-Bissau where its open and closed-forest decreased by the same rate while savannah-woodland and mangroves increased $0.76 \%$ and $0.83 \%$ respectively, between 1990 and 2007 (Oom et al. 2009) (Fig. 6.1). This deforestation has been caused by 'slash and burn' agriculture and the amount of land for crops is continually expanding due to expanding human populations, particularly in Cantanhez (Hockings and Sousa 2011). Few trees appeared to be cut following the national legislation, and loggers seem to respect more the symbolic or traditional taboos instead. The numbers of licensed pitsawyers remain unknown as well as the timber permits conceded by the Forestry Department. Permits for clearing land are sometimes only obtained near traditional chiefs and this deregulation could generate conflicts between the guards in the parks, and loggers (pers. observation). 
In the two years of my fieldwork study the forests of Canamina, Cafatche, Amidara in Cantanhez has been severely damaged. Similarly the forested area of the Cufada Lagoons Natural Park in the Quínara region were reduced by half during 2009-2010 (Cristina Schwarz pers. communication) and the bushfires for agroforestry in the Boé sector have increased dramatically (Joost van Schinjdel pers. communication). Moreover, the timber trade seems to be highly organized and due to local poverty few local forest owners are able to easily sell their land tenure. This scenario of forest depletion will have serious consequences for chimpanzees in the future.

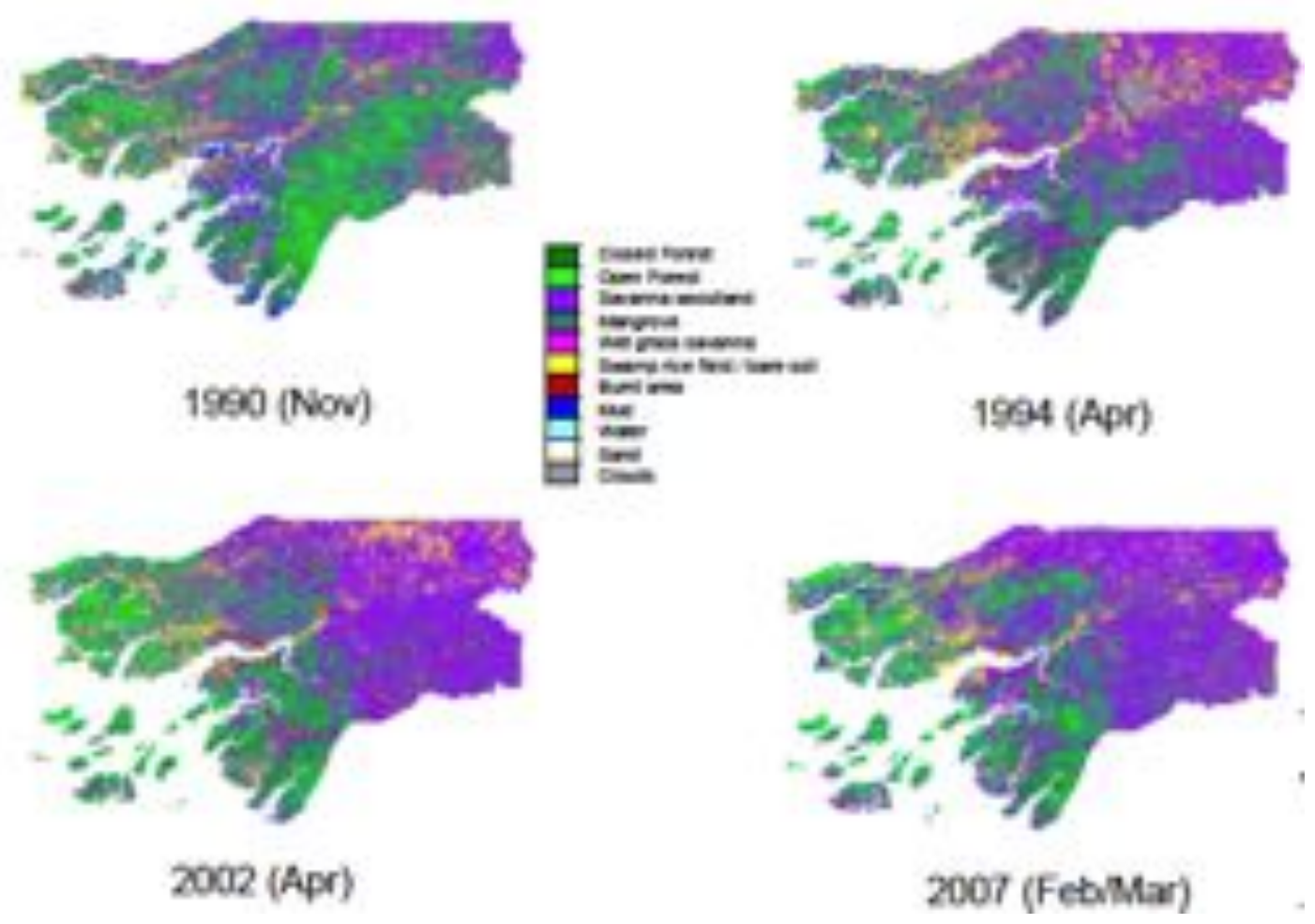

Figure 6.1: Forest change in Guinea-Bissau between 1990 and 2007 (after Oom et al. 2009, CARBOVEG-GB PROJECT:364).

\subsection{Conservation recommendations}

The recommendations proposed by Casanova and Sousa (2007) should be addressed seriously by the Guinea-Bissau national agencies and local NGO's. Biodiversity management authorities in Guinea-Bissau (IBAP and Direcção Geral de Florestas e Fauna) have introduced new laws to regulate the trade in wild meat (e.g. 
recently, the hunting of primates throughout the country was prohibited (Anon., 2011). However, limited resources and lack of awareness of management authorities and politicians is hindering law enforcement in the country. At the international level, conservation agencies should re-examine their strategies to mitigate the illegal chimpanzee body parts trade, and, at the national level, specific programmes should be designed and applied to empower all actors involved (e.g. park rangers, Customs officers, the military, police, etc.), complemented at the same time by provision of environmental education for the local communities. The political instability in the country has neglecting CITES, that was never ratified, thus the government and political authorities need to rethink their position.

The chimpanzee pet trade within the country is frequent and usually the animals live in miserable conditions. The local authorities should not facilitate this kind of practice by confiscating the animals and releasing them into sanctuaries or rescue centers (Casanova and Sousa 2007). Although this kind of facilities do not exist in the country, with international help it will be possible to secure them abroad.

The creation of the national parks by IBAP was a good conservation strategy, as in principle they can protect the genetic diversity of the chimpanzee populations, however, in reality, the Parks are lacking, infrastructure, monitoring and seizure resources. The guards should be empowered with field equipment and adequate material, and they should receive, in a regular basis, adequate payments for their services either from the official agencies and local NGO's, or from research members as well as adequate training.

Based on the genetic approach two chimpanzee phylogeographical clusters were identified: one south of Cantanhez, and a second encompassing the remaining regions. The first group (constituted by Farim, Catomboi, Cafatche and Canghode) in South Cantanhez is in eminent risk of becoming extinct, as they are under intense anthropogenic pressure. Significant conservation efforts should be directed towards them. In the other group, three major priority areas should be taking into consideration: the northern area of Cantanhez constituted by: Cadique, Lautchande, Amidara and Mejo and the communities of Buba Intchingue and Injassane in Cufada (i.e. Quínara region); the area of Catió-Empada area where they will become isolated 
if the corridor of Nhala disappear and the Boé region: especially the populations of Béli, Aicum, Vendu Leidi and Dinguirai.

Chimpanzee gastrointestinal surveys should be implemented on a regular basis, every two years in order to monitor their health status, pathogen status, and epidemiological surveillance. Baseline information was established with this study. However, it is necessary that further studies proceed the monitoring, as infectious diseases in wild great apes are one of the major threats to their survival. Research of chimpanzee infections is of importance for the understanding of the role and circulation of neglected and emergent infectious diseases, not only for the species, but also for other species, including humans.

Finally, local people must be empowered economically with sustainable activities (i.e. local handicraft, regional products: honey, jams, beverages, etc.) to sell at a national and eventually at an international level, where the producers should be paid adequately in a fair trade basis. Effective conservation projects must be implemented and developed with the full engagement of local and national stakeholders (Ancrenaz et al. 2007). Chimpanzees have great potential value for attracting ecotourism and this opportunity can be explored across Guinea-Bissau.

Evidence suggests that the western lesser spot-nosed guenons (Cercopithecus petaurista buettikoferi) seem to be already extinct in the continental part of Guinea-Bissau, only occurring in the Bijago Archipelago (see Appendix J), and if nothing is done chimpanzees might follow the same tendency.

\section{4- Conclusion: Why should we conserve chimpanzees in Guinea-Bissau?}

Chimpanzee numbers across Africa are fast declining and their conservation must be a bioethical imperative (Caldecott and Miles 2005; Oates et al. 2011). Each population is indispensable. Each chimpanzee community is unique in their ecological, behavioural and cultural characteristics (Whiten et al. 2001) and each study site contributes with important information for the understanding of their biology. The chimpanzees of Guinea-Bissau are located in the most western limit of the species distribution. They have a strong preference for constructing their nests in 
palm trees (Sousa et al. 2011), and the genetic approach of this dissertation revealed important insights about gene flow patterns, genetic diversity and structure of this population. It also demonstrated that when compared to other study areas CNP chimpanzees have a higher prevalence of whipworms. Such information is crucial not only from a scientific point of view, but also for a future conservation framework. The establishment of long-term research sites in Guinea-Bissau will certainly provide more knowledge about this species. However, it is urgent to act now in order to prevent our closest living relatives from going extinct in this country. Pleading for the protection of chimpanzees seems futile considering the absence of compassion that humans show regularly to each others. I feel pessimistic about the future of chimpanzees in West Africa and I wonder how many species one ecosystem must loose before it collapses? How many chimpanzees must be killed before we humans are doomed too? In this sense, I position myself near the discourse of the multispecies anthropology, where multispecies ethnographers are studying contact zones where lines separating nature from culture have been broken down, where encounters between humans and other species generate mutual ecologies and shared niches (Kirksey and Helmreich 2010).

\section{5- References}

Ancrenaz M, Dabek L, O’Neil S. 2007. The costs of exclusion: recognizing a role for local communities in biodiversity conservation. PLoS Biology 5, e289.

Anon. 2011. Decreto-Lei 5/2011 de 22 Fevereiro. Boletim Oficial da República da Guiné-Bissau 8, 1-13.

Arandjelovic M. et al. 2010. Effective non-inasive genetic monitoring of multiple wild western gorilla groups. Biological Conservation 143, 1780-1791.

Alves RR, Souto WM, Barboza RR. 2010. Primates in traditional folk medicine: a world overview. Mammal Review 42, 155-180. 
Caldecott, J. and Miles, L. (eds) 2005. World Atlas of Great Apes and their Conservation. Berkeley, University of California Press.

Carlsen, F., Leus, K., Traylor-Holzer, K., McKenna, A. (Editors). 2012. Western Chimpanzee Population and Habitat Viability Assessment for Sierra Leone: Final Report. IUCN/SSC Conservation Breeding Specialist Group - Europe (CBSG Europe), Copenhagen, Denmark.

Casanova C. Sousa C. 2007. Plano de acção nacional para a conservação das populações de chimpanzés, cólobus vermelhos ocidentais e cólobos brancos e pretos ocidentais na República da Guiné-Bissau. Bissau. IBAP. Ministério do Desenvolvimento Rural, Agricultura, Recursos Naturais e Ambiente, Bissau. 101 p.

Chapman C et al. 2006. Do food availability, parasitism, and stress have synergistic effects on red colobus populations living in forest fragments? American Journal of Physical Anthropology 131, 525-534.

Colding, J, Folke C. 1997. The relations among threatened species, their protection, and taboos. Conservation Ecology 1: e6.

Cutillas C. et al. 2009. Trichuris suis and Trichuris trichiura are different nematode species. Acta Tropica 111, 299-307.

Engels D, Savioli L. 2006. Reconsidering the underestimated burden caused by neglected tropical diseases.Trends Parasitol 22, 363-366.

FAO. 2007. State of World Forests. Forestry Department, FAO, United Nations, Rome. 
Fuentes A, Hockings K. 2010. The ethnoprimatological approach in primatology. American Journal of Primatology 72:841-847.

Gagneux P, Wills C, Gerloff U, et al. 1999. Mitochondrial sequences show diverse evolutionary histories of African hominoids. Proceedings of the National Academy of Sciences 96: 5077-5082.

Gillespie TC, Chapman CA, Greiner EC. 2005a. Effects of logging on gastrointestinal parasite infections and infection risk in African primates. Journal of Applied Ecology 42: 699-707.

Goldberg TL, Ruvolo M. 1997b. Molecular phylogenetics and historical biogeography of east African chimpanzees. Biological Journal of the Linnean Society 61: 301-324.

Gonder MK, Disotell TR. 2006. Contrasting phylogeographic histories of chimpanzees in Nigeria and Cameroon: A multilocus analysis. Primate Biogeography. Lehman and Fleagle (eds.). Plenun/Kluwer Press, New York.

Guillot G. et al. 2005. A Spatial Statistical Model for Landscape Genetics. Genetics. $170,1261-1280$.

Hobbs Gl. et al. 2006. Landscape Genetics applied to a recovering otter (Lutra lutra) population in the UK: preliminary results and potential methodologies. Hystrix International Journal of Mammology. 17, 47-63.

Hockings K, Sousa C. 2011. Human-chimpanzee sympatry and interactions in Cantanhez National Park, Guinea-Bissau: Current Research and future directions. Primate Conservation 26.

Holderegger R. Wagner HH. 2006. A brief guide to Landscape Genetics. Landscape 
Ecology. 21, 793-796.

Hotez PJ et al. 2007. Control of neglected tropical diseases. New England Journal of Medicine 357, 1018-1027.

Hotez PJ et al. 2009. Rescuing the bottom billion through control of neglected tropical diseases. The Lancet. 373, 1570-1575.

Huffman MA, Chapman C.: Primate parasite ecology: The dynamics of host-parasite relationships. Cambridge: Cambridge University Press. 297-310.

Hunter PR, Nichols G. 2002. Epidemiology and clinical features of Cryptosporidium infection in immunocompromised patients. Clinical Microbiology Review 15, 145154.

IUCN. 2010. IUCN Red list of threatened species. Version 2010.4. www.iucn.org. Viewed in 21 April 2011.

Kirksey SE, Helmreich S. 2010. The emergence of multispecies ethnography. Cultural Anthropology 25, 545-576.

Kuntz RE, Meyers BJ. 1967. Nonhuman primates in biomedical research: Diseases. Primates. 8, 75-82.

Leypey F, Fomine M. 2010. Edible wild animals as source of medication in Cameroon. Petit Propos Cullinaires 90, 99-117.

Manel S., et al. 2003. Landscape genetics: combining landscape ecology and population genetics. Trends in Ecology and Evolution 18, 189-197.

Manel S. Segelbacher G. 2009. Perspectives and chalenges in landscape genetics. Molecular Ecology 18, 1821-1822. 
Morin PA, Moore JJ, Chakraborty, R. et al. 1994. Kin selection, social structure, gene flow, and the evolution of chimpanzees. Science 265: 1193-1201.

Oates JF, et al. 2011. Pan troglodytes. In: IUCN Red List of Threatened Species. Version 2010.3. Website: www.iucnredlist.org

Ooi HK, Tenora F, Itoh K, Kamiya M. 1993. Comparative study of Trichuris trichiura from non-human primates and from man, and their difference with $T$. suis. Journal of Veterinary Medicine Sciences 55:363-366.

Oom D. et al. 2009. Quantification of deforestation rates in Guinea-Bissau- a baseline carbon trading under REDD. $33^{\text {rd }}$ International Symposium on Remote Sensing of Environment, 4-8 May 2009, Stresa, Italy.

Pedersen AB, Jones KE, Nunn CL, Altizer S. 2007. Infectious diseases and extinction risk in wild animals. Conservation Biology 21: 1269-1279.

Soulsby EJL 1982. Helminths, Arthropods and Protozoa of domesticated animals. London: Bailliere Tindall.

Sousa, J., Barata, A., Sousa, C., Casanova, C., and Vicente, L. Chimpanzee oil-palm use in southern Cantanhez National Park, Guinea-Bissau. 2011. American Journal of Primatology 73:1 -13.

Starr MC, Montgomery SP. 2011. Soil-transmitted helminthiasis in the United States: A systematic review -1940-2010. American Journal of Medicine and Hygiene 85, 680-684.

Whiten A. et al. 2001. Charting cultural variation in chimpanzees. Behaviour 138, 
1481-1516.

Wolfe LD, Fuentes A. 2007. Ethnoprimatology. In: Primates in Perspective, Campbell CJ, Fuentes A, et al. (eds). Oxford University Press, pp. 691-70. 


\section{Appendixes}

"In the end we will conserve only what we love. We will love only what we understand. We will understand only what we are taught."

- Baba Dioum, Senegalese Poet 


\section{APPENDIXES}

Appendix A: Prevalence table of gastrointestinal symbionts of Chimpanzees in Cantanhez, Cufada, and Boé, Guinea-Bissau (2010)

\begin{tabular}{|c|c|c|}
\hline Parasite & Samples $(n=116)$ & Prevalence \\
\hline \multicolumn{3}{|l|}{ Protozoa } \\
\hline Entameeba sp. & 19 & $16.38 \%$ \\
\hline Entamoeba coll & 41 & $3534 \%$ \\
\hline Iodamoeba bucrschlih & 22 & $18.97 \%$ \\
\hline Endolinnax nana & 4 & $3.45 \%$ \\
\hline Giardia duoderalis & 12 & $10.34 \%$ \\
\hline Chilomasrix mesnilii & 6 & $5.17 \%$ \\
\hline Blastocystis sp. & 46 & $39.66 \%$ \\
\hline Troglodyzella abraxsarzi & 82 & $70.69 \%$ \\
\hline Troglecorys cava & 13 & $1121 \%$ \\
\hline \multicolumn{3}{|l|}{ Cestoda } \\
\hline Bertiella sp. & 13 & $1121 \%$ \\
\hline \multicolumn{3}{|l|}{ Nematoda } \\
\hline $\begin{array}{l}\text { Srrongovida fam. gen. sp. } \\
\text { (Hookworms) }\end{array}$ & 36 & $31.03 \%$ \\
\hline Ascaris sp. & 2 & $1.72 \%$ \\
\hline Trichuris sp. & 9 & $7.76 \%$ \\
\hline Probstmayria gombensis & 1 & $0.86 \%$ \\
\hline Srrongloides stercoralis & 1 & $0.86 \%$ \\
\hline Srrongloides fulleborni & 4 & $3,45 \%$ \\
\hline Overall & 103 & $88.79 \%$ \\
\hline
\end{tabular}


Appendix B: Prevalence table of gastrointestinal symbionts of babboons in Cantanhez National Park, Guinea-Bissau (2010)

\begin{tabular}{lcc}
\hline Parasite & Samples (n=48) & Prevalence \\
\hline Protozoa & 39 & $81.25 \%$ \\
\hline Entamoeba sp. & 17 & $35.42 \%$ \\
Entamoeba coli & 17 & $35.42 \%$ \\
Iodamoeba buetschlii & 3 & $6.25 \%$ \\
Endolimax nana & 13 & $27.08 \%$ \\
Giardia duodenalis & 10 & $20.83 \%$ \\
Chilomastix mesnilii & 31 & $64.58 \%$ \\
Blastocystis sp. & 11 & $22.92 \%$ \\
Balantidium coli & & \\
& & \\
Nematoda & 31 & $64.58 \%$ \\
Strongylida fam. gen. sp. & 7 & $14.58 \%$ \\
(Hookworms) & 37 & $77.08 \%$ \\
Strongyloides stercoralis & 3 & $6.25 \%$ \\
Trichuris sp. & 48 & $100 \%$ \\
Spirurida fam. gen. sp. & & \\
Overall & & \\
\hline
\end{tabular}


Appendix C: Prevalence table of gastrointestinal symbionts of Western red colobus in Cantanhez National Park, Guinea-Bissau (2010)

\begin{tabular}{lcc}
\hline \multicolumn{1}{c}{ Parasite } & Samples $(\mathbf{n}=\mathbf{3 0})$ & Prevalence \\
\hline Protozoa & 21 & $70 \%$ \\
\hline Entamoeba sp. & 3 & $10 \%$ \\
Entamoeba coli & 6 & $20 \%$ \\
Iodamoeba buetschlii & 1 & $3.33 \%$ \\
Endolimax nana & 7 & $23.33 \%$ \\
Giardia duodenalis & 3 & $10 \%$ \\
Chilomastix mesnilii & 2 & $6.66 \%$ \\
Blastocytis sp. & & \\
Cestoda & 1 & $3.33 \%$ \\
Bertiella sp. & & \\
Nematoda & 9 & $30 \%$ \\
Strongylida fam. gen. & & \\
sp. (Hookworms) & & $70 \%$ \\
Trichuris sp. & 21 & $96.6 \%$ \\
Overall & 29 & \\
\hline
\end{tabular}


Appendix D: Prevalence table of gastrointestinal symbionts of Black and White colobus in Cantanhez National Park, Guinea-Bissau (2010)

\begin{tabular}{lcc}
\hline \multicolumn{1}{c}{ Parasite } & Samples $(\mathbf{n}=\mathbf{3 3})$ & Prevalence \\
\hline 'Totozoa & 27 & $81.82 \%$ \\
\hline Entamoeba sp. & 2 & $6.06 \%$ \\
Entamoeba coli & 8 & $24.24 \%$ \\
'odamoeba buetschlii & 1 & $3.03 \%$ \\
Endolimax nana & 5 & $15.15 \%$ \\
Giardia duodenalis & 4 & $12.12 \%$ \\
Chilomastix mesnilii & 7 & $21.21 \%$ \\
Blastocystis sp. & & \\
& & \\
Vematoda & 8 & $24.24 \%$ \\
Strongylida fam. gen. sp. & 8 & $24.24 \%$ \\
Hookworms) & 10 & $30.30 \%$ \\
Strongyloides stercoralis & & $90.91 \%$ \\
Trichuris sp. & & \\
Jverall & & \\
\hline
\end{tabular}


Appendix E: Prevalence table of gastrointestinal symbionts of Humans in Cantanhez National Park, Guinea-Bissau (2010)

\begin{tabular}{lcc}
\hline \multicolumn{1}{c}{ Parasite } & Samples (n =72) & Prevalence \\
\hline Protozoa & & \\
\hline Entamoeba sp. & 14 & $19.44 \%$ \\
Entamoeba coli & 58 & $80.56 \%$ \\
Iodamoeba buetschlii & 16 & $22.22 \%$ \\
Endolimax nana & 9 & $12.5 \%$ \\
Giardia duodenalis & 13 & $18.06 \%$ \\
Chilomastix mesnilii & 13 & $18.06 \%$ \\
Blastocystis sp. & 49 & $68.06 \%$ \\
& & \\
Nematoda & & \\
\hline Strongylida fam. gen. sp. & 39 & $54.17 \%$ \\
(Hookworms) & 13 & \\
Ascaris lumbricoides & 7 & $19.06 \%$ \\
Trichuris sp. & 3 & $9.72 \%$ \\
Oesophagostomum sp. & 1 & $1.17 \%$ \\
Spirurida fam. gen.sp. & 1 & $1.39 \%$ \\
Enterobius vermicularis & 6 & $8.33 \%$ \\
Strongyloides stercoralis & 6 & $8.33 \%$ \\
Strongyloides fulleborni & & \\
& 70 & $97.22 \%$ \\
Overall & & \\
\hline
\end{tabular}


Appendix F: List of Guinea-Bissau chimpanzees HVR1 haplotypes, to be deposited in GenBank

$>\mathrm{H} 1$ Cancira4

TAATTTAAACTATTCTCTGTTCTTTCATGGGGAAGCAAATTTAAGTACCACCTAAGTACT GGCTCATTCATTACAACCGCTATGTATTTCGTACATTACTGCCAGCCACCATGAATATTG TACAGTACCATAATCACCCAACCACCTATAGCACATAAAATCCAC-CTCACATTAAAACC TTCACCCCATGCTTACAAGCACGCACAACAATCAACCCCCAACTATCGAACATAAAACAC AACTCCAACGACACTTCTCCCCCACCCTAATACCAACAAACCTACCCTCCCTT-GACAAA ACATAATACATACAATCACACACCGTACATAGCACATTACAGTCAAATCCATCCTTGCCC CCACGGATGATCCCCCTCAGATGGGAATCCCTTGACCACCATCCTCCGTGAAATCAATAT CCCGCACAAGAGTACTACTCTCCTCGCTCCGGGCCCATAACATCTGGGGGTAGCTAAAGT GA $>$ H2_MEJ2O3 TAATTTAAACTATTCTCTGTTCTTTCATGGGGAAGCAAATTTAAGTACCACCTAAGTACT GGCTCATTCATTACAACCGCTATGTATTTCGTACATTACTGCCAGCCACCATGAATATTG TACGGTACCATAATCACCCAACTACCTATAACACATAAAACCCAC-CCCACATTAAAACC TTCACCCCATGCTTACAAGCACGCACAACAATCAACCTCTAACTATCAAACATAAAACAC AACTCCAACGACACTTCTCCCCCACCCCGATACCAACAAACCTACCCCCCCTT-GACAAA ACATAGTACATACAATCACACACCGTACATAGCACATTACAGTCAAATCCATCCTCGCCC CCACGGATGATCCCCCTCAGATAGGAATCCCTTGACCACCATCCTCCGTGAAATCAATAT CCCGCACAAGAGTGCTACTCTCCTCGCTCCGGGCCCATAACATCTGGGGGTAGCTAAAGT GA

>H3_CUF41

TAATTTAAACTATTCTCTGTTCTTTCATGGgGAAGCAAATTTAAGTACCACCTAAGTACT GGCTCATTCATTACAACCGCTATGTATTTCGTACATTACTGCCAGCCACCATGAATATTG TACGGTACCATAATCACCCAACCACCTATAATACATAAAACCCAC-CCCACATTAAAACC TTCACCCCATGCTTACAAGCACGCACAACAATCAACCTCCAACTATCGAACATAAAACAC AACCCCAACGACACTCCTCCCCCACCCCGATACCAACAAACCCACCCCCCCTT-GACAAG 
ACATAGTACATACAATCATACATCGTACATAGCACATTACAGTCAAATCCATCCTTGTCC CCACGGATGACCCCCCCCAGATGGGAATCCCTTGACCACCATCCTCCGTGAAATCAATAT CCCGCACAAGAGTACTACTCCCCTCGCTCCGGGCCCATAACATCTGGGGGTAGCTAAAGT GA

$>\mathrm{H} 4$ _CANCIRA3

TAATTTAAACTATTCTCTGTTCTTTCATGgGgAAGCAAATTTAAGTACCACCTAAGTACT GGCTCATTCATTACAACCGCTATGTATTTCGTACATTACTGCCAGCCACCATGAATATTG TACAGTACCATAATCACCCAACTACCTATAACACATAAAATCCACTCCCACACCAAAACC TTCACCCCATGCTTACAAGCACGCACAACAATCAACCTCCAACTGTCGAACATAAAACAC AACTCCAACGACACCCCTCCCCCACCCCGATATCAACAGACCTACCCCCCCTT-GACAGA ACATAGTACATACAATCATACACCGTACATAGCACATTACAGTCAAATTCTTCCTCGTCC CCACGGATGCCCCCCCTCAGATAGGAATCCCTTGGTCACCATCCTCCGTGAAATCAATAT CCCGCACAAGAGTGCTACTCTCCTCGCTCCGGGCCCATAACATCTGGGGGTAGCTAAAGT GA

$>$ H5_CUF48

TAATTTAAACTATTCTCTGTTCTTTCATGGGGAAGCAAATTTAAGTACCACCTAAGTACT GGCTCATTCATTACAACCGCTATGTATTTCGTACATTACTGCCAGCCACCATGAATATTG TACGGTACCATAACTACCCAACTACCTATAACACATAAAACCCAC-CCCACATTAAAACC TTCACCCCATGCTTACAAGCACGCACAACAATCAACCTCTAACTATCAAACATAAAACAC AACTCCAACGACACTTCTCCCCCACCCCGATACCAACAAACCTACCCCCCCTT-GACAAA ACATAGTACATACAATCACACACCGTACATAGCACATTACAGTCAAATCCATCCTCGCCC CCACGGATGATCCCCCTCAGATAGGAATCCCTTGACCACCATCCTCCGTGAAATCAATAT CCCGCACAAGAGTGCTACTCTCCTCGCTCCGGGCCCATAACATCTGGGGGTAGCTAAAGT GA >H6_CUF46 TAATTTAAACTATTCTCTGTTCTTTCATGGgGAAGCAAATTTAAGTACCACCTAAGTACT GGCTCATTCATTACAACCGCTATGTATTTCGTACATTACTGCCAGCCACCATGAATATTG TACAGTACCATAATCACCCAACTACCTATAATACATAAAATCCACTCCCACACCAAAACC 
TTCACCCCATGCTTACAAGCACGCACAACAATCAACCTCCAACTGTCGAACATAAGACAC AACTCCAACGACACCCCTCCCCCACCCCGATATCAACAGACCTACCCCCCCCC-GACAGA ACATAGTACATACAATCATACACCGTACATAGCACATTACAGTCAAACTCTTCCTCGTCC CCACGGATGCCCCCCCTCAAATAGGAATCCCTTGGTCACCATCCTCCGTGAAATCAATAT CCCGCACAAGAGTGCTACTCTCCTCGCTCCGGGCCCATAACATCTGGGGGTAGCTAAAGT GA

$>$ H7_CUF43

TAATTTAAACTATTCTCTGTTCTTTCATGGGGAAGCAAATTTAAGTACCACCTAAGTACT GGCTCATTCATTACAACCGCTATGTATTTCGTACATTACTGCCAGCCACCATGAATATTG TACAGTACCATAATCACCCAACTACCTATAATACATAAAATCCACTCCCACACCAAAACC TTCACCCCATGCTTACAAGCACGCACAACAATCAACCTCCAACTGTCGAACATAAGACAC AACTCCAACGACACCCCTCCCCCCCCCCGATATCAACAGACCTACCCCCCCCC-GACAGA ACATAGTACATACAATCATACACCGTACATAGCACATTACAGTCAAACTCTTCCTCGTCC CCACGGATGCCCCCCCTCAGATAGGAATCCCTTGGTCACCATCCTCCGTGAAATCAATAT CCCGCACAAGAGTGCTACTCTCCTCGCTCCGGGCCCATAACATCTGGGGGTAGCTAAAGT GA

>H8_CUF39

TAATTTAAACTATTCTCTGTTCTTTCATGGGGAAGCAAATTTAAGTACCACCTAAGTACT GGCTCATTCATTACAACCGCTATGTATTTCGTACATTACTGCCAGCCACCATGAATATTG TACAGTACCATAATCACCCAACTACCTATAACACATAAAATCCACTCCCACACCAAAACC TTCACCCCATGCTTACAAGCACGCACAACAATCAACCTCCAACTGTCAAACATAAAACAC AACTCCAACGACACCCCTCCCCCACCCCGATATCAACAGACCTACCCCCCCTT-GACAGA ACATAGTACATACAATCATACACCGTACATAGCACATTACAGTCAAATTCTTCCTCGTCC CCACGGATGCCCCCCCTCAGATAGGAATCCCTTGGTCACCATCCTCCGTGAAATCAATAT CCCGCACAAGAGTGCTACTCTCCTCGCTCCGGGCCCATAACATCTGGGGGTAGCTAAAGT GA >H9_CUF34 TAATTTAAACTATTCTCTGTTCTTTCATGGGGAAGCAAATTTAAGTACCACCTAAGTACT GGCTCATTCATTACAACCGCTATGTATTTCGTACATTACTGCCAGCCACCATGAATATTG 
TACAGTACCATAATCACCCAACTACCTATAATACATAAAATCCACTCCCACACCAAAACC TTCACCCCATGCTTACAAGCACGCACAACAATCAACCTCCAACTGTCGAACATAAAACAC AACTCCAACGACACCCCTCCCCCACCCCGATATCAACAAACCTACCCCCCCTT-GACAGA ACATAGTACATACAATCATACACCGTACATAGCACATTACAGTCAAACTCTTCCTCGTCC CCACGGATGCCCCCCCTCAGATAGGAATCCCTTGGTCACCATCCTCCGTGAAATCAATAT CCCGCACAAGAGTGCTACTCTCCTCGCTCCGGGCCCATAACACCTGGGGGTAGCTAAAGT GA >H10_CUF29 TAATTTAAACTATTCTCTGTTCTTTCATGGGGAAGCAAATTTAAGTACCACCTAAGTACT GGCTCATTCATTACAACCGCTATGTATTTCGTACATTACTGCCAGCCACCATGAATATTG TACGGTACCATAATCACCCAACTACCTATAACACATAAAACCCAC-CCCACATTAAAACC TTCACCCCATGCTTACAAGCACGCACAACAATCAACCTCTAACTATCAAACATAAAACAC AACTCCAACGACACTTCTCCCCCACCCCGATACCAACAAACCTACCCCCCCTT-GACAAA ACATAGTACATACAATCACACATCGTACATAGCACATTACAGTCAAATCCATCCTCGCCC CCACGGATGATCCCCCTCAGATAGGAATCCCTTGACCACCATCCTCCGTGAAATCAATAT CCCGCACAAGAGTGCTACTCTCCTCGCTCCGGGCCCATAACATCTGGGGGTAGCTAAAGT GA

>H11_CUF24 TAATTTAAACTATTCTCTGTTCTTTCATGGgGAAGCAAATTTAAGTACCACCTAAGTACT GGCTCATTCATTACAACCGCTATGTATTTCGTACATTACTGCCAGCCACCATGAATATTG TACAGTACCATAATCACCCAACTACCTATAACACATAAAATCCACTCCCACACCAAAACC TTCACCCCATGCTTACAAGCACGCACAACAATCAACCTCCAACTGTCGAACATAAAACAC AACTCCAACGACACCCCTCCCCCCCCCCGATATCAACAGACCTACCCCCCCCT-GACAAA ACATAATACATACAATCATACACCGTACATAGCACATTACAGTCAAATTCTTCCTCGTCC CCACGGATGCCCCCCCCCAAATAGGAATCCCTTGGTCACCATCCTCCGTGAAATCAATAT CCCGCACAAAAGTGCTACTCCCCTCGCTCCGGGCCCATAACATCTGGGGGTAGCTAAAGT GA 
$>$ H12_CUF12

TAATTTAAACTATTCTCTGTTCTTTCATGGGGAAGCAAATTTAAGTACCACCTAAGTACT GGCTCATTCATTACAACCGCTATGTATTTCGTACATTACTGCCAGCCACCATGAATATTG TACAGTACCATAATCACCCAACTACCTATAATACATAAAATCCACTCCCACACCAAAACC TTCACCCCATGCTTACAAGCACGCACAACAATCAACCTCCAACTGTCAAACATAAAACAC AACTCCAACGACACCCCTCCCCCACCCCGATATCAACAGACCTACCCCCCTT--GACAGA ACATAGTACATACAATCATACACCGTACATAGCACATTACAGTCAAACTCTTCCTCGTCC CCACGGATGCCCCCCCTCAGATAGGAATCCCTTGGTCACCATCCTCCGTGAAATCAATAT CCCGCACAAGAGTGCTACTCTCCTCGCTCCGGGCCCATAACACCTGGGGGTAGCTAAAGT GA $>$ H13_CNP1047 TAATTTAAACTATTCTCTGTTCTTTCATGgGgAAGCAaATTTaaGTACCACCtAAGTAcT GgCTCAttCATtACAACCGCTATGTATTTCGTACATTACTGCCAGCCACCATGAATATtG TACGGTACCATAAATACccaACCACCTaTAGTACATAAAAACCacATCCACATCAAAACC ttCaCCCCATGCTTACAAGCAcGcACAaCAATCAACCTcCAACTATCAaACATaAAAcaC AACTCCAAcGaCACCCCTCcCCCACccGAATACCAACAAACCTACCCACCCTT-gACAGT ACATAGTACATAcAatCATacACCGTACATAGCACATTACAGTCAAATCCCTTCTCGTCC CCAcGGATGACCCCCCTCAGATAGGaaTCCCTTGACCACCATCCTCCGTGAAATCAATAT CCCGCACAAGAGTGCTACTCTCCTCGCTCCGGGCCCATAACACCTGGGGGTAGCTAAAGT GA $>$ H14_CNP10123 TAATTTAAACTATTCTCTGTTCTTTCATGGGGAAGCAAATTTAAGTACCACCTAAGTACT GGCTCATTCATTACAACCGCTATGTATTTCGTACATTACTGCCAGCCACCATGAATATTG TACGGTACCATAATTACCCAACTACCTATAACACATAAAACCCAC-CCCACATTAAAACC TTCACCCCATGCTTACAAGCACGCACAACAATCAACCTCTAACTATCAAACATAAAACAC AACTCCAACGACACTTCTCCCCCACCCCGATACCAACAAACCTACCCCCCCTT-GACAAA ACATAGTACATACAATCACACACCGTACATAGCACATTACAGTCAAATCCATCCTCGCCC CCACGGATGATCCCCCTCAGATAGGAATCCCTTGACCACCATCCTCCGTGAAATCAATAT CCCGCACAAGAGTGCTACTCTCCTCGCTCCGGGCCCATAACATCTGGGGGTAGCTAAAGT 
$>$ H15_CNP10118

TAATTTAAACTATTCTCTGTTCTTTCATGGGGAAGCAAATTTAAGTACCACCTAAGTACT GGCTCATTCATTACAACCGCTATGTATTTCGTACATTACTGCCAGCCACCATGAATATTG TACAGTACCATAATCACCCAACCACCTATAATACATAAAACCCAC-CCCACATTAAAACC TTCACCCCATGCTTACAAGCACGCACAACAATCAACCTCCAACTATCGAACATAAAACAC AACCCCAACGACACTCCTCCCCCACCCCGATACCAACAAACCCACCCCCCCTT-GACAAG ACATAGTaCATACAATCATACATCGTACATAGCACATTACAGTCAAATCCATCCTTGTCC CCACGGATGACCCCCCCCAGATGGGAATCCCTTGACCACCATCCTCCGIGAAATCAATAT CCCGCACAAGAGTACTACTCCCCTCGCTCCGGGCCCATAACATCTGGGGGTAGCTAAAGT GA

$>$ H16_848T

TAATTTAAACTATTCTCTGTTCTTTCATGGGGAAGCAAATTTAAGTACCACCTAAGTACT GGCTCATTCATTACAACCGCTATGTATTTCGTACATTACTGCCAGTCACCATGAATATTG TACAGTACCATAATCACCCAACTACCTATAATACATAAAATCCACTCCCACACCAAAACC TTCACCCCATGCTTACAAGCACGCACAACAATCAACCTCCAACTGTCAAACATAAAACAC AACCCCAACGACACCCCTCCCCCACCCCGATATCAACAGACCTACCCCCCTT--GACAGA ACATAGTACATACAATCATACACCGTACATAGCACATTACAGTCAAACTCTTCCTCGTCC CCACGGATGCCCCCCCTCAGATAGGAATCCCTTGGTCACCATCCTCCGTGAAATCAATAT CCCGCACAAGAGTGCTACTCTCCTCGCTCCGGGCCCATAACACCTGGGGGTAGCTAAAGT GA

>H17_CNP10251

TAATTTAAACTATTCTCTGTTCTTTCATGGGGAAGCAAATTTAAGTACCaCCTAAGTACT GGCTCATTCATTACAACCGCTATGTATTTCGTACATTACTGCCAGCCACCATGAATATTG TACAGTACCATAATCACCCAACTACCTATAACACATAAAATCCACTCCCaCaCCAAAACC TTCaCCCCATGCTTACAAGCACGCACAACAATCAACCTCCAACTGTCGAACATAAAACAC AACTCCAACGACACCCCTCCCCCACCCCGATATCAACAGACCTACCCCCCCCTTGACAAA ACATAGTACATACAATCATACACCGTACATAGCACATTACAGTCAAATTCTTCCTCGTCC 
CCACGGATGCCCCCCCTCAAATAGGAATCCCTTGGTCACCATCCTCCGTGAAATCAATAT CCCGCACAAAAGTGCTACTCTCCTCGCTCCGGGCCCATAACATCTGGGGGTAGCTAAAGT GA >H18_CNP10175 TAATTTAAACTATTCTCTGTTCTTTCATGGgGAAGCAAAtTTAAGTACCACCTAAGTACT GGCTCATTCATTACAACCGCTATGTATTTCGTACATTACTGCCAGCCACCATGAATATTG TACGGTACCATAATTACCCAACTACCTATAACACATAAAACCCAC-CCCACATTAAAACC TTCACCCCATGCTTACAAGCACGCACAACAATCAACCTCTAACTATCAAACATAAAGCAC AACTCCAACGACACTTCTCCCCCACCCCGATACCAACAAACCTACCCCCCCTT-GACAAA ACATAGTACATACAATCACACACCGTACATAGCACATTACAGTCAAATCCATCCTCGCCC CCACGGATGATCCCCCTCAGATAGGAATCCCTTGACCACCATCCTCCGTGAAATCAATAT CCCGCACAAGAGTGCTACTCTCCTCGCTCCGGGCCCATAACATCTGGGGGTAGCTAAAGT GA >H19_B28 TAATTTAAACTATTCTCTGTTCTTTCATGGGGAAGCAAATTTAAGTACCACCTAAGTACT GGCTCATTCATTACAACCGCTATGTATTTCGTACATTACTGCCAGCCACCATGAATATTG TACAGTACCATAATCACCCAACCACCTATAGCACATAGAATCCAC-TTCACATTAAAACC TTCACCCCATGCTTACAAGCACGCACAACAATCAACCCCCAACTATCGAACATAAAACAC AACTCCAACGACACTTCTCCCCCACCCTAATACCAACAAACCTACCCTCCCTT-GACAAA ACATAATACATACAATCACACACCGTACATAGCACATTACAGTCAAATCCATCCTTGCCC CCACGGATGATCCCCCTCAGATGGGAATCCCTTGACCACCATCCTCCGTGAAATCAATAT CCCGCACAAGAGTACTACTCTCCTCGCTCCGGGCCCATAACATCTGGGGGTAGCTAAAGT GA $>$ H20_CNP10126 TAATTTAAACTATTCTCTGTTCTTTCATGGGGAAGCAAATTTAAGTACCACCTAAGTACT GGCCCATTCATTACAACCGCTATGTATTTCGTACATTACTGCCAGTCACCATGAATATTG TACAGTACCATAATCACCCAACTACCTATAATACATAAAATCCACTCCCACACCAAAACC TTCACCCCATGCTTACAAGCACGCACAACAATCAACCTCCAACTGTCAAACATAAAACAC 
AACTCCAACGACACCCCTCCCCCACCCCGATATCAACAGACCTACCCCCCTT--GACAGA ACATAGTACATACAATCATACACCGIACATAGCACATTACAGTCAAACTCTTCCTCGTCC CCACGGATGCCCCCCCTCAGATAGGAATCCCTTGGTCACCATCCTCCGTGAAATCAATAT CCCGCACAAGAGTGCTACTCTCCTCGCTCCGGGCCCATAACACCTGGGGGTAGCTAAAGT GA >H21_CCT14 TAATTTAAACTATTCTCTGTTCTTTCATGGGGAAGCAAATTTAAGTACCACCTAAGTACT GGCTCATTCATTACAACCGCTATGTATTTCGTACATTACTGCCAGCCACCATGAATATTG TACGGTACCATAATCACCCAACCACCTATAATACATAAAACCCAC-CCCACATTAAAACC TTCACCCCATGCTTACAAGCACGCACAACAATCAACCTCCAACTATCGAACATAAAGCAC AACCCCAACGACACTCCTCCCCCACCCCGATACCAACAAACCCACCCCCCCTT-GACAAG ACATAGTACATACAATCATACATCGTACATAGCACATTACAGTCAAATCCATTCTTGTCC CCACGGATGACCCCCCCCAGATGGGAATCCCTTGACCACCATCCTCCGTGAAATCAATAT CCCGCACAAGAGTACTACTCCCCTCGCTCCGGGCCCATAACATCTGGGGGTAGCTAAAGT GA $>$ H22_B10 TAATTTAAACTATTCTCTGTTCTTTCATGGGGAAGCAAATTTAAGTACCACCTAAGTACT GGCTCATTCATTACAACCGCTATGTATTTCGTACATTACTGCCAGCCACCATGAATATTG TACAGTACCATAATCACCCAACCACCTATAACACATAGAATCCAC-CTCACATTAAAACC TTCACCCCATGCTTACAAGCACGCACAACAATCAACCCCCAACTATCGAACATAAAACAC AACTCCAACGACACTTCTCCCCCACCCTAATACCAACAAACCTACCCTCCCTT-GACAAA ACATAATACATACAATCACACATCGTACATAGCACATTACAGTCAAATCCATCCTTGCCC CCACGGATGATCCCCCTCAGATGGGAATCCCTTGACCACCATCCTCCGTGAAATCAATAT CCCGCACAAGAGTACTACTCTCCTCGCTCCGGGCCCATAACATCTGGGGGTAGCTAAAGT GA $>$ H23_CCT12 TAATTTAAACTATTCTCTGTTCTTTCATGGGGAAGCAAATTTAAGTACCACCTAAGTACT GGCTCATTCATTACAACCGCTATGTATTTCGTACATTACTGCCAGTCACCATGAATATTG TACAGTACCATAATCACCCAACTACCTATAATACATAAAATCCACTCCCACACCAAAACC 
TTCACCCCATGCTTACAAGCACGCACAACAATCAACCTCCAACTGTCAAACATAAAACAC AACTCCAACGACACCCCTCCCCCACCCCGATATCAACAGACCTACCCCCCTT--GACAGA ACATAGTACATACAATCATACACCGTACATAGCACATTACAGTCAAACTCTTCCTCGTCC CCACGGATGCCCCCCCTCAGATAGGAATCCCTTGGTCACCATCCTCCGTGAAATCAATAT CCCGCACAAGAGTGCTACTCTCCTCGCTCCGGGCCCATAACACCTGGGGGTAGCTAAAGT GA $>$ H24_CCT19 TAATTTAAACTATTCTCTGTTCTTTCATGGGGAAGCAAATTTAAGTACCACCTAAGTACT GGCTCATTCATTACAACCGCTATGTATTTCGTACATTACTGCCAGCCACCATGAATATTG TACAGTACCATAATCACCCAACTACCTATAATACATAAAATCCACTCCCACACCAAAACC TTCACCCCATGCTTACAAGCACGCACAACAATCAACCTCCAACTGTCGAACATAAAACAC AACTCCAACGACACCCCTCCCCCACCCCGATATCAACAAACCTACCCCCCCTT-GACAGG ACATAGTACATACAATCATACACCGTACATAGCACATTACAGTCAAACTCTTCCTCGTCC CCACGGATGCCCCCCCTCAGATAGGAATCCCTTGGTCACCATCCTCCGTGAAATCAATAT CCCGCACAAGAGTGCTACTCTCCTCGCTCCGGGCCCATAACACCTGGGGGTAGCTAAAGT GA $>$ H25_CCT17 TAATTTAAACTATTCTCTGTTCTTTCATGGGGAAGCAAATTTAAGTACCACCTAAGTACT GGCTCATTCATTACAACCGCTATGTATTTCGTACATTACTGCCAGCCACCATGAATATTG TACGGTACCATAATCACCCAACCACCTATAATACATAAAACCCAC-CCCACATTAAAACC TTCACCCCATGCTTACAAGCACGCACAACAATCAACCTCCAACTATCGAACATAAAACAC AACCCCAACGACACTCCTCCCCCACCCCGATACCAACAAACCCACCCCCCCTT-GACAAG ACATAGTACATACAATCATACATCGTACATAGCACATTACAGTCAAATCCATTCTTGTCC CCACGGATGACCCCCCCCAGATGGGAATCCCTTGACCACCATCCTCCGTGAAATCAATAT CCCGCACAAGAGTACTACTCCCCTCGCTCCGGGCCCATAACATCTGGGGGTAGCTAAAGT GA 
$>$ H26_B22

TAATTTAAACTATTCTCTGTTCTTTCATGGGGAAGCAAATTTAAGTACCACCTAAGTACT GGCTCATTCATTACAACCGCTATGTATTTCGTACATTACTGCCAGCCACCATGAATATTG TACAGTACCATAATCACCCAACTACCTATAATACATAAAATCCACTCCCACACCAAAACC TTCACCCCATGCTTACAAGCACGCACAACAATCAACCTCCAACTGTCGAACATAAAACAC AACTCCAACGACACCCCTCCCCCACCCCGATATCAACAGACCTACCCCCCCTT-GACAGA ACATAGTACATACAATCATACACCGTACATAGCACATTACAGTCAAACTCTTCCTCGTCC CCACGGATGCCCCCCCTCAGATAGGAATCCCTTGGTCACCATCCTCCGTGAAATCAATAT CCCGCACAAGAGTGCTACTCTCCTCGCTCCGGGCCCATAACATCTGGGGGTAGCTAAAGT GA $>$ H27_CANCIRA2 TAATTTAAACTATTCTCTGTTCTTTCATGGGGAAGCAAATTTAAGTACCACCTAAGTACT GGCTCATTCATTACAACCGCTATGTATTTCGTACATTACTGCCAGCCACCATGAATATTG TACAGTACCATAATCACCCAACTACCTATAGCACATAAAACCCAC-CCCACATTAAAACC TTCACCCCATGCTTACAAGCACGCACAACAATCAACCTCTAACTATCAAACATAAAACAC AACTCCAACGACACCTCTCCCCCACCCCGATACCAACAAACCTACCCCCCCTT-GACAAA ACATAGTACATACAATCACACACCGTACATAGCACATTACAGTCAAATCCATCCTTGCCC CCACGGATGATCCCCCTCAGATAGGAATCCCTTGACCACCATCCTCCGTGAAATCAATAT CCCGCACAAGAGTGCTACTCTCCTCGCTCCGGGCCCATAACACCTGGGGGTAGCTAAAGT GA >H28_CADIQUE1015 TAATTTAAACTATTCTCTGTTCTTTCATGGGGAAGCAAATTTAAGTACCACCTAAGTACT GGCTCATTCATTACAACCGCTATGTATTTCGTACATTACTGCCAGCCACCATGAATATTG TACAGTACCATAATCACCCAACCACCTATAGCACATAAAATCCAC-CTCACATCAAAACC TTCACCCCATGCTTACAAGCACGCACAACAATCAACCCCCAACTATCGAACATAAAACAC AACTCCAACGACACTTCTCCCCCACCCTAATACCAACAAACCTACCCTCCCTT-GACAAA ACATAATACATACAATCACACACCGTACATAGCACATTACAGTCAAATCCATCCTTGCCC CCACGGATGATCCCCCTCAGATGGGAATCCCTTGGCCACCATCCTCCGTGAAATCAATAT CCCGCACAAGAGTACTACTCTCCTCGCTCCGGGCCCATAACATCTGGGGGTAGCTAAAGT 
>H29_CADIQUE1013

TAATTTAAACTATTCTCTGTTCTTTCATGGGGAAGCAAATTTAAGTACCACCTAAGTACT GGCTCATTCATTACAACCGCTATGTATTTCGTACATTACTGCCAGCCACCATGAATATTG TACAGTACCATAATCACCCAACTACCTATAATACATAAAATCCACTCCCACACCAAAACC TTCACCCCATGCTTACAAGCACGCACAACAATCAACCTCCAACTGTCGAACATAAAACAC AACTCCAACGACACCCCTCCCCCACCCCGATATCAACAGACCTACCCCCCCCTTGACAGA ACATAGTACATACAATCATACACCGTACATAGCACATTACAGTCAAACTCTTCCTCGTCC CCACGGATGCCCCCCCTCAAATAGGAATCCCTTGGTCACCATCCTCCGTGAAATCAATAT CCCGCACAAAAGTGCTACTCTCCTCGCTCCGGGCCCATAACATCTGGGGGTAGCTAAAGT GA >H30_CADIQUE1009 TAATTTAAACTATTCTCTGTTCTTTCATGGGGAAGCAAATTTAAGTACCACCTAAGTACT GGCTCATTCATTACAACCGCTATGTATTTCGTACATTACTGCCAGCCACCATGAATATTG TACGGTACCATAATTACCCAACTACCTATAACACATAAAACCCAC-CCCACATTAAAACC TTCACCCCATGCTTACAAGCACGCACAACAATCAACCTCTAACTATCAAACATAAAACAC AACTCCAACGACACTTCTCCCCCCCCCCCATACCAACAAACCTACCCCCCCTT-GACAAA ACATAGTACATACAATCACACACCGTACATAGCACATTACAGTCAAATCCATCCTCGCCC CCACGGATGATCCCCCTCAGATAGGAATCCCTTGACCACCATCCTCCGTGAAATCAATAT CCCGCACAAGAGTGCTACTCTCCTCGCTCCGGGCCCATAACATCTGGGGGTAGCTAAAGT GA

>H31_CADIQUE1001 TAATTTAAACTATTCTCTGTTCTTTCATGGGGAAGCAAATTTAAGTACCACCTAAGTACT GGCTCATTCATTACAACCGCTATGTATTTCGTACATTACTGCCAGCCACCATGAATATTG TACAGTACCATAATCACCCAACTACCTATAATACATAAAATCCACTCCCACACCAAAACC TTCACCCCATGCTTACAAGCACGCACAACAATCAACCTCCAACTGTCGAACATAAAACAC AACTCCAACGACACCCCTCCCCCCCCCCGATATCAACAGACCTACCCCCCCCTTGACAGA ACATAGTACATACAATCATACACCGTACATAGCACATTACAGTCAAACTCTTCCTCGCCC 
CCACGGATGCCCCCCCTCAAATAGGAATCCCTTGGTCACCATCCTCCGTGAAATCAATAT CCCGCACAAGAGTGCTACTCTCCTCGCTCCGGGCCCATAACATCTGGGGGTAGCTAAAGT GA $>$ H32_BOE18 TAATTTAAACTATTCTCTGTTCTTTCATGGGGAAGCAAATTTAAGTACCACCTAAGTACT GGCTCATTCATTACAACCGCTATGTATTTCGTACATTACTGCCAGCCACCATGAATATTG TACAGTACCATAATCACCCAACTACCTATAATACATAAAATCCACTCCCACACCAAAACC TTCACCCCATGCTTACAAGCACGCACAACAATCAACCTCCAACTGTCAAACATAAAACAC AACTCCAACGACACCCCTCCCCCACCCCGATATCAACAGACCTACCCCCCC-TTGACAGA ACATAGTACATACAATCATACACCGTACATAGCACATTACAGTCAAACTCTTCCTCGTCC CCACGGATGCCCCCCCTCAAATAGGAATCCCTTGGTCACCATCCTCCGTGAAATCAATAT CCCGCACAAGAGTGCTACTCTCCTCGCTCCGGGCCCATAACATCTGGGGGTAGCTAAAGT GA $>$ H33_BOE17 TAATTTAAACTATTCTCTGTTCTTTCATGGGGAAGCAAATTTAAGTACCACCTAAGTACT GGCTCATTCATTACAACCGCTATGTATTTCGTACATTACTGCCAGCCACCATGAATATTG TACGGTACCATAATTACCCAACTACCTATAACACATAAAACCCAC-CCCACATTAAAACC TTCACCCCATGCTTACAAGCACGCACAACAATCAACCTCTAACTATCAAACATAAAACAC AACTCCAACGACACTTCTCCCCCACCCCGATACCAACAAACCTACCCCCCCCT-GACAAA ACATAGTACATACAATCACACACCGTACATAGCACATTACAGTCAAATCCATCCTCGCCC CCACGGATGATCCCCCTCAGATAGGAATCCCTTGACCACCATCCTCCGTGAAATCAATAT CCCGCACAAGAGTGCTACTCTCCTCGCTCCGGGCCCATAACATCTGGGGGTAGCTAAAGT GA $>$ H34_BOE13 TAATTTAAACTATTCTCTGTTCTTTCATGGGGAAGCAAATTTAAGTACCACCTAAGTACT GGCTCATTCATTACAACCGCTATGTATTTCGTACATTACTGCCAGCCACCATGAATATTG TACAGTACCATAATCACCCAACTACCTATAGTACATAAAATCCACTCCCACATCAAAACC TTCACCCCATGCTTACAAGCACGCACAACAATCAACCCCCAACTGTCGAACATAAAACAC 
AACTCCAACGACACCCCTCCCCCACCCCGATACCAACAGACCTATCTCCCCTT-GACAGA ACATAGTACATACAATCATACACCGTACATAGCACATTACAGTCAAACCCCTCCTCGCCC CCACGGATGCTCCCCCTCAGATAGGAATCCCTTGGTCACCATCCTCCGTGAAATCAATAT CCCGCACAAGAGTGCTACTCTCCTCGCTCCGGGCCCATAACATCTGGGGGTAGCTAAAGT GA

$>$ H35_BOE08

TAATTTAAACTATTCTCTGTTCTTTCATGGGGAAGCAAATTTAAGTACCACCTAAGTACT GGCTCATTCATTACAACCGCTATGTATTTCGTACATTACTGCCAGCCACCATGAATATTG TACAGTACCATAATCACCCAACTACCTATAACACATAAAATCCACTCCCACACCAAAACC TTCACCCCATGCTTACAAGCACGCACAACAATCAACCTCCAACTGTCGAACATAAAACAC AACTCCAACGACACCCCTCCCCCACCCCGATATCAACAGACCTACCCCCCCTT-GACAAA ACATAATACATACAATCATACACCGTACATAGCACATTACAGTCAAATCCTTCCTCGTCC CCACGGATGCCCCCCCCCAGATAGGAATCCCTTGGTCACCATCCTCCGTGAAATCAATAT CCCGCACAAGAGTGCTACTCTCCTCGCTCCGGGCCCATAACATCTGGGGGTAGCTAAAGT GA

$>$ H36_BOE07

TAATTTAAACTATTCTCTGTTCTTTCATGGGGAAGCAAATTTAAGTACCACCTAAGTACT GGCTCATTCATTACAACCGCTATGTATTTCGTACATTACTGCCAGCCACCATGAATATTG TACAGTACCATAATCACCCAACTACCTATAACACATAAAATCCACTCCCACACCAAAACC TTCACCCCATGCTTACAAGCACGCACAACAATCAACCTCCAACTGTCGAACATAAAACAC AACTCCAACGACACCCCTCCCCCACCCCGATATCAACAGACCCACCCCCCCTT-GACAGA ACATAATACATACAATCATACACCGTACATAGCACATTACAGTCAAATTCTTCCTCGTCC CCACGGATGCCCCCCCTCAAATAGGAATCCCTTGGTCACCATCCTCCGTGAAATCAATAT CCCGCACAAGAGTGCTACTCTCCTCGCTCCGGGCCCATAACATCTGGGGGTAGCTAAAGT GA $>$ H37_BOE06 TAATTTAAACTATTCTCTGTTCTTTCATGGGGAAGCAAATTTAAGTACCACCTAAGTACT GGCTCATTCATTACAACCGCTATGTATTTCGTACATTACTGCCAGCCACCATGAATATTG 
TACAGTACCATAATCACCCAACTACCTATAACACATAAAATCCACTCCCACACCAAAACC TTCACCCCATGCTTACAAGCACGCACAACAATCAACCTCCAACTGTCGAACATAAAACAC AACTCCAACGACACCCCTCCCCCACCCCGATATCAACAGACCTACCCCCCCTT-GACAGA ACATAGTACATACAATCATACACCGTACATAGCACATTACAGTCAAATTCTTCCTCGTCC CCACGGATGCCCCCCCTCAAATAGGAATCCCTTGGTCACCATCCTCCGTGAAATCAATAT CCCGCACAAGAGTGCTACTCTCCTCGCTCCGGGCCCATAACATCTGGGGGTAGCTAAAGT GA $>$ H38_B5 TAATTTAAACTATTCTCTGTTCTTTCATGGGGAAGCAAATTTAAGTACCACCTAAGTACT GGCTCATTCATTACAACCGCTATGTATTTCGTACATTACTGCCAGCCACCATGAATATTG TACAGTACCATAATCACCCAACCACCTATAATACATAAAACCCAC-CCCACATTAAAACC TTCACCCCATGCTTACAAGCACGCACAACAATCAACCTCCAACTATCGAACATAAAACAC AACCCCAACGACACTCCTCCCCCACCCCGATACCAACAAACCCACCCCCCCTT-GACAAG ACATAGTACATACAATCATACATCGTACATAGCACATTACAGTCAAATCCATCCTTGTCC CCACGGATGACCCCCCCCAGATGGGAATCCCTTGACCACCATCCTCCGTGAAATCAATAT CCCGCACAAGAGTACTACTCTCCTCGCTCCGGGCCCATAACATCTGGGGGTAGCTAAAGT GA $>$ H39_B33 TAATTTAAACTATTCTCTGTTCTTTCATGGGGAAGCAAATTTAAGTACCACCTAAGTACT GGCTCATTCATTACAACCGCTATGTATTTCGTACATTACTGCCAGCCACCATGAATATTG TACGGTACCATAATCACCCAACTACCTATAGCACATAAAACCCAC-CCCACATTAAAACC TTCACCCCATGCTTACAAGCACGCACAACAATCAACCTCTAACTATCAAACATAAAACAC AACTCCAACGACACCTCTCCCCCACCCCGATACCAACAAACCTACCCCCC-TT-GACAAA ACATAGTACATACAATCACACACCGTACATAGCACATTACAGTCAAATCCATCCTTGCCC CCACGGATGATCCCCCTCAGATAGGAATCCCTTGACCACCATCCTCCGTGAAATCAATAT CCCGCACAAGAGTGCTACTCTCCTCGCTCCGGGCCCATAACATCTGGGGGTAGCTAAAGT GA $>$ H40_B29 TAATTTAAACTATTCTCTGTTCTTTCATGGGGAAGCAAATTTAAGTACCACCTAAGTACT 
GGCTCATTCATTACAACCGCTATGTATTTCGTACATTACTGCCAGCCACCATGAATATTG TACAGTACCATAATCACCCAACTACCTATAATACATAAAATCCACTCCCACACCAAAACC TTCACCCCATGCTTACAAGCACGCACAACAATCAACCTCCAACTGTCGAACATAAAACAC AACTCCAACGACACCCCTCCCCCACCCCGATATCAACAGACCTACCCCCCCCT-GACAGA ACATAATACATACAATCATACACCGTACATAGCACATTACAGTCAAACTCTTCCTCGTCC CCACGGATGCCCCCCCTCAGATAGGAATCCCTTGGTCACCATCCTCCGTGAAATCAATAT CCCGCACAAGAGTGCTACTCTCCTCGCTCCGGGCCCATAACATCTGGGGGTAGCTAAAGT GA $>$ H41_B26 TAATTTAAACTATTCTCTGTTCTTTCATGgGgAAGCAAATTTAAGTACCACCTAAGTACT GGCTCATTCATTACAACCGCTATGTATTTCGTACATTACTGCCAGCCACCATGAATATTG TACAGTACCATAATCACCCAACTACCTATAGCACATAAAACCCACTCCCACATCAAAACC TTCACCCCATGCTTACAAGCACGCACAACAATCAACCCCCAACTATCAAACATAAAACAC AACTCCAACGACACCCCTCCCCCACCCCGATACCAACAAACCTACCTCCCCTT-GACAAA ACATAGTACATACAATCACACACCGTACATAGCACATTACAGTCAAACCCCTCCTCGCCC CCACGGATGCTCCCCCTCAGATAGGAATCCCTTGACCACCATCCTCCGTGAAATCAATAT CCCGCACAAGAGTGCTACTCTCCTCGCTCCGGGCCCATAACATCTGGGGGTAGCTAAAGT GA $>$ H42_B23 TAATTTAAACTATTCTCTGTTCTTTCATGGgGAAGCAAATTTAAGTACCACCTAAGTACT GGCTCATTCATTACAACCGCTATGTATTTCGTACATTACTGCCAGCCACCATGAATATTG TACAGTACCATAATCACCCAACTACCTATAATACATAAAATCCACTCCCACACCAAAACC TTCACCCCATGCTTACAAGCACGCACAACAATCAACCTCCAACTGTCGAACATAAAACAC AACTCCAACGACACCCCTCCCCCACCCCGATATCAACAAACCTACCCCCCCCT-GACAGA ACATAATACATACAATCACACACCGTACATAGCACATTACAGTCAAACTCTTCCTCGTCC CCACGGATGCCCCCCCTCAGATAGGAATCCCTTGGTCACCATCCTCCGTGAAATCAATAT CCCGCACAAGAGTGCTACTCTCCTCGCTCCGGGCCCATAACATCTGGGGGTAGCTAAAGT GA 
$>$ H43_B19

TAATTTAAACTATTCTCTGTTCTTTCATGGGGAAGCAAATTTAAGTACCACCTAAGTACT GGCTCATTCATTACAACCGCTATGTATTTCGTACATTACTGCCAGCCACCATGAATATTG TACGGTACCATAATCACCCAACCACCTATAATACATAAAACCCAC-CCCACATTAAAACC TTCACCCCATGCTTACAAGCACGCACAACAATCAACCTCCAACTATCGAACATAAAACAC AACCCCAACGACACTCCTCCCCCACCCCGATACCAACAAACCCACCCCCCCTT-GACAAG ACATAGTACATACAATCATACATCGTACATAGCACATTACAGTCAAATCCATCCTTGTCC CCACGGATGACCCCCCCCAGATGGGAATCCCTTGACCACCATCCTCCGTGAAATCAATAT CCCGCACAAGAGTACTACTCTCCTCGCTCCGGGCCCATAACATCTGGGGGTAGCTAAAGT GA $>$ H44_B11 TAATTTAAACTATTCTCTGTTCTTTCATGGGGAAGCAAATTTAAGTACCACCTAAGTACT GGCTCATTCATTACAACCGCTATGTATTTCGTACATTACTGCCAGCCACCATGAATATTG TACGGTACCATAATCACCCAACTACCTATAGCACATAAAACCCAC-CCCACATTAAAACC TTCACCCCATGCTTACAAGCACGCACAACAATCAACCTCTAACTATCAAACATAAAACAC AACTCCAACGACACCTCTCCCCCACCCCGATACCAACAAACCTACCCCCCCTT-GACAAA ACATAGTACATACAATCACACACCGTACATAGCACATTACAGTCAAATCCATCCTTGCCC CCACGGATGATCCCCCTCAGATAGGAATCCCTTGACCACCATCCTCCGTGAAATCAATAT CCCGCACAAGAGTGCTACTCTCCTCGCTCCGGGCCCATAACATCTGGGGGTAGCTAAAGT GA >H45_883T TAATTTAAACTATTCTCTGTTCTTTCATGGGGAAGCAAATTTAAGTACCACCTAAGTACT GGCTCATTCATTACAACCGCTATGTATTTCGTACATTACTGCCAGCCACCATGAATATTG TACAGTACCATAATCACCCAACTACCTATAGCACATAAAACCCAC-CCCACATTAAAACC TTCACCCCATGCTTACAAGCACGCACAACAATCAACCTCTAACTATCAAACATAAAACAC AACTCCAACGACACCTCTCCCCCACCCCGATACCAACAAACCTACCCCCC-TT-GACAAA ACATAGTACATACAATCACACACCGTACATAGCACATTACAGTTAAATCCATCCTTGCCC CCACGGATGATCCCCCTCAGATAGGAATCCCTTGACCACCATCCTCCGTGAAATCAATAT CCCGCACAAGAGTGCTACTCTCCTCGCTCCGGGCCCATAACACCTGGGGGTAGCTAAAGT 
$>$ H46_850T

TAATTTAAACTATTCTCTGTTCTTTCATGGGGAAGCAAATTTAAGTACCACCTAAGTACT GGCTCATTCATTACAACCGCTATGTATTTCGTACATTACTGCCAGTCACCATGAATATTG TACAGTACCATAATCACCCAACTACCTATAATACATAAAATCCACTCCCACACCAAAACC TTCACCCCATGCTTACAAGCACGCACAACAATCAACCTCCAACTGTCAAACATAAAACAC AACTCCAACGACACCCCTCCCCCACCCCGATATCAACAGACCTACCCCCCTT--GACAGA ACATAGTACATACAATCATACACCGTACATAGCACATTACAGTCAAACTCTTCCTCGTCC CCACGGATGCCCCCCCTCAGATAGGAATCCCTTGGTCACCATCCTCCGTGAAATCAATAT CCCGCACAAGAGTGCTACTCTCCTCGCTCCGGGCCCATAACATCTGGGGGTAGCTAAAGT GA $>$ H47_842T TAATTTAAACTATTCTCTGTTCTTTCATGGGGAAGCAAATTTAAGTACCACCTAAGTACT GGCTCATTCATTACAACCGCTATGTATTTCGTACATTACTGCCAGCCACCATGAATATTG TACAGTACCATAATCACCCAACTACCTATAATACATAAAATCCACTCCCACACCAAAACC TTCACCCCATGCTTACAAGCACGCACAACAATCAACCTCCAACTGTCGAACATAAAACAC AACTCCAACGACACCCCTCCCCCACCCCGATATCAACAGACCTACCCCCCCCTTGACAGA ACATAGTACATACAATCATACACCGTACATAGCACATTACAGTCAAACTCTTCCTCGTCC CCACGGATGCCCCCCCTCAGATAGGAATCCCTTGGTCACCATCCTCCGTGAAATCAATAT CCCGCACAAGAGTGCTACTCTCCTCGCTCCGGGCCCATAACATCTGGGGGTAGCTAAAGT GA $>$ H48_830T TAATTTAAACTATTCTCTGTTCTTTCATGGGGAAGCAAATTTAAGTACCACCTAAGTACT GGCTCATTCATTACAACCGCTATGTATTTCGTACATTACTGCCAGCCACCATGAATATTG TACAGTACCATAATCACCCAACCACCTATAATACATAAAACCCAC-CCCACATTAAAACC TTCACCCCATGCTTACAAGCACGCACAACAATCAACCTCCAACTATCGAACATAAAACAC AACCCCAACGACACTCCTCCCCCACCCCGATACCAACAAACCCACCCCCCCTT-GACAAG ACATAGTACATACAATCATACATCGTACATAGCACATTACAGTCAAATCCATTCTTGTCC 
CCACGGATGACCCCCCCCAGATGGGAATCCCTTGACCACCATCCTCCGTGAAATCAATAT CCCGCACAAGAGTACTACTCCCCTCGCTCCGGGCCCATAACATCTGGGGGTAGCTAAAGT GA $>$ H49_826T TAATTTAAACTATTCTCTGTTCTTTCATGGGGAAGCAAATTTAAGTACCACCTAAGTACT GGCTCATTCATTACAACCGCTATGTATTTCGTACATTACTGCCAGCCACCATGAATATTG TACAGTACCATAATCACCCAACTACCTATAACACATAAAATCCACTCCCACACCAAAACC TTCACCCCATGCTTACAAGCACGCACAACAATCAACCTCCAACTGTCGAACATAAAACAC AACTCCAACGACACCCCTCCCCCACCCCGATATCAACAGACCTACCCCCCCCTTGACAGA ACATAGTACATACAATCATACACCGTACATAGCACATTACAGTCAAATTCTTCCTCGTCC CCACGGATGCCCCCCCTCAGATAGGAATCCCTTGGTCACCATCCTCCGTGAAATCAATAT CCCGCACAAGAGTGCTACTCTCCTCGCTCCGGGCCCATAACATCTGGGGGTAGCTAAAGT GA >H50_804T TAATTTAAACTATTCTCTGTTCTTTCATGGGGAAGCAAATTTAAGTACCACCTAAGTACT GGCTCATTCATTACAACCGCTATGTATTTCGTACATTACTGCCAGCCACCATGAATATTG TACAGTACCATAATCACCCAACTACCTATAATACATAAAATCCACTCCCACACCAAAACC TTCACCCCATGCTTACAAGCACGCACAACAATCAACCTCCAACTGTCGAACATAAAACAC AACTCCAACGACACCCCTCCCCCACCCCGATATCAACAAACCTACCCCCCCTT-GACAGA ACATAGTACATACAATCATACACCGTACATAGCACATTACAGTCAAACTCTTCCTCGTCC CCACGGATGCCCCCCCTCAGATAGGAATCCCTTGGTCACCATCCTCCGTGAAATCAATAT CCCGCACAAGAGTGCTACTCTCCTCGCTCCGGGCCCATAACATCTGGGGGTAGCTAAAG 
Appendix G: Chimpanzee symbiont identification microphotographs

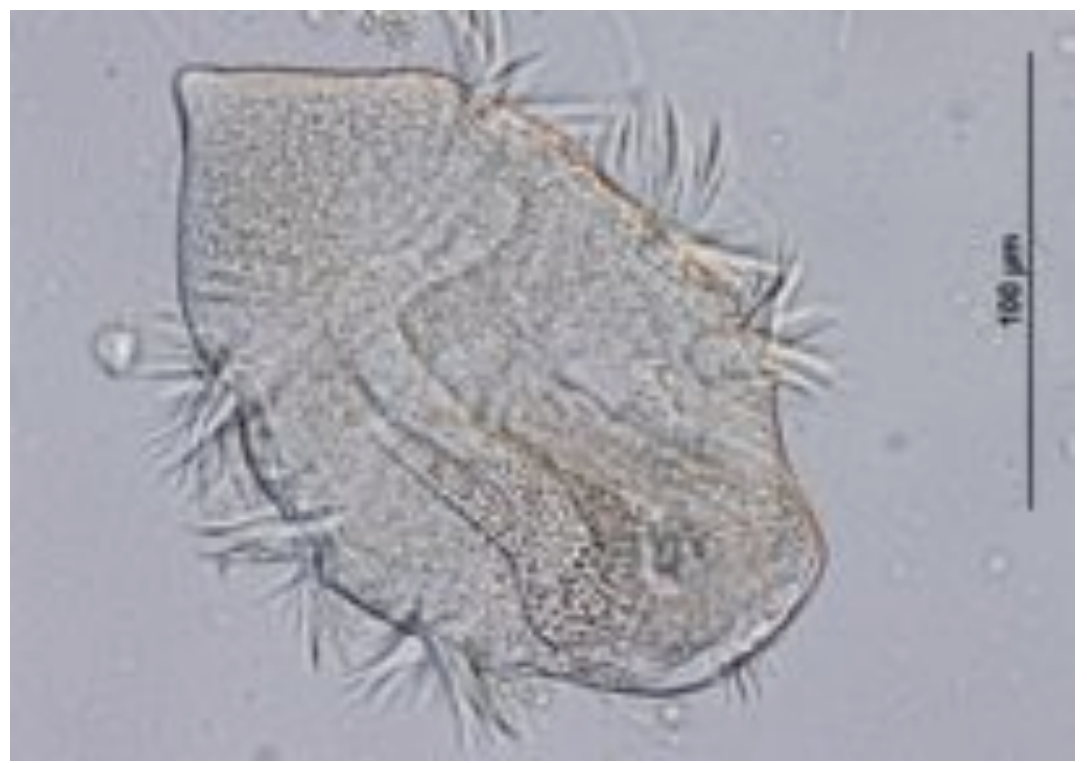

Trophozoite of

Troglodytella abrassarti, fecal sample $P$. troglodytes verus, Cantanhez, GuineaBissau.

Trophozoite of Troglocorys cava, fecal sample $P$. troglodytes verus, Cantanhez, Guinea-Bissau. 


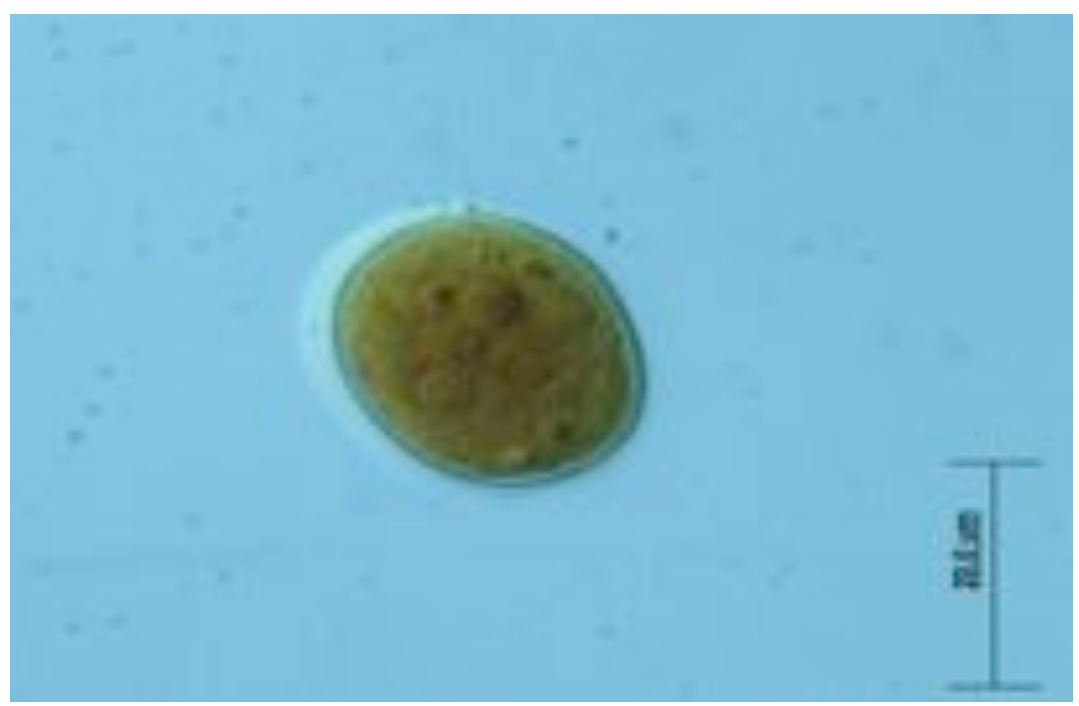

Multinuclear and thick-

walled cyst of Entamoeba

coli, fecal sample $P$.

troglodytes verus,

Cantanhez, Guinea-Bissau;

stained with Lugol's iodine.

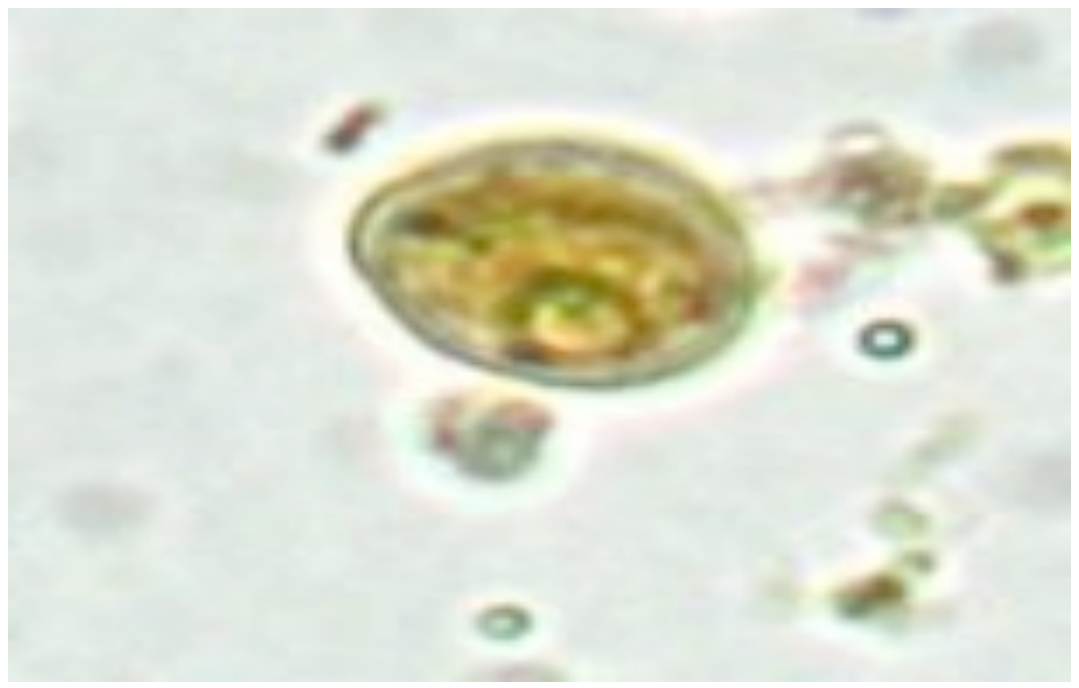

Lemon-shaped cyst of

Chilomastix mesnili, fecal

sample $P$. troglodytes

verus, Cantanhez, Guinea-

Bissau, stained with Lugol's

lodine.

Vacuolar-shapped cyst of

Blastocystis sp., fecal

sample $P$. troglodytes

verus, Boé, Guinea-Bissau. 


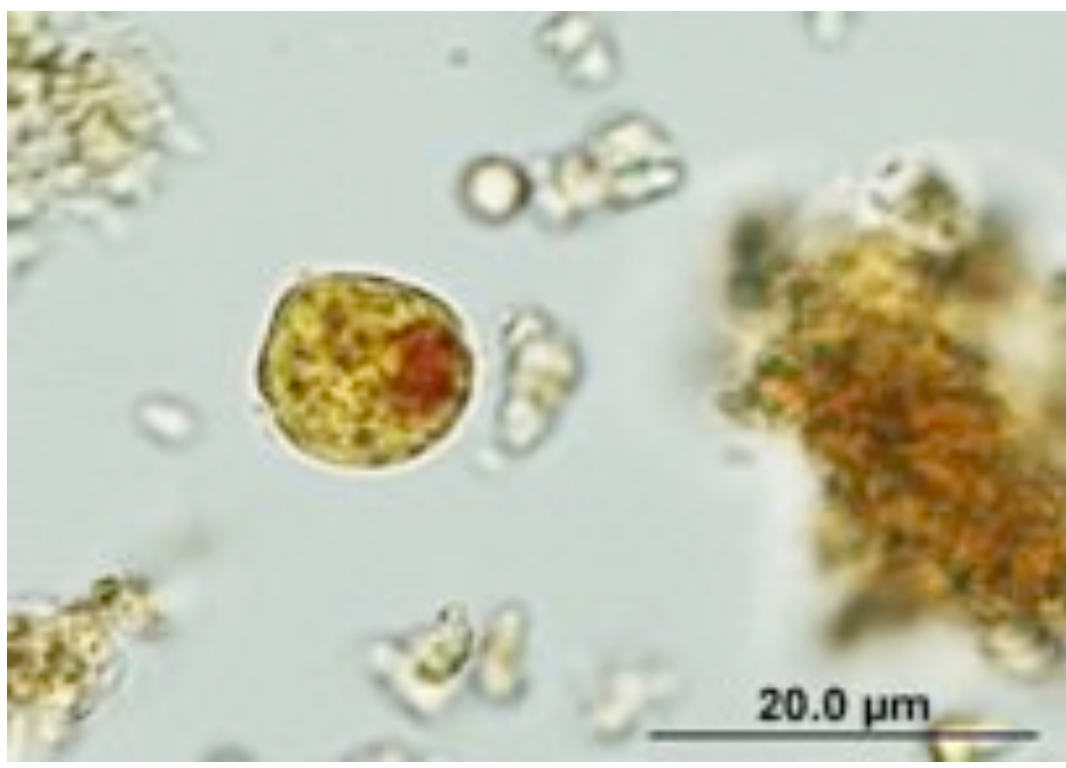

Cyst of lodamoeba

buetschlii, with dark-

staining glycogen mass

readily seen, fecal sample

P. troglodytes verus,

Cantanhez, Guinea-Bissau;

stained with Lugol's iodine.

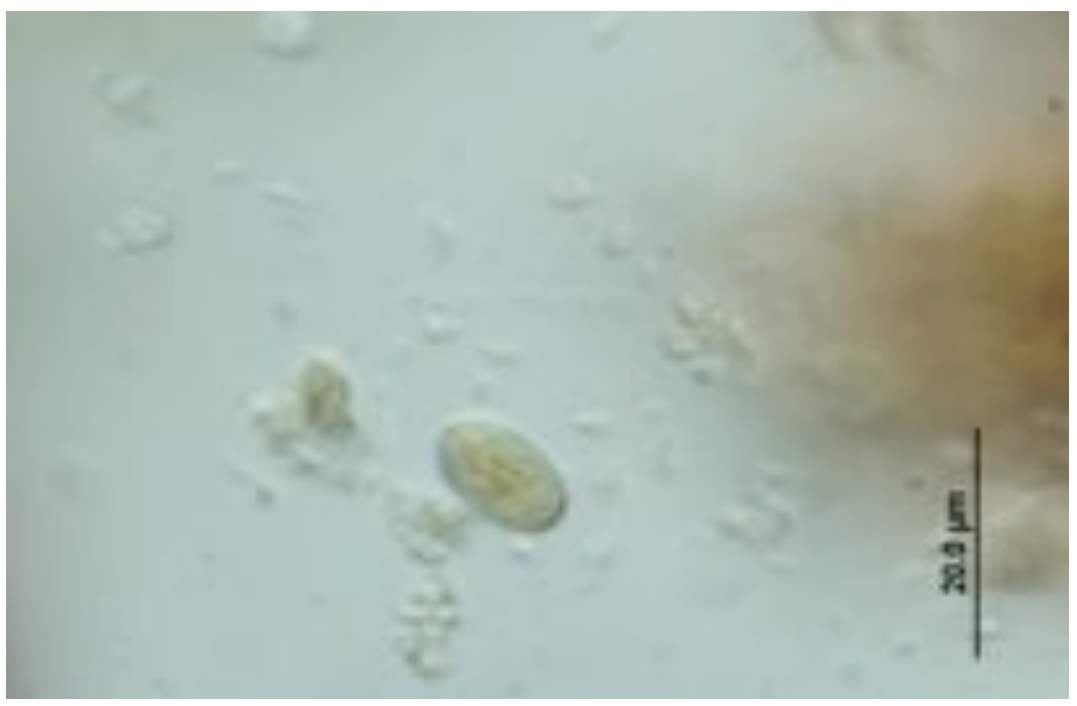

Ellipsoidol cyst of Giardia

intestinalis, fecal sample $P$.

troglodytes verus,

Cantanhez, Guinea-Bissay;

stained with Lugol's iodine.

Tapeworm egg of Bertiella

sp., fecal sample

troglodytes verus, Cufada,

Guinea-Bissau. 


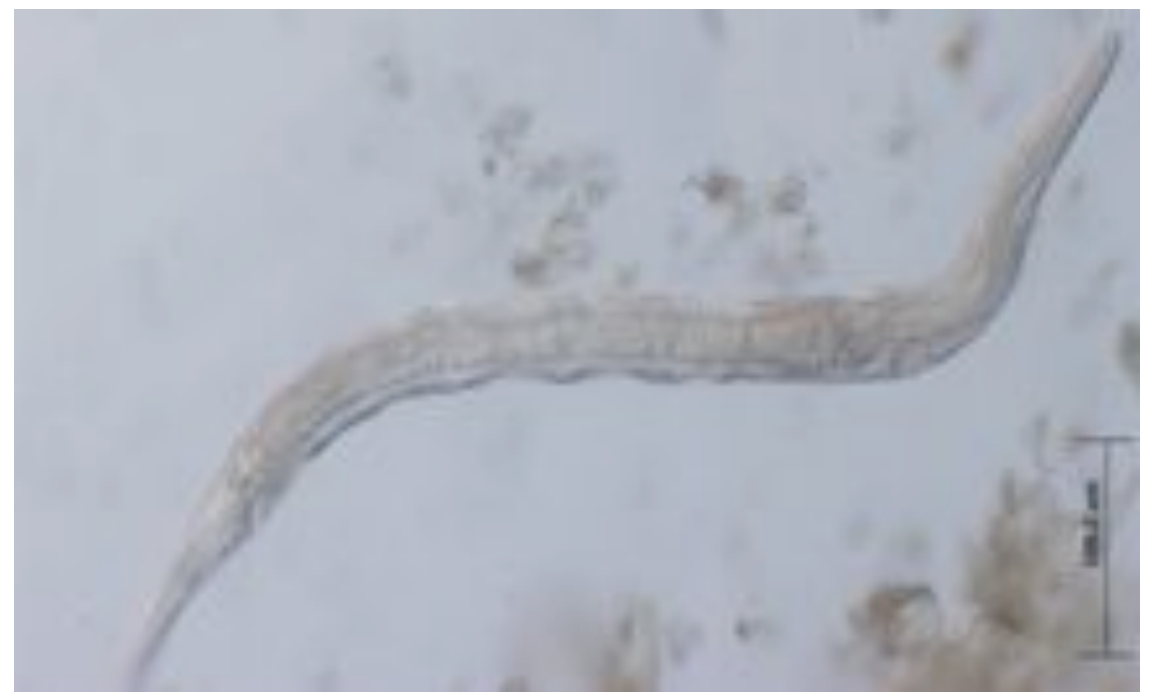

Larvae of Probstmayria

gombensis, fecal sample $P$.

troglodytes verus,

Cantanhez, Guinea-Bissau.

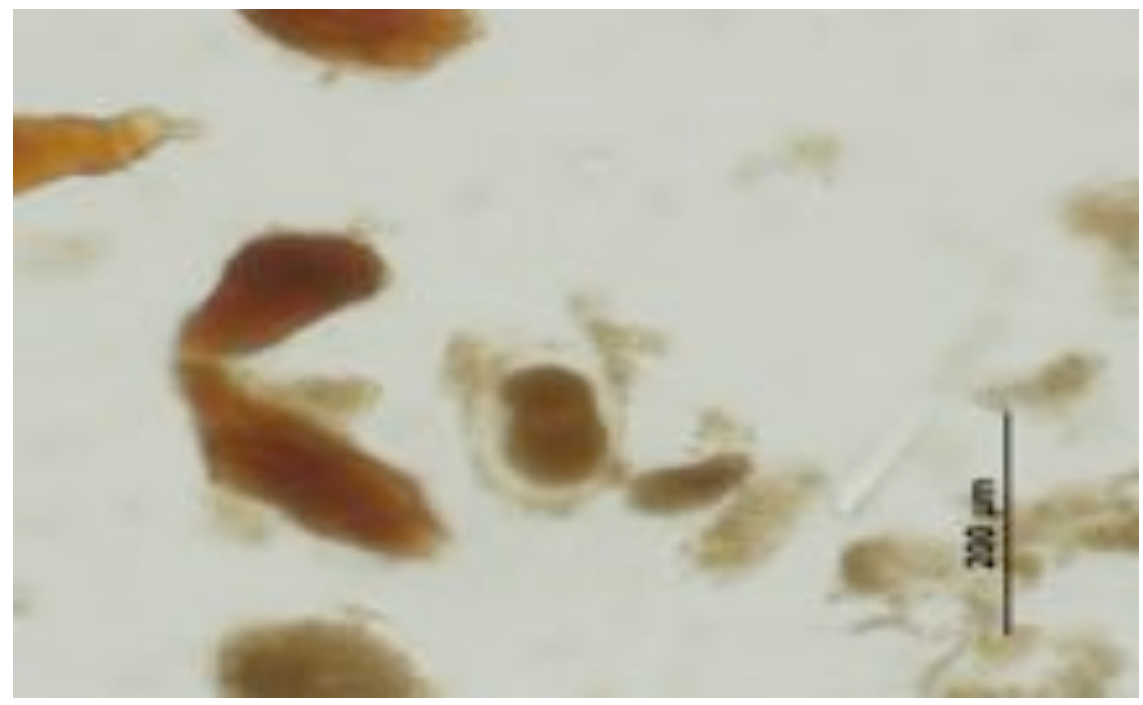

Unidentified hookworm

egg, Strongylida fam. gen.

sp., fecal sample $P$.

troglodytes verus,

Cantanhez, Guinea-Bissau;

stained with Lugol's iodine.

Larva of Strongylloides

stercoralis, fecal sample $P$.

troglodytes verus, Boé,

Guinea-Bissau; stained with

Lugol's iodine. 
Thin-walled egg of

Strongylloides fuelleborni, fecal sample $P$. troglodytes verus,

Cantanhez, Guinea-Bissau.

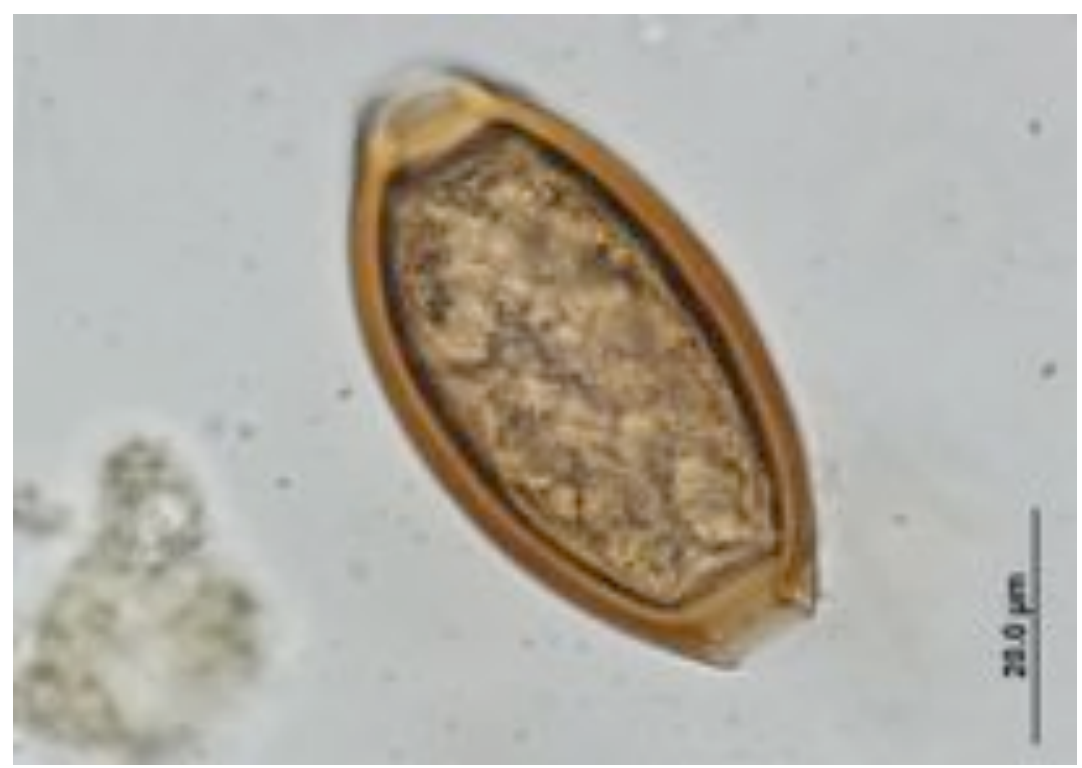

Typical barrel-shapped egg of

Trichuris sp., fecal sample $P$. troglodytes verus, Cantanhez, Guinea-Bissau. 
Appendix H: CITES and DEFRA permits

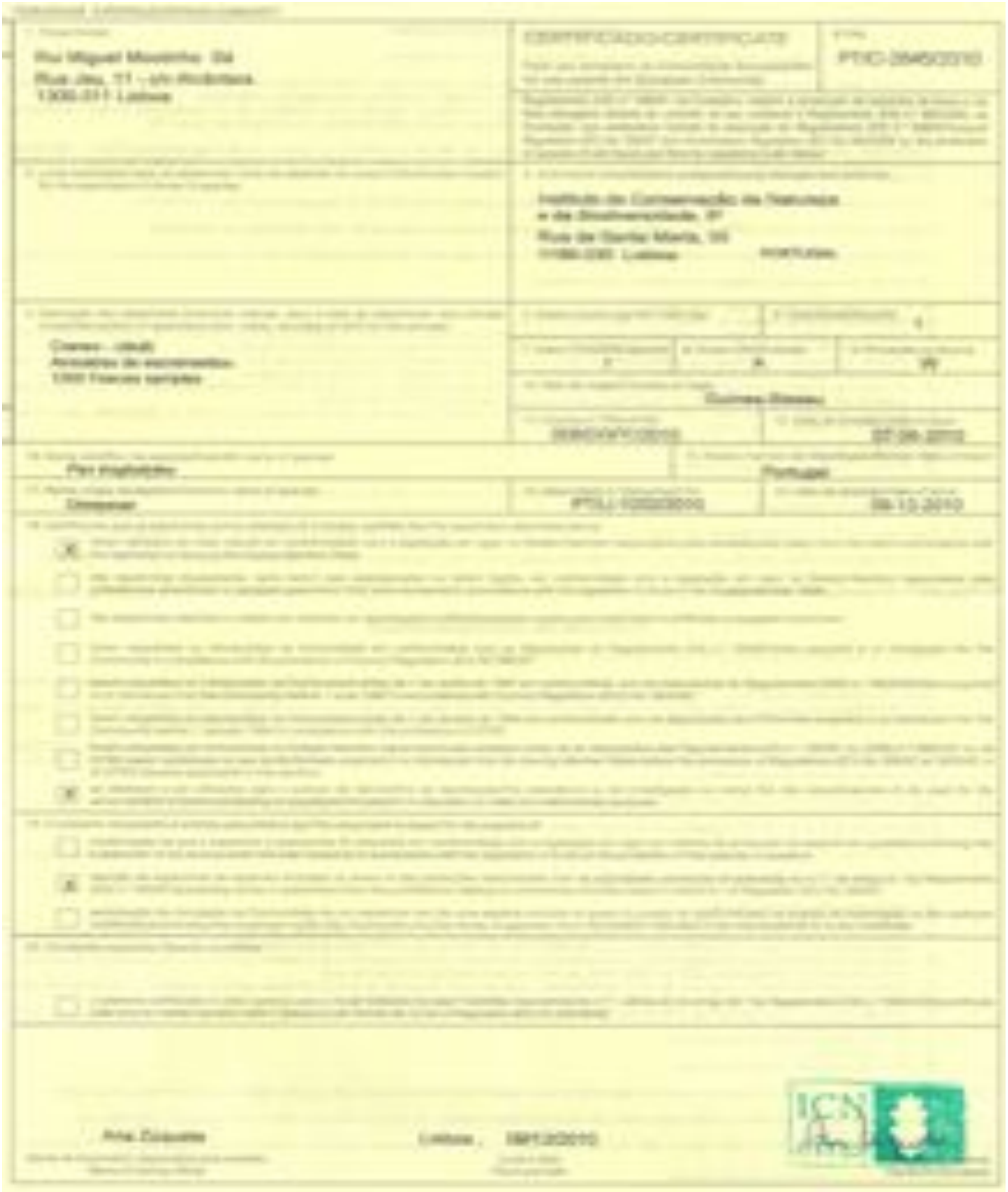




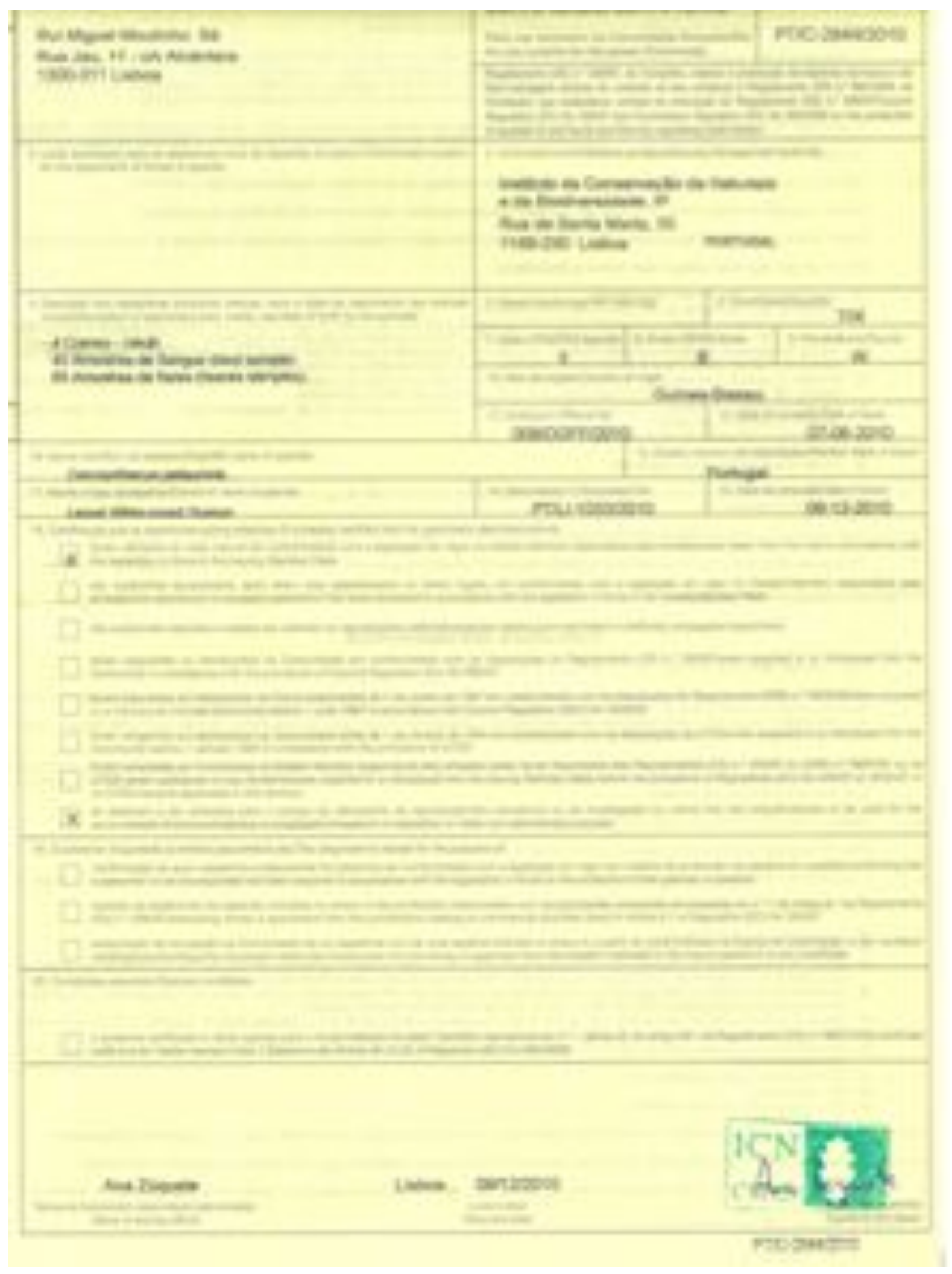




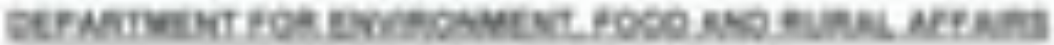

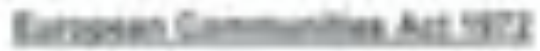

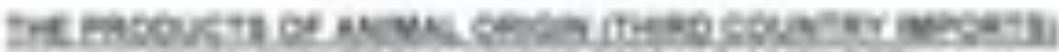

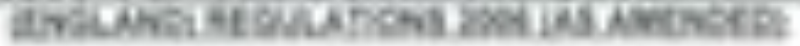

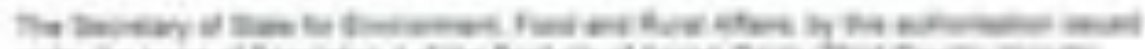

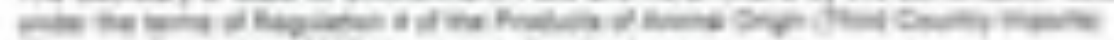

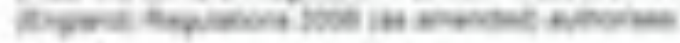

\begin{tabular}{|c|c|}
\hline 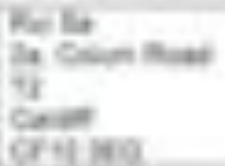 & 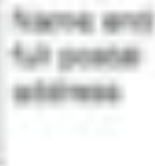 \\
\hline
\end{tabular}

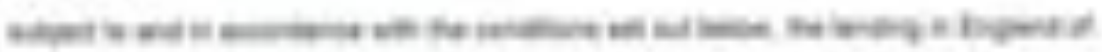

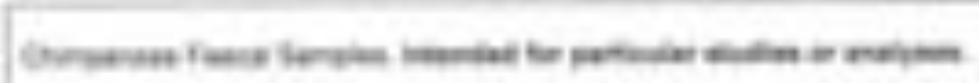

Nivest

has

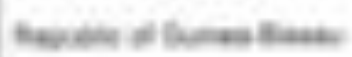

Covarem inger

at

\section{inos lines}

harta ill art?

16=

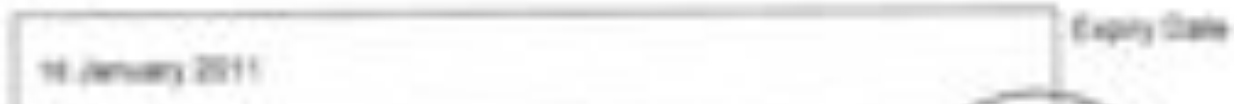

Dalet w Delamis 3ors 


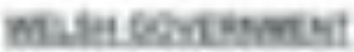

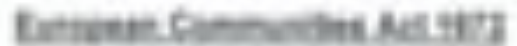

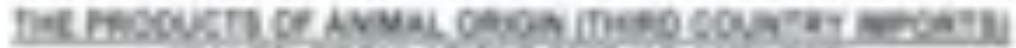

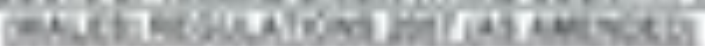

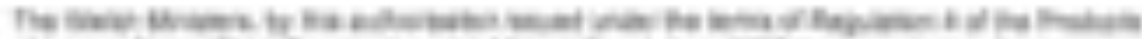

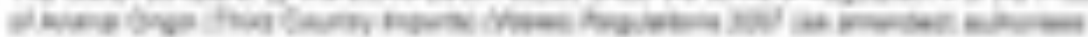

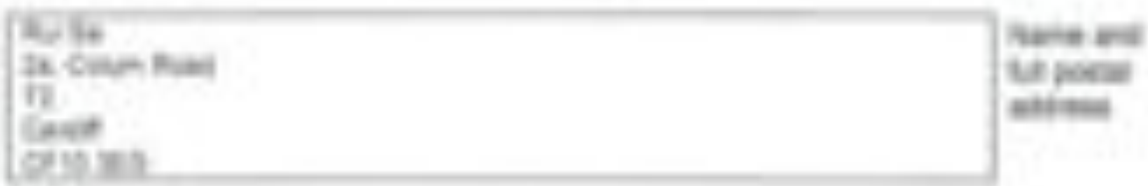

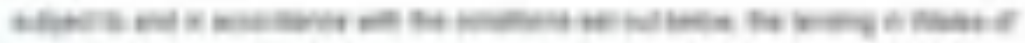

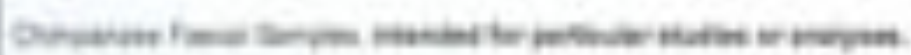
hovenell

$t=$

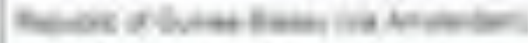

Stomesos a $y_{10}$

s.

Pant anmen

water

vidasit

fisenter

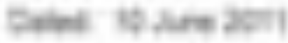

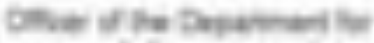

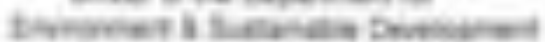




\title{
Appendix I: Characterization of the urban primate bushmeat trade in Guinea Bissau using molecular tools for species identification [in prep.]
}

\author{
Minhós T, Wallace E, Ferreira da Silva M, Sá R, Carmo M, Barata A, Bruford MW
}

\section{INTRODUCTION}

Unsustainable overhunting is compelling large mammal and slowreproducing species, such as nonhuman primates, to extinction (Ape Alliance 2006; Mainka \& Trivedi 2002; Kümpel et al. 2010). In Africa, for example, this escalating threat is considered to have a much larger impact than habitat destruction (Linder \& Oates 2011; Rovero 2012). Human consumption of hunted wildlife for meat (i.e. bushmeat) is today recognized as a world crisis and a great conservation concern (Milner-Gulland et al. 2003; Nielsen 2006; Davies \& Brown 2007; Macdonald et al. 2012). Bushmeat is leading to severe primate population declines and local extirpations, particularly in West and Central Africa (Allebone-Webb et al. 2011). This practice is not only a strategy for alternative protein income and subsistence for the rural poor, but also for trade that has been fostered by an increased entrance in remote forests by loggers (Wilkie et al. 2000) and/or by the greater access to sophisticated weapons by hunters (Bowen-Jones \& Pendry 1999; Macdonald et al. 2012). Other factors associated with bushmeat consumption are connected with cultural or taste reasons, even when people have available alternatives (Bennett 2002; Bennett et al. 2006). A significant part of the bushmeat trade is due to a luxury preference where prices of wild meat are higher than those of domestic livelihood meat (Wilkie \& Godoy 2001; Brashares et al. 2004).

A recent study estimated that 273 tons of bushmeat is imported every year into Paris-Charles de Gaulle Airport via Air France carriers therefore demonstrating the transnational scale of this traffic (Chaber et al. 2010). Additionally, several authors recognize that primate bushmeat consumption is a source of zoonotic disease emergence such as many retrovirus implied for example, in the HIV global spread (Courgnaud et al. 2004: Switzer \& Heneine 2011; Smith et al. 2012). Pourrut et al. (2011) also alert for the cross-species transmission of several parasites with 
zoonotic potential between nonhuman primate consumption and humans, raising the food security concern aspect of this trade.

Collecting reliable information on bushmeat consumption is difficult because many species are protected by national and international laws and informants may be reluctant to discuss their involvement in such an undisclosed subject (Jenkins et al. 2011). Furthermore, other frequent problem concerning bushmeat assessment for conservation management is the inability to correctly identify the harvested species in order to determine their proportional consumption frequency, specially in cases where many of the animal body parts are seized already processed, smoked or powdered, and consequently, the morphological identification is almost impossible or very inaccurate (Fong et al. 2007; Rönn et al. 2009; Ntie et al. 2010). Hence, only molecular approaches can shed light on reliable species identification. Within this context, and as a result of the search for solutions to this problem, several authors have emphasized the use of forensic genetics and DNA as a tool for bushmeat mitigation (Malisa et al. 2005; Domingo-Roura et al. 2006; Herke et al. 2007). DNA barcoding derived from mtDNA sequences, for example, has been proposed as a suitable technique for the species identification (Hebert et al. 2004; Herke et al. 2007). The majority of nonhuman primate species are included in Appendix 2 of the Convention on International Trade in Endangered Species of Wild Fauna and Flora (CITES), but remarkably few studies have used these molecular approaches. Lorenz et al. (2005), in the context of the Integrated Primate Biomaterials and Information Resource (www.IPBIR.org) used the Cytochrome C Oxidase Subunit I of the mtDNA to verify the identity of the samples and generated a database of DNA barcodes for nonhuman primates advocating its use for the effective prosecution of poachers involved in the bushmeat traffic. Similarly, Rönn et al. (2009) developed a genotyping system in a microarray format for identification of primate species used in the bushmeat trade. More recently, by combining DNA-typing techniques to bushmeat surveys and questionnaires in Nigerian urban markets, Olayemi et al. (2011) demonstrated that this integrative approach was successful to determine the trade of 17 mammalian orders including the white-throated monkey, Cercopithecus erythrogaster an endemic vulnerable species of Nigeria.

Much research of the bushmeat trade has focused on West and Central 
African urban markets (Fa et al. 2006; Allebone-Webb et al. 2011; Kamins et al. 2011; Dupain et al. 2012; van Vliet et al. 2012). However, little is known about the bushmeat trade in Guinea-Bissau and its characteristics were never assessed although previous reports have claimed that large quantities of primates have been hunted to be sold in the capital (Bissau), or in other important urban areas (Cá 2008). There are currently 10 primate species in Guinea-Bissau. Two species are classified as endangered including the West African chimpanzee (Pan troglodytes verus) and the Temminck's red colobus (Procolobus badius temminckii) (Casanova \& Sousa 2007).

Here, we assessed the contribution of DNA-typing identification of African nonhuman primates in Guinea-Bissau' bushmeat markets. We followed the trade at two markets in Bissau across four months and we used a DNA barcoding approach (mitochondrial DNA Cytochrome c Oxidase subunit I and 12S rRNA fragment) to test the accuracy of morphological identification; determine the diversity of nonhuman primates sold in those markets; and to estimate the quantities of carcasses sold.

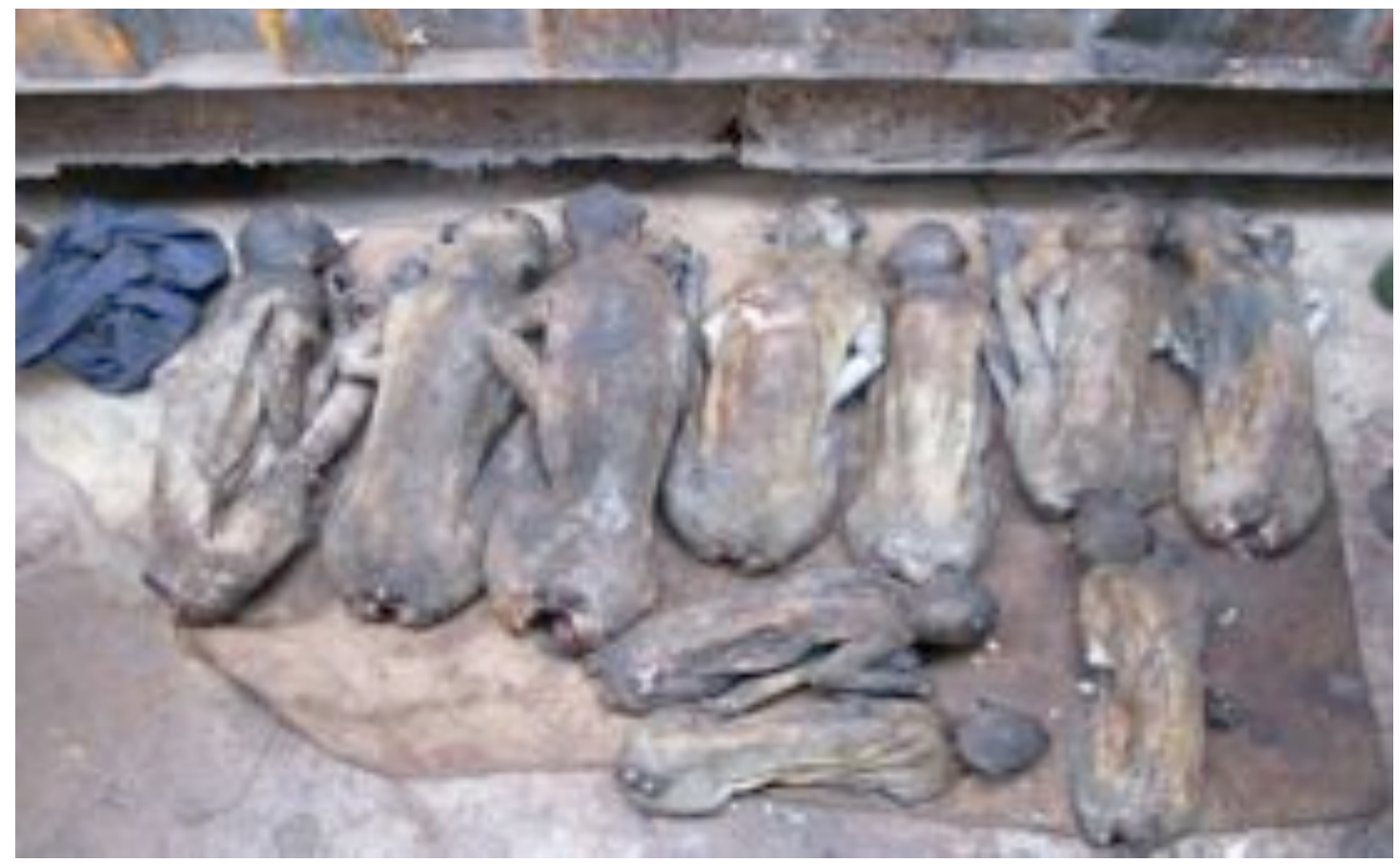

Figure 1: Morphological aspect of primates being sold in Bissau (Chapa market). 


\section{MATERIAL AND METHODS}

\section{Bushmeat market}

During March 2010 we were able to locate two bushmeat markets in Bissau: "Chapa" and "Rampa". Chapa market is a permanent "butcher stalls" type of market, selling not only bushmeat (Fig 1) but also domestic meat (cow, goat and domestic pig). Rampa market is close to a harbour in Bissau and is the final destiny of shipments, including bushmeat, fish and meat derived from domestic animals. The goods, in most cases pre-ordered by the customers, arrive by boat to Bissau across the Geba River. All goods in Rampa would be sold just a few minutes after the daily boat arrived, and this market seems to be less permanent than Chapa.

We visited both markets in the dry season during 19 days, divided in three different periods: five days from 1st to $5_{\text {th }}$ March; five days between 30th March and 10th April and nine days between 19th May and 6th June. During our daily visits that did not last more than 15 minutes, we counted the number of primate carcasses present in the market and recorded the morphological identification provided by the traders (Table 1). We inquired the price and the original location of the individuals. We were unable to follow the trade along entire days since our presence was considered inconvenient for the normal function of the commerce. In these short visits, we were able to list the nonprimate species being sold but were not capable to follow their trade. We also visited restaurants where primate bushmeat is cooked and consumed to obtain more information on how primate meat consumption takes place.

In order to estimate an error rate associated with the morphological identification, we collected 50 tissue samples for DNA analysis (see table 1), stored it in tubes with $99 \%$ ethanol and labelled with the morphological identification provided by the traders.

\section{Molecular Identification}

\section{DNA Extraction, PCR amplification and sequencing}

To improve DNA extraction success, we aimed to extract from unburned tissue. Whole genomic DNA was extracted using DNeasy Blood and Tissue kits (Qiagen, (C), following the manufacturer's protocol but allowing overnight lysis of tissues.

We amplified a mitochondrial DNA fragment of approximately 700 base pair 
(bp) long from the standard barcode region of the first half of COI (Cytochrome $c$ Oxidase subunit I) using the three primer sets used by Lorenz et al. (2005). All samples were first tested with primer set "OWMCOI" since it was successful in the amplification of 8 out of the 9 primate genera tested by Lorenz et al. (2005), three of which analysed in this study (Papio, Cercopithecus and Chlorocebus). "VERTCOI" primers proved to be less successful in Lorenz et al. (2005) study, allowing the sequencing of only 6 out of the 13 primate genera tested. Since in Lorenz et al. (2005) study, the "VERTCOI" pair worked for some genera that were not tried with "OWMCOI", we used this primer pair for samples that did not amplify any PCR product after using the "OWMCOI" primer set. "FOLMER" primer set (designed by Folmer et al. 1994, also in Lorenz et al. 2005) was only used for samples that did not yield any PCR product with neither of the first two primer sets.

The PCR reaction mix contained 10 $\mu$ l Qiagen (C) Master Mix (containing HotStarTaq, DNA polymerase, Multiplex PCR buffer and dNTP mix), $6 \mu$ l RNase free water and $2 \mu l$ 10x primer mix (containing each primer at $2 \mu \mathrm{M}$ ). $2 \mu \mathrm{l}$ of template DNA was added for a final volume of $20 \mu \mathrm{l}$. The cycling protocol was optimised for the primers and samples. The thermal cycling programme involved $15 \mathrm{~min}$ at $95^{\circ} \mathrm{C}$ (a Taq activation step), 40 cycles of $30 \mathrm{sec}$ denaturing at $94^{\circ} \mathrm{C}, 90 \mathrm{sec}$ annealing at $50^{\circ} \mathrm{C}$ and $90 \mathrm{sec}$ extending at $72^{\circ} \mathrm{C}$. Finally a final extension step of $10 \mathrm{~min}$ at $72^{\circ} \mathrm{C}$ was included. Thermal cycling was performed on an Applied Biosystems GeneAmp PCR System 9700. PCR products were visualised by agarose gel electrophoresis, with $1 \%$ agarose gels stained with ethidium bromide, and viewed under UV light. For sequencing, PCR products were purified with 10 units of Exonuclease I and 5 units of Antarctic Phosphatase (New England Biolabs), using a cycling programme of $37^{\circ}$ for 30 mins, $80^{\circ}$ for 20 mins and $12^{\circ}$ for 5 mins. Samples were sequenced bidirectionally by Macrogen Europe's EZ-seq direct service.

\section{Query sequence specific assignment}

Using Bioedit Version 7.0.5.3 (Hall 1999), a consensus was made between the forward and reverse sequences for each sample by visual comparison. All sequences were manually aligned and then trimmed to the maximum same length of 623 base pairs.

Sequences were checked for the presence of NUMTS, which may be signified 
by frameshift mutations (insertions or deletions), ghost bands on gels, or unlikely phylogenetic placement in trees (following Bensasson et al. 2001 and Song 2008). No evidence of the presence of NUMTS was found in this study.

To assign each $\mathrm{COI}$ sequence obtained from the samples to a specific level (the "query" sequence) we used a sequential method (Frézal \& Leblois 2008): 1) we searched in a complete database for the most similar sequences; then 2) we chose the most similar sequences as "voucher" sequences; and finally 3) we used a phylogenetic approach (using genetic distances and maximum likelihood algorithms) to correctly assign the samples to the species level.

Therefore, each query sequence was compared to all $\mathrm{COI}$ reference sequences on NCBI (http://www.ncbi.nlm.nih.gov/genbank/) using the Basic Local Alignment Search Tool for nucleotides (BLASTn within NCBI, Altschul et al. 1990). BLASTn optimises alignments based on a similarity (threshold distance) algorithm.

The most similar $\mathrm{COI}$ sequences for each of the alleged species were obtained from NCBI (http://www.ncbi.nlm.nih.gov/genbank/) and Inprimat databases (www.inprimat.org) to serve as voucher sequences. We included in the alignment sequences from E. patas (ERYTHROCEBUS PATAS 1, accession number EF568610.1 and ERYTHROCEBUS PATAS 2, accession number AY972702.1), C. sabaeus (CHLOROCEBUS SABAEUS 1, accession number EF597503.1 and CHLOROCEBUS SABAEUS 2, accession number NC_008066.1) and P. papio (PAPIO PAPIO 1, accession number AY972684.1 and PAPIO PAPIO 2, accession number AY972678.1) found on both Inprimat and NCBI. We used two vouchers for $P$. badius: a sequence found only in NCBI/GENBANK (PROCOLOBUS BADIUS 1, accession number NC_008219.1) along with a faecal sample collected and extracted by T. Minhos from a visually confirmed P. badius (PROCOLOBUS BADIUS 2) and sequenced for the mtDNA region under study. Although we found the same degree of similarity between two query samples and two different species (Colobus polykomos and Colobus guereza samples, see results section) we only included in the alignment $C$. polykomos voucher samples (COLOBUS POLYKOMOS 1, accession number AB016731.1 and COLOBUS POLYKOMOS 2, accession number AY972692.1). According to Lorenz et al. (2005), this discrepancy might be related with the wrong labelling for this sequence in particular. Also, according to current knowledge (Gippoliti and Dell'Omo 2003) there 
is only one Colobus species present in Guinea-Bissau - C. polykomos. Currently there are no Cercopithecus campbelli $\mathrm{COI}$ sequences on databases and we were unable to obtain a voucher sample from a visually confirmed C. campbelli. Therefore, we sequenced a fragment of the $12 \mathrm{~S}$ rRNA gene for all samples suspected to be $C$. campbelli and compared it with the sequences available on NCBI (including two C.cambelli sequences, accession numbers AY665618.1 and AY665619.1) to obtain the specific identification.

Finally, we constructed a Neighbour joining (NJ) tree to view clustering of sequences with bootstrap support (1000 replicates) of each node using Mega 5.01 (see Fig 4 ). We included all sequences obtained by this study, and voucher sequences obtained via INPRIMAT and NCBI/GENBANK databases, in this analysis. Intra and Inter cluster variation was computed using Arlequin.

Species morphological identification error and calculation of the specific identification correction factor

We calculated the error rate associated with the morphological identification for each species by dividing the number of samples in which the molecular identification did not correspond to the morphological identification by the total number of tissue samples collected.

For each species, we present the number of individuals traded as being within the range between a minimum number of individuals molecularly assigned to that species and a maximum number of individuals, obtained through a correction factor calculated after the specific molecular assignment. To calculate the correction factor, we assumed that collection of tissue samples was representative of the number of individuals identified morphologically at the markets as more than $20 \%$ of the individuals observed all species were sampled (see table 1). To calculate the maximum number of individuals at the market we summed the true positive identifications frequency (TPF) with the false negatives frequency (FNF) in each species. Therefore for any species,

Maximum number of individuals for that species $=$ TPF + FNF

TPF $=N R M x$ 
NTS

NRM - the number of morphological records

NPTS - number of tissue samples labelled and assigned to that species

NTS - number of tissue samples collected for that species

$\mathrm{FNF}=\mathrm{ONS} \mathrm{x}$ NES

NSOS

ONS: the total number of individuals observed at the market minus the number of individuals observed using morphological identification for each species

NES: samples assigned to the species but not initially labelled as that species

NSOS: total number of tissue samples collected minus tissue samples molecularly assigned to that species

Corrected frequencies of the bushmeat trade and projection of the trade for the dry season

We calculated the relative percentage of each traded species using the maximum values obtained per species using the correction factor. We then extrapolated the trade for the entire dry season (November to May, 212 days). Using the relative percentages of trade for each species, we estimated the amount of individuals per species traded during the dry season.

\section{RESULTS}

\section{Trade at Bissau Markets}

During the 19 days of study, we observed 150 primate carcasses being sold in Bissau, with more primates being sold at Chapa market (113) than Rampa market (37). We found that six species of primates are sold at Bissau markets: Procolobus badius (Western Red Colobus), Colobus polykomos (Western Black-and-White Colobus), Cercopithecus campbelli (Campbell's Mona), Papio papio (Guinea Baboon) Erythrocebus patas (Patas monkey) and Chlorocebus sabaeus (Green Monkey).

Non-primate specimens observed at the markets included a species locally called "farfana", which is likely to be the Greater Cane Rat, Thryonomys 
swinderianus, the Crested Porcupine (Hystrix cristata, locally called "porco ispinho"), pangolins (Manidae sp., locally called "tu(r)cutacar"), Red River Hog (Potamochoerus porcus, locally called porco do mato) and duikers (Cephalophus sp., local names including "cabra do mato" and "fritamba").

The price of primates at market seemed to be related to their size and not their weight. The traders did not have scales at the stall and based their prices in the size of the specimens. $P$. papio males are the biggest and therefore most expensive carcasses at the markets, being sold at between 10,000 and 15,000 CFA (approximately $17 €-25 €$ ). The price of baboon females and females and males of the other species varied between 4,000 and 8,000 CFA (approximately 6-12€). Carcasses were mostly sold whole and to restaurants, although some private customers were also observed.

The restaurants that specialise in serving bushmeat meals are locally called Abafatórios. Here, primate meat is most often consumed as a snack whilst drinking alcohol. It is cooked in a stew (see Fig. 2) and eaten with bread. The meal (4 pieces of primate meat, not including bread) cost around 1,250 CFA (approximately $2 €$ ). Primate hands, feet and heads were referred as greatly appreciated by the customers.

Daily frequency of trade in Bissau markets varied across the dry season (Fig 3). In the first period of the study (1st to 5th March) trade averaged 9.6 primates per day across both markets (7.4 in Chapa and 2.2 in Rampa). In the second period of the study (30th March to 10th April), the trade increased to 16.8 primates per day across both markets (11.6 and 5.2 primates per day in Chapa and Rampa respectively). In the third period of the study (19th May to 6th June), approaching the start of the rainy season, we found a sharp decrease in the commerce (only 2 primates per day in Chapa market and no trade at all in Rampa market). The average and standard deviation of trade across periods is $9.46 \pm 7.4$ primates per day.

In the majority of cases, the primates were attributed to coming from the south of Guinea-Bissau. "Cacine" (a village in the Tombali Administrative region) was the origin most frequently recalled/named, followed by Cossé and Xitole (in Bafatá). These locations follow the main road from Bissau to the south of the country, so may 
not represent the places where the primates were actually hunted, but instead the origin of transportation.

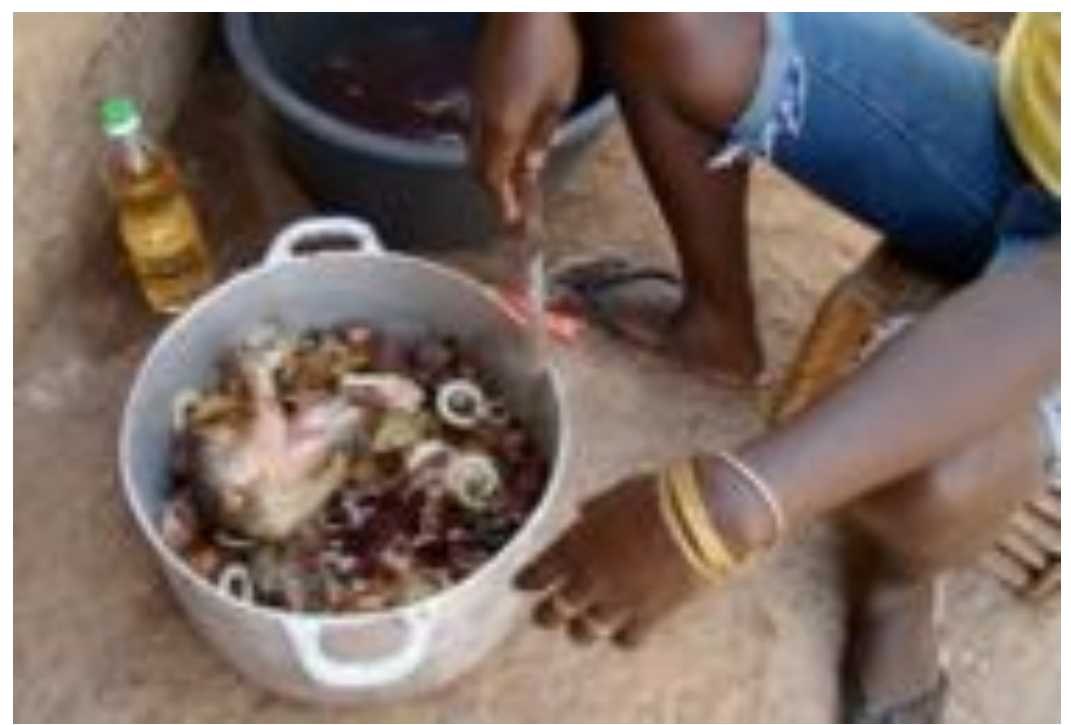

Figure 2 Preparation of primate meat stew at "Abafatórios" restaurant. Baboon and green monkey heads are visible.

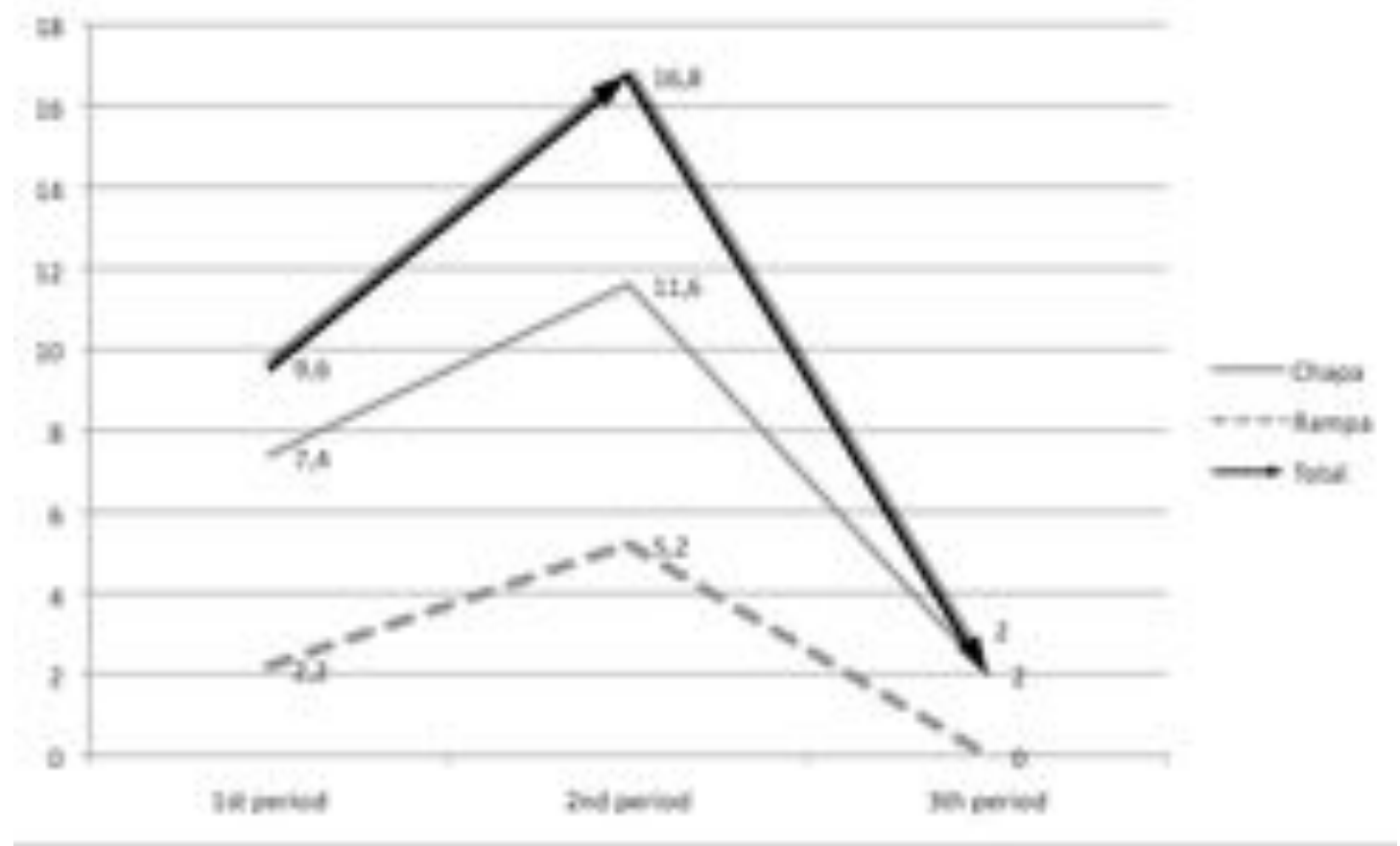

Figure 3 Daily frequency of trade across periods for Chapa and Rampa markets. The total values are also indicated. 
Species assignment

All the tissue samples collected were successfully extracted and sequenced for a $623 \mathrm{bp}$ fragment. We were able to sequence 46 samples with the OWMCOI primer set. Two samples (labelled as Procolobus badius and Cercopithecus campbelli) were sequenced using the VERTCOI primers and the two samples labelled as Colobus polykomos samples were sequenced using the FOLMER primer set.

All sequences were 'blasted' and compared with $\mathrm{NCBI}$ database $\mathrm{COI}$ sequences (using BLASTn, Altschul et al. 1990). Across species and discounting Cercopithecus campbelli, we obtained a $0-6 \%$ range of dissimilarity. Two samples showed a 95\% similarity to Colobus polykomos but also with Colobus guereza; seven samples were 99\% similar with Procolobus badius; 12 samples showed 99-100\% similarity with Papio papio; 15 samples were $99-100 \%$ similar to Chlorocebus sabaeus and two samples were $94 \%$ similar to Erythrocebus patas sequences. Twelve samples, suspected to be Cercopithecus campbelli, showed $89 \%$ similarity with both Cercopithecus pogonias and Cercopithecus wolfi. However, since there are no sequences identified as Cercopithecus campbelli in Genbank for the COI barcode region, we identified this species using a fragment of the 12srRNA gene (similarlity with 12sRNA gene).

All the sequences belonging to the same species are grouped together along with the respective voucher sequence in six clusters supported by $100 \%$ of the bootstrap replicates in the Neighbour-Joining tree constructed (Fig. 4). The six highly supported clusters corresponded to the six species sold at the bushmeat markets at Bissau: C. campbelli, P. badius C. polykomos, P. papio, E. patas and C. sabaeus, agreeing with the information given by the sellers based on morphological identification.

Morphological Identification error and corrected number of specimens per species

On average, the morphological identification error rate across species was of 23.4\%. We found the greatest morphological identification error in C. campbelli (59.1\%), followed by P. badius (40\%), C. polykomos (33.33\%) and P. papio (7.70\%). 
We didn't find any error in the morphological identification of E. patas and $C$. sabaeus. Most samples mislabelled in the morphological identification were molecularly assigned to $C$. sabaeus: 10 samples initially labelled as $C$. campbelli and 3 samples labelled as $P$. badius. Accordingly, after applying the correction factor to the total number of specimens observed at the markets, the total number of $C$. campbelli decreased in 35 specimens, while all other species increased in number, on average by 18 specimens. We found an increase of 13 specimens for $P$. papio, 5 specimens for E. patas, 1 for P. badius, 1 for $C$. polykomos and 57 for $C$. sabaeus (see Fig. 5). Therefore, our results suggest that at the Bissau markets two species are predominately traded, at similar frequencies: C. sabaeus (32.2\%) and C. campbelli (30.6 \%). P. papio was the third most traded species (19.26\%) followed by E. patas (4.9\%), P. badius (11.5\%) and C. polykomos (1.4\%) (see Fig. 6). 


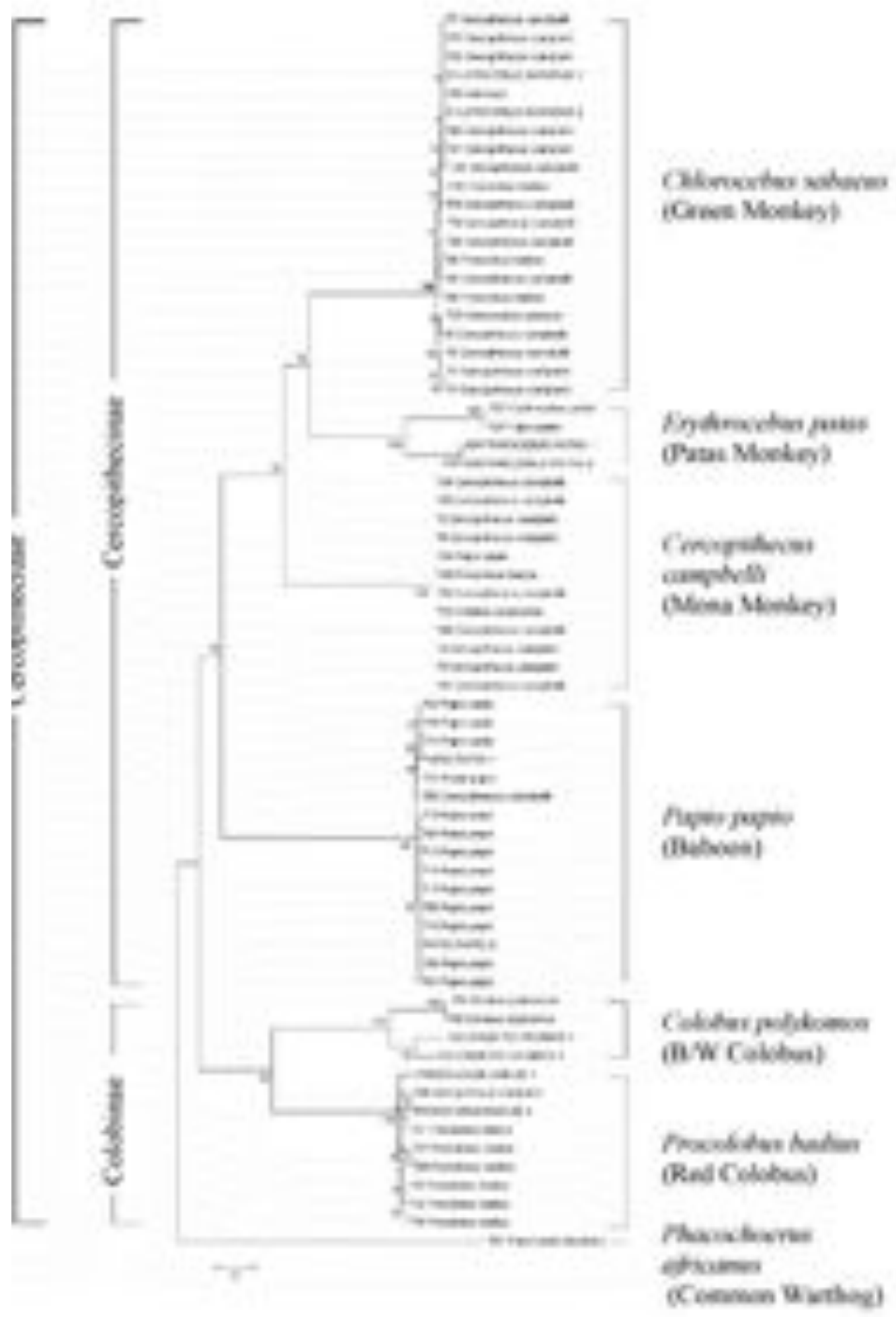

Figure 4 Neighbour-joining tree with bootstrap values supporting molecular identification 


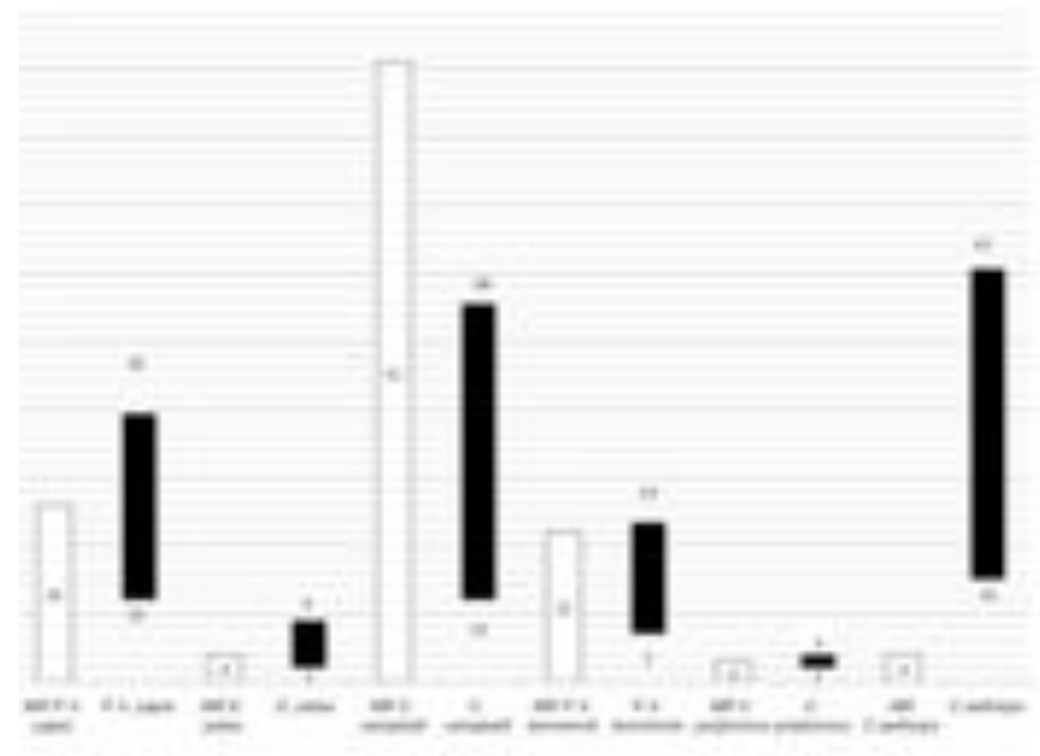

Figure 5 Total number of specimens per species. White bars refer to the morphological identification (MR). Numbers inside white bars represent the number of specimens identified morphologically at the markets. Black bars represent the potential range in frequency of specimens after the molecular identification correction. Numbers below black bars represent the minimum number of specimens per species (i.e.. samples molecularly assigned to that species). Numbers above black bars represent the estimated/potential maximum number of individuals at the markets.

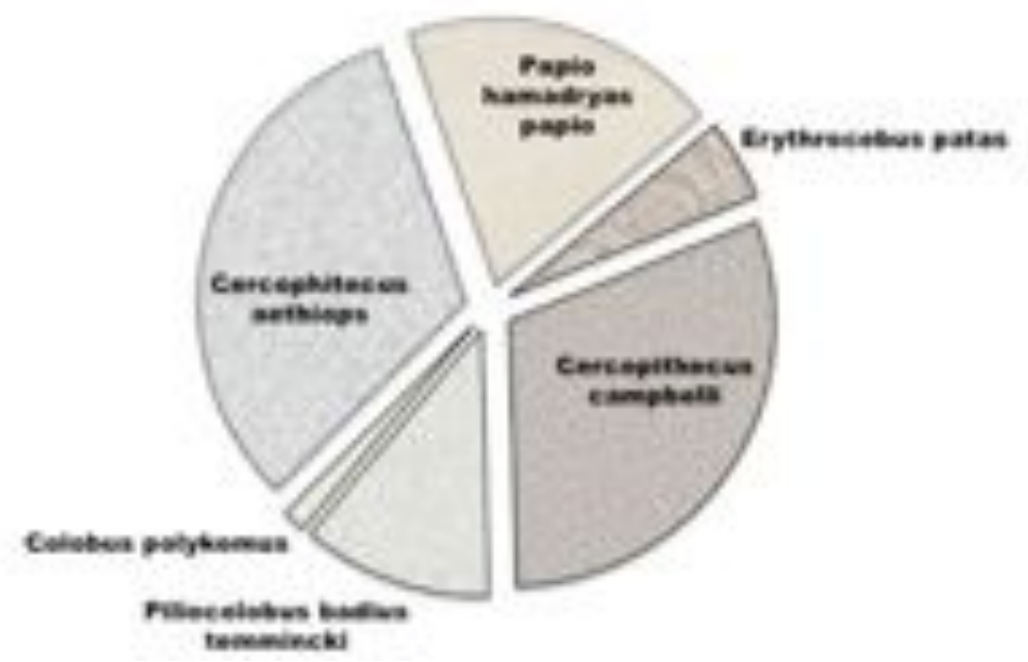

Figure 6 Relative percentage of species traded at Bissau markets. 
Projection of the primate bushmeat trade in Guinea-Bissau

We extrapolated the number of primates traded in Bissau over the entire dry season (212 days). Using the average daily trade across the three periods, 2006.9 primates are traded every dry season. During this period, and assuming the relative percentages for the 19 days of study, we predict that 646 specimens of $C$. sabaeus, 616 of $C$. campbelli, 387 specimens of $P$. papio, 99 specimens of $E$. patas, 232 specimens of $P$. badius and 28 specimens of $C$. polykomos are traded in the bushmeat markets in Bissau.

Table 1: Data collection and molecular species assignment

\begin{tabular}{|c|c|c|c|c|c|c|c|c|c|c|}
\hline \multirow{2}{*}{ 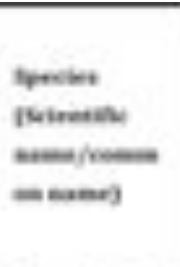 } & \multicolumn{3}{|c|}{ 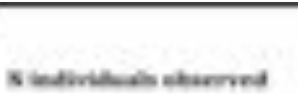 } & \multicolumn{3}{|c|}{ \& thites } & \multirow{2}{*}{ 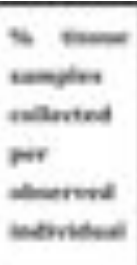 } & \multirow{2}{*}{ 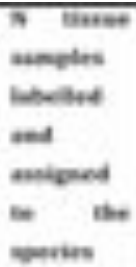 } & \multirow{2}{*}{$\begin{array}{l}\text { Erras } \\
\text { ente }\end{array}$} & \multirow{2}{*}{ 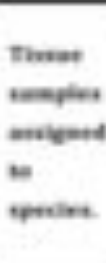 } \\
\hline & Coupe & Eampe & Telse & Chepe & vinget & $\begin{array}{l}\text { Thas } \\
1\end{array}$ & & & & \\
\hline 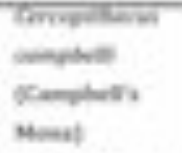 & F & $n$ & w & $\mathrm{rt}$ & 3 & 37 & 2120 & $\%$ & 90.15 & 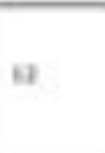 \\
\hline 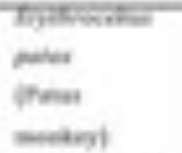 & 1 & I & 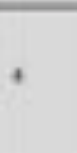 & n & " & 3 & 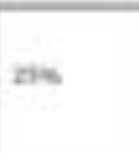 & 1 & e & $z$ \\
\hline 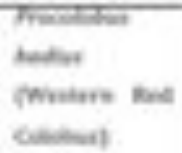 & in & 4 & 12 & ea & = & at & stos & $=$ & $\tan$ & 7 \\
\hline 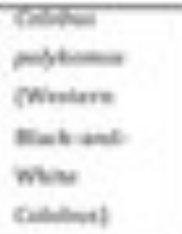 & 1 & 9 & t & , & a & 3 & iveth & 7 & $\begin{array}{l}\text { min } \\
\text { th }\end{array}$ & 2 \\
\hline 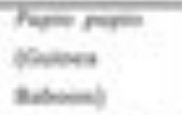 & is & $*$ & is & w & 4 & 111 & uent & 12 & 28 & G \\
\hline 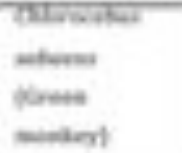 & $x$ & t & $t$ & a & " & 3 & 210 & 1 & ens & It \\
\hline Tlas & 137 & $m$ & ise & is & 3 & sa & & & & \\
\hline
\end{tabular}


Appendix J: Mitochondrial DNA variation of the lesser spot-nosed guenon

(Cercopithecus petaurista) from the Canhabaque Island, Bijago Archipelago, West Africa [in prep.]

\author{
R. M. Sá ${ }^{1,2,3,4}$ N. Thomas ${ }^{1}$, M. Ferreira da Silva ${ }^{1,4,5}$, T. Minhos $^{1,4,6}$, M.W. Bruford ${ }^{1}$ \\ ${ }^{1}$ Cardiff School of Biosciences, Cardiff University, Cardiff, UK; ${ }^{2}$ Department of Anthropology, \\ New University of Lisbon, Lisbon, Portugal; ${ }^{3}$ CRIA-Centre for Research in Anthropology, \\ Portugal; ${ }^{4}$ APP-Portuguese Primatological Society, Portugal; ${ }^{5} \mathrm{CIBIO}$-Centro de Investigação \\ em Biodiversidade e Recursos Genéticos, Faculdade de Ciências, Universidade do Porto, \\ Porto, Portugal; ${ }^{6}$ CBA-Centro de Biologia Ambiental, Faculdade de Ciências, Universidade de \\ Lisboa, Lisboa, Portugal
}

\begin{abstract}
Little is known about the Western lesser spot-nosed guenon (Cercopithecus petaurista buettikoferi) with a paucity of studies on the species. The Bijago Archipelago in Guinea-Bissau, West Africa represents the westerly limit of the species. There has been a significant decline in population abundance and distribution over the past twenty years due to intensive hunting for bushmeat trade. Canhabaque Island represents one of the only four known extant populations in the country. Non-invasive sampling was undertaken over four sample sites (Menegue, Bane, Inhoda and Inorei) encompassing the entire island. Amplification of the HVR1 of the mtDNA was undertaken to determine the genetic variation of the island population as well as to infer past demographic events and some life history traits, such as dispersal sex. A total of 47 sequences of $520 \mathrm{bp}$ were obtained showing 12 haplotypes with 26 polymorphic sites. These included nine singleton variable sites and 17 parsimony informative sites, comprising 24 transitions and 2 transversions. Rare haplotypes dominated the dataset with 9 haplotypes having a frequency of less than three. The dataset showed a high haplotype diversity (Hd) of 0.809 and a low nucleotide diversity $(\pi)$ of 0.00850 suggesting a post-bottleneck demographic expansion of the population. Neutrality tests, although negative were not significant. Mismatch distribution showed a unimodal pattern and a high raggedness statistic ( $r$ $=0.1371)$. The results of the AMOVA test indicated more variation within subpopulations than between sub-populations with the $F_{S T}$ value of 0.21773 suggesting population substructure. The high $\mathrm{Hd}$ and low $\pi$ values shown in the dataset are in agreement with those of other species in the Cercopithecidae family. The role that primates play in seed dispersal is discussed along with the potential for $C$. petaurista to be labelled as an 'umbrella species' under a taxon lead conservation strategy in Canhabaque Island.
\end{abstract}

Keywords: Cercopithecus petaurista, Canhabaque Island, mtDNA, genetic diversity. 


\section{Introduction}

The guenons are the largest and most diverse primate group in Africa, where they are endemic to the sub-Saharan region (Groves 2001; Grubb et al. 2002). First described by Linnaeus in 1758, there is some debate over which species should be included in the Guenon taxon. Currently the most widely accepted and broad definition is that a guenon is a monkey from the tribe Cercopithecini (Butynski 2002). This definition includes all the species of the genus Cercopithecus as well as Miopithecus spp., Chlorocebus spp., Allenopithecus nigroviridis and Ethryrocebus patas. The number of species and sub-species recognised varies considerably, with two recent studies recognising 23 species (Grubb et al. 2002) and 36 species (Groves 2001) respectively. Regardless of which definition is considered the authority for the term guenon, the Cercopithecus genus is the most speciose in the primate order (Fleagle 1999). The diversity seen in habitat, pelage, ecology and social structure has resulted in the guenons being of great interest to evolutionary biologists (Butynski 2002). The first guenon fossils date back to the Pliocene, 3 million years ago (mya), although it is believed that most of the evolutionary radiation of the genus has occurred in the last one million years (Leakey 1988). Considering the relatively recent radiation of the genus it is likely that it is still undergoing speciation (GautierHion et al. 1988). The Cercopithecine monkeys have a complex and unclear phylogeny, with different phylogenies obtained for different characters (Appendix i): karyotypes (Ledbetter 1981; Dutrillaux et al. 1988), blood proteins (Ruvolo 1988), dental, cranial and postcranial morphology (Strasser \& Delson 1987), skull morphology (Groves 2000), mitochondrial DNA (mtDNA) (Disotell and Raaum 2002) and Y-chromosome sequence (Tosi et al. 2002). These taxonomic ambiguities could be attributed to their relatively recent speciation. Little is known about the lesser spot-nosed guenon (Cercopithecus petaurista; Schreber 1774) with a paucity of studies in existence, largely focusing on behaviour (McGraw 2000) and inter-specific interactions (Buzzard 2006a, 2006b, 2010). Data such as facial markings (Kingdon 1980), chromosomes (Dutrillaux et al., 1988), vocalisations (Gautier 1988) and proteins (Ruvolo 1988) suggest that C. petaurista is grouped into the superspecies 
Cephus, which includes the currently described Cercopithecus cephus, C. ascanius, $C$. erythrotis and C. erythrogaster species. C. petaurista ranges from Guinea Bissau in the North-East to Togo in the South-West, although there has been a recent report of a single male lesser spot-nosed guenon observed in Fongoli study site in SouthEast Senegal (Pruetz et al. 2010), which could suggest a Northern range distribution of the species. Lesser spot-nosed guenons are quadrupedal primates that live predominantly in the top layer of

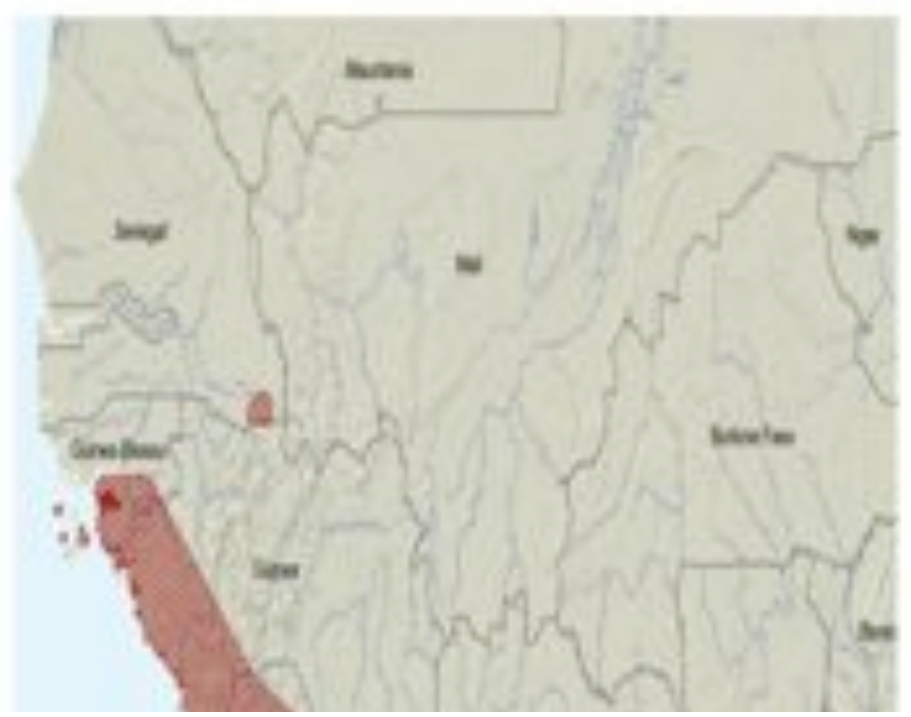
the forest canopy. Their diet is mainly frugivorous with over $77 \%$ consisting of fruit (McGraw 2000). The species is currently divided into two subspecies depending on region, the Western lesser spot-nosed guenon (Cercopithecus petaurista buettikoferi; Jentink, 1886) and

Figure 1: Range of C. petaurista with sub species range the Eastern lesser Spot-nosed (http://www.iucnredlist.org/apps/redlist/details/4225/0) guenon

(Cercopithecus petaurista petaurista; Schreber, 1774). The two sub-species are divided by the Cavally River in Liberia which acts as a geographic barrier (Figure 1) (Kingdon 2001; Oates et al. 2008). This study is concerned with the Western subspecies, C. p. buettikoferi, as samples were collected from the Canhabaque Island in the Bijagos Archipelago off the coast of Guinea Bissau to the west of the Cavally River. There has been no genetic analysis carried out on $C$. p. buettikoferi to date and thus the genetic diversity of the subspecies and relative diversity compared to other closely related species is still unknown. Here we described the HVR1 genetic variation of the Western lesser spot-nosed guenons of Canhabaque Island, we assessed their genetic structure explored their demographic history.

\section{Material and Methods}




\section{Study Site}

Canhabaque Island $\left(11^{\circ} 15^{\prime} 2^{\prime \prime} \mathrm{N}, 15^{\circ} 43^{\prime} 3^{\prime \prime} \mathrm{W}\right)$ lies on the Bijago Archipelago off the coast of Guinea-Bissau, West Africa (Figure 2) and is part of the João Vieira-Poilão Marine National Park.

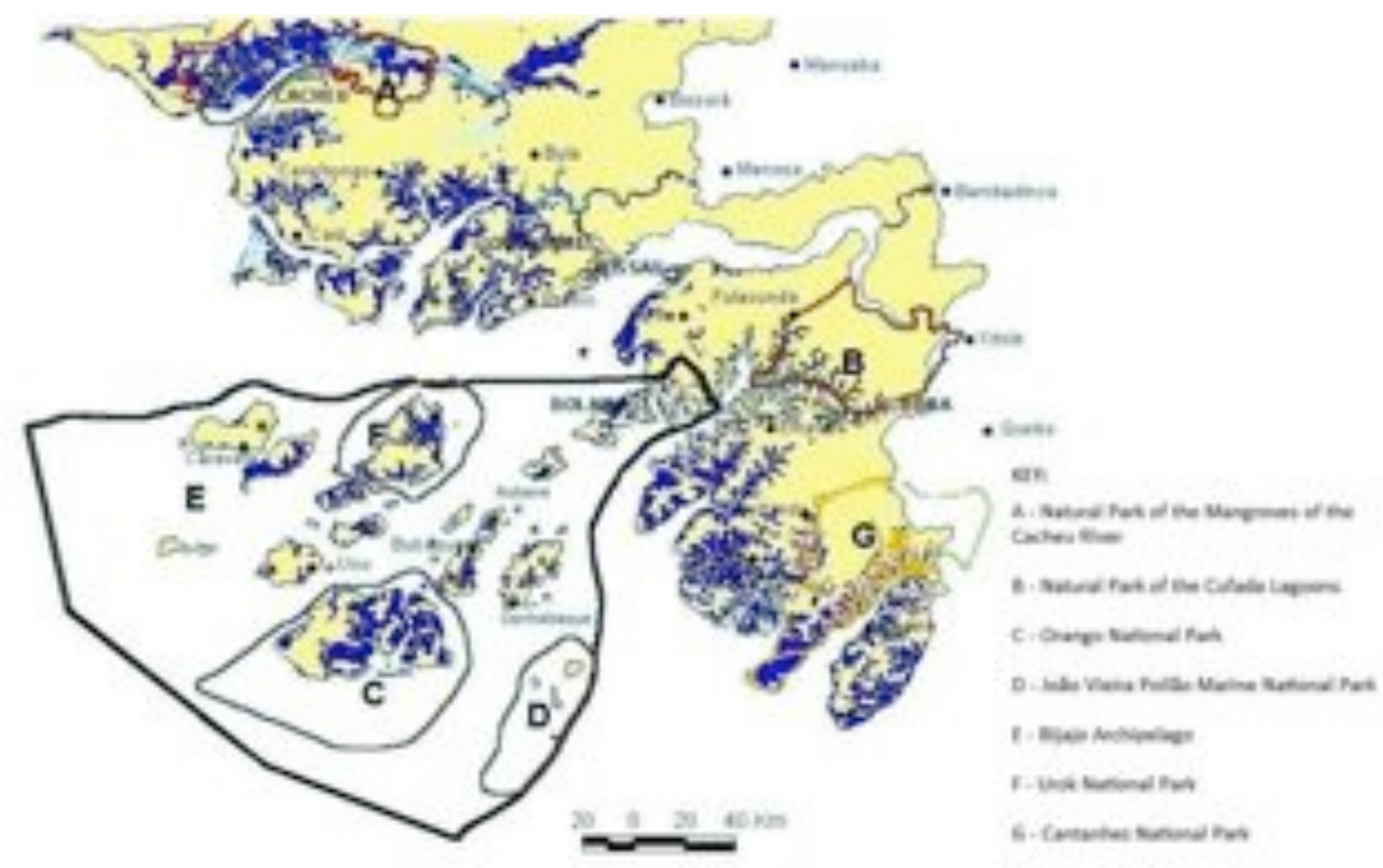

Figure 2: Map of Guinea-Bissau (http://www.ibapgbissau.org/Coneccoes/apzcgb.html)

The Bijago Archipelago represents an area of significant ecological importance, not only for birds and marine fauna but also for terrestrial fauna. The area is current a Biosphere Reserve with an application for UNESCO World Heritage Hotspot ongoing (UNESCO 2006). Canhabaque Island represents one of the areas where $C$. petaurista populations still persist. The average temperature is $26^{\circ} \mathrm{C}$ and average humidity $70 \%$, with the rainy season occurring from May to October and the dry season from 
November to April. The island comprises three main habitat types: mangroves, tropical lowland forest and grassland and only three mammal species are present on the island: C. petaurista, duikers (Cephalophus spp.) and the Gambian rat (Cricetomys gambianus) (R. Sá, personal communication, $15^{\text {th }}$ November 2010).

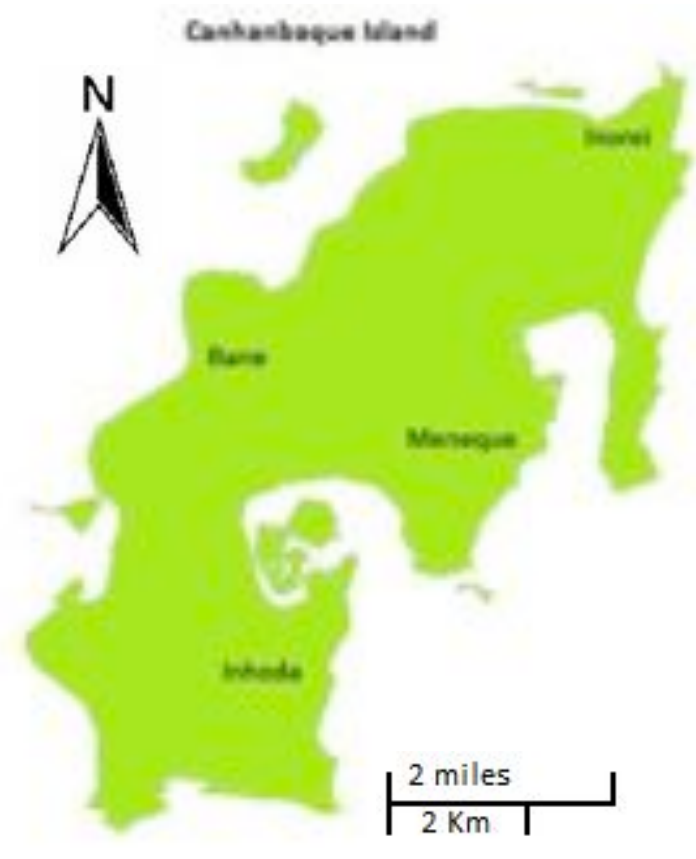

Figure 3: Map of study sites on Canhabaque Island.

Non-invasive faecal sampling was undertaken during the dry season (FebruaryJune 2010) at four main study sites, Menegue, Bane, Inorei and Inhoda covering the entire island (Figure 3). A total of 96 samples were collected, each sample received a unique identification code along with a record of the place of origin, which will allow the geographic structuring of genetic variation on the island to be determined. Faecal samples were stored in one of four ways: silica, ethanol, DMSO or two steps (Roeder et al. 2004). Tissue samples were also collected from individuals killed by local villagers for bushmeat consumption and were stored either in ethanol or in DMSO. A record of sample preservation method was taken so that amplification success rates for the four different methods could be determined. Amplification success rates of preserved samples will be compared between faecal and tissue samples to see if there are any statistically significant differences.

DNA samples were transported from Guinea-Bissau to the United Kingdom in agreement with the Convention on International Trade in Endangered Species (CITES) and for pathogen control regulations (DEFRA). 


\section{DNA Extraction}

Tissue samples were stored either in ethanol or $20 \%$ Dimethyl sulfoxide (DMSO) salt solution. All tissue samples were extracted under sterile conditions using a Qiagen DNeasy Blood and Tissue Kit following an optimised version of the protocol. Two extraction negatives (reagents only) were included in each extraction set to allow monitoring for contamination (Handt et al. 1994).

Faecal samples were stored by either DMSO, silica, ethanol or two step method. Extractions were performed under sterile conditions using a Qiamp mini stool kit following an optimised version of the

\section{HVR1 Primers}

Primers specific to Cercopithecidae were created in the D-loop region of the mtDNA by aligning whole mitochondrial and D-loop sequences from old world monkeys (OWM) and great apes (using Bioedit software (version 7.0.5.3, Hall 1999). Primers were then designed in the regions where the sequence was conserved for all Cercopithecidae, but had one or two substitutions in the human and/or chimpanzee sequences making them more specific to OWM mtDNA and reducing the chance of human cross amplification. The resulting primer pair was LNIAHVR1 (5'-CTC-AAATGA-ACT-TGC-CTT-3') and HNIAHVR1 (5'-TGA-GGT-AAG-AAC-CAG-ATG-3'). Bases which are substituted in great apes are underlined. The primers were tested using Oligo Analyser (http://eu.idtdna.com/analyzer/applications/oligoanalyzer) for basic parameters such as GC content, hairpin, self-dimer and hetero-dimer. Primer optimisation indicated an optimal annealing temperature of $59^{\circ} \mathrm{C}$ and yielded a fragment size around $656 \mathrm{bp}$ in $C$. petaurista. This is an approximate value as no $C$. petaurista sequences were available when the primers were designed.

\section{HVR1 PCR Protocol}

PCR was performed on a total volume of $15 \mu$ l and contained: $7 \mu$ multiplex (x2), $2 \mu \mathrm{l}$ of primer mix $(2 \mu \mathrm{m}), 0.1 \mu \mathrm{l}$ BSA $(10 \mathrm{mg} / \mathrm{ml})$, topped up with $3.9 \mu \mathrm{l}$ ultrapure water and $2 \mu \mathrm{l}$ template DNA. Cycling conditions were $95^{\circ} \mathrm{C}$ for 15 minutes, then 45 cycles 
of $94^{\circ} \mathrm{C}$ for 30 seconds, $59^{\circ} \mathrm{C}$ for 30 seconds and $72^{\circ} \mathrm{C}$ for 1 minute with a final extension step of $72^{\circ} \mathrm{C}$ for 10 minutes. Samples that did not produce a band at the $59^{\circ} \mathrm{C}$ annealing temperature underwent a second PCR cycle at a lower annealing temperature of $54^{\circ} \mathrm{C}$ as during optimisation this was the annealing temperature at which no samples dropped out. Samples which failed at this reduced annealing temperature were considered as failed extractions. Two PCR blanks (reagents and water) were included in each set of PCR reactions to detect any possible contamination. In order to test the amplification, $2 \mu$ l of PCR product was mixed with $3 \mu \mathrm{l}$ of $1 \mathrm{x}$ loading dye and then PCR fragments were then separated on $2 \%$ agarose gels (120 V, 40 minutes) using gel electrophoresis and visualised using $2 \mu \mathrm{l}$ ethidium bromide staining $(5 \mathrm{mg} / \mathrm{ml})$ per $100 \mathrm{ml}$ of agarose gel under a UV transluminator.

\section{DNA sequencing}

The Exo-Sap (Endonuclease I - Shrimp Alkaline Phosphate) method (New England BioLabs) was used to purify all PCR products before sequencing. This protocol removes excess primer and nucleotides from the PCR product, thus purifying the sample. A final volume of $6 \mu \mathrm{l}$, containing $2.5 \mu \mathrm{l}$ Sap buffer (10x), $1 \mu \mathrm{l}$ Sap (5000 $\mathrm{U} / \mathrm{ml}), 0.5 \mu \mathrm{l}$ exo $(20,000 \mathrm{U} / \mathrm{ml})$ and $2 \mu \mathrm{l} \mathrm{H}_{2} \mathrm{O}$, was added to $13 \mu \mathrm{l}$ of PCR product. Cycle conditions were $37^{\circ} \mathrm{C}$ for 30 minutes, $80^{\circ} \mathrm{C}$ for 15 minutes and $12^{\circ} \mathrm{C}$ for 5 minutes. $8 \mu \mathrm{l}$ of purified sample was then added to $5 \mu$ l of either forward or reverse NIAHVR1 primer $(5 \mathrm{pnol} / \mu \mathrm{l})$ for sequencing using Macrogen Europe's EZ-sequencing service.

\section{Data Analysis}

Statistical Analysis

Minitab 15.1.20.0 (Minitab Inc 2007) was used to perform chi-squared tests on the amplification success rates of different sample preservation methods. This test indicates whether observed data deviates significantly from expected results. In this 
case the expected amplification success rates were calculated as equal proportions of the amplification success for each sample type. Amplification success was defined as presence of a band i.e. DNA amplification, after PCR.

Sequence Alignment and Editing

Forward and reverse DNA fragments were edited by eye and aligned into contig sequences using Sequencher 4.9 (Gene Codes Corp., Ann Arbor, Michigan, USA). The contigs were then re-checked by eye for any discrepancies between the two fragments before conversion into consensus sequences. All consensus sequences were confirmed using BLAST - Basic Local Alignment Search Tool in NCBI to confirm they were $C$. petaurista. The sequences were then exported to Bioedit 7.0.5.3 (Hall 1999) and aligned using CLUSTAL W algorithm. All polymorphic sites and insertions were then re-confirmed through the chromatographs in Sequencher. Polymorphic sites were determined and all insertions, transversion and transistion polymorphisms were re-checked using the chromatograms. Sequences were then corrected so that only true polymorphic sites were present. All sequences were cut to the length of the shortest sequence and exported as a FASTA file for genetic diversity analysis.

Genetic Diversity

DnaSP, version 5 (Librado and Rozas 2009) was used to analyse HVR1 mtDNA sequence polymorphisms. Divergence between populations was calculated for the sequences grouped into location as well as polymorphism and divergence analysis. Mismatch distributions and neutrality tests were conducted including Tajima's D (Tajima 1989), Fu and Li $D^{*}$ and $F^{*}$ (Fu and Li 1993). Haplotype data files were generated. 
Arlequin 3.11 (Excoffier et al. 2005) was used to conduct Analysis of Molecular Variance (AMOVA) to indicate any population substructure in the dataset. Samples were split into groups based on study site for this analysis. AMOVA provides a description of the diversity both within and between populations through presentation of percentage variance described by each component. This is undertaken through analysis of variance of gene frequencies which accounts for the mutational distance between haplotypes (Excoffier et al. 2005). The Fixation Index $\left(\mathrm{F}_{\mathrm{ST}}\right)$ provided indicates the degree of differentiation between the population as a whole and sub-populations, ranging from 0 (no differentiation) to 1 (complete differentiation).

\section{Median Joining Network}

Network 4.6.0.0 (Fluxus Technology Ltd.) was used to create median joining networks (MJN) of the dataset. Two networks were drawn, one including all sample information and one containing only samples of known origin. A MJN is the combination of all minimum spanning trees (MST) combined into a single network (MSN) using the modified algorithm proposed by Excoffier and Smouse (1994). Missing intermediate nodes are then added to the network via median vectors using a parsimony criterion (Bandelt et al. 1999).

\section{RESULTS}

A total of 47 sequences of $520 \mathrm{bp}$ were obtained showing 12 haplotypes with 26 polymorphic sites including nine singleton variable sites and 17 parsimony informative sites. These comprised 24 transitions and 2 transversions, indicating a 12:1 transition: transversion ratio. The most common haplotype was H4 with 16 individuals having this sequence. There were also a large number of rare haplotypes with six singletons. Overall, nine of the 12 haplotypes contained three or fewer 
individuals and only three haplotypes exhibited a higher frequency. This shows that the dataset is dominated by rare haplotypes with few common haplotypes present.

\section{Demographic History}

The mismatch distribution analysis using the constant population size model shows the distribution of pairwise nucleotide site differences for observed (dataset) and expected (stable population) values. The graph presented in Figure 4 shows a unimodal pattern; indicating a population bottleneck. The raggedness statistic $r=$ 0.1371 (Harpending et al. 1993) also indicates a bottleneck with subsequent demographic expansion, giving an erratic distribution and non-equilibrium population (Weber et al. 2004).

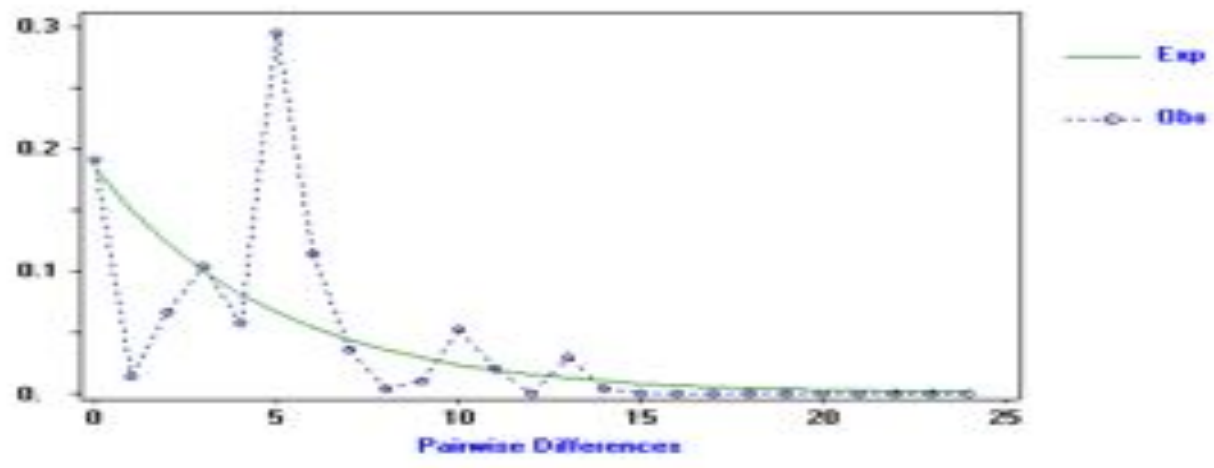

Figure 1: Mismatch distribution for $C$. petaurisa mtDNA HVR1 sequences showing the frequencies of pairwise differences. The dashed blue line represents the observed pattern and the solid green line represents the expected pattern under the constant population size model.

Geographic Division of the mtDNA Diversity

Only sequences of known origin, i.e. no 'whole island' sequences, were considered for this genetic diversity analysis. The removal of the whole island dataset meant that 2 haplotypes only occurring in these individuals were also lost. 
Table 2: Haplotype diversity by location.

\begin{tabular}{c|c|c|c|c|c} 
Location & $\mathrm{N}$ & $\mathrm{h}$ & $\mathrm{Hd}$ & $\theta^{2}$ & $\pi$ \\
\hline Menegue & 20 & 6 & 0.742 & 0.074 & $0.00627( \pm 0.00065)$ \\
Bane & 1 & 1 & - & - & - \\
Inhoda & 3 & 2 & 0.667 & 0.314 & $0.01282( \pm 0.00604)$ \\
Inorei & 2 & 2 & 1.000 & 0.500 & $0.00385( \pm 0.00192)$ \\
All locations & 26 & 10 & 0.831 & 0.053 & $0.00897( \pm 0.00132)$
\end{tabular}

In all locations there are high haplotype diversities (Table 7), although small sample sizes for some areas e.g. Inorei, result in a probable over estimation of haplotype diversity. Results from areas with small sample sizes are presented in italics and must be interpreted with caution as lack of sequences can bias the results. DNA polymorphism analysis could not be carried out for Bane, as only one individual was sequenced from this location. The more reliable data from Menegue and all locations support the pattern of high $\mathrm{Hd}$ and low $\pi$.

\section{Differentiation of Sub-populations}

Table 3: AMOVA results.

\begin{tabular}{l|c|c|c|c}
\multicolumn{1}{c|}{$\begin{array}{c}\text { Source of } \\
\text { Variation }\end{array}$} & $\begin{array}{c}\text { Degrees } \\
\text { of } \\
\text { freedom }\end{array}$ & SSD & $\begin{array}{c}\text { Variance } \\
\text { components }\end{array}$ & $\begin{array}{c}\text { Percentage of } \\
\text { variance (\%) }\end{array}$ \\
\hline $\begin{array}{l}\text { Among sub- } \\
\text { populations }\end{array}$ & 3 & 2.168 & $0.10395 \mathrm{Va}$ & 21.77 \\
$\begin{array}{l}\text { Within sub- } \\
\text { populations }\end{array}$ & 22 & 8.217 & $0.37348 \mathrm{Vb}$ & 78.23 \\
Total & 25 & 10.385 & 0.47743 & \\
\hline Fixation index & $\mathrm{F}_{\text {ST }: 0.21773}$ & &
\end{tabular}

The results of AMOVA analysis (Table 8 ) indicate that there is more variation within sub-populations than between sub-populations, the percentage variance explained being $78.23 \%$ and $21.77 \%$ respectively. However there is a large skew in the number of individuals from each location, with Menegue having a considerably larger $\mathrm{N}$ than any other location. This may have confounded the results of the AMOVA, as Menegue also has the largest number of haplotypes which would have resulted in a high within sub-population variation value for this location. The $F_{S T}$ value of 0.21773 given suggests great genetic differentiation between sub-populations (Wright 1978), 
indicating that there is substructure of the populations. The significance tests of this AMOVA have a significant $\rho$-value $=0.00782 \pm 0.00242$, thus showing the significance of the Fixation Index.

Median Joining Networks

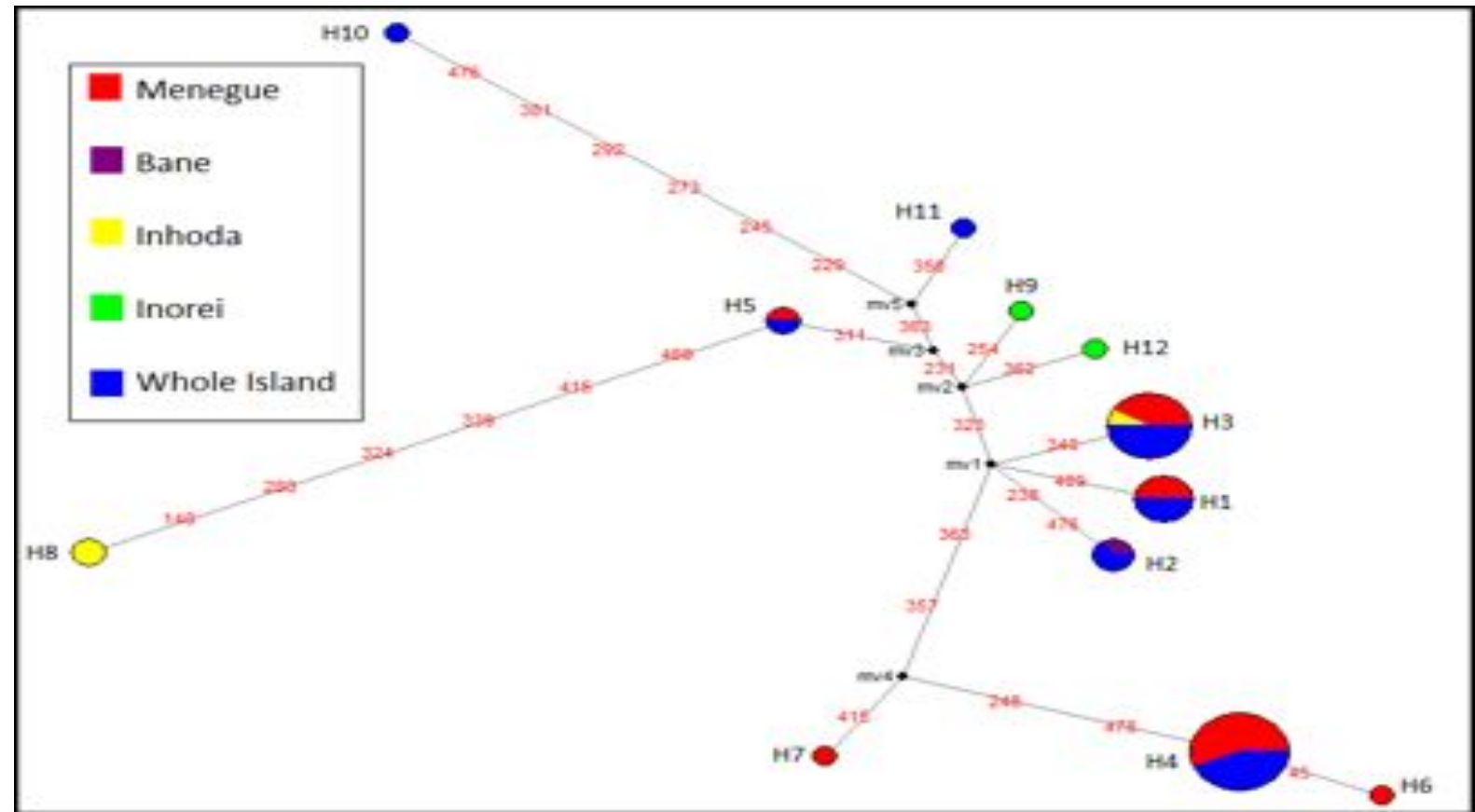

Figure 2: Median Joining Network for the entire dataset of lesser spot-nosed guenons on Canhabaque. Each circle represents and haplotype. Circle sizes are proportional to haplotype frequency. Mutational steps are indicated by the red numbers represent the sequence sites that have undergone mutations. Black dots are median vectors of unsampled or missing haplotypes. 
The network (Figure 5) shows a complex pattern with 12 haplotypes and 14 mutational steps separating the two most distant haplotypes. The diagram shows a mixture of a few distinct haplotypes ( $\mathrm{H} 8$ and $\mathrm{H} 10)$ and many haplotypes that are only two or three mutation steps removed from one another. The diagram shows high haplotype diversity with many rare haplotypes having been sampled. Some differentiation of haplotypes by location is shown; however, the inclusion of 'whole island' samples of unknown origin resulted in reduced clarity in the differentiation of haplotypes by location.

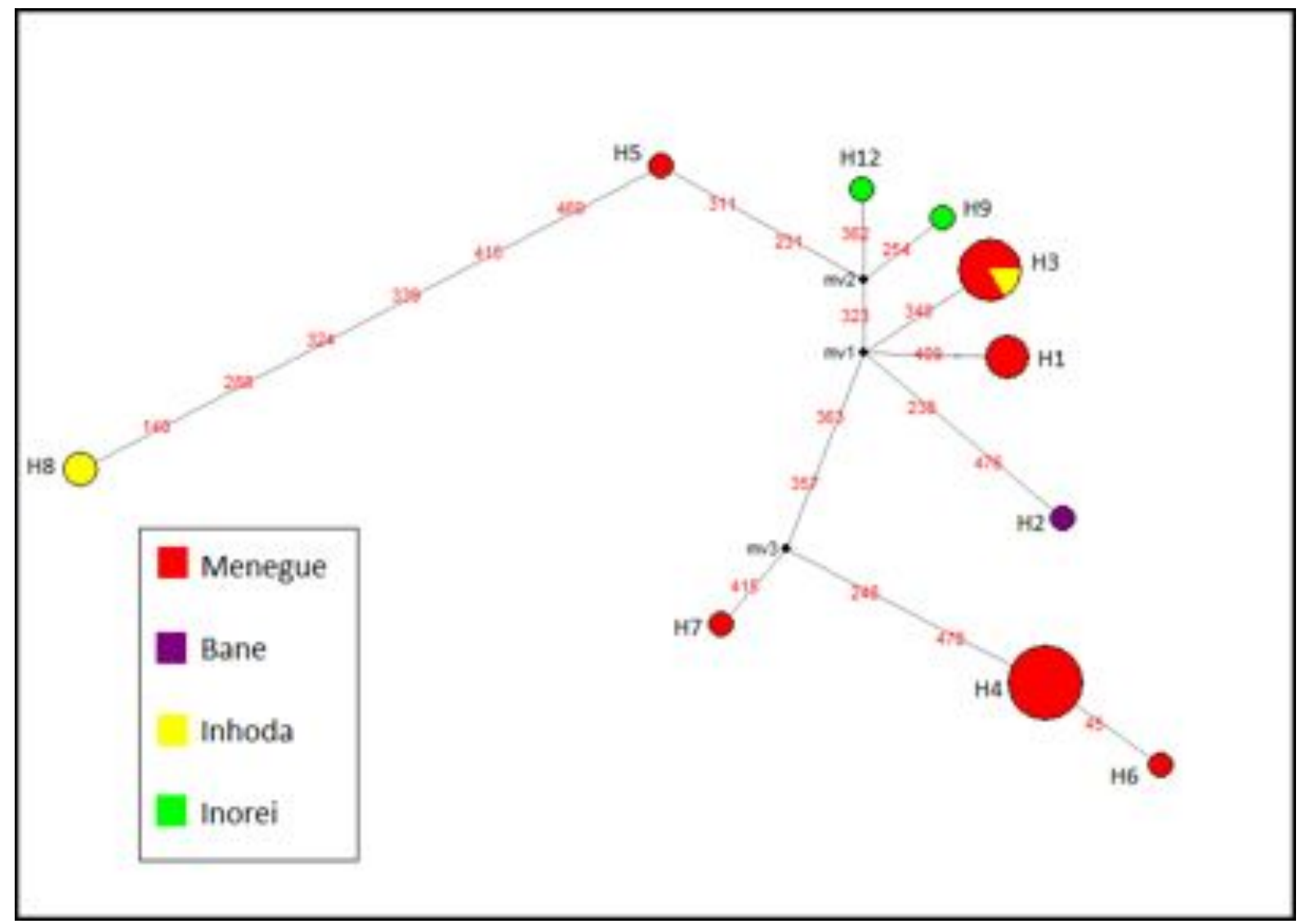

Figure 6: Median joining network diagram for the dataset of know origin samples of lesser spot-nosed guenons from Canhabaque. Each circle represents a haplotype. Circle sizes are proportional to haplotype frequency. Mutational steps are indicated in red numbers and represent site that have undergone mutations. Black dots are median vectors of unsampled or missing haplotypes. 
The network diagram containing samples of known origin only (Figure 6) shows more clearly the differentiation of haplotypes between different locations on Canhabaque Island. There is high haplotype diversity (10 haplotypes in 27 samples) and 14 mutational steps between the two most distant haplotypes. However, most of the haplotypes are only two or three mutations removed from one another, suggesting relatively recent divergence, with one outlying haplotype $(\mathrm{H} 8)$ having 6 mutations to the closest haplotype. Most haplotypes are distinct to a specific area, although low sample size in Bane, Inhoda and Inorei suggests that this result is not definite, as a wide range of haplotypes have not been collected from these areas and missing haplotypes may represent shared haplotypes between different areas.

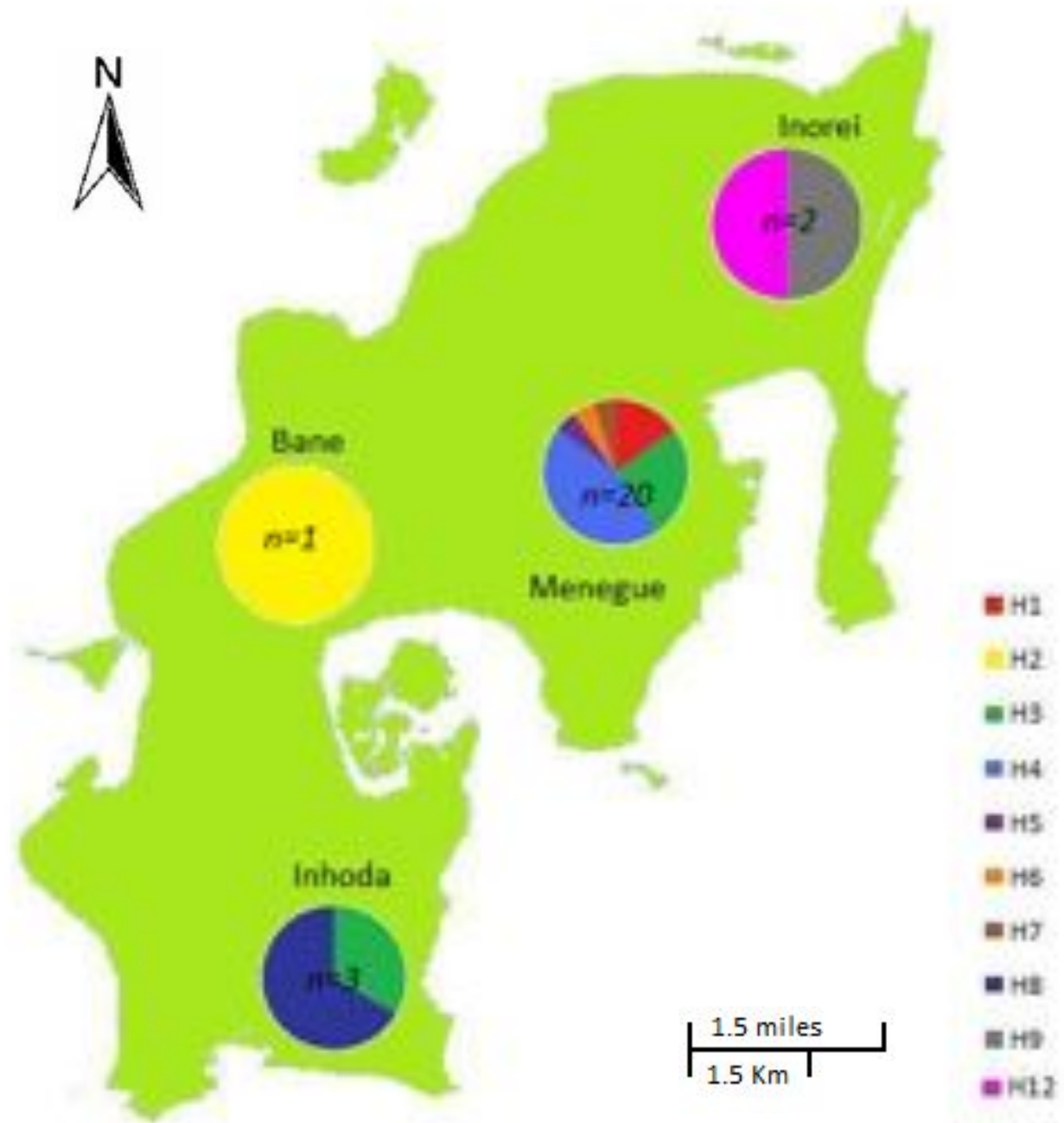

Figure 3: Map of Canhabaque Island with haplotype frequencies by location. 
Figure 7 shows the haplotype frequencies found at each data collection site on the island, haplotypes 10 and 11 are not present in this figure as they only occur in the 'whole island' sample set. The haplotype frequencies infer high differentiation between sub-populations with only one common haplotype - haplotype 3 - shared between Inhoda and Menegue. This figure contradicts the results of the AMOVA test as there appears to be a significant level of variation between the populations. However this may have been masked by the large number of haplotypes found at Menegue due to the larger dataset size.

\section{DISCUSSION}

The Western lesser spot-nosed guenons of Canhabaque Island have high haplotype diversity $(H d)$ and low nucleotide diversity $(\pi)$ a pattern which suggests a past bottleneck followed by a population expansion (Grant and Bowen 1998). Genetic loss during bottlenecks occurs more rapidly in mtDNA than nuclear DNA due to maternal inheritance and therefore a lower effective population size. During population expansion, mutations will accumulate more rapidly in the mtDNA than in the nuclear DNA due to the faster evolutionary rate of mtDNA (Grant and Bowen 1998). This explains the pattern seen in the data, especially as the sequence used was from the hypervariable region of the mtDNA therefore having an even faster evolutionary rate (Howell et al 1996). The results of the three neutrality tests performed on the dataset were negative, suggesting population expansion; however the $\rho$-values were all greater than 0.05 (Table 6), showing that the $C$. $p$. buettikoferi population of Canhabaque Island is not significantly expanding.

The unimodal mismatch distribution suggests a population bottleneck (Slatkin and Hudson 1991; Rogers and Harpending 1992).The raggedness statistic agrees with this indicating a bottleneck with subsequent demographic expansion (Weber et al. 2004). The $x$-axis value $\tau=2 \mu$ t indicates that $\tau$ is a function of time and that mutation rate and time (generations) are directly proportional; therefore the distance of the peak along the $x$-axis is a function of time since the bottleneck event (Rogers 1995). In this case the apex of the peak is at $\tau=5$, indicating a relatively 
recent but not contemporaneous bottleneck event. This interpretation agrees with results from the haplotype and nucleotide diversity analysis and the neutrality tests that the population is in post-bottleneck demographic expansion.

The results of the AMOVA were inconclusive. The results suggested higher variance within sub populations however this may have been due to the large skew in sample size towards Menegue. More samples from Inhoda, Inorei and Bane are needed to investigate these results further and determine whether there truly is more variation within the populations, or whether the results are due to different dataset sizes.

The network diagrams show high haplotype diversity with a large number of rare haplotypes present. It is therefore surprising that more common haplotypes are not present, with five missing haplotypes inferred in the diagram. There are several reasons why these sequences could be missing: they truly are extinct haplotypes, data collection was not extensive enough to collect samples of these haplotypes or some individuals have come from other islands bringing new haplotypes without the corresponding ancestral lineage. Nevertheless, the network diagrams conform with the fixation index $\left(\mathrm{F}_{\mathrm{ST}}\right)$ from the AMOVA analysis in suggesting population structure by location for the samples analysed.

To the best of my knowledge this is the first study on the population genetics of $C$. petaurista with the results providing some insights into the population structure, past demographic events and life history of the species. The haplotype sequences gained from this study will be submitted to Genbank for use in future research. Comparison of haplotype diversity $(\mathrm{Hd})$ and nucleotide diversity $(\pi)$ with other species from the family Cercopithecidae allows the results of this study to be placed in a broader context by determining whether the values are higher or lower than related species. Table 10 shows the $\mathrm{Hd}$ and $\pi$ from other studies. Comparison of these results with the values obtained for $C$. p. buettikoferi shows that many other closely related species also exhibit high $\mathrm{Hd}$ and low $\pi$. The $\mathrm{Hd}$ for C. p. buettikoferi falls in the middle of the range of values found, indicating that many Cercopithecine species have high haplotype diversity. In fact the species with the highest haplotype diversity, Procolobus rufomitratus, is known to have gone through a recent large bottleneck, however this may have been too contemporaneous to be expressed in 
the genetic diversity yet (Mbora and McPeek 2010). Therefore although C. $p$. buettikoferi has a relatively high $\mathrm{Hd}$ this does not mean that the population is not in need of conservation protection.

\section{REFERENCES}

Bandelt, H-J., P. Forester \& A. Röhl (1999). Median-joining networks for inferring intraspecific phylogenies. Molecular Biology and Evolution 16: 37-48.

Butynski, T. M. (2002). The Guenons: An Overview of Diversity and Taxonomy. In: Glenn M. E. \& M. Cords (eds.), The Guenons: Diversity and Adaptation in African Monkeys. Kluwer Academic/Plenum Publishers, New York, 5pp.

Buzzard, P. J. (2006a). Ecological Partitioning of Cercopithecus campbelli, C. petaurista, and C. Diana in the Taï Forest. International Journal of Primatology 27 (2): 529-558.

Buzzard, P. J. (2006b). Ranging Patterns in Relation to Seasonality and Frugivory Among Cercopithecus campbelli, C. petaurista, and C. diana in the Taï Forest. International Journal of Primatology 27 (2): 559-573.

Buzzard, P. J. (2010). Polyspecific associations of Cercopithecus campbelli and C. petaurista with C. diana: what are the costs and benefits? Primates 51: 307-314.

Disotell, T. R. \& R. L. Raaum (2002). Molecular Timescale and Gene Tree Incongruence in the Guenons. In: Glenn, M. E. \& M. Cords (eds), The Guenons: Diversity and Adaptation in African Monkeys. Kluwer Academic/Plenum Publishers, New York, 27-36pp.

Dutrillaux, B., M. Muleris \& J. Courturier (1988). Chromosomal evolution of the Cercopithecinae. In: Gautier-Hion, A., F. Bourlière, J-P. Gautier \& J. Kingdon (eds), A 
Primate Radiation: Evolutionary Biology of the African Guenons. Cambridge University Press, New York, 150-159pp.

Excoffier, L. \& P. E. Smouse (1994). Using allele frequencies and geographic subdivision to reconstruct gene trees within a species: molecular variance parsimony. Genetics 136: 343-359.

Excoffier, L., G. Laval \& S. Schneider (2005). Arlequin ver. 3.0: An intergrated software package for population genetics data analysis. Evolutionary Bioinformatics Online 1: 47-50.

Fleagle, J. G. (1999). Primate Adaptation and Evolution, Academic Press, New York.

Fu, Y. X. \& W. H. Li (1993). Statistical tests of neutrality of mutations. Genetics 133: 693-709.

Gautier, J. P. (1988). Interspecific affinities among guenons as deduced from vocalizations. In Gautier-Hion, A., F. Bourliere, J-P. Gautier \& J. Kingdon (eds.), A Primate Radiation: Evolutionary Biology of the African Guenons. Cambridge University Press, Cambridge, UK, 194-226pp.

Gautier-Hion, A., F. Bourlière, J-P. Gautier \& J. Kingdon (eds). (1988). Introduction. A Primate Radiation: Evolutionary Biology of the African Guenons. Cambridge University Press, Cambridge 1-3 pp.

Grant, W. S. \& B. W. Bowen (1998). Shallow population histories in deep evolutionary lineages of marine fishes: Insights from sardines and anchovies and lessons for conservation. The American Genetic Association 89: 415-426.

Groves, C. P. (2000). The Phylogeny of the Cercopithecodiea. In: Whitehead, P. F. \& J. C. Jolly (eds.), Old World Monkeys. Cambridge University Press, New York, 77-98 pp. 
Groves, C. P. (2001). Primate Taxonomy. Smithsonian Institution Press, Washington.

Grubb, P., T. M. Butynski, J. F. Oates, S. K. Bearder, T. R. Disotell, C. P. Groves, \& T. T. Struhsaker (2002). An assessment of the diversity of African primates. Unpublished report. IUCN/SSC Primate Specialist Group, Washington, DC.

Hall, T.A. (1999). BioEdit: a user-friendly biological sequence alignment editor and analysis program for Windows 95/98/NT. Nucleic Acids Symposium Series 41: 95-98.

Handt, O., M. Höss, M. Krings \& S. Pääbo (1994). Ancient DNA - methodological challenges . Experientia 50: 524-529.

Harpending, H. C., S. T. Sherry, A. R. Rogers \& M. Stoneking (1993). The genetic structure of ancient human populations. Current Anthropology 34: 483-496.

Howell, N., I. Kubacka \& D. A. Mackey (1996). How rapidly does the human mitochondrial genome evolve? American Journal of Human Genetics 59: 501-509.

Kingdon, J. (1980). The role of visual signals and face patterns in African forest monkeys (guenons) of the genus Cercopithecus. Transactions of the Zoological Society of London 35: 425-475.

Leakey M. (1988). Fossil evidence for the evolution of the guenons. In: Gautier-Hion, A., F. Bourlière, J-P. Gautier \& J. Kingdon (eds.), A Primate Raditation: Evolutionary Biology of the African Guenons. Cambridge University Press, Cambridge, 7-12 pp.

Ledbetter, D. H. (1981). Chromosomal Evolution and Speciation in the Genus Cercopithecus (Primates, Cercopithecinae). Ph.D. Thesis, University of Texas, Austin.

Librado, P. \& J. Rozas (2009). DnaSP v5: Software for comprehensive analysis of DNA polymorphism data. Bioinformatics 25: 1451-1452. 
Mbora, D. N. M. \& M. A. McPeek, (2010). Endangered species in small habitat patches can possess high genetic diversity: the case of the Tana River red colobus and mangabey. Conservation genetics 11: 1725 - 1735.

McGraw, W. S. (2000). Positional behaviour of Cercopithecus petaurista. International Journal of Primatology 21(1): 157-182.

Minitab Inc. (2007). Minitab for Windows, release 15.1.20.0

Oates, J. F., S. Gippoliti \& C. P. Groves (2008). Cercopithecus petaurista. In: IUCN 2010. IUCN Red List of Threatened Species. Version 2010.4. <www.iucnredlist.org>. Downloaded on 13 December 2010.

Pruetz J. D., A. Socha \& D. Kante (2010). New Range Record for the Lesser Spotnosed Guenon (Cercopithecus petaurista) in Southeastern Senegal. African Primates 7(1): 64-66.

Roeder, A. D., F. I. Archer, H. N. Poinar \& P. A. Morin (2004). A novel method for collection and preservation of faeces for genetic studies. Molecular Ecology 4: 761764.

Rogers, A. R. \& H. Harpending (1992). Population growth makes waves in the distribution of pairwise genetic differences. Molecular Biology and Evolution 9: 552569.

Rogers, A. R. (1995). Genetic evidence for a Pleistocene population explosion. Evolution 49(4): 608-615.

Ruvolo, M. (1988). Genetic evolution in the African guenons. In: Gautier-Hion, A., F. Bourlière, J-P. Gautier \& J. Kingdon (eds), A Primate Radiation: Evolutionary Biology of the African Guenons. Cambridge University Press, New York, 127-149 pp. 
Slatkin, M. \& R. R. Hudson (1991). Pairwise comparisons of mitochondrial DNA sequences in stable and exponentially growing populations. Genetics 129: 555-562.

Strasser, E. \& E. Delson (1987). Cladistic analysis of cercopithicid relationships. Journal of Human Evolution 16: 81-99.

Tajima, F. (1989). Statistical method for testing the neutral mutation hypothesis by DNA polymorphism. Genetics 123: 585-595.

Tosi, A. J., J. C. Morales \& D. J. Melnick (2002). Y-chromosome data and tribal affiliations of Allenopithecus and Miopithecus. International Journal of Primatology 23: 161-178.

UNESCO (2006). Réserve de Biosphère de l'Archipel des Bijagos [online]. Available at: http://whc.unesco.org/en/tentativelists/5081/ [Accessed on: $16^{\text {th }}$ February 2011].

Weber, D. S., B. S. Stewart \& N. Lehman (2004). Genetic consequences of a severe population bottleneck in the Guadalupe fur seal (Arctocephalus townsendi). Journal of Heredity 95(2): 144-153.

Wright, S. (1978). Evolution and the Genetics of Populations. Vol. 4. Variability Within and Among Natural Populations. University of Chicago Press, Chicago. 
the nature EDUCATION

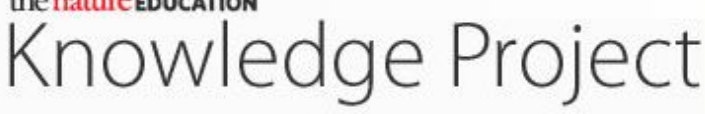

Powered by Scitable

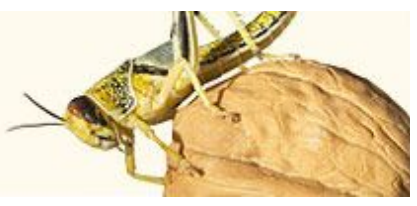

ADVANCED

| Lead Editor: Sigurdur Greipsson CONSERVATION AND RESTORATION

\section{Using Genetics as a Tool in Primate Conservation}

By: Maria J. Ferreira da Silva (Cardiff University, CIBIO-Porto University), Tania Minhos (Cardiff

University, CESAM-Lisbon University), Rui M. Sa (Cardiff University, New University of Lisbon,

CRIA) \& Michael W. Bruford (Cardiff University) $\odot 2012$ Nature Education

(1)

Citation: Ferreira da

Silva, M. J., Minhos, T., Sa, R. M. \& Bruford, M. W. (2012) Using Genetics as a Tool in Primate Conservation. Nature Education Knowledge 3(10):89

"Here I am, in the middle of this forest, and I can't see the primates? How can I learn more about the species I am studying?" This question can be answered with the help of recent advances in non-invasive molecular genetics.

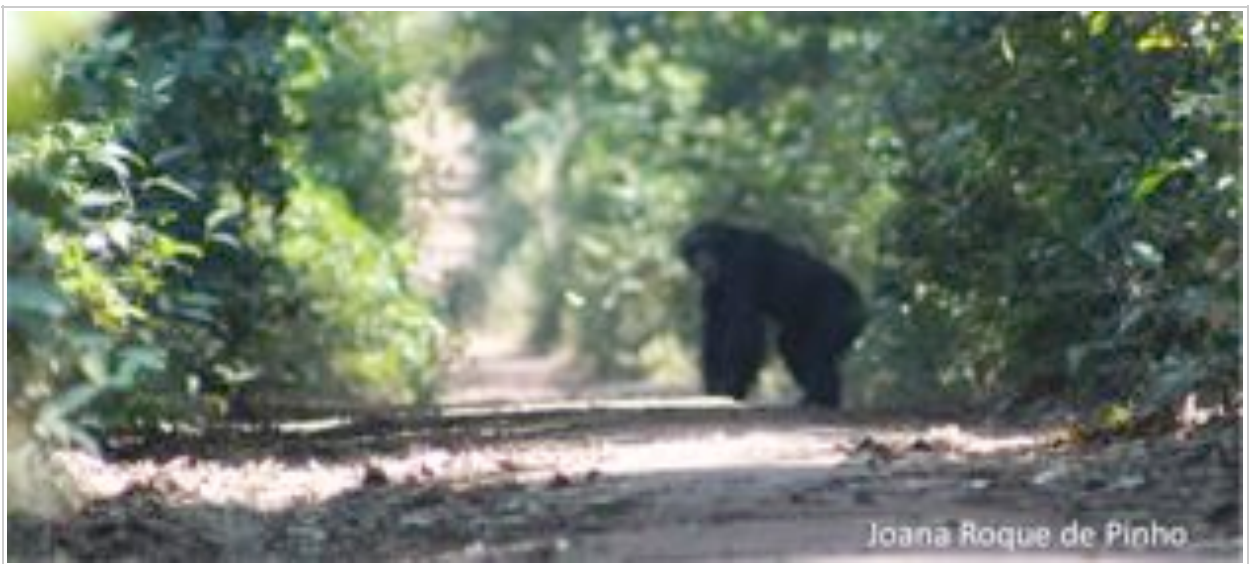

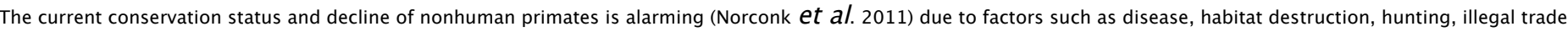
and climate change (WWF 2010). Unfortunately, their restricted geographical range, resource requirements, long lifespan and slow reproduction rate, dispersal needs, and

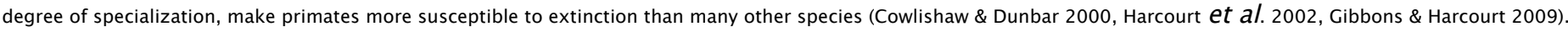

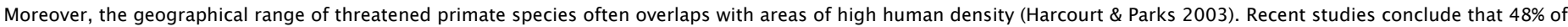

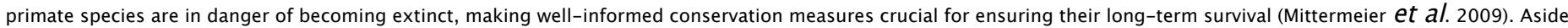

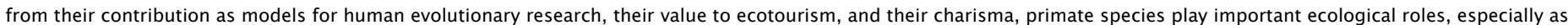

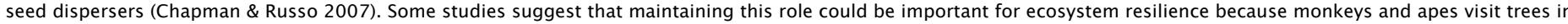
social groups where they tend to stay longer during feeding periods than other mammals or birds (Lambert 2011). 


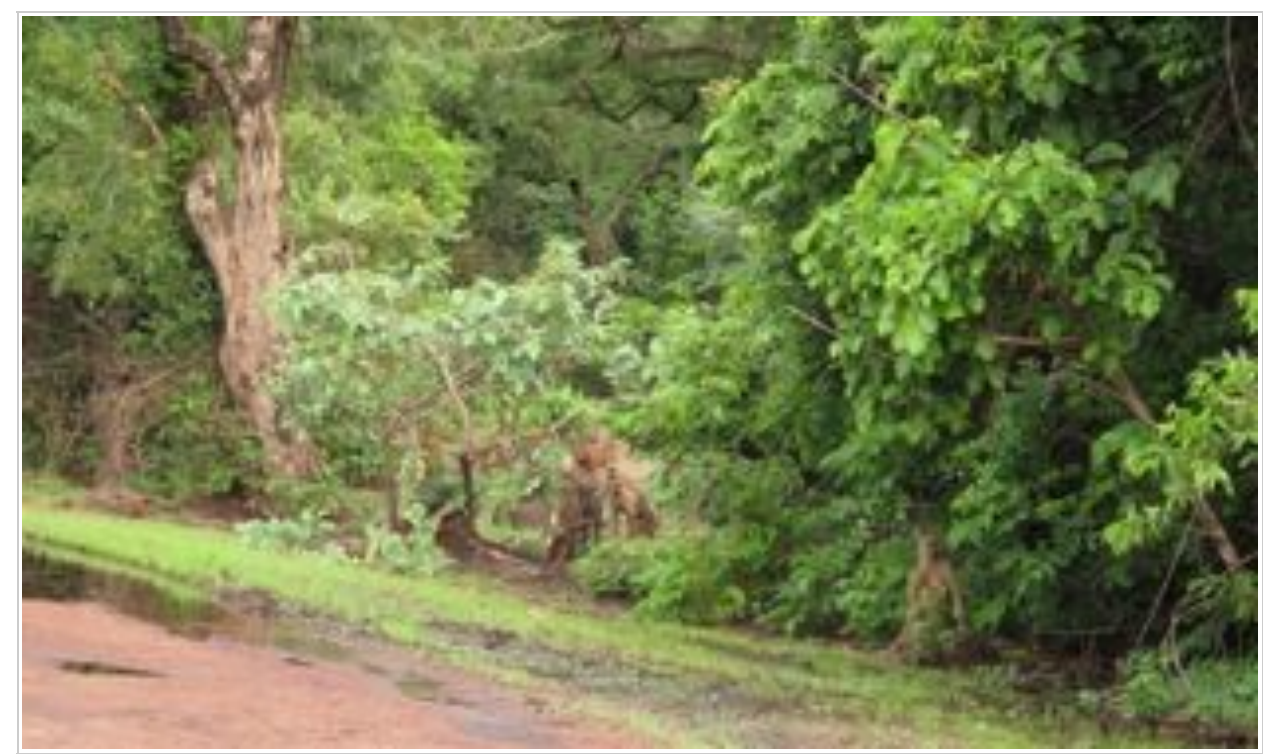

Figure 1: Elusive animals.

Guinea baboons (Papio hamadryas papio) live in dense forested habitats and are very hard to observe. By using molecular tools, primatologists can gather information about this elusive species.

(c) 2012 Nature Education Photo courtesy of Chimbo Foundation. All rights reserved. (1)

\section{Non-Invasive Genetic Analysis}

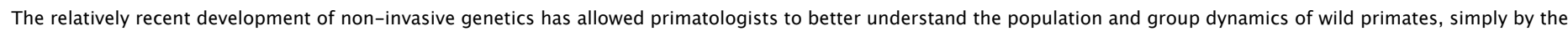
fact that it is now possible to obtain genetic information by extracting DNA from by-products such as feces, shed hair, and urine. The first study of this kind was in

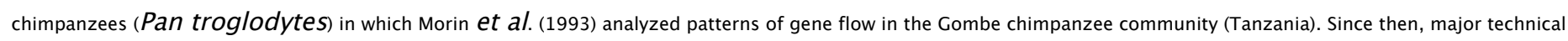

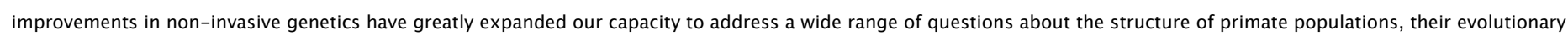

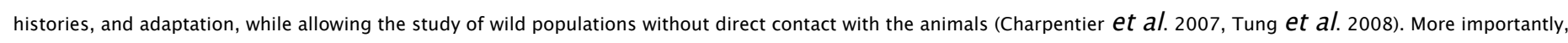
the combination of genetics with long-term socio-ecological data has enabled comprehensive analysis at an individual and social group level for a wide range of primate species.

DNA obtained non-invasively can be analyzed in individuals and populations for a wide range of molecular genetic markers such as microsatellites, minisatellites,

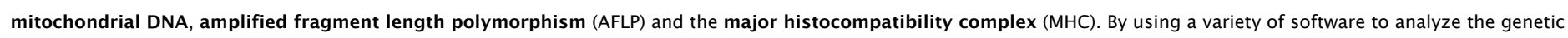
data produced, primatologists can now obtain information on effective population size, parentage, relatedness, sex, dispersal, population structure, population

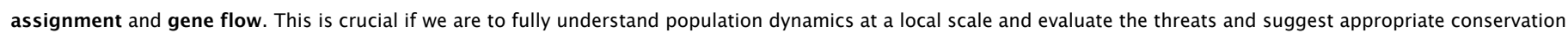
measures (Goossens \& Bruford 2009).

\section{Threats to Primate Conservation}

\section{Habitat fragmentation}

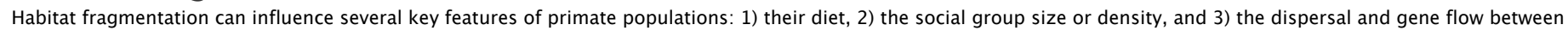

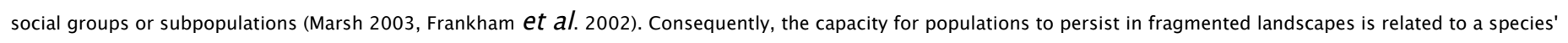

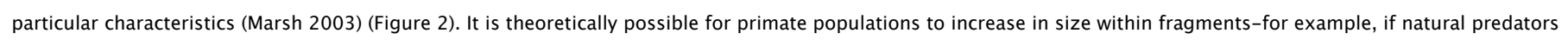

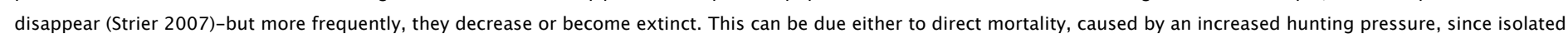

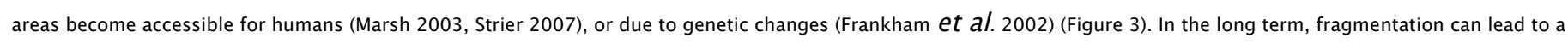

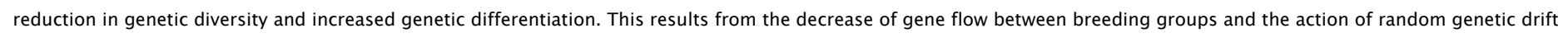
and/or inbreeding (Frankham et al. 2002). 


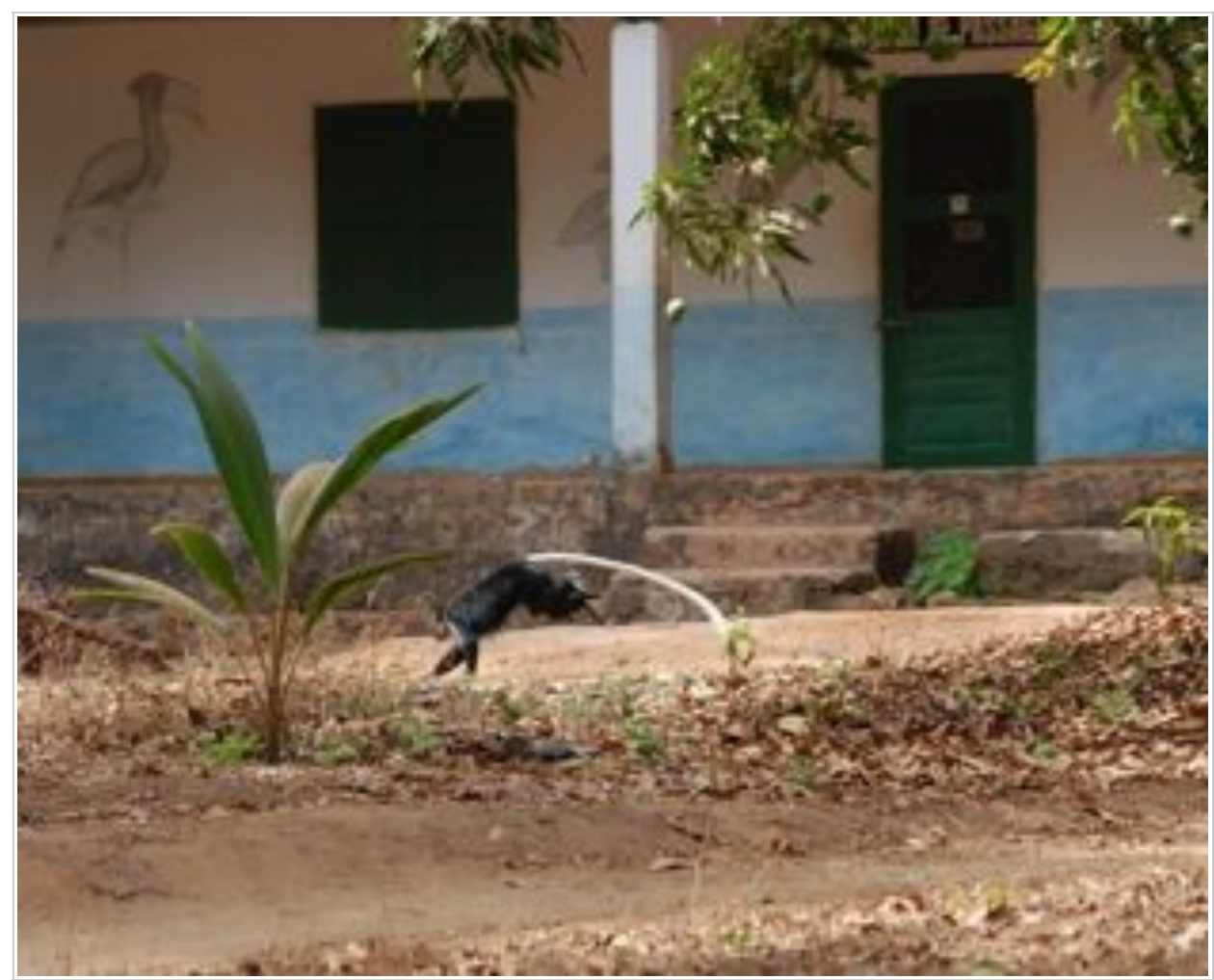

Figure 2: Behavioral adaptation to habitat fragmentation.

Black-and-white colobus are almost exclusively arboreal. Fragmentation may force the adaptation to new habitats or result in local extinctions.

() 2012 Nature Education All rights reserved. (1)

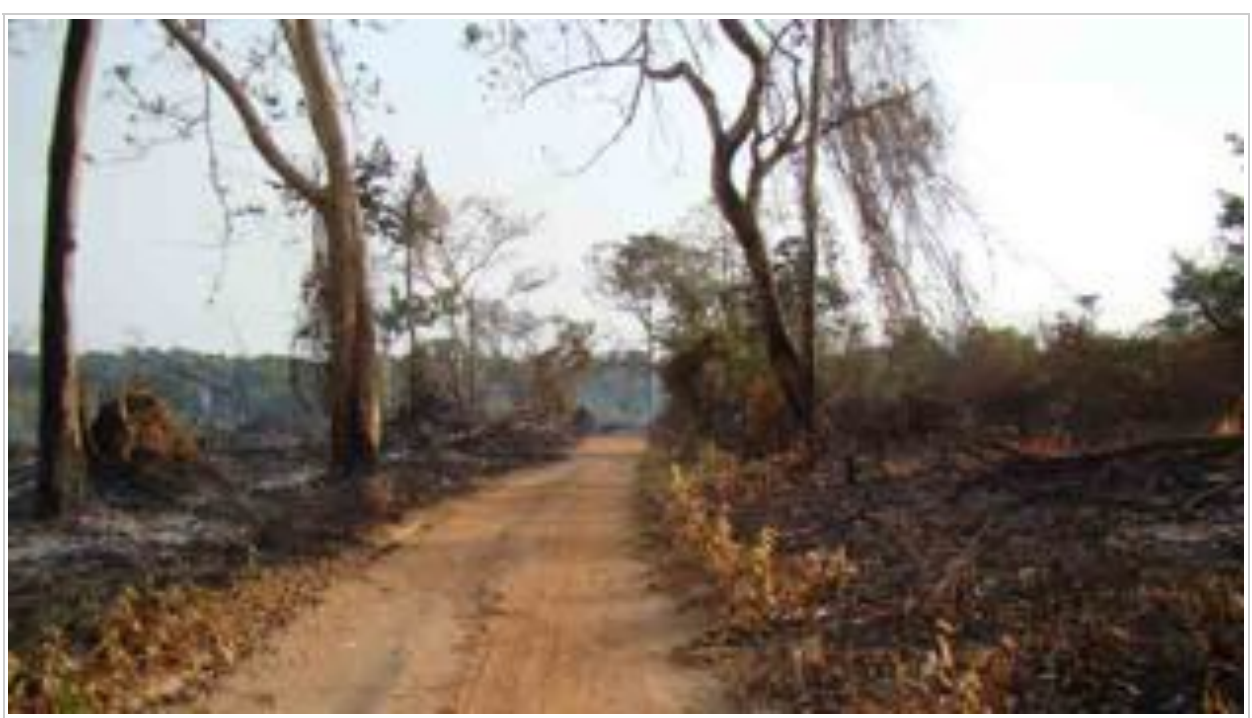

Figure 3: Habitat loss and deforestation.

Deforestation is happening at an accelerated rate and can be caused by logging, collection of non-timber forest products, and fires. It not only promotes isolation of populations but also increases hunting pressure and contributes to climate change.

() 2012 Nature Education All rights reserved. (1)

Each population fragment may show different levels of genetic diversity and significantly different allele frequencies from the other fragments. The risk of inbreeding depression is increased if the population is smaller and isolated, with lower genetic diversity. Migration of individuals between fragments and subsequent reproduction will introduce new alleles into the population (increasing genetic diversity) and it will counterbalance the effects of genetic drift and inbreeding, preventing complete fixation of alleles (Frankham et al. 2002). By using non-invasive genetic methods it is possible to identify the genetic structure of a fragmented population, and levels of gene flow between units, and determine whether ecological corridors should be created/maintained, or individuals should be translocated (e.g., Bruford et al. 2010). 
In the fragmented range of the Cross River Gorilla (Gorilla gorilla diehli) three sub-populations have been uncovered using microsatellite markers (Bergl \& Vigilant 2007). Although this genetic structure corresponds broadly to the pattern of habitat fragmentation, migrants between fragments could be identified. Since different levels of genetic diversity were found between the sub-populations, it was suggested that the conservation of the most genetically diverse sub-population should be prioritized. Also, habitat corridors between fragments, along with measures to control hunting in areas between fragments, were recommended (Bergl et al. 2008). The Bornean orang-utan (Pongo pymaeuS), living in forest fragments of the Lower Kinabatangan flood plain in Sabah, Malaysia, shows a different pattern: high levels of heterozygosity within fragments, with

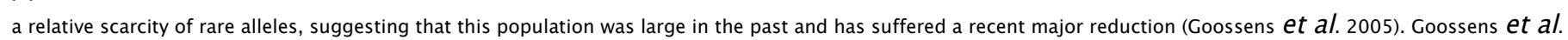

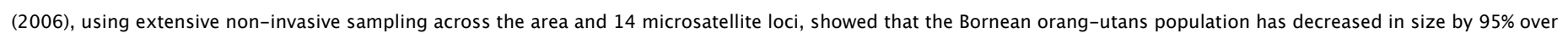

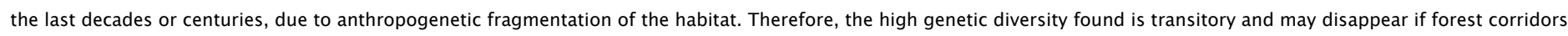
alongside the riverbank are not established (Bruford et al. 2010).

\section{Hunting}

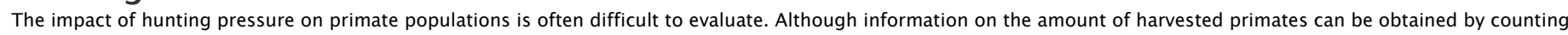
carcasses in urban bushmeat markets, morphological identification can be hindered if a carcass has been processed, or if the meat has been smoked (Figure 4).

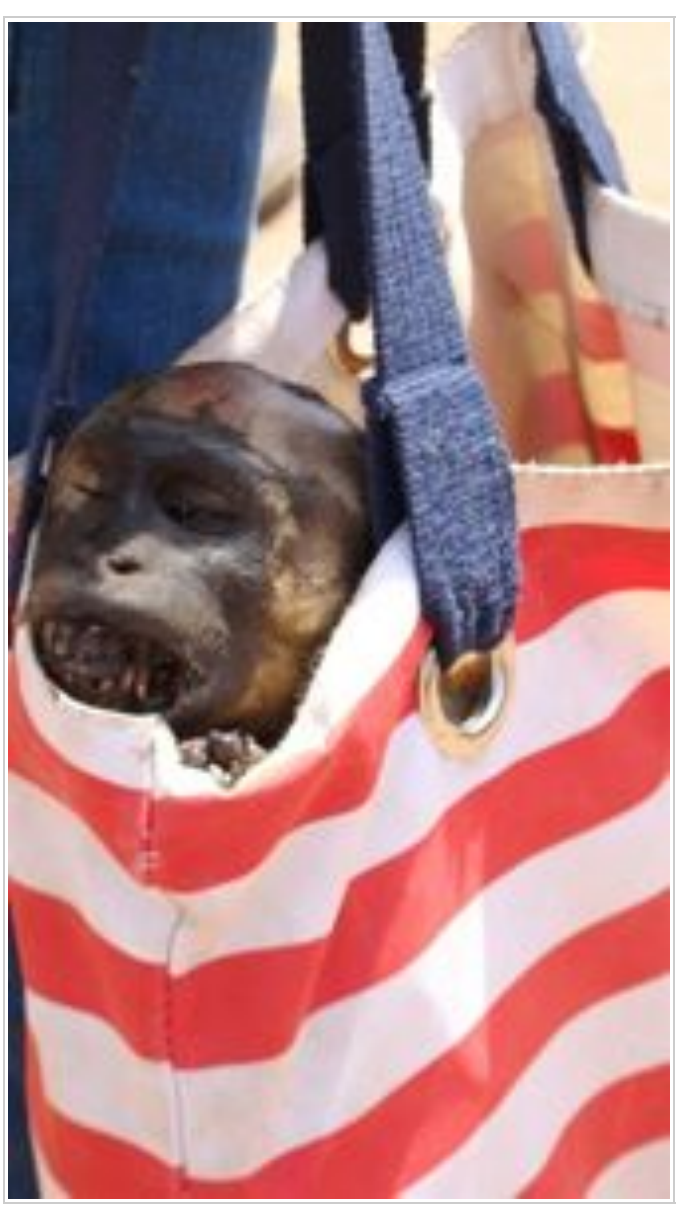

Figure 4: Bushmeat markets.

Hunting of primates is occurring at very high rates. Primate meat is consumed in rural areas for subsistence and in urban centers as a delicacy. It is the result of an illegal, organized trade.

(C) 2012 Nature Education All rights reserved. (])

Primatologists can use molecular PCR-based tools to taxonomically identify unknown specimens. After extracting DNA and amplifying a specific DNA fragment, these fragments can then be compared with other DNA fragments obtained from specimens of known species. The comparison can also be accomplished by verifying the presence/size of the fragment after PCR: for a review of the techniques see Fajardo et al. (2010).

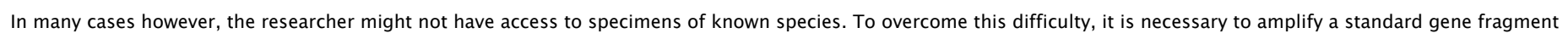

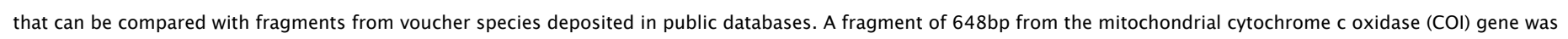

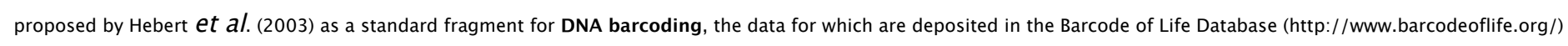

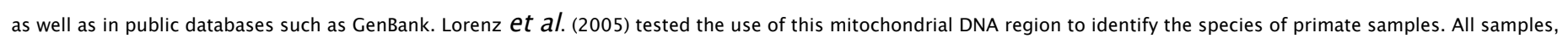

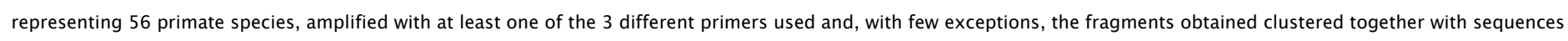

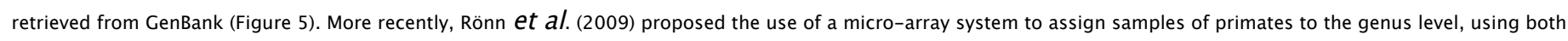




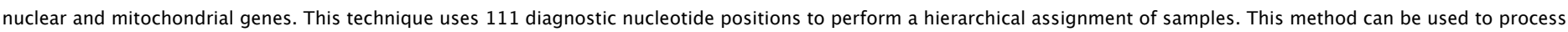
a large number of samples at a relatively low cost, and 45 out of the 64 samples were correctly assigned to their Primates genus.
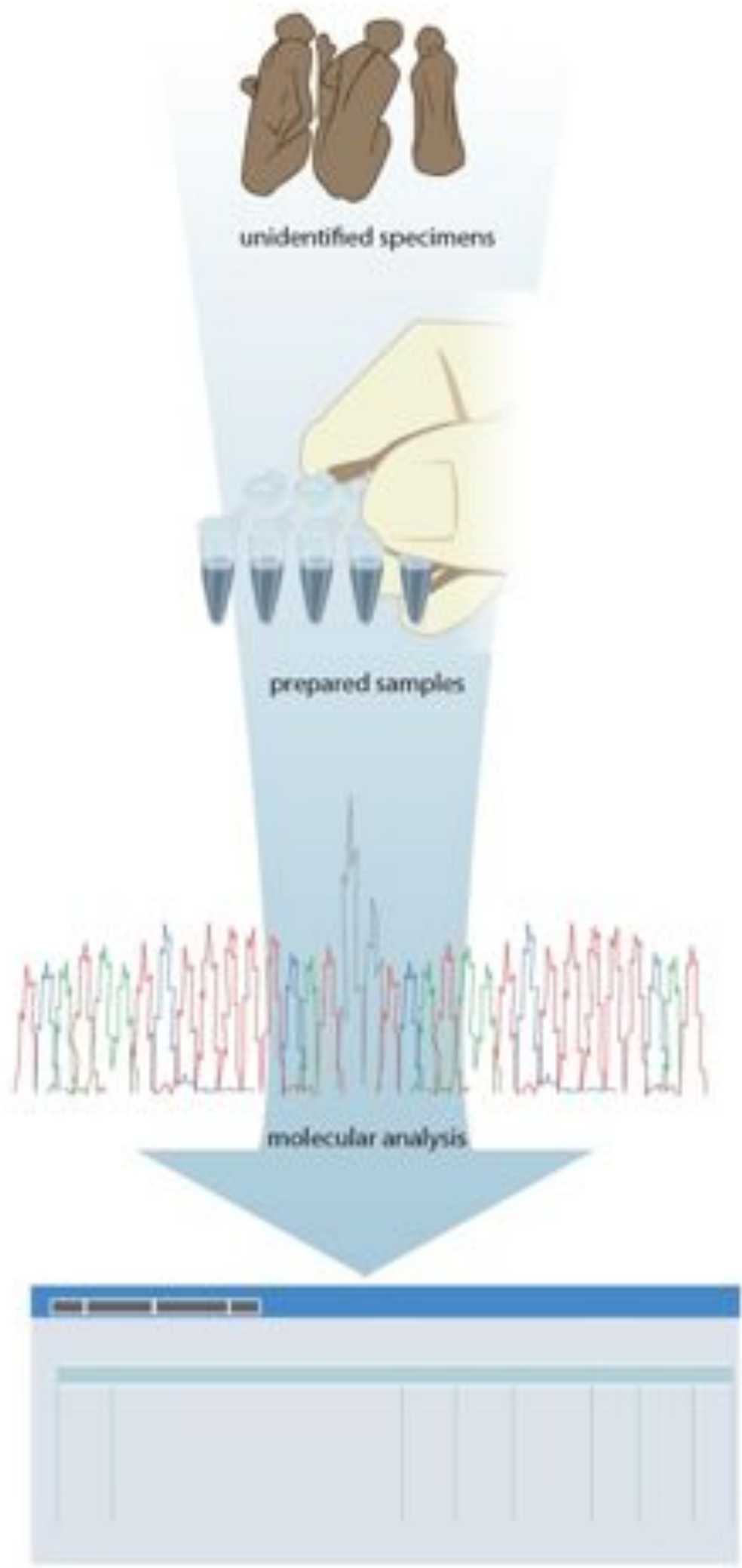

comparison results 
Figure 5: Molecular identification of bushmeat.

Morphological identification can be difficult if carcasses have been processed. Molecular identification is the easiest and most reliable tool available.

(c) 2012 Nature Education All rights reserved.

\section{Diseases}

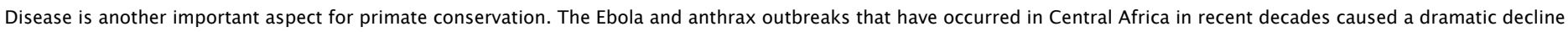

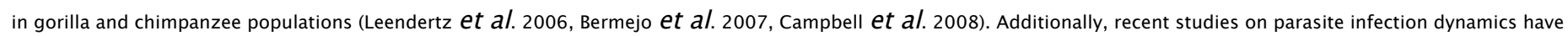

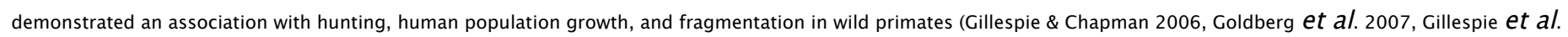
2008, Riley \& Fuentes 2011). With the incorporation of molecular approaches to epidemiology, Johnston et al. (2010) have demonstrated cross species transmission of

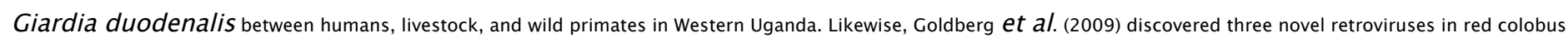

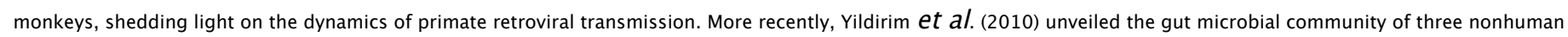

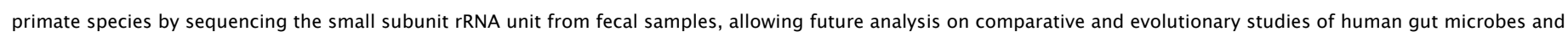

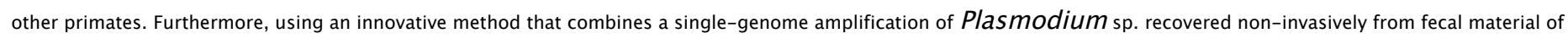

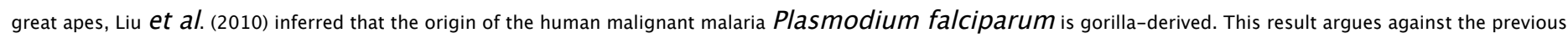

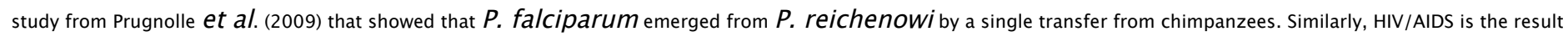
of a cross-species transmission event of simian immunodeficiency virus (SIV) to humans from non-human African primates, and much attention has been paid to the understanding of the evolutionary history of these emerging infection diseases (Gao et al. 1999, Damond et al. 2004, Liu et al. 2008). By using a molecular dating

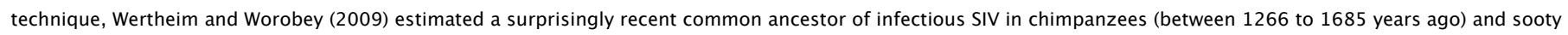

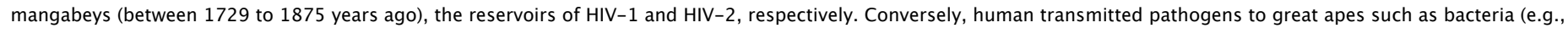

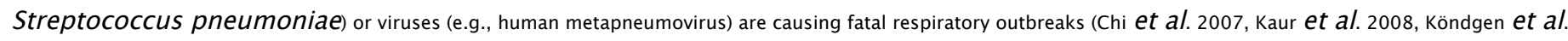

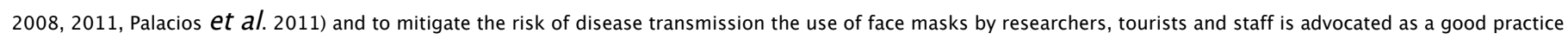

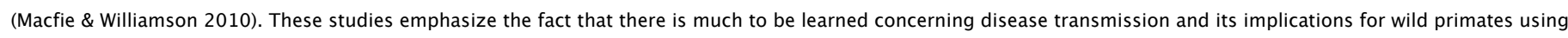
molecular tools.

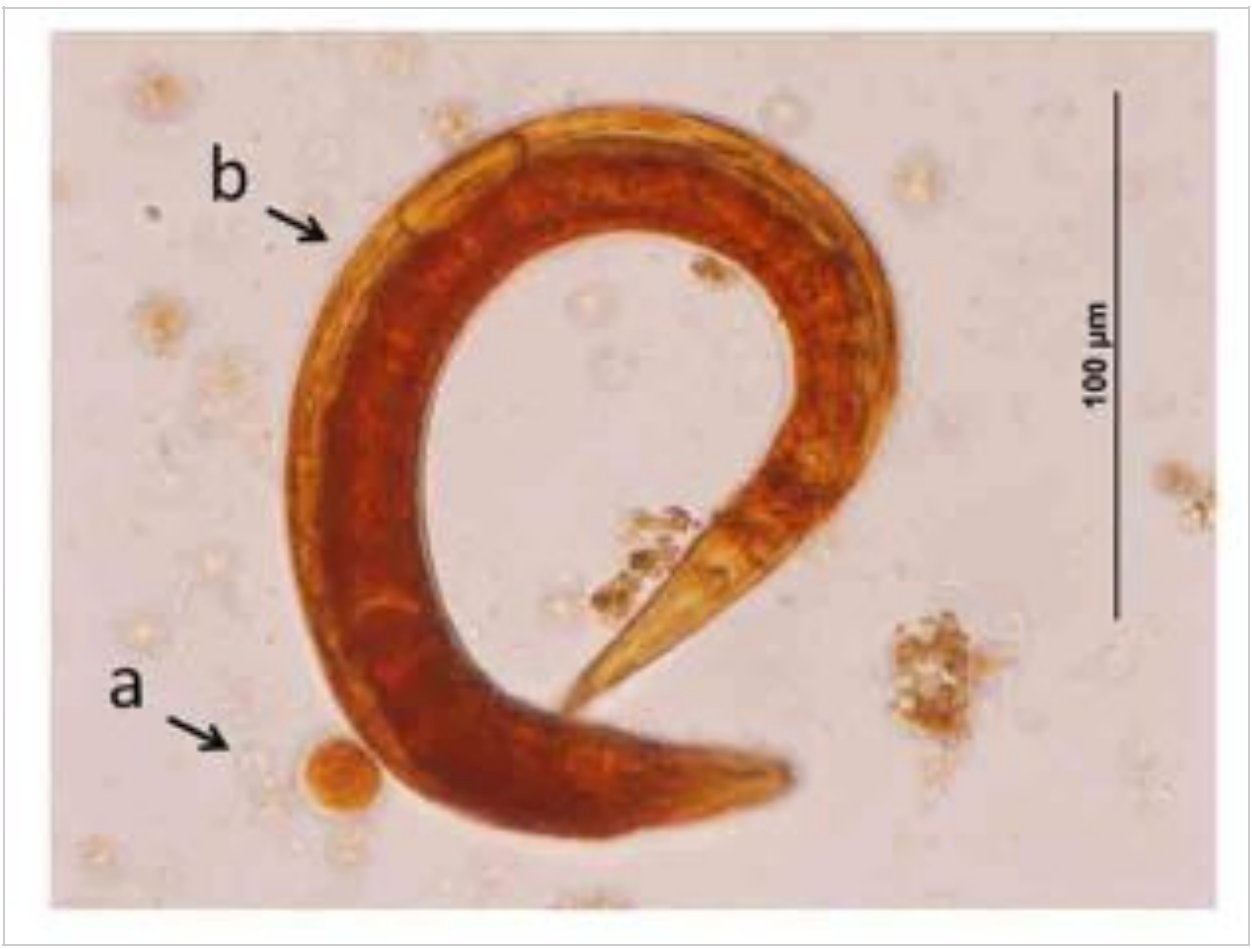

Figure 6: Primate parasites.

a) Entamoeba sp. and b) Strongylida fam. gen. sp. (Hookworms) are gastrointestinal parasites that can cause severe infections and weaken the health of the host.

(c) 2012 Nature Education All rights reserved. (1)

\section{Applying Conservation Genetics}

\section{Primate census}

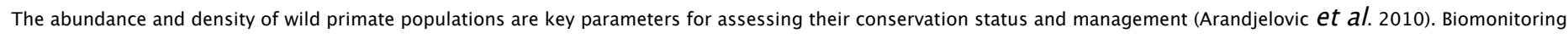

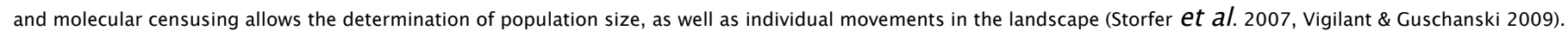

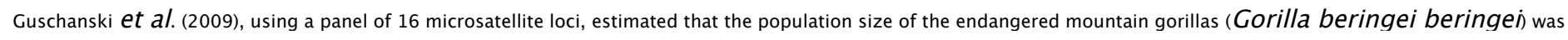




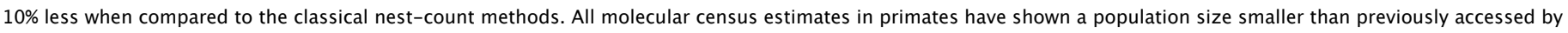
traditional methods. In contrast, Zhan et al. (2006), comparing the numbers of traditional survey methods with molecular censusing, demonstrated that the DNA-based

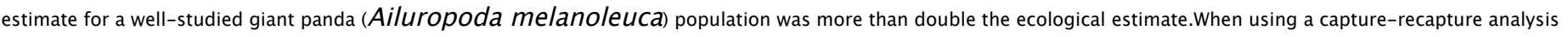

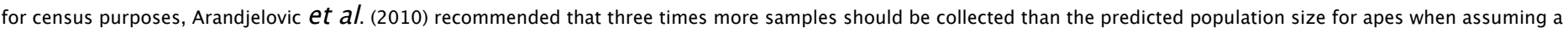
closed population model. Therefore, molecular surveys provide a complementary method to more traditional census approaches.

\section{"Evolutionary significant units" (ESUs) and "management units" (MUs)}

ESUs and MUs are two types of conservation units described using genetic information: ESUs have been defined as needing to be reciprocally monophyletic mitochondrial

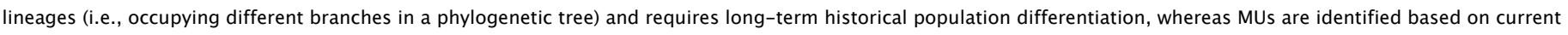
demographic isolation (i.e., no current or recent gene-flow), evidenced by differences in allele frequency distributions and significantly different frequencies for both

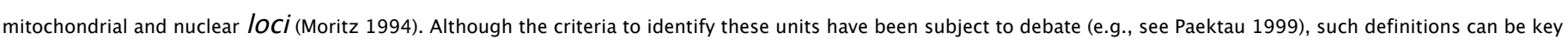

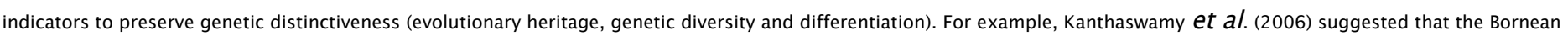
and Sumatran orangutans should be considered two distinct MUs based on the analysis of mtDNA and microsatellite loci, and consequently the authors advised against the inter-island translocation of animals.

\section{Population and habitat viability analysis}

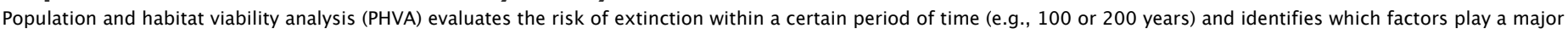

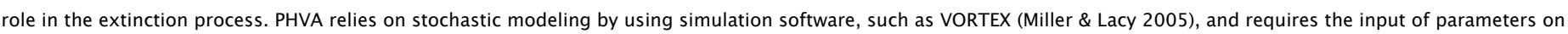

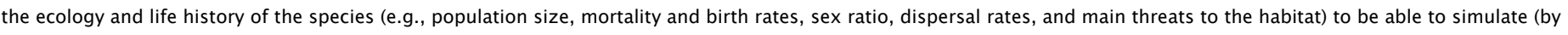
Monte Carlo iterations) species responses that are realistic. Molecular census and genetic data can also be very important parameters for PHVA. Moreover, it allows the

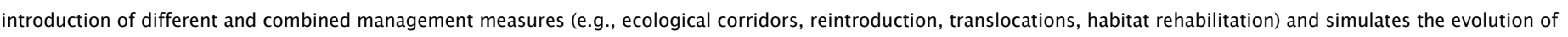

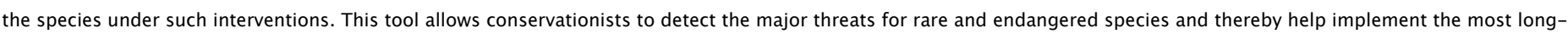
term viable conservation actions.

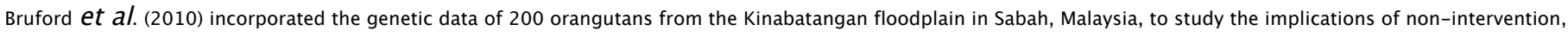

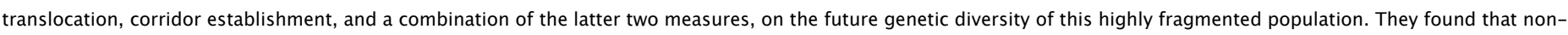

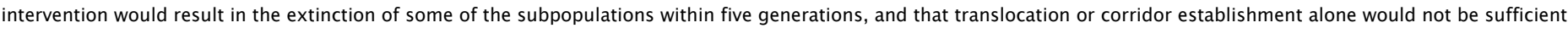

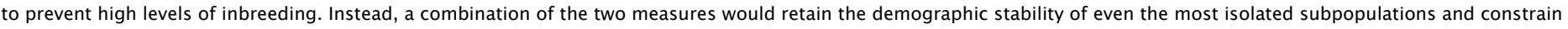
localized inbreeding to a sustainable threshold (Figure 7). 


\begin{tabular}{|c|c|c|c|c|c|c|c|c|c|}
\hline & \multirow{2}{*}{\begin{tabular}{|l|} 
Campiag \\
capasiny
\end{tabular}} & \multirow{2}{*}{\begin{tabular}{|l|} 
Shan \\
$(r)$
\end{tabular}} & \multirow[t]{2}{*}{$S D$} & \multirow{2}{*}{$\frac{P(x) \text { affer }}{\mathrm{B} / \mathrm{J} / \mathrm{C} / 250 \mathrm{yr}}$} & \multirow{2}{*}{$\begin{array}{l}\text { Ieitialf } \\
\text { Eeas fical }\end{array}$} & \multirow[t]{2}{*}{ st } & \multirow{2}{*}{$\begin{array}{l}\text { Enealaed GD after } \\
\text { 25/1W/250y }\end{array}$} & \multirow{2}{*}{$\frac{\text { Sfea t after }}{25 / 100 / 251 \mathrm{gr}}$} & \multirow{2}{*}{$\begin{array}{l}\text { Sreas } \\
\text { II }\end{array}$} \\
\hline & & & & & & & & & \\
\hline \multicolumn{10}{|c|}{ Toher indrieder degresise } \\
\hline PSE 1 & 230 & 40.001 & 0.04 & $0 / 010$ & 2801157.7 & 273 & $0994 / 0981 / 0984$ & $0 / 0.01010 .036$ & \\
\hline $\mathrm{PSC} 2$ & 351 & 0.001 & 0.04 & 0.010 & 209 & 39.2 & $0994 / 8965 / 0967$ & $010.009: 0.003$ & ‥ \\
\hline PST 3 & 108 & 0 & 0.00 & $0 / 0 / 0.001$ & $63 / 71 / 48$ & 172 & Q960/8949/0.8996 & $\begin{array}{r}0.001 / 0.0307 \\
0.056\end{array}$ & 0 \\
\hline $\mathrm{PSO} 4$ & 72 & 40001 & 0.05 & $0 / 0 / 0.017$ & $61 / 4436$ & 14.1 & $9977 / 0933 / 0.837$ & $\begin{array}{r}0.001 \times 0.0376 \\
0131\end{array}$ & 1922 \\
\hline PSO 5 & $3 ! 3$ & 40.001 & 0.04 & $0 / 010$ & $93 / 21165$ & 36.5 & $0995 / 0596 / 0906$ & $0 / 0.008 / 0.007$ & 0 \\
\hline PST 6 & 62 & 4.002 & 0.09 & 0.0 .0390 .036 & 5513772 & 12.3 & $0976 / 0923 / 0.906$ & $\begin{array}{r}0.001 / 0.041 \\
0.130\end{array}$ & 1878 \\
\hline $\mathrm{PSC} 7$ & 54 & 0 & $0.0 \mathrm{~d}$ & $0.0 .019 / 0.122$ & $25 / 3595$ & 11.5 & $0947 / 0.964 .0 .730$ & $\begin{array}{r}0.003 / 0.060 \\
0216\end{array}$ & 149.5 \\
\hline PSU 8 & 97 & 0.003 & $0 . \mathrm{ad}$ & $0.0 .022 / 0.076$ & $22 / 51.4]$ & 19.1 & $0.946 / 0.878 / 0.796$ & $\begin{array}{r}0.003 / 0.079 \\
0174\end{array}$ & 1375 \\
\hline PSt 9 & 49 & -0.003 & $0 \mathrm{~cd}$ & $0.0 .006 / 0.079$ & $49 / 21.45$ & 109 & $0971 / 09010760$ & $\begin{array}{r}0.001 / 0.002 \\
0.204\end{array}$ & 1852 \\
\hline $\begin{array}{l}\text { PSO } \\
10\end{array}$ & 31 & 40.003 & 0.59 & $0.0 .069 / 0.349$ & $25 / 17.13$ & 7,45 & $094 / 0827 / 0648$ & $\begin{array}{r}0.00010,069 \\
0199\end{array}$ & 1223 \\
\hline $\begin{array}{l}\mathrm{PSU} \\
11\end{array}$ & 120 & 40.001 & 0.04 & $0 / 0 / 0$ & $97 / 7902$ & 19.3 & $0987 / 0906 / 0906$ & $\begin{array}{r}0.001 / 0.021 \\
\text { o ote }\end{array}$ & \\
\hline \multicolumn{10}{|c|}{ 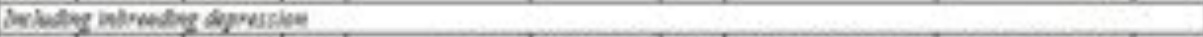 } \\
\hline 7501 1 & 280 & 40002 & 004 & $0 / 810$ & 230514429 & 203 & [994/6991/6950] & $010009 / 0060$ & \\
\hline FSU2 & 351 & 9 & 004 & $019 / 0$ & 309122710 & 199 & $6991 / 995 / 996$ & $0 / 0008.0008$ & Q \\
\hline 7803 & 108 & $.0,001$ & 006 & $070 / 0.016$ & $65 \times 5280$ & 19.5 & $096010.919: 0874$ & $\begin{array}{r}0001 / 0003 \\
9001\end{array}$ & 215 \\
\hline 7501 & 72 & $.0,004$ & 006 & $0.0001 / 0.068$ & $61 / 35.45$ & 14.5 & $6909 / 0953 / 0506$ & $\begin{array}{r}9001 / 9050 \\
0133\end{array}$ & 158.1 \\
\hline 750 5 & 313 & 4090 & 004 & 0.010 & $298 / 302 \times 5$ & 381 & $1.000 / 969610965$ & $0 / 90081008$ & 9 \\
\hline PST \& & $\$ 2$ & .0 .005 & 000 & 00005,0122 & $55 / 2437$ & 122 & 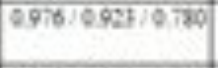 & $\begin{array}{r}9001 / 0039 \\
0128\end{array}$ & $187 / 4$ \\
\hline FSt 7 & 34 & $.0,004$ & Q0न & 0.00020148 & 2511197 & 10.2 & 6947/6965/Q702 & $\begin{array}{r}000010009 \\
0213\end{array}$ & 173 \\
\hline PSt 8 & का & .0002 & Q⿱一⿻丿口日乀 & 0.0014 .0278 & $2 5 \longdiv { 3 3 5 7 }$ & 193 & $69610 \$ 21075:$ & $\begin{array}{r}000970063 \\
0161 .\end{array}$ & $187 / 4$ \\
\hline PSt 9 & का & .0000 & 007 & 0.000510274 & 5911.1 & 102 & $697 / 6.90016728$ & $\begin{array}{r}000170050 \\
0150\end{array}$ & 194. \\
\hline $\begin{array}{l}\text { PSt } \\
16\end{array}$ & 71 & .6000 & 000 & $0.0091 / 0,700$ & 2517510 & 6.37 & 69u/OST/E 811 & $\begin{array}{r}000670090 \\
0233\end{array}$ & 1642 \\
\hline $\begin{array}{l}\text { PSt } \\
11\end{array}$ & 130 & .0002 & 004 & 070,0000 & $97 / 44007$ & 207 & $6941 / 606 / 0.997$ & $\begin{array}{r}000670050: \\
\text { edte. }\end{array}$ & 2031 \\
\hline
\end{tabular}

Figure 7: Population viability analysis.

The table shows the result of demographic and genetic parameters of the vortex simulation for 25 to 250 years under a non-intervention scenario. Note the mean extinction time (column TE) for most of the sub-populations (PSU) is less than 250 years. P(E): probability of extinction; Pop: population; GD: genetic diversity (from Bruford et al. 2010).

(C) 2012 Nature Education All rights reserved. (])

\section{Summary}

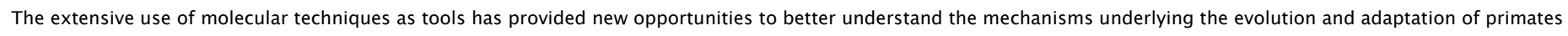

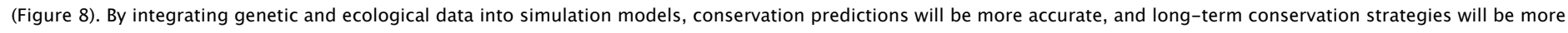
effective. 


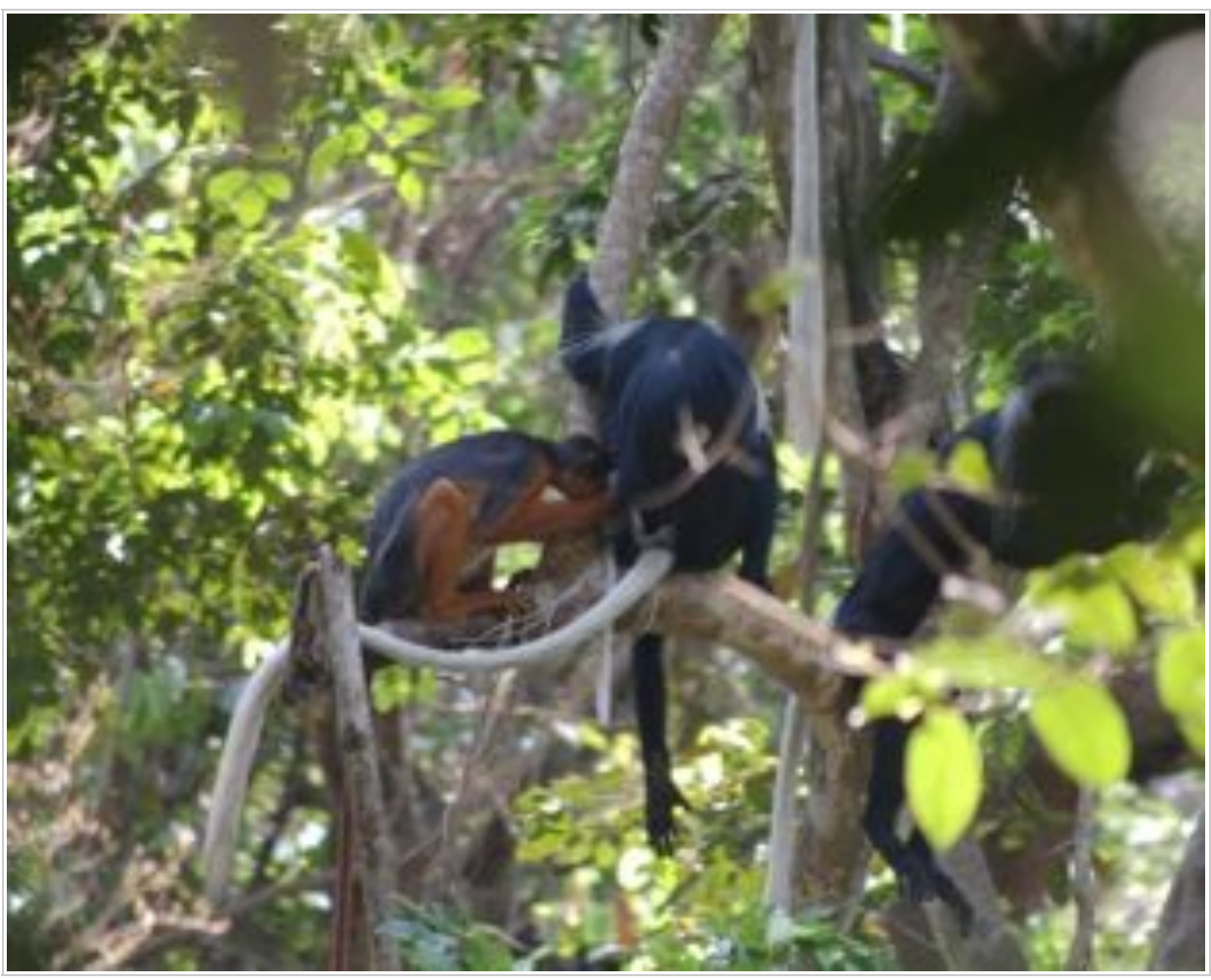

Figure 8: Survival of endangered species.

Interspecific association between western Red and Black-and-white colobus (Cantanhez National Park, Guinea Bissau). Prospects for the survival of these endangered species will benefit from the use of non-invasive genetic tools.

(c) 2012 Nature Education All rights reserved. ()

All authors have contributed equally to this article.

\section{References and Recommended Reading}

Arandjelovic M. et al. Effective non-inasive genetic monitoring of multiple wild western gorilla groups. Biological Conservation 143, $1780-1791$ (2010).

Bergl, R. \& Vigilant, L. Genetic analysis reveals population structure and recent migration within the highly fragmented range of the Cross River gorilla (Gorilla gorilla diehli). Molecular Ecology 16, 501-516 (2007).

Bergl, R. A. et al. Effects of habitat fragmentation, population size and demographic history on genetic diversity: The Cross River gorilla in a comparative context. American Journal of Primatology 70, 848-859 (2008).

Bermejo, M. et al. Ebola outbreak killed 5000 gorillas. Science 314, 1564 (2006).

Bruford, M. W. et al. Projecting genetic diversity and population viability for the fragmented orangutan population in the Kinabatangan floodplain, Sabah, Malaysia.

Endangered Species Research 12, 249-261 (2010).

Campbell, G. et al. Alarming decline of West African chimpanzees in Côte d' Ivoire. Current Biology 18, 903-904 (2008).

Chapman, C. A. \& Russo, S. E. "Primate seed dispersal: Linking behavioral ecology with forest community structure," in Primates in Perspective, eds. C. J. Campbell et al. (New York, NY: Oxford University Press, 2007) 510-525.

Charpentier, M. J. E. et al. Inbreeding depression in non-human primates: A historical review of methods used and empirical data. American Journal of Primatology 69, 1370-1386 (2007).

Chi, F. et al. New Streptococcus pneumoniae clones in deceased wild chimpanzees. Journal of Bacteriology 189, 6085-6088 (2007).

Cowlishaw, G. \& Dumbar, R. Primate Conservation Biology. Chicago, IL: Chicago University Press, 2000.

Damond, F. et al. Identification of a highly divergent HIV type 2 and proposal for a change in HIV type 2 classification. AIDS Research and Human Retroviruses 20, 666-672 (2004).

Fajardo, V. et al. A review of current PCR-based methodologies for the authentication of meats from game animal species. Trends in Food Science \& Technology 
21, 408-421 (2010)

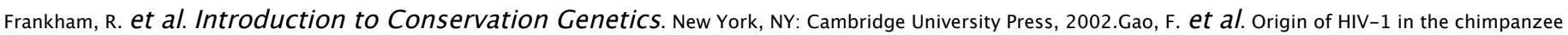
Pan troglodytes troglodytes. Nature 397, 436-441 (1999).

Gibbons, M. A. \& Harcourt, A. H. Biological correlates of extinction and persistence of primates in small forest fragments: A global analysis. Tropical Conservation Science 2, 388-403 (2009).

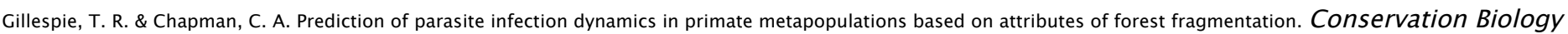
20, 441-448 (2006).

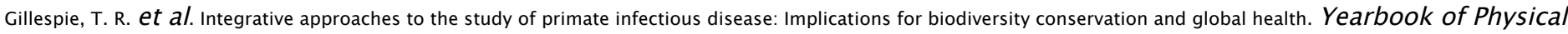
Anthropology 51, 53-69 (2008).

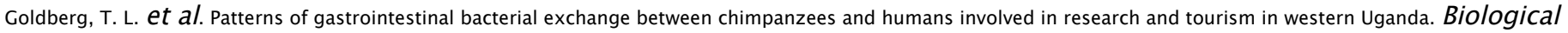
Conservation 135, 511-517 (2007).

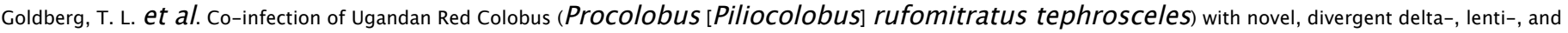
spumaretroviruses. Journal of Virology 83, 11318-11329 (2009).

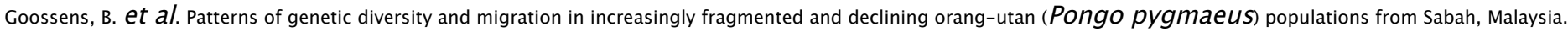
Molecular Ecology 14, 441-456 (2005).

Goossens, B. et al. Genetic signature of anthropogenic population collapse in orang-utans. PLoS Biology 4, e25 (2006).

Goossens, B. \& Bruford, M. W. "Non-invasive genetic analysis in conservation," in Population Genetics for Animal Conservation, eds. G. Bertorelle et al. (Cambridge, UK: Cambridge University Press, 2009) 167-201.

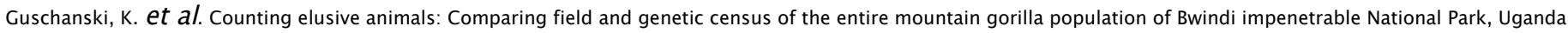
Biological Conservation 142, 290-300 (2009).

Harcourt, A. H. et al. Rarity, specialization and extinction in primates. Journal of Biogeography 29, 445-456 (2002).

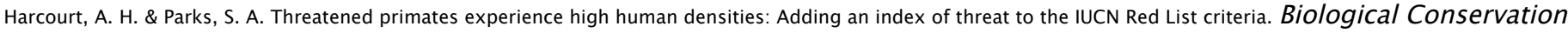
109, 137-149 (2003).

Hebert, P. et al. Barcoding animal life: Cytochrome c oxidase subunit 1 divergences among closely related species. Proceedings of the Royal Society B:

Biological Sciences 270 (Supplement), S96-S99 (2003).

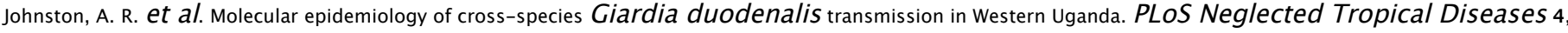
683-689 (2010).

Kaur, T. et al. Descriptive epidemiology of fatal respiratory outbreaks and detection of a human-related metapneumovirus in wild chimpanzees (Pan troglodytes) at Mahale Mountains National Park, Western Tanzania. American Journal of Primatology 70, 755-765 (2008).

Köndgen, S. et al. Pandemic human viruses cause decline of endangered great apes. Current Biology 18, 260-264 (2008).

Köndgen, S. et al. Pasteurella multocida involved in respiratory diseases of wild chimpanzees. PLoS ONE 6, e24236 (2011).

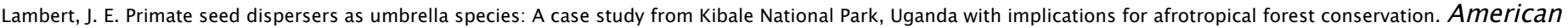
Journal of Primatology 73, 9-24 (2011).

Leendertz, F. H. et al. Pathogens as drivers of population declines: The importance of systematic monitoring in great apes and other threatened mammals. Biological Conservation 131, 325-337 (2006).

Liu, w. et al. Origin of the human malaria parasite Plasmodium falciparum in gorillas. Nature 467, 420-425 (2010).

Liu, W. et al. Molecular ecology and natural history of simian foamy virus infection in wild-living chimpanzees. PLoS Pathogens 4, e1000097 (2008).

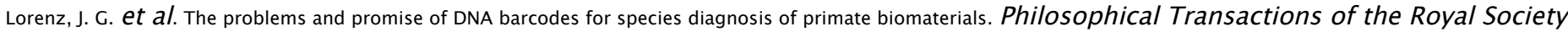
B: Biological Sciences 360, 1869-1877 (2005).

Macfie, E. \& Williamson, E. Best Practice Guidelines for Great Ape Tourism. Gland, Switzerland: IUCN/SSC Primate Specialist Group, 2010.

Marsh, L. K. "The nature of fragmentation," in Primates in Fragments: Ecology and Conservation, ed. L. K. Marsh (New York, NY: Kluwer Academic/Plenum Publishers, 2003) 1-10.

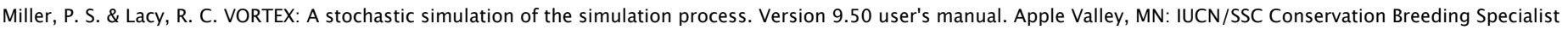
Group, 2005. 
Mittermeier, R. A. et al. Primates in peril: The world's 25 most endangered primates 2008-2010. Primate Conservation 24, 1-57 (2009).

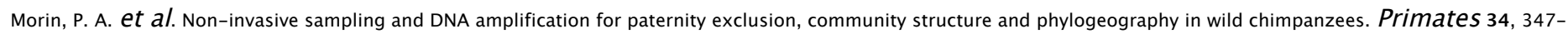
356 (1993).

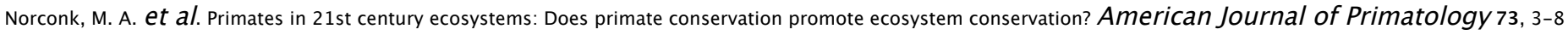
(2011).

Paetkau, D. Using genetics to identify intraspecific conservation units: A critique of current methods. Conservation Biology 13, 1507-1509 (1999).

Palacios, G. et al. Human metapneumovirus infection in wild mountain gorillas, Rwanda. Emerging Infectious Diseases 17, 711-713 (2011).

Prugnolle, F. et al. African great apes are natural hosts of multiple related malaria species, including Plasmodium falciparum. Proceedings of National Academy of Sciences of the United States of America 107, 1458-1463 (2010).

Riley, E. P. \& Fuentes, A. Conserving social-ecological systems in Indonesia: Human-nonhuman primate interconnections in Bali and Sulawesi. American Journal of Primatology 73, 62-74 (2011).

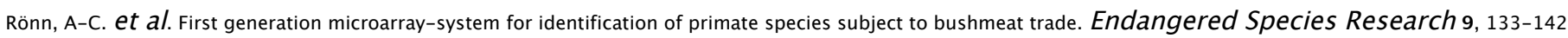
(2009).

Storfer, A. et al. Putting the "landscape" in landscape genetics. Heredity 98, 128-142 (2007).

Strier, K. B. Primate Behavioral Ecology. Boston, MA: Pearson, 2000.

Tung, J. et al. Genetic evidence reveals temporal change in hybridization patterns in a wild baboon population. Molecular Ecology 17, 1998-2011 (2008).

Vigilant, L. \& Guschanski, K. Using genetics to understand the dynamics of wild primate populations. Primates 50, 105-120 (2009).

Wertheim, J. \& Worobei, M. Dating the age of the SIV lineages that gave rise to HIV-1 and HIV-2. PLoS Computational Biology 5, e1000377 (2009).

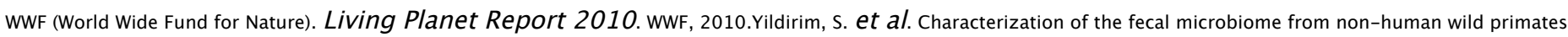
reveals species specific microbial communities. PLOS ONE 5, 13963-13976 (2010).

Zhan, X. et al. Molecular censusing increases key giant panda population estimate by more than 100\%. Current Biology 16, 451-452 (2006).

Outline | Keywords FEEDBACK

\section{Explore This Topic}

BASIC

Conservation of Biodiversity

Conservation Biology

Restoration Ecology

Conservation and Restoration

Introduction

Phytoremediation

ADVANCED

Using Genetics as a Tool in Primate

Conservation
INTERMEDIATE

Population Viability Analysis: Origins and Contributions

Applications of Decision Theory to Conservation Planning and

Management

Notes from the Field: A

Primatologist's Point of View 


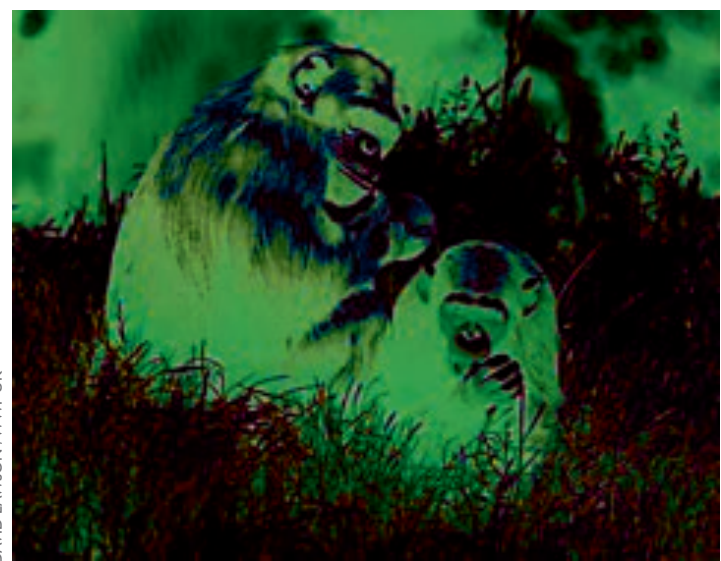

The Trade and Ethnobiological Use of Chimpanzee Body Parts in Guinea-Bissau: Implications for Conservation

\section{Rui Miguel Moutinho Sá, Maria Ferreira da Silva, Fernando Miguel Sousa and Tânia Minhós}

\section{INTRODUCTION}

$\mathrm{G}$ uinea-Bissau represents the western-most limit of the endangered West African Chimpanzee Pan troglodytes verus (Sousa et al., 2005). During the 1980s, Chimpanzees were erroneously considered to be extinct in the country due to a total absence of information owing largely to political and civil unrest (Lee et al., 1988). In 1994, a preliminary survey was conducted and the presence of Chimpanzees was reconfirmed (Gippoliti and Dell' Omo, 1995; 1996). More recently, research has been carried out in cooperation with national and local authorities, establishing a system for the systematic monitoring and management of this great ape (Casanova and Sousa, 2007). Within the country, Chimpanzees are distributed across the south of the Corubal River. Their presence is confirmed in two protected areas - Cantanhez National Park (CNP) and Cufada Lagoons Natural Park (CLNP) in the southwestern region - and in the eastern region of Boé (Casanova and Sousa 2007; Brugière et al., 2009).

Due to high levels of exploitation, loss of habitat and habitat quality as a result of human activities, this subspecies is estimated to have experienced a significant population reduction in the past 20 to 30 years (IUCN, 2011). However, no recent data are available to allow for an estimation of rates of decline (IUCN, 2011). The most recent figures available, from 1996 (Gippoliti et al., 2003), estimate that the number of Chimpanzees in Guinea-Bissau ranges from between 600 and 1000 individuals. It is estimated that Chimpanzee density in the southern area of CNP is of 2.34 nest builders $/ \mathrm{km}^{2}$ in a total area of $17.225 \mathrm{~km}^{2}$, corresponding to 40 individuals (Sousa et al., 2011), while in the neighbouring area east of Gadamael, just outside the CNP area, this value decreases to 0.89 nest builders $/ \mathrm{km}^{2}$ in a total area of
$36.513 \mathrm{~km}^{2}$, which corresponds to 33 individuals (Sousa, 2009). However, the exact number of individuals and communities for the whole CNP and the rest of the country remains unclear; with the aid of a molecular census, however, it will be possible to infer its effective population size (Sá et al., 2009).

Anthropogenic disturbances such as habitat loss and fragmentation (e.g. logging activities and shifting land occupation for the purposes of agriculture and food production, e.g. cashew nuts), the hunting of infant animals for the pet trade, and casual deaths from crop raiding allied to extrinsic factors such as disease, are the main threats, not only to Chimpanzees but to all nonhuman primates in Guinea-Bissau (Gippoliti et al., 2003; Casanova and Sousa, 2007; Brugière et al., 2009). The species is classified by IUCN as Endangered, and listed in CITES Appendix I, and is also protected in GuineaBissau. Even though most primate species in GuineaBissau are traded for meat consumption, there is no evidence that this is the case for Chimpanzees (Minhos et al., in prep.).

This paper reports on the use and trade of Chimpanzee body parts in Guinea-Bissau for traditional practices (e.g. for nutritional, medicinal or ritual purposes, or "animistic myths"). Informal interviews were conducted and observations made with a view to providing insight into how these human traditions and myths might pose an additional threat.

\section{METHODS}

Seven visits, of approximately four hours each, were made to Bandim market, the largest market in Bissau, the capital, during two weeks in September 2008 and a similar period in June 2010. Some 10-15 men were found to be offering wild animal body parts for sale (e.g. skin, bones, teeth, horns and scales). Where possible, morphological identification of the specimens viewed was made and photographs taken.

An ethnoprimatological approach (i.e. the study of human and non-human primate interactions) aims to understand the incorporation of non-human primates into folklore, myths, the hunting of non-human primates for food, keeping non-human primates as pets, indigenous knowledge of non-human primate behaviour, among others (Wolfe and Fuentes, 2007; Fuentes and Hockings, 2010). In this study, the authors were interested in understanding and placing into context the social inclusion of Chimpanzee body parts for human traditional practices using informal interviews and ethnographic observations, although not enough data were collected to provide an in-depth analysis for such an approach.

Most of the vendors encountered were male. Five urban vendors in Bandim market and 17 rural informants in villages in the CNP and the Boé region were informally interviewed following an unstructured script, in order to document the geographical origin and use of Chimpanzee body parts, prices and the scale of the trade, i.e. whether at a national, regional, or transnational level. Direct observations of the trade were conducted in the market 


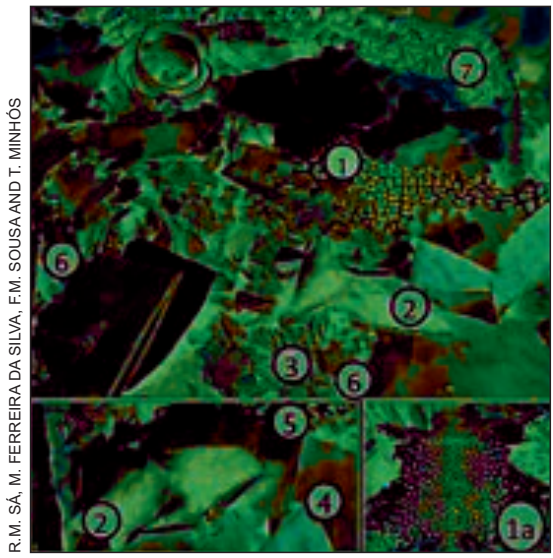

1. Leopard Panthera pardus (1a complete).

CITES Appendix I/IUCN Near Threatened;

2. Chimpanzee Pan troglodytes verus. CITES Appendix I/IUCN Endangered;

3. Nile Crocodile Crocodylus niloticus. CITES Appendix I/II/IUCN Lower Risk/Least Concern.

4. Guinea Baboon Papio papio. CITES Appendix II/IUCN Near Threatened.

5. Possibly Lion Panthera leo. CITES I/IUCN Vulnerable.

6. Possibly African Civet Civettictis civetta. CITES Appendix III/IUCN Least Concern. 7. Antelope horns (species not identified).

Fig. 1. All animal-derived products for human traditional purposes in Bandim market, Bissau, Guinea-Bissau.

and field notes were taken. Informants were assured that the purpose of the work was not to condemn or report their practices to the local authorities. Every observation heard and/or seen was recorded and notes/interviews organized into social demographic categories (e.g. urban traders, local villagers, gender, ethnic group). Only information relevant to the research topic was assigned to these categories (Rubin and Rubin, 1995).

Only pieces of animal skins were seen for sale during the surveys (which could have derived from one or more specimens). As the vendors were reluctant to answer questions related to the animal numbers involved in the trade, it was not possible to estimate the number of skins being offered for sale for each species recorded. This paper therefore focuses on the morphological identification of the species and not to the number of skins traded.

\section{Results AND Discussion}

\section{Traded species}

During visits to Bandim market, morphologically identified dried Chimpanzee skins were found being sold for traditional medicinal purposes. Additionally, dried skins from Temminck's Red Colobus monkeys Procolobus badius temminckii, Guinea Baboons Papio papio and Olive Baboons Papio anubis were also found. The authors also detected trade in dried skins of several non-primate species such as Leopard Panthera pardus, Nile Crocodile Crocodylus niloticus, African Civet Civettictis civetta, elephant Loxodonta sp., hare Lepus sp., African Buffalo Syncerus caffer, Spotted Hyaena Crocuta crocuta and several species of antelopes, snakes and lizards, as well as skins alleged to be of Wild Dog Lycaon pictus and Lion Panthera leo (Fig. 1). Other animal body parts observed included bones, Crested Porcupine Hystrix cristata spines, teeth, antelope horns, pangolin Manis sp. scales, mollusc shells, fish bones and feathers. Morphologically specific identification was not possible in most cases due to the similarity of those body parts to other species, as well as to their condition. A few sellers mentioned that some of the bones being offered for sale were from primates.
All the species mentioned above are reported as occurring in Guinea Bissau except for Olive Baboons, whose western limit of distribution is reported to be in Mali and the Republic of Guinea (IUCN, 2011). The Olive Baboon skin seen was morphologically quite different to the Guinea baboon skins found at the market. While Guinea Baboon skins present red/brownish coloration, the Olive Baboon skin had a green hue, typical of what has been described for the subspecies (Groves, 2001).

\section{Costs, origin and scale}

Interviews with urban traders revealed that the cost of a piece of Chimpanzee skin was relatively high, ranging from XOF1500 (CFA Francs) to XOF90 000 (USD2.9 to USD173.96, based on an exchange rate in 2008 of XOF460.77 to USD1). The average monthly wage in 2008 was XOF40 000 (approximately USD88.00) (UNDP, 2010).

All urban vendors reported that the Chimpanzee and other animal body parts (apart from the elephant hide seen) originated from the "southern part", and frequently mentioned the regions of Cantanhez and Gabú specifically. Vendors considered the "southern part" every location south of Bissau. The authors were told that the elephant hide had come from Senegal. According to Blanc et al., 2007, at least one, and at most 10 elephants remain in Senegal. Most vendors said that consumers were of both sexes, different ethnic groups and social status.

It was apparent to the authors that witchdoctors are not the only people to buy animal-derived products for traditional medicine or protection fetishes. For example, according to statements from three vendors:

"All sort of people buy. Men and women, poor or rich... Fulas, Pepel, Balanta, even Europeans. Every kind. Not only djamba kuss [witchdoctors] to please the irans [magical and religious entities]."

According to Robillard, in litt. to TRAFFIC, July 2011, it is common practice in Africa for people who are unwell to buy their own products based on a list provided by the traditional doctor. See also Marshall (1998). 
Two of the vendors also mentioned that individuals from neighbouring countries such as Senegal, Guinea or Gambia are involved in the trade within the country: "Other foreigners also buy and sell their own plants, shells or skins".

\section{Symbolic and medicinal use}

Most male informants in rural CNP and Boé villages associated the use of Chimpanzee-derived products with the needs of women, as revealed by one elder Fula respondent in Béli, Boé:

"Dári [chimpanzee] is mezinho [traditional medicine] of women."

Three Balanta women in CNP confirmed that Chimpanzee skin is used to: "prepare a cleansing mixture against hideousness when they are pregnant or their children are still babies in the event they see a lonely chimpanzee cross their way". Likewise, another woman said that "the leaves of the nest where a menstruating female chimpanzee sleeps can be applied to heal mental problems".

One informant admitted that he uses a stitched amulet made of chimpanzee body parts to help provide awareness to protect him and his friends while in the bush (Rui Sá, pers. obs., 2008).

\section{Guinea-Bissau in the context of previous studies}

One possible explanation for the lack of information on magic practices and traditional medicines using animal body parts in Guinea-Bissau is the difficulty in collecting information on such an undisclosed subject, as well as both a lack of interest and in-depth study of such practices. As a result, the authors' observations are opportunistic. However, the use of animals' body parts for medicinal purposes could seriously threaten the biodiversity of Guinea-Bissau and, in particular, constitutes an additional and significant threat to Chimpanzee populations already menaced by habitat loss and fragmentation, the pet trade and crop-raiding conflicts. Therefore, this phenomenon deserves to be thoroughly investigated (Cá, 2008).

Although not previously reported for Guinea-Bissau, the use of non-human primate body parts in traditional medicine is not unusual elsewhere in the world (Alves et al., 2010; Leypey and Fomine, 2010). In a recent review, Alves et al. (2010) reported the use of 101 species of primates in folk/magic-religious practices, most frequently in Africa, Latin America and Asia. Although Cercopithecidae species are the most affected, Chimpanzees are also referred to as a remedy for diseases and for use in folk medicine (Alves et al., 2010). In Nigeria, Mali, Sierra Leone, Congo and Guinea, Chimpanzee body parts are used to cure male impotency, epilepsy, bone fractures and infertility in women (Dedeke and Aboyami, 2006). In Cameroon, the Bakweri people believe that by using the liquid derived from boiled Chimpanzee bones, the bones of children or babies will become stronger (Leypey and Fomine, 2010). Additionally, in the forested areas, people use
Chimpanzee body parts in birth and circumcision rituals (Mallart Guimera, 1981). The Yoruba people of southwestern Nigeria believe in the magical properties of Chimpanzee body parts in appeasing witches and fortune tellers (Dedeke and Aboyami, 2006). However, it is not easy for people to obtain these remedies or to gain access to these animals. In Central Africa, the consumption of Chimpanzee meat is taboo for young men, pregnant women and children (Robillard, in litt. to TRAFFIC, July 2011).

The presence in Bandim market of the skin of an Olive Baboon suggests a foreign origin for some of the animal body parts being offered for sale. While the distribution area for this species (Papio anubis) includes neighbouring Guinea and Mali, it does not occur in Guinea-Bissau (Soewu, 2008). The Guinea Baboon Papio papio is the only baboon species reported and observed in the country (IUCN, 2011). There are striking differences in morphology between both baboon species (namely coat coloration (Groves, 2001)), which enables a distinction to be made based on their skins. Furthermore, in Colobane and Boucotte markets in Senegal (in Dakar and Ziguinchor, respectively), several species of reptiles and mammals, including primate species (data not shown) were found in trade for use in traditional medicinal practices and/or magic ceremonies (Fernando Sousa, pers. obs., 2008). According to information provided by the sellers, those animal body parts were brought from Niger, Nigeria, Ivory Coast and Mali. Chimpanzee skins were also found in these Senegalese markets (Fernando Sousa, pers. obs., 2008). The respondents pinpointed Cassamance (on the border between Senegal and Guinea-Bissau) as the putative origin of Chimpanzee skins at Boucotte market, and Guinea-Bissau and the Republic of Guinea as the possible origin of the Chimpanzee skins being sold at Colobane market. The possibility that the Chimpanzee skins found in Bandim market could also be from the Republic of Guinea cannot be excluded since sellers mentioned the "south" as the origin but not specifically the south of Guinea-Bissau.

\section{Implications for conservation}

The suggested transnational interest for Guinea-Bissau Chimpanzee skins may constitute an even bigger threat for the conservation of this population. Since Chimpanzee populations are declining in West African countries (IUCN, 2010), foreign hunters could be attracted to Guinea-Bissau and the hunting of Chimpanzees could therefore increase in the near future. Biodiversity management authorities in Guinea-Bissau (IBAP and Direcção Geral de Florestas e Fauna) have introduced new laws to regulate the trade in wild meat (e.g. recently, the hunting of primates throughout the country was prohibited (Anon., 2011). However, the lack of resources and lack of awareness of management authorities and politicians is hindering law enforcement in the country. At the international level, conservation agencies should re-examine their strategies to mitigate this trade, and, at the national level, specific programmes should be designed and applied to empower all actors involved (e.g. 
park rangers, Customs officers, the military, police, etc.), complemented at the same time by provision of environmental education for the local communities.

Further work by the authors will include the molecular determination of the origin of the skins observed in the markets and of the species involved. This will assist in evaluating the scale of the trade. Finally, an ethnographic study specifically centred on the use of non-human primate body parts by traditional medicine using more indepth techniques, such as participant observation or longterm observation, will allow the authors to draw up possible differences in the use of distinct animal parts and determine how such practices are disseminated.

\section{ACKNOWLEDGEMENTS}

The authors are enormously thankful to the Institute of Biodiversity and Protected Areas (IBAP) in Guinea-Bissau for facilitating their research in Guinea-Bissau, and for providing logistical support. Particular thanks go to Milza Nanqui whose assistance facilitated the gathering of information at the market in Bissau and to all the informants for agreeing to and trusting the authors to talk about sensitive issues. The authors are also very grateful to M.W. Bruford, C. Sousa and C. Casanova for their helpful discussion and comments that improved the quality of the manuscript. The authors would also like to thank David Greer, WWF's African Great Apes Programme Co-ordinator; Marine Robillard, expert in environmental anthropology, consultant for AnthropoLinks and research associate at the National Museum of Natural History of Paris; and an anonymous reviewer, for their helpful comments on an early draft.

\section{REFERENCES}

Alves, R.R., Souto, W.M., and Barboza, R.R. (2010). Primates in traditional folk medicine: a world overview. Mammal Review. 40(2):155-180.

Anon. (2011). Decreto-Lei 5/2011 de 22 Fevereiro. Boletim Oficial da República da Guiné-Bissau, 8:1-13.

Blanc, J.J., Barnes, R.F.W., Craig, G.C., Dublin, H.T., Thouless, C.R., Douglas-Hamilton, I., and Hart, J.A. (2007). African Elephant Status Report 2007: an Update from the African Elephant Database. Occasional Paper Series of the Species Survival Commission, No. 33. IUCN/SSC African Elephant Specialist Group. IUCN, Gland, Switzerland. vi +276 pp.

Brugière, D., Badjinca, I., Silva, C., and Serra, A. (2009). Distribution of chimpanzees and interactions with humans in Guinea-Bissau and Western Guinea, West Africa. Folia Primatologica 80:353-358.

Cá, Augusto. (2008). Estudos sobre a caça e mercado de primatas em Tombali, Sul da Guiné-Bissau. MSc thesis. Universidade Federal de Minas Gerais, Brazil.

Casanova, C., and Sousa, C. (2007). Action Plan for the Conservation of Chimpanzees, Red Western Colobus and King Colobus in Guinea-Bissau Republic. IBAP, Guiné-Bissau.

CITES (2011). http://www.cites.org/. Viewed on 30 September.

Dedeke, G.A., and Aboyami, F. (2006). Ethnozoological trade and practices among the Ijebu people of southwestern Nigeria and the impact on some mammalian species. Indilinga 5(2):175-187.

Fuentes, A., and Hockings, K. (2010). The ethnoprimatological approach in primatology. American Journal of Primatology 72:841-847.
Gippoliti, S., and Dell'Omo, G. (1995). Status and conservation of the chimpanzee Pan troglodytes verus in Guinea-Bissau. African Primates 1:3-5.

Gippoliti, S., and Dell'Omo, G. (1996). Primates of the Cantanhez Forest and the Cacine Basin, Guinea-Bissau. Oryx 30:74-80.

Gippoliti, S., Embalo, D., and Sousa, C. (2003). Guinea-Bissau. In: West African Chimpanzees: Status Survey and Conservation Action Plan. Kormos, R., Boesch, C., Bakarr, M., and Butynski, T. (Eds), IUCN, Gland, Switzerland. Pp.55-61.

Groves, C., (2001). Primate Taxonomy. Smithsonian Institution Press, Washington, DC.

IUCN (2010). IUCN Red List of Threatened Species. Version 2010.4. www.iucnredlist.org. Viewed on 21 April 2011.

Lee, P.C., Thornback, J. and Bennett, E.L. (1988). Threatened Primates of Africa. Gland, Switzerland.

Leypey F., and Fomine M. (2010). Edible Wild Animals as Source of Medication in Cameroon. Petits Propos Culinaires. 90:99-117.

Mallart Guimera, L. (1981). Ni dos ni ventre. Religion, magie et sorcellerie Evuzok. Paris: Société d'ethnographie.

Marshall, N.T. (1998). Searching for a Cure: Conservation of Medicinal Wildlife Resources in East and southern Africa. TRAFFIC International. $112 \mathrm{pp}+$ xiv.

Minhos, T., Sá, R., Ferreira da Silva, M., Wallace, E., Barata, A., Carmo, M. and Bruford, M.W. (in prep.). Characterization of the urban primate bushmeat trade in Guinea Bissau using molecular tools for species identification.

Rubin, H.J. and Rubin, I.S. (1995). Qualitative Interview: The Art of Hearing Data. Thousand Oaks: Sage Publications.

Sá, R., Sousa, C., and Bruford, M.W. (2009) (Abstract). Conservation genetics and phylogeography of the chimpanzees in Guinea-Bissau. Folia Primatologica 80(2):172.

Sousa, F.M. (2009). Pan troglodytes verus densities and the use of natural resources in Gadamael area, Guinea-Bissau. MSc thesis. Lisbon University, Lisbon, Portugal.

Sousa, J., Barata, A.V., Sousa, C., Casanova, C., and Vicente, L. (2011). Chimpanzee oil-palm use in southern Cantanhez National Park, Guinea-Bissau. American Journal of Primatology 73:1-13.

Sousa, C., Gippoliti, S., and Akhlas, M. (2005). Republic of Guinea-Bissau. In: World Atlas of Great Apes and their Conservation, Caldecott, J., Miles, L. (Eds). University of California Press, London. Pp.362-365.

Soewu, D.A. (2008). Wild animals in ethnozoological practices among the Yorubas of southwestern Nigeria and the implications for biodiversity conservation. African Journal of Agricultural Research. 3(6):421-427.

Wolfe, L.D., and Fuentes, A. (2007). Ethnoprimatology. In: Primates in Perspective, Campbell, C.J., Fuentes, A., Mackinnon, K.C., Panger, M., and Bearder, S.K. (Eds). Oxford University Press, Oxford, Pp.691-705.

UNDP (United Nations Development Programme) (2010). Human Development Report 2010. UNDP, New York.

Rui Miguel Moutinho Sá ${ }^{1,2,3,6}$, Maria Ferreira da Silva ${ }^{2,5,6}$, Fernando Miguel Sousa ${ }^{4}$ and Tânia Minhós ${ }^{2,4,6}$

${ }^{1}$ Departamento de Antropologia, Faculdade de Ciências Sociais e Humanas, Universidade Nova de Lisboa, Portugal. Email: ruimoutinhosa@gmail.com; ${ }^{2} \mathrm{School}$ of Biosciences, Cardiff University, UK; ${ }^{3}$ CRIA-Centre for Research in Anthropology, Portugal; ${ }^{4} \mathrm{Centre}$ for Environmental Biology, University of Lisbon, Portugal; ${ }^{5} \mathrm{CIBIO}-$ University of Porto, Portugal. ${ }^{6}$ These authors contributed equally to the preparation of this paper. 


\title{
Distribution of the Entodiniomorphid Ciliate Troglocorys cava Tokiwa, Modrý, Ito, Pomajbíková, Petrželková, \& Imai, 2010, (Entodiniomorphida: Blepharocorythidae) in Wild and Captive Chimpanzees
}

\author{
KATEŘINA POMAJBÍKOVÁ, ${ }^{a}$ KLÁRA J. PETRŽELKOVÁ, ${ }^{\mathrm{b}, \mathrm{c}}$ JANA PETRÁŠOVÁ, ${ }^{\mathrm{a}}$ ILONA PROFOUSOVÁ, ${ }^{\mathrm{a}, \mathrm{b}}$ BARBORA \\ KALOUSOVÁ, ${ }^{\mathrm{b}}$ MILOSLAV JIRKŮ, ${ }^{\mathrm{d}}$ RUI M. SÁ ${ }^{\mathrm{e}, \mathrm{f}}$ and DAVID MODRÝ ${ }^{\mathrm{d}, \mathrm{g}}$ \\ ${ }^{a}$ Department of Pathology and Parasitology, Faculty of Veterinary Medicine, University of Veterinary and Pharmaceutical Sciences, \\ Palackého 1-3, 612 42, Brno, Czech Republic, and \\ ${ }^{\mathrm{b}}$ Institute of Vertebrate Biology, Academy of Sciences of the Czech Republic, Květná 8, 60365, Brno, Czech Republic, and \\ ${ }^{\mathrm{c}}$ Liberec Zoo, Masarykova 1347/31, 460 01, Liberec, Czech Republic, and \\ ${ }^{\mathrm{d}}$ Biology Centre, Institute of Parasitology, Academy of Sciences of the Czech Republic, Branišovská 31, 370 05, České Budéjovice, Czech \\ Republic, and \\ ${ }^{\mathrm{e}}$ Biodiversity and Ecological Processes Group, School of Biosciences, Cardiff University, Cardiff, United Kingdom, and \\ ${ }^{\mathrm{f}}$ Anthropology Department, Human and Social Sciences Faculty, Universidade Nova de Lisboa, Portugese, and \\ ${ }^{\mathrm{g}}$ CEITEC - Central European Institute of Technology, University of Veterinary and Pharmaceutical Sciences, Brno, Czech Republic
}

\begin{abstract}
Trophozoites of Troglocorys cava were detected in all but one of the wild chimpanzee populations from Rubondo Island (Tanzania), with a prevalence ranging between $20 \%$ and $78 \%$. However, the ciliate was absent in all captive groups. Prevalence appeared to increase with the number of sequential samples taken from a particular individual and reached $95.5 \%$ in wild individuals sampled at least 4 times.
\end{abstract}

Key Words. Chimpanzees, Entodiniomorphida, intestinal ciliates, prevalence, Troglocorys cava.

$\mathrm{T}$ HE intestine of apes is colonized by a spectrum of protists that cause no or little harm to their host and can be classified as mutualists or commensals. Among them, ciliates are the most prominent group, as they apparently participate in the hindgut fermentation (e.g. Profousová et al. 2010). Reports about the presence of intestinal ciliates in wild apes were mostly a by-product of parasitological examinations (Ashford, Reid, and Wrangham 2000; Murray et al. 2000). However, the proper classification of ciliates requires specialized techniques other than those used for the routine coproscopic detection of parasites, thus representing a serious drawback in their research (Imai et al. 1991).

Most intestinal ciliates of great apes belong to the order Entodiniomorphida and are classified in the genera Troglodytella, Gorillophilus and Prototapirella. In addition, a species that had been referred to as a "small" or "unidentified ciliate" (Ashford et al. 2000; Bakuza and Nkwengulila 2009; Murray et al. 2000) was named Troglocorys cava and assigned to the family Blepharocorythidae (Tokiwa et al. 2010); the study aimed to investigate the occurrence of $T$. cava in both wild and captive chimpanzees. Herein, we report on the prevalence, diagnostics, and geographical distribution of $T$. cava in populations of wild chimpanzees and discuss the absence of $T$. cava in captive chimpanzees in European facilities, African sanctuaries, and in an introduced chimpanzee population in Tanzania.

\section{MATERIAL AND METHODS}

The set of fecal samples of wild $(n=511)$ and captive chimpanzees $(n=203)$ largely corresponds with those discussed by Pomajbíková et al. (2010). It also includes two additional wild chimpanzee populations and one captive facility: Goualougo Triangle, Republic of Congo (DRC) $(n=20)$; Cantanhez National Park (NP), Guinea Bissau $(n=102)$; and Sweetwaters

Corresponding Author: Kateřina Pomajbíková, Department of Pathology and Parasitology, Faculty of Veterinary Medicine, University of Veterinary and Pharmaceutical Sciences, Palackého 1-3, 61242 Brno, Czech Republic-Telephone number: + 420541562269; FAX number: +420541562266; e-mail: kpomajbik@gmail.com
Chimpanzee Sanctuary, Kenya $(n=42)$. In addition, the numbers of samples from Ugalla and Rubondo Island NP were extended to 119 and 206, respectively. Samples were preserved by $10 \%$ formalin and examined by merthiolate-iodine-formaldehyde sedimentation (MIFC), following Pomajbíková et al. (2010).

We calculated the prevalence of $T$. cava differently for habituated (chimpanzees are used to being around people) and unhabituated (the opposite to previous) populations. For a habituated population, the prevalence was expressed as the percentage of individuals infected with $T$. cava; for unhabituated populations, as the percentage of samples positive for $T$. cava. To determine the effect of sequential sampling on the prevalence of $T$. cava, we calculated the cumulative prevalence for selected animals from Kalinzu Forest Reserve. We chose samples only from the wet season $(n=195)$ and calculated the cumulative prevalence based on number of samples per individual: (i) one sample ( $n=36$ animals); (ii) two sequential samples $(n=29)$; (ii) three sequential samples $(n=25)$; and (iv) four or more sequential samples $(n=22)$.

For scanning electron microscopy (SEM), trophozoites of T. cava from a chimpanzee from Kalinzu FR were obtained from a filtrated fecal sediment and were preserved with $10 \%$ formalin, following the protocol of Jirků et al. (2009).

\section{RESULTS AND DISCUSSION}

The general trophozoite morphology, determined by light microscopy and confirmed by NIC, was uniform throughout all localities and consistent with the original description of T. cava (Tokiwa et al. 2010) (Fig. 1).

The geographical distribution of $T$. cava includes localities in Tanzania, Uganda, and Gabon (e.g. Krief et al. 2005; Landsoud-Soukate, Tutin, and Fernandez 1995; Murray et al. 2000). We detected T. cava in chimpanzee fecal samples from seven of the eight studied wild populations and extended its known distribution in Uganda and Tanzania, and added localities in Nigeria, DRC, and Guinea Bissau. Its prevalence in wild populations ranged from $5 \%$ to $98 \%$ (Ashford et al. 2000; File, McGrew, and Tutin 1976; Krief et al. 2005; Landsoud-Soukate et al. 1995; Murray et al. 2000). Our 

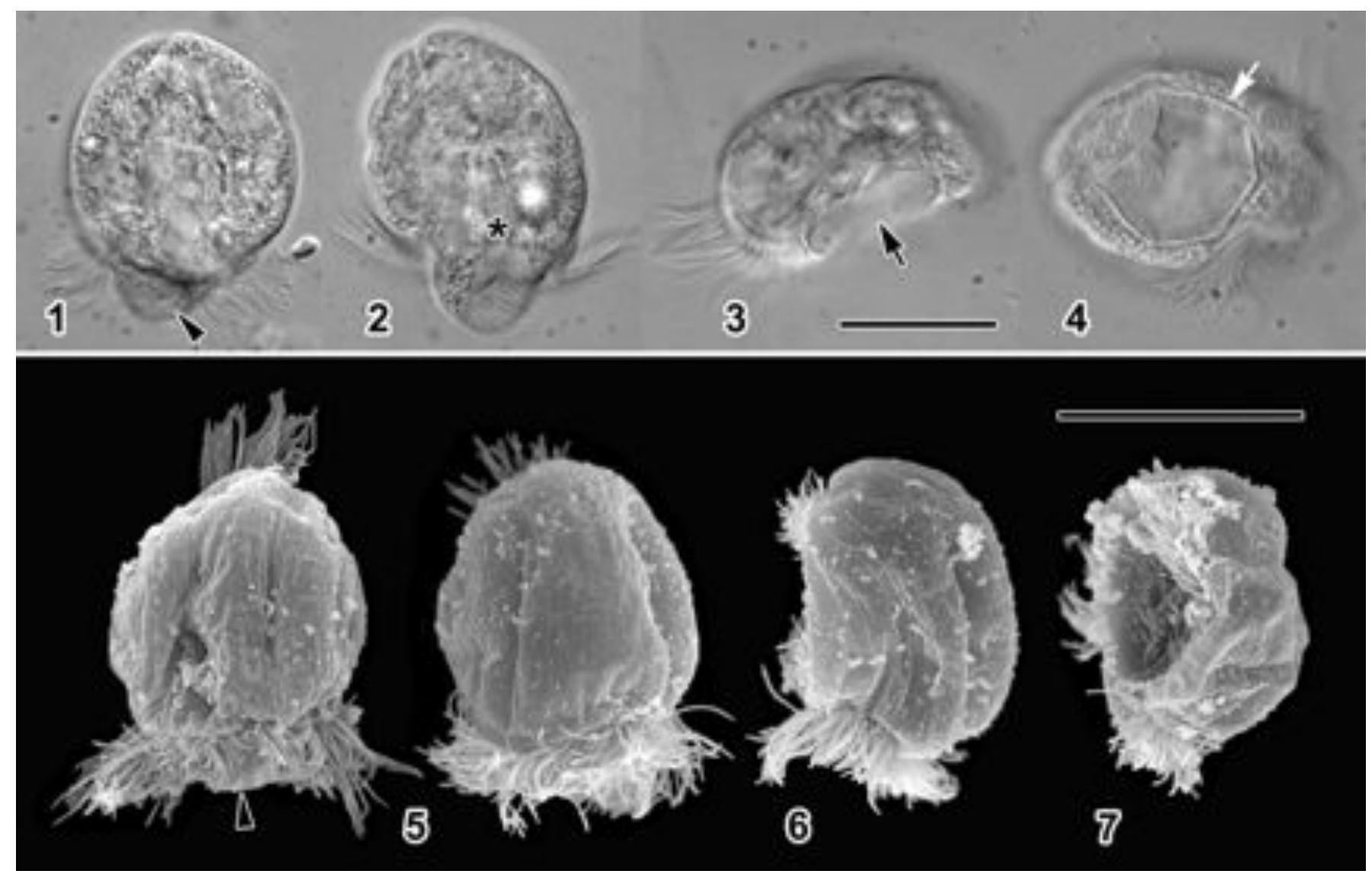

Fig. 1-7. Diagnostic features of Troglocorys cava revealed by light microscopy (1-4) and scanning electron microscopy (5-7) from a formalinfixed fecal sample from Pan troglodytes schweinfurthii, Kalinzu Forest Reserve, Uganda. 1. Right side of the trophozoite showing frontal lobe (arrowhead) surrounded by adoral ciliae. 2. Trophozoite showing vestibulum (asterisk). 3. Left concavity (arrow) in dorso-ventral view. 4. Left side of the trophozoite showing the concavity clearly demarcated by a hexagonal line formed by bases of lips (white arrow). 5. Right side of two trophozoites showing typical surface longitudinal striation and both adoral (bottom) and left cilia (above). Arrowhead indicates position of frontal lobe hidden by adoral ciliae. 6. Dorso-ventral view showing asymmetrical shape of the trophozoite. The concavity, invisible in this view, is located on the flat left side. 7. Dorso-lateral view of the trophozoite showing the prominent left concavity possessing small round projections on its surface. Scale bars $=20 \mu \mathrm{m}$. Fig. 1-4 and 5-7, respectively, are in the same scale.

results fell within this range: Budongo FR, Ugalla - 20\%; Cantanhez NP - 25\%; Gashaka Gumti NP - 33\%; Kyambura George $-40 \%$; Goualougo Triangle $-65 \%$; and Kalinzu FR - $78 \%$. In contrast, we did not find $T$. cava in any captive chimpanzees. Troglocorys cava was absent also in the wild population of chimpanzees on Rubondo Island, having been introduced onto the island in the 1960s using founders that had spent some period in captivity (Petrželková et al. 2010). Thus, T. cava apparently disappears during the captivity; this is confirmed by its total absence in zoos and sanctuaries. These findings are in contrast to the common occurrence of Troglodytella abrassarti in captive chimpanzees (Pomajbíková et al. 2010). Since nothing is known about the biology of T. cava in hindgut ecosystem, its absence cannot be unambiguously explained.

Generally, the populations of commensal ciliates fluctuate greatly, which was demonstrated both in rumen ciliates and T. abrassarti (Pomajbíková 2008; Williams and Coleman 1991). As a result of this fluctuation, the numbers of $T$. cava in some fecal samples can be reduced below the threshold level of detection. To address this problem we examined serial fecal samples from the same individual and calculated their cumula- tive prevalence. Prevalence of $T$. cava reached $55.5 \%$ in individuals sampled only once, $79.3 \%$ in individuals sampled twice, $92 \%$ in individuals sampled 3 times, and $95.5 \%$ if four and more samples were collected. These results conform to other studies suggesting that ideally three or four samples per animal are necessary to assess the real prevalence of a particular parasite/symbiont (Huffman et al. 1997; Muehlenbein 2005). Therefore, we predict that $T$. cava is present in all individuals in wild chimpanzee populations, a pattern documented previously for T. abrassarti (Pomajbíková et al. 2010). Despite the fact that none of previous studies included either morphological descriptions or microphotographs, we assume that also other findings of the "small ciliate" in chimpanzees by previous researchers refer to T. cava.

\section{ACKNOWLEDGMENTS}

This work could not have been done without the willingness and close collaboration with many zoos, localities in Africa, and local authorities. We are grateful to all keepers, curators, and veterinarians, namely Liberec Zoo, CZ (David Nejedlo); Plzeň Zoo, CZ (Ivo Tetál); Ostrava Zoo, CZ (Jana Kálnová); 
Hodonín Zoo, CZ (Jaroslav Hyjánek); Dvůr Králové Zoo, CZ (Zdena Jeřábková); Brno Zoo, CZ (Stanislav Mazánek); Bratislava Zoo, SK (Martin Krug); Spišská Nová Ves, SK (Karol Dzurik); Zoologischer Garten Augsburg, Germany (Wilhelm Moeller); Burger's Zoo En Safari Arnhem, Netherlands (Wineke Schoo); Antwerp Zoo, Belgium (Francis Vercammen); Chester Zoo, UK (Stewe Unwin); Twycross Zoo, UK (Nie Masters); Zoo Aquarium Madrid, Spain (Eva Martinez Nevado); Parc Zoologic De Barcelona, Spain (Teresa Abelló); Dierenpark Amersfoort, Netherlands (Adrien van Zanten); Zürich Zoo, Switzerland (Hanspeter W. Steinmetz); La Vallée des Singes Zoo, Fr (Jan Vermeer); Zoologischer Garten Leipzig, Germany (Klaus Eulenberger); La Palmyre Zoo, Fr (Benoit Quintard and Thierry Petit); Biomedical Primate Research Centre, Netherland (Peter J. Heidt); Phoenix Park Dublin, Ireland (Sandra Devaney); Limbe Wildlife Centre, Cameroon (Felix Lankester) and Sweetwaters Chimpanzee Sanctuary, Ol Pejeta, Kenya (Martin Mulama), who provided us with samples of captive apes. We express our sincere thanks to Nicol Simmons (Kyambura Gorge, Queen Elizabeth National Park, Uganda), Klaus Zuberbuhler, Zarin Machanda and Fred Babweteera (Budongo Conservation Field Station, Uganda and Royal Zoological Society of Scotland), Alex Piel (Ugalla Primate Project, Tanzania), Crickette Sanz and David Morgan (Goualougo Triangle Chimpanzee Project, Republic of Congo), and Volker Sommer (Gashaka Primate Project, Nigeria) for the collection of samples from wild apes. Our research in Kalinzu FR (Uganda) was approved by the Uganda National Council for Science and Technology, Uganda Wildlife Authority and Uganda National Forest Authority. We would like to acknowledge the help of Chie Hashimoto, Takeshi Furuichi (PRI, Kyoto University, Japan; supported by the Japanese Ministry of Environment Global Environment Research Fund \#F- 061). Our research on the Rubondo Island NP (Tanzania) was approved by the Tanzanian Wildlife Institute, Tanzanian Commission for Science and Technology and Tanzania National Parks. We express our special thanks to the Rubondo Island NP management, Mike A. Huffman (PRI, Kyoto University, Japan), Taranjit Kaur and Jatinder Singh (Virginia Polytechnic Institute and State University).). Our research in Cantanhez National Park in Guinea-Bissau was approved by IBAP (Biodiversity and Protected Areas Institute), whom we would like to acknowledge as well as the CNP guards. This work was supported by the project "CEITEC - Central European Institute of Technology" (CZ.1.05/1.1.00/02.0068) from the European Regional Development Fund, by the grants from the Grant Agency of the Czech Republic (524/06/0264 and 206/09/0927), the Leakey's Foundation, the Grant Agency of the Academy of Sciences of the Czech Republic (KJB600930615), and Hlavka's Foundation.

\section{LITERATURE CITED}

Ashford, R. W., Reid, G. D. F. \& Wrangham, R. W. 2000. Intestinal parasites of the chimpanzee (Pan troglodytes) in Kibale Forest, Uganda. Ann. Trop. Med. Parasitol., 94:173-179.

Bakuza, J. S. \& Nkwengulila, G. 2009. Variation over time in parasite prevalence among free-ranging chimpanzees at Gombe National Park, Tanzania. Int. J. Primatol., 30:43-53.

File, S. K., McGrew, W. C. \& Tutin, C. E. G. 1976. The intestinal parasites of a community of feral chimpanzees, Pan troglodytes schweinfurthii. J. Parasitol., 62:259-261.

Huffman, M. A., Gotoh, S., Turner, L. A., Hamai, M. \& Yoshida, K. 1997. Seasonal trends in intestinal nematode infection and medical plant use among chimpanzees in the Mahale Mountains, Tanzania. Primates, 38:111-125.

Imai, S., Ikeda, S. I., Collet, J. Y. \& Bohnome, A. 1991. Entodiniomorphid ciliates from the wild lowland gorilla with description of a new genus and three new species. Europ. J. Protist., 26:270-278.

Jirků, M., Jirků, M., Oborník, M., Lukeš, J. \& Modrý, D. 2009. Goussia Labbé, 1986 (Apicomplexa, Eimeriorina) in Amphibia: diversity, biology, molecular phylogeny and comments on the status of the genus. Protist, 160:123-136.

Krief, S., Huffman, M. A., Sévenet, T., Guillot, J., Bories, C., Hladik, C. M. \& Wrangham, R. W. 2005. Non-invasive monitoring of the health of Pan troglodytes schweinfurthii in the Kibale National Park, Uganda. Int. J. Primatol., 26:467-490.

Landsoud-Soukate, J., Tutin, C. E. G. \& Fernandez, M. 1995. Intestinal parasites of sympatric gorillas and chimpanzees in the Lopé Reserve, Gabon. Ann. Trop. Med. Parasitol., 89:73-79.

Muehlenbein, M. P. 2005. Parasitological analyses of the male chimpanzees (Pan troglodytes schweinfurthii) at Ngogo, Kibale National Park, Uganda. Am. J. Primatol., 65:167-179.

Murray, S., Stem, C., Boudreau, B. \& Goodall, J. 2000. Intestinal parasites of baboons (Papio cynocephalus) and chimpanzees (Pan troglodytes) in Gombe National Park. J. Zoo. Wildl. Med., 31:176178.

Petrželková, K. J., Hasegawa, H., Appleton, C. C., Huffman, M. A., Archer, C. E., Moscovice, L. R., Mapua, M. I., Singh, J. \& Kaur, T. 2010. Gastrointestinal parasites of the chimpanzee population introduced into Rubondo Island National Park, Tanzania. Am. J. Primatol., 72:307-316.

Pomajbíková, K. 2008. Entodiniomorph Ciliates of Gastrointestinal Tract of Great Apes [Diploma Thesis]. University of Veterinary and Pharmaceutical Sciences, Brno, Czech Republic.

Pomajbíková, K., Petrželková, K. J., Profousová, I., Petrášová, J., Kišidayová, S., Varádyová, Z. \& Modrý, D. 2010. A survey of entodiniomorphid ciliates in chimpanzees and bonobos. Am. J. Phys. Anthropol., 142:42-48.

Tokiwa, T., Modrý, D., Ito, A., Pomajbíková, K., Petrželková, K. J. \& Imai, S. 2010. A new entodiniomorphid ciliate, Troglocorys cava n. g., n. sp., from the wild eastern chimpanzee (Pan troglodytes schweinfurthii) from Uganda. J. Eukaryot. Microbiol., 57:115-120.

Williams, A. G. \& Coleman, G. S. 1991. The Rumen Protozoa. Springer-Verlag New York Inc., New York.

Received: 08/02/2011; accepted: 08/31/2011 